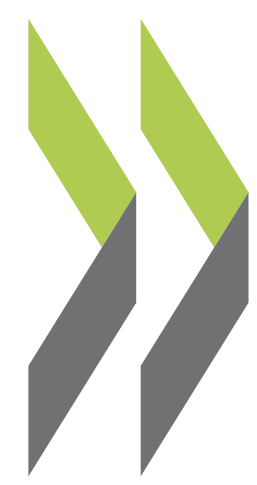

OECD Science, Technology and Industry Working Papers $2008 / 05$

Fostering Entrepreneurship for Innovation
Axel Mittelstädt, Fabienne Cerri 
Organisation de Coopération et de Développement Économiques

Organisation for Economic Co-operation and Development

12-Jan-2009

DIRECTORATE FOR SCIENCE, TECHNOLOGY AND INDUSTRY

English text only

FOSTERING ENTREPRENEURSHIP FOR INNOVATION

STI WORKING PAPER 2008/5

Statistical Analysis of Science, Technology and Industry

Axel Mittelstädt and Fabienne Cerri 


\section{STI WORKING PAPER SERIES}

The Working Paper series of the OECD Directorate for Science, Technology and Industry is designed to make available to a wider readership selected studies prepared by staff in the Directorate or by outside consultants working on OECD projects. The papers included in the series cover a broad range of issues, of both a technical and policy-analytical nature, in the areas of work of the DSTI. The Working Papers are generally available only in their original language - English or French - with a summary in the other.

Comments on the papers are invited, and should be sent to the Directorate for Science, Technology and Industry, OECD, 2 rue André-Pascal, 75775 Paris Cedex 16, France.

The opinions expressed in these papers are the sole responsibility of the author(s) and do not necessarily reflect those of the OECD or of the governments of its member countries.

\section{http://www.oecd.org/sti/working-papers}

(C) OECD/OCDE, 2008 


\title{
FOSTERING ENTREPRENEURSHIP FOR INNOVATION
}

\author{
Axel Mittelstädt* and Fabienne Cerri \\ Structural Policy Division \\ Directorate for Science, Technology and Industry, OECD \\ Contact: fabienne.cerri@oecd.org
}

\begin{abstract}
Entrepreneurship and firm creation have long been recognised as a vital force driving innovation. With globalization and the co-incident shift towards a knowledge-based economy, the link between entrepreneurship policy and innovation has received renewed attention. By underpinning firm creation and firm expansion entrepreneurship policies strengthen innovation, increasing productivity in the enterprise sector. In return, policies fostering innovation will tend to spur firm creation as the results of R\&D are commercialized. Many countries have taken initiatives since early 2000 to test the potential of entrepreneurship and SME policies, articulating these with an innovation-oriented policy approach. This report consists of a synthesis report based on four country case studies on the role of entrepreneurship policies in supporting innovation in Korea, Mexico, Norway and Turkey. These country case studies are appended to the synthesis report.
\end{abstract}

* External consultant to the OECD. 


\title{
PROMOUVOIR L'ENTREPRENEURIAT POUR SOUTENIR L'INNOVATION
}

\author{
Axel Mittelstädt* et Fabienne Cerri \\ Division de la politique structurelle \\ Direction de la science, de la technologie et de l'industrie, OCDE \\ Contact : fabienne.cerri@oecd.org
}

\begin{abstract}
RESUME
L'entrepreneuriat et les créations d'entreprises sont traditionnellement considérés comme l'un des principaux moteurs de l'innovation. Avec la mondialisation et la transition concomitante vers une économie du savoir, le lien entre les politiques de l'innovation et celles en faveur de l'entrepreneuriat revient sur le devant de la scène. En soutenant la création d'entreprises et leur expansion les politiques en faveur de l'entrepreneuriat renforcent l'innovation et la croissance de la productivité. Réciproquement, les politiques de soutien à l'innovation favorisent généralement la création d'entreprises, car les résultats des activités de R-D sont commercialisés. De nombreux pays ont engagé, dès le début des années 2000, un examen systématique des politiques en faveur de l'entrepreneuriat et des PME, en optant pour une approche axée sur l'innovation. Ce rapport consiste d'un rapport de synthèse basé sur quatre études de cas portant sur le rôle joué par les politiques en faveur de l'entrepreneuriat dans la promotion de l'innovation en Corée, au Mexique, en Norvège et en Turquie. Chacune de ces études de cas est annexée au rapport de synthèse.
\end{abstract}

* Consultant externe auprès de l’OCDE. 


\section{ACKNOWLEDGEMENTS}

The report was prepared by Axel Mittelstädt and Fabienne Cerri under the direction of Marcos Bonturi. Jeoung Yeol Yu and Dincer Kara deserve special thanks for their significant contribution to the country case studies section. Thanks are also due to Laurent Moussiegt for statistical advice and to Florence Hourtouat and Sarah Ferguson who prepared the document for discussion at the Committee on Industry, Innovation and Entrepreneurship meeting on 3 April 2008. Last but not least the authors would like to express their gratitude to experts from the four member countries who responded to the questionnaire and provided essential input to the report. 


\section{TABLE OF CONTENTS}

\section{FOSTERING ENTREPRENEURSHIP FOR INNOVATION}

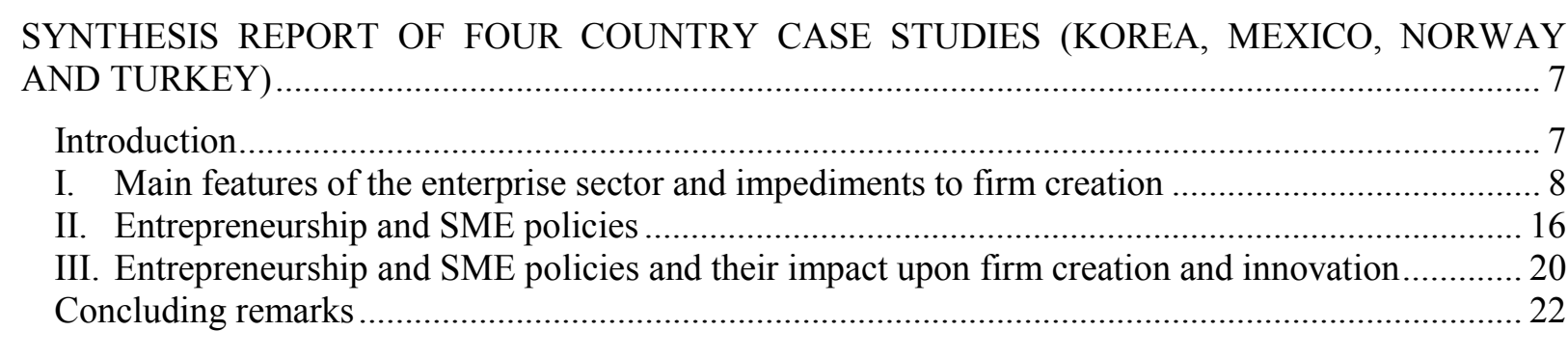

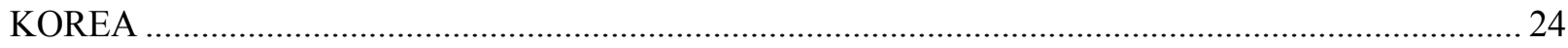

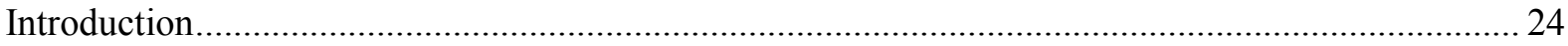

I. Main features of the enterprise sector and impediments to firm creation ....................................24

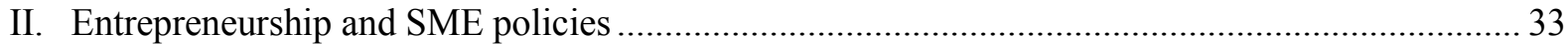

III. Entrepreneurship and SME policies and their impact upon firm creation and innovation............. 41

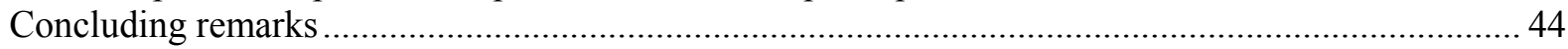

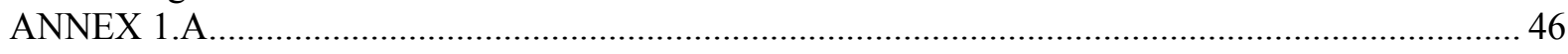

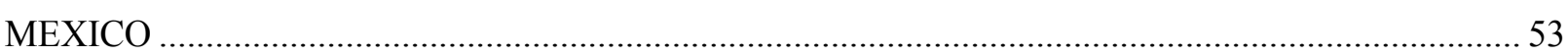

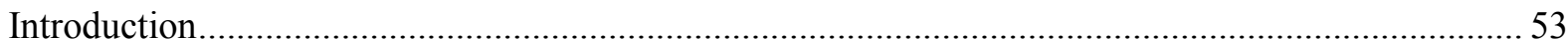

I. Main features of the enterprise sector and impediments to firm creation ....................................53

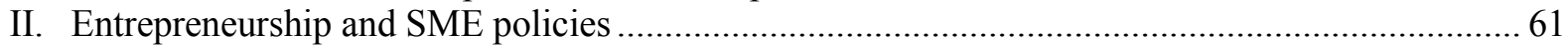

III. Entrepreneurship and SME policies and their impact upon firm creation and innovation............. 69

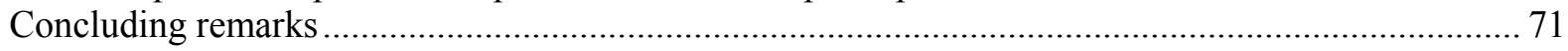

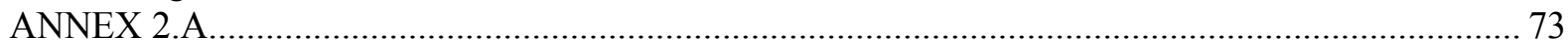

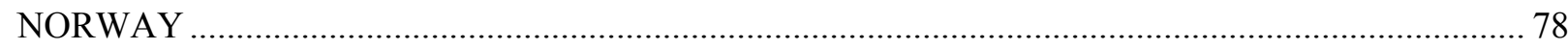

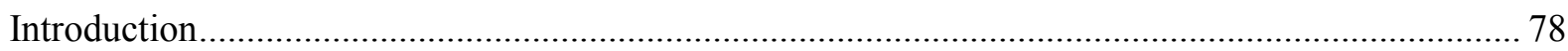

I. Main features of the enterprise sector and impediments to firm creation .................................... 78

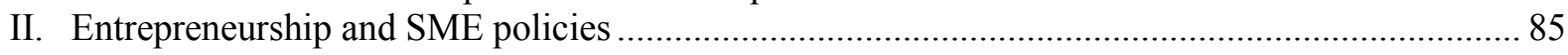

III. Entrepreneurship and SME policies and their impact upon firm creation and innovation............. 92

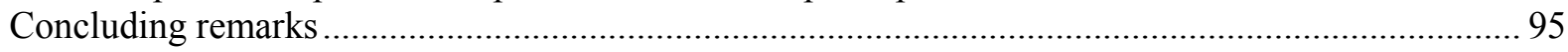

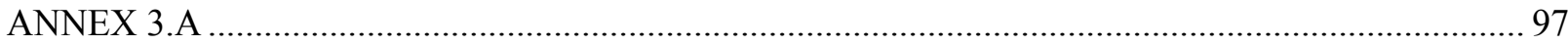

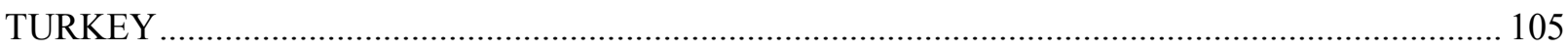

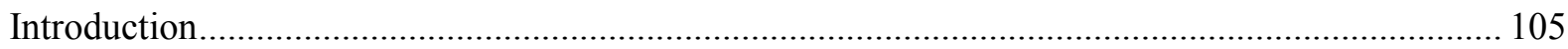

I. Main features of the enterprise sector and impediments to firm creation ................................. 105

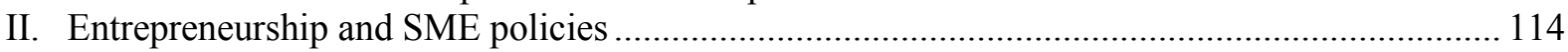

III. Entrepreneurship and SME policies and their impact upon firm creation and innovation............ 121

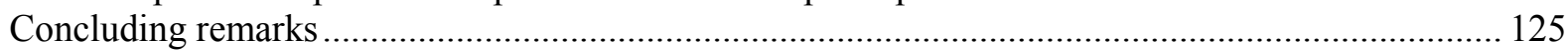

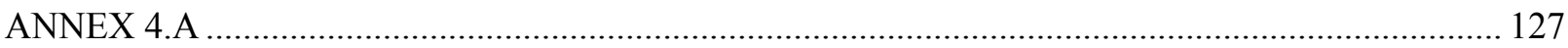


DSTI/DOC(2008)5

\title{
FOSTERING ENTREPRENEURSHIP FOR INNOVATION
}

\author{
SYNTHESIS REPORT OF FOUR COUNTRY CASE STUDIES \\ (KOREA, MEXICO, NORWAY AND TURKEY)
}

\section{Introduction}

Entrepreneurship and firm creation have long been recognised as vital forces driving innovation. Experience shows that interactions between innovation and entrepreneurship policies stimulate gains in productivity. ${ }^{1}$ The link between entrepreneurship policy and innovation is, by nature, indirect and co-dependent. By underpinning firm creation and firm expansion entrepreneurship and SME policies will strengthen innovation, while policies fostering innovation will tend to spur firm creation, as the results of $R \& D$ are commercialised.

With globalisation and the co-incident shift towards a knowledge-based economy, this link has come under renewed attention. Interest in entrepreneurship policy has flourished as a consequence, with many countries taking new initiatives to test its potential. ${ }^{2}$ Aware of these potential benefits, in the early 2000s many countries have undertaken a systematic review of entrepreneurship and SME policies, shifting towards an innovation-oriented programme approach. Among the countries moving in this direction were Korea, Mexico, Norway and Turkey. This synthesis report attempts to assess these countries' new policies from an international perspective, hopefully enriching the international debate about the co-dependence of entrepreneurial activity (firm creation and firm expansion) and innovation.

This synthesis report consists of three parts. The first part highlights main features of the four countries' business sector and identifies principal impediments to entrepreneurial activity. The second part presents different policy approaches seeking to stimulate entrepreneurial and innovative activities. The third and final part evaluates entrepreneurship and SME policies in the light of national adjustment requirements and international best-practice experience.

1 OECD (2005), SME and Entrepreneurship Outlook and A.N. Hoffmann (2007), A General Framework for Entrepreneurship Policy Review.

2 Entrepreneurship policy is usually defined as aiming at the pre-start, start up and post-start up phase of the entrepreneurial process. Its primary aim is to boost innovation and productivity growth and to make entrepreneurship a viable option for professional development. This calls for a set of organic conditions favouring people's access to the nascent pre-start phase with consequent moves into the infancy and early stages of new firms. 


\section{Main features of the enterprise sector and impediments to firm creation}

\section{Main features of the enterprise sector}

Reflecting population size, the number of enterprises differs sharply across the four countries. Mexico with far the highest population has the highest number of firms in the formal economy (about 4 million enterprises). At the other extreme is Norway with about 350000 firms. Enterprise intensity (enterprise per capita) is strong for Norway and Korea, but low for Mexico and Turkey (Table 1). The difference, though, is mainly fictional as large numbers of Mexico's and Turkey's enterprises operate in the informal economy. Adjusting for this bias raises the 'enterprise intensity' of both Mexico and Turkey close to levels observed in Korea and Norway. On the other hand, Mexico and Turkey have by far the highest regional dispersion of per-capita GDP in the OECD area, calling for strong regionoriented entrepreneurship and SME policies.

Table 1. Broad indicators

\begin{tabular}{|c|c|c|c|c|}
\hline & Korea & Mexico & Norway & Turkey \\
\hline Population (million) & 48.3 & 107.4 & 4.6 & 72.1 \\
\hline $\begin{array}{l}\text { Firm population (million) (total } \\
\text { formal economy) }\end{array}$ & 3.2 & 4.0 & 0.35 & 2.0 \\
\hline Firm population in $\%$ of population & 6.6 & 3.7 & 7.6 & 2.8 \\
\hline $\begin{array}{l}\text { GDP per head in (USD, constant } \\
\text { prices, constant PPPs in \% of } \\
\text { OECD average) }\end{array}$ & 77 & 27 & 147 & 33 \\
\hline $\begin{array}{l}\text { Regional dispersion of GDP per } \\
\text { capita (index of Gini, 2001) }\end{array}$ & 0.18 & 0.27 & 0.12 & 0.32 \\
\hline $\begin{array}{l}\text { Manufacturing firm population } \\
\text { (thousands) }\end{array}$ & 340 & 329 & 25 & 272 \\
\hline
\end{tabular}

Source: OECD (2005), The Database on Statistics on Enterprises by Size-Class (SEC) and Country statistical profile database

Common to the four countries under review is a high degree of SME-predominance (less than 250 employees). ${ }^{3}$ In each of the four countries, SMEs accounted for more than $99 \%$ of the total business population (total formal economy). While similar measures of preponderance are noted for manufacturing (Table 2), the structure of firm size is vastly different. Manufacturing micro firms (less than 10 employees) strongly dominate in Mexico and Turkey (exceeding $90 \%$ of manufacturing firms). This compares with a share of only $50 \%$ for Korea and of $60 \%$ for Norway. Moreover, small firms (10-49 employees) display a much stronger presence in Korea (42\% of SMEs) and Norway (nearly 30\%) than in Mexico and Turkey (Table 2). Large firms are strongly represented in Norway and weakly so in Turkey. 
Table 2. Main features of the enterprise sector

\begin{tabular}{|c|c|c|c|c|}
\hline & Korea & Mexico & Norway & Turkey \\
\hline \multicolumn{5}{|l|}{$\begin{array}{l}\text { Total economy } \\
\text { (\% of firm population) }\end{array}$} \\
\hline Number of SMEs & 99.1 & 99.2 & 99.5 & 99.6 \\
\hline \multicolumn{5}{|c|}{$\begin{array}{l}\text { Manufacturing sector } \\
\text { (\% of manufacturing firm population) }\end{array}$} \\
\hline $\begin{array}{l}\text { Manufacturing SMEs } \\
(<250 \text { employees })\end{array}$ & 98.9 & 99.1 & 98.3 & 99.6 \\
\hline $\begin{array}{l}\text { Large firms } \\
(>250 \text { employees })\end{array}$ & 1.1 & 0.9 & 1.7 & 0.4 \\
\hline $\begin{array}{l}\text { Medium-sized firms } \\
(50-<250 \text { employees })\end{array}$ & 6.8 & 2.2 & 7.8 & 4.9 \\
\hline $\begin{array}{l}\text { Small firms } \\
(10-<50 \text { employees })\end{array}$ & 42.0 & 6.0 & 29.6 & $\ldots$ \\
\hline $\begin{array}{l}\text { Micro Firms } \\
\text { (<10 employees) }\end{array}$ & 50.1 & 91.0 & 60.8 & 94.7 \\
\hline
\end{tabular}

Source: OECD (2007), Statistics on Enterprises by Size Class (SEC) database.

The relative productive efficiency of different SME categories can be gauged by dividing the output share by the respective firm population share. The implicit efficiency ratios (Table 3 ) show the customary positive correlation between firm size and efficiency levels (three tiers of efficiency). In the four countries under consideration, large manufacturing firms (representing around $1 \%$ of the firm population) produce between one-half and threequarters of manufacturing output, the highest output share being indicated for Mexico (74\%) and the lowest for Norway (49\%).

In contrast, micro firms, though dominant in terms of firm population, account for only a small portion of manufacturing output ranging from $4 \%$ for Mexico to $7 \%$ for Norway. The implied efficiency ratio is particularly low for Mexico and Turkey. On the other hand, Mexico and Turkey's medium-sized firms (MSES) in manufacturing concentrated in metropolitan areas record high efficiency ratios; this could be the sign of a successful integration of these companies into the global economy. 
Table 3. Efficiency ratio by size class

(Manufacturing output share divided by enterprise population share)

\begin{tabular}{lcccc}
\hline & Korea & Mexico & Norway & Turkey \\
\hline $\begin{array}{l}\text { Large firms } \\
(>250 \text { employees })\end{array}$ & 50.9 & 82.2 & 28.8 & 53.5 \\
$\begin{array}{l}\text { Medium-sized firms } \\
(50-<250 \text { employees })\end{array}$ & 2.9 & 7.2 & 3.3 & 5.7 \\
$\begin{array}{l}\text { Small firms } \\
(10-<50 \text { employees })\end{array}$ & 0.5 & 0.8 & 0.6 & $\ldots$ \\
$\begin{array}{l}\text { Micro firms } \\
(<10 \text { employees })\end{array}$ & 0.10 & 0.04 & 0.11 & 0.06 \\
\hline
\end{tabular}

Source: OECD (2007), Statistics on Enterprises by Size Class (SEC) database.

Overall, the spectrum of efficiency ratios across manufacturing SME categories is much larger for Mexico and Turkey than for Korea and Norway. The highly polarised profile of productivity levels by size class is typical of countries with a large number of subsistence entrepreneurs and a corresponding lack of efficient growth-oriented entrepreneurial activity. For this mismatch to narrow, a 'bottom-up convergence' of productivity levels needs to take place, allowing Mexico and Turkey's small and micro firms to catch up with high-income countries.

Business start ups (a proxy of entrepreneurial activity) tend to shift resources from inefficient to innovative firms enhancing gains in aggregate firm productivity. ${ }^{4}$ The productivity effects are particularly strong in high-tech industries, where start ups are vibrant. For Norway, FORA indicators ${ }^{5}$ show high business start-up rates for most categories of SMEs, backed by widespread entrepreneurial education, high bankruptcy recovery rates and, more recently, by new legislation on the taxation of dividends (2006). Bankruptcy recovery rates are also high in Korea where unified bankruptcy laws and improved re-start possibilities contribute to rapid firm turn-over. Survival rates of newly created Mexican firms appear to have risen over the past few years. This could be a consequence of the more intensive use of business incubators.

\section{Selected factors driving firm creation and expansion}

The concepts of entrepreneurship and firm creation are closely related. ${ }^{6}$ New firms and associated innovations tend to spring up from the interplay of three principal factors: Opportunity, skills and resources. Opportunities are created by market conditions and expectations. Skills include the ability of entrepreneurs and their access to business advice, while resources comprise access to capital, R\&D and technology. From the entrepreneur's perspective, these three factors drive firm

S. Scarpetta, P.Hemmings, T. Tressel and J. Woo (2002), "The Role of Policy and Institutions for Productivity and Firm Dynamics. Evidence from Micro and Industry Data", Working Paper No. 329, Internal Working Document, Economics Department, OECD, Paris.

FORA (2007), Quality Assessment of Entrepreneurship Indicators.

Innovation can be fuelled from external sources to the firm, but one should also take into account the internal sources (in-house), which are often a main source of innovation activity. Some aspects of entrepreneurship policies, such as building internal capability through skills development, is therefore a key resource for both new and existing enterprises. 
creation. ${ }^{7}$ Even so, a hostile regulatory framework and adverse cultural attitudes may hinder firm creation.

Market conditions and the regulatory framework are key determinants of entrepreneurship, but are not treated thoroughly in these case studies. This is the case for instance for bankruptcy legislation. The outline of the case studies is largely based upon major determinants of entrepreneurship excluding market conditions and the regulatory framework. These determinants of entrepreneurial activity can be seen as potential areas for entrepreneurship policy:

- Resources: access to technology ${ }^{8}$ and finance.

- Skills: capabilities and access to skilled labour.

- Cultural factors.

- Opportunities (market conditions): not treated in the case studies.

- Regulatory framework: not treated in the case studies. ${ }^{9}$

a) Access to new technology, including ICT

ICT plays a central role in the interplay between entrepreneurial policy and innovative activity. Wide ICT diffusion can ease the creation and expansion of business support centres ("service stations"). It facilitates network building, data collection and information exchange among service stations of the same kind as well as among different support units. The result is often a finessed, synergetic programme approach apt to respond more adequately to specific needs of different business categories.

On the demand side, ICT raises the visibility of programme support stimulating their take-up, especially by small and micro firms. ICT thus improves supply as well as demand conditions for business support services and represents a major tool of entrepreneurship and SME policies. Within the business sector, ICT and e-business applications provide further benefits across a wide range of intra- and inter-firm processes and transactions, including the internationalisation of SME activities. ${ }^{10}$

ICT also impacts directly upon two principal intervention areas of entrepreneurship and SME policies. In the financial sector, rising ICT diffusion enhances banks' credit assessment capacity and augments the transparency of data on firm performance and credit conditions. By kindling competition among financial institutions ICT helps ease barriers to finance, with a consequent fall in bank lending rates for SMEs relative to benchmark interest rates (interest rate convergence).

In the domain of skilled labour, ICT and related basic training courses for would-be and actual entrepreneurs favours the absorption of non-R\&D based innovations. In schools, universities and research centres, ICT is an indispensable tool for spreading the values of entrepreneurial education. Overall, ICT makes entrepreneurship and SME policies more effective, spurring both entrepreneurial activity and innovative momentum.

7 A.N. Hoffmann (2007), A General Framework for Entrepreneurship Policy Review.

8 The issue of access to technology is treated only to the extent that it affects entrepreneurial activity.

Some issues relating to the regulatory framework will be treated in this chapter only to the extent that they affect entrepreneurship directly.

OECD (2004), "ICT, E-Business and SMEs". $2^{\text {nd }}$ OECD Conference of Ministers Responsible for Small and Medium-Sized Enterprises (SMEs), Istanbul, June. 


\section{ICT Diffusion}

Broadly in line with income levels, countries differ widely in the diffusion of information and communication technology and in R\&D intensity. All indicators point to a weak ICT diffusion in Mexico and Turkey, representing fractional values of the OECD average (Figure 1). In both countries, exceptionally high prices for using ICT aggravate the effect from low income levels. Looking at individual ICT indicators, though, reveals some noteworthy differences. While Turkey has stronger fixed telephone access paths, cellular mobiles and broadband access than Mexico, the opposite is true of Internet subscribers to fixed networks. ICT diffusion also varies with the size of firms. In terms of Internet access, Turkey's large firms have recently reached parity with the European Union. Korea's diffusion of ICT surpasses OECD averages in all areas, signifying a strong ICT presence, especially considering its belowaverage income position ( $80 \%$ of OECD per capita income). Norway's above-average performance is in tune with its high-income level.

Figure 1. Diffusion of Information and Communication Technology per 100 inhabitants (2005)

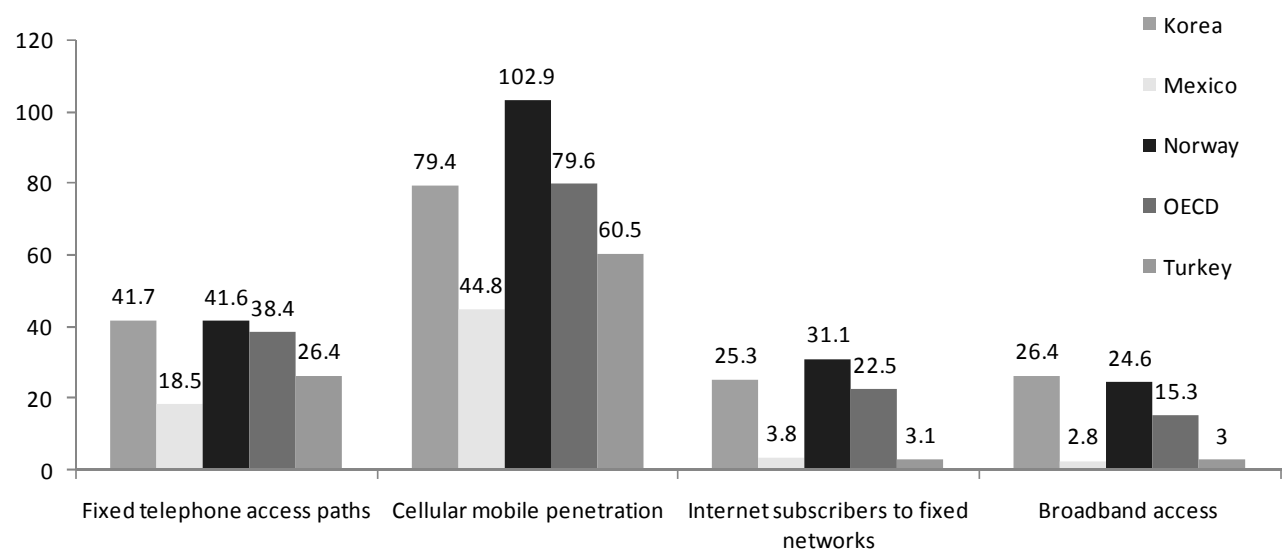

Note: Data for broadband access is for 2006 instead of 2005.

Source: OECD Communications Outlook 2007.

\section{Transmission of public $R \& D$}

The transmission of public R\&D benefits to private business is weak in Korea, Mexico and Turkey. This mainly reflects mismatches between industry needs and research routes followed by universities and public research institutions. Weak collaborative links between academia and the business sector seem to underlie this dichotomy.

In Korea, only one tenth of public R\&D funds is directly allocated to SMEs. High private R\&D spending is strongly concentrated in large firms (nearly 80\%) operating in two sectors (ICT and automobiles, nearly $50 \%$ ). The resultant innovations are mostly product innovations ${ }^{11}$. Overall, judging by the low output of codified knowledge in the form of patents and publications, Korea may not enjoy the full benefits from sizeable R\&D spending. In Turkey, the co-operation between academia, public institutions and industry is inadequate, notwithstanding a significant rise in the number of Turkish scientists' publications. Most Turkish R\&D employees work for universities as distinct from research centres. In

\footnotetext{
${ }^{11}$ OECD (2007), Science, Technology and Industry Scoreboard.
} 
Mexico, transmission links, though still insufficient, have recently improved with the strong build-up of business incubators and innovation laboratories.

Both Korea and Norway display average degrees of SMEs collaborating in innovation activities (Figure 2). For both countries, OECD Scoreboard 2007data point to a scale of collaboration of only half of that recorded in Denmark and Sweden. Only a quarter of Norway's enterprises conducted innovationrelated activities in 2002-2004. Comparable data for Mexico and Turkey do not exist.

Figure 2. SMEs collaborating in innovation activities (2002-2004)

As a percentage of all firms

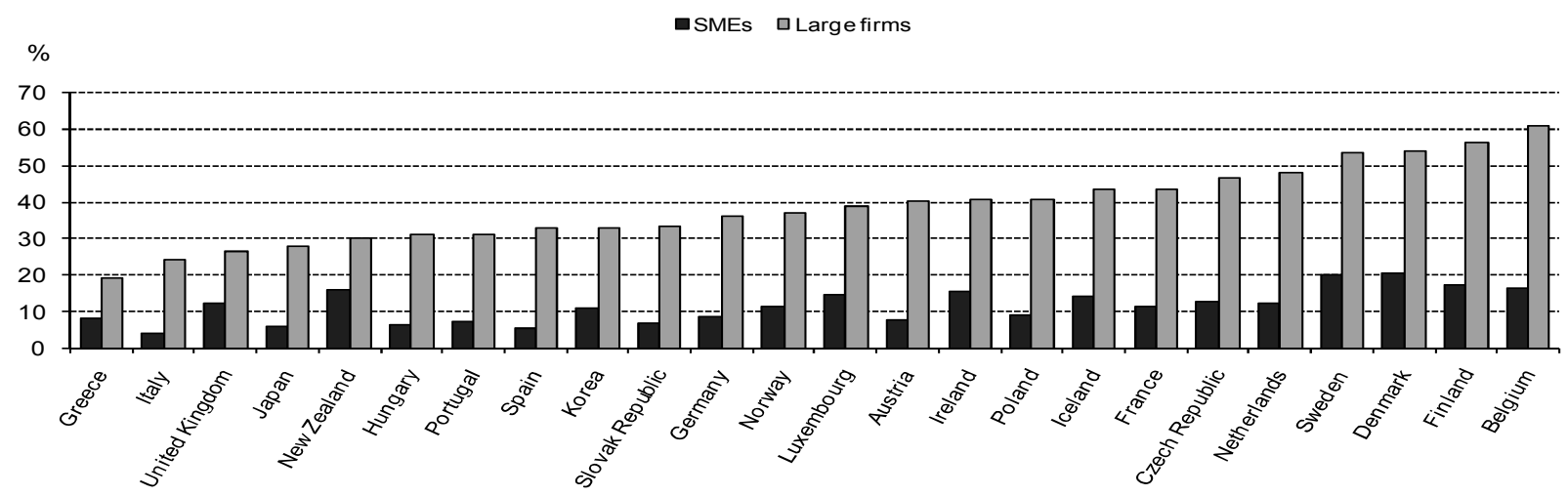

Note: SMEs: 10-249 employees for European countries, Australia and Japan; 10-99 for New Zealand, 10-299 for Korea.

Source: OECD Scoreboard 2007 based on Eurostat.

b) Access to finance

Bank credit and venture capital are important for firm creation and innovation. Barriers to finance affect disproportionally small and micro firms, often due to lack of collateral. ${ }^{12}$ Bank lending rates thus tend to be high for small and micro firms. Start-ups of small innovative firms also confront difficulties in accessing risk capital. Mexico, Turkey, and to a lesser extent Korea and Norway, are no exception to this pattern.

Largely in tune with their income position, efficiency levels of financial markets (as measured by net interest margins and total loans to private sector and securities market capitalisation in per cent of GDP) also vary strongly across countries. ${ }^{13}$ Mexico and Turkey both combine extremely high net interest margins with extremely low loan/GDP ratios (Figure 3), pointing to difficult access to finance for smaller firms. In both countries, low ICT penetration reduces competitive pressure in banking services and may also impact the capacity of credit risk assessment, especially in the domain of small-scale lending. The opposite (lower margins and higher 'loan/GDP ratios') is noted for Korea and Norway.

\footnotetext{
$12 \quad$ OECD (2006), The SME Financing Gap.

13 OECD (2006), Going for Growth.
} 
Figure 3. Net interest margins and total loans to private sector and securities market capitalisation

Net interest margins

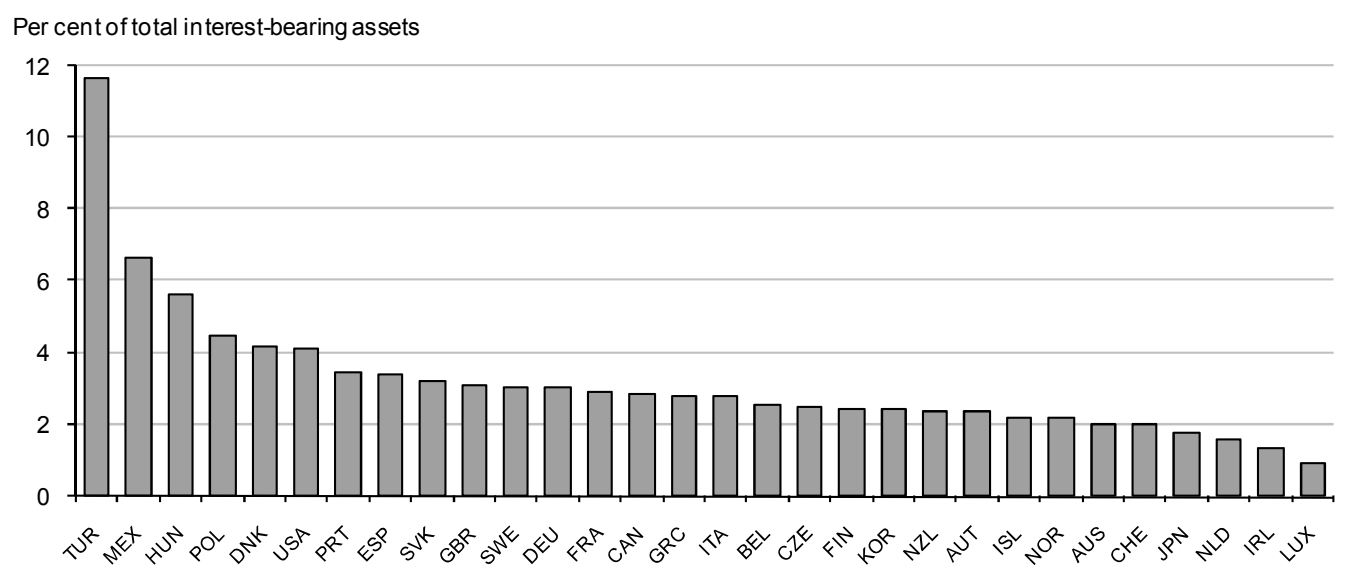

Total loans to the private sector and securities market capitalisation as a ratio of GDP

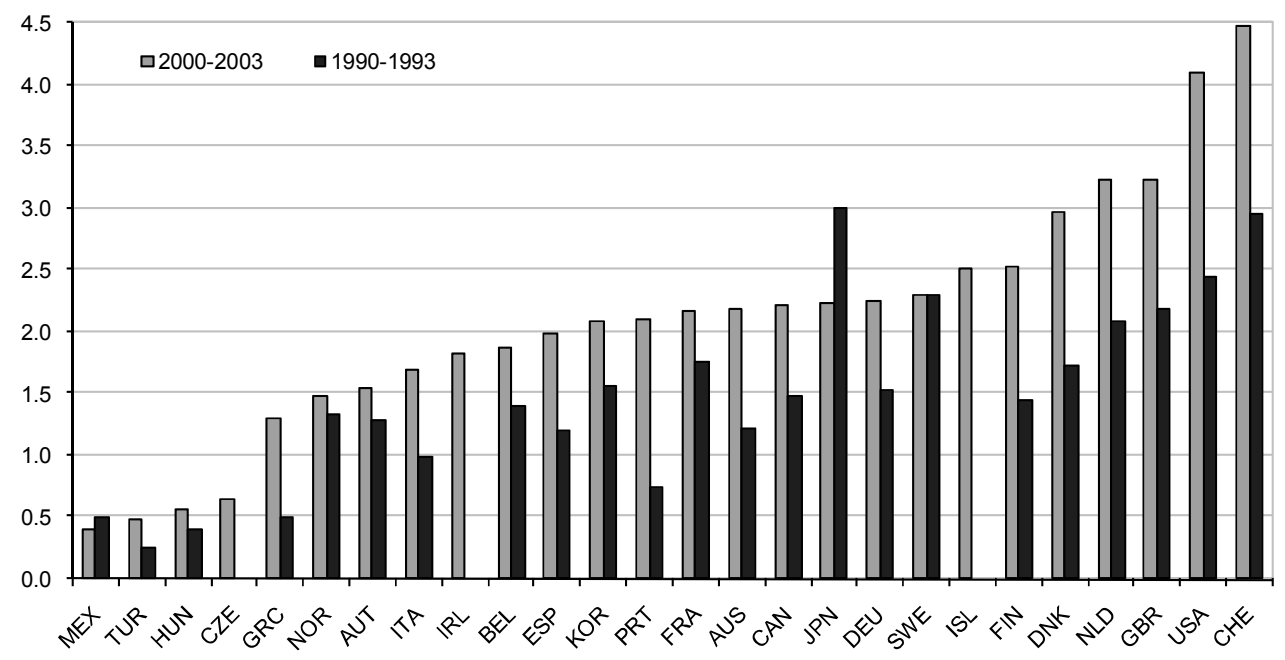

Source, OECD Going for Growth, 2006.

High average interest rates imply high required rates of return on capital for firm creation and innovations. But, in addition, they imply a particularly wide dispersion of firm-size related lending rates around the high average (sharp asymmetry of effective lending rates). Comparative cost disadvantages for small and micro firms thus tend to be much larger in low-income countries than in high-income countries. In Mexico, for example, costly suppliers' credits account for as much as two-thirds of finance for small enterprises. In Turkey, only around 5\% of available bank credit is provided to industrial SMEs, which account for no less than $99.5 \%$ of all industrial establishments. In both countries, a broad financial infrastructure for micro firms is inexistent. In contrast, EU-based SMEs meet about four-fifths of their financing needs through bank finance.

Stringent collateral requirements are another source of financing difficulties. According to FORA data (2007), obtaining a bank loan without collateral is difficult in Korea, but easier in Norway. In Turkey, small firms view collateral requirements imposed by commercial banks as the most important barrier to 
finance, ${ }^{14}$ far exceeding problems posed by high interest rates. In Mexico, banks' propensity to lend to SMEs has been damped, until recently, by inadequate rules for recovering guarantees.

Business start-ups based upon innovations require special modes of finance. Loan originators, unable to discriminate between high and low-risk borrowers, often provide no funds for start-ups and young firms (credit rationing). In this setting, supplies of venture capital are essential for the birth and growth of ISMEs and HGSMEs. The government and financial institutions are the main suppliers of venture capital in Korea, business angels playing a minor role. Norway ranks moderately higher than Korea regarding venture capital flows in 2005 (Figure 4). For both countries, the greater part of venture capital investment is devoted to firm expansion. In Norway, the state and local institutions provide two-thirds of these funds, private investors the remainder. Mexico and Turkey, with no broadly based government support, have been plagued, until recently, by acute shortages of venture capital.

Figure 4. Venture capital investment flows in percent of GDP (2006)

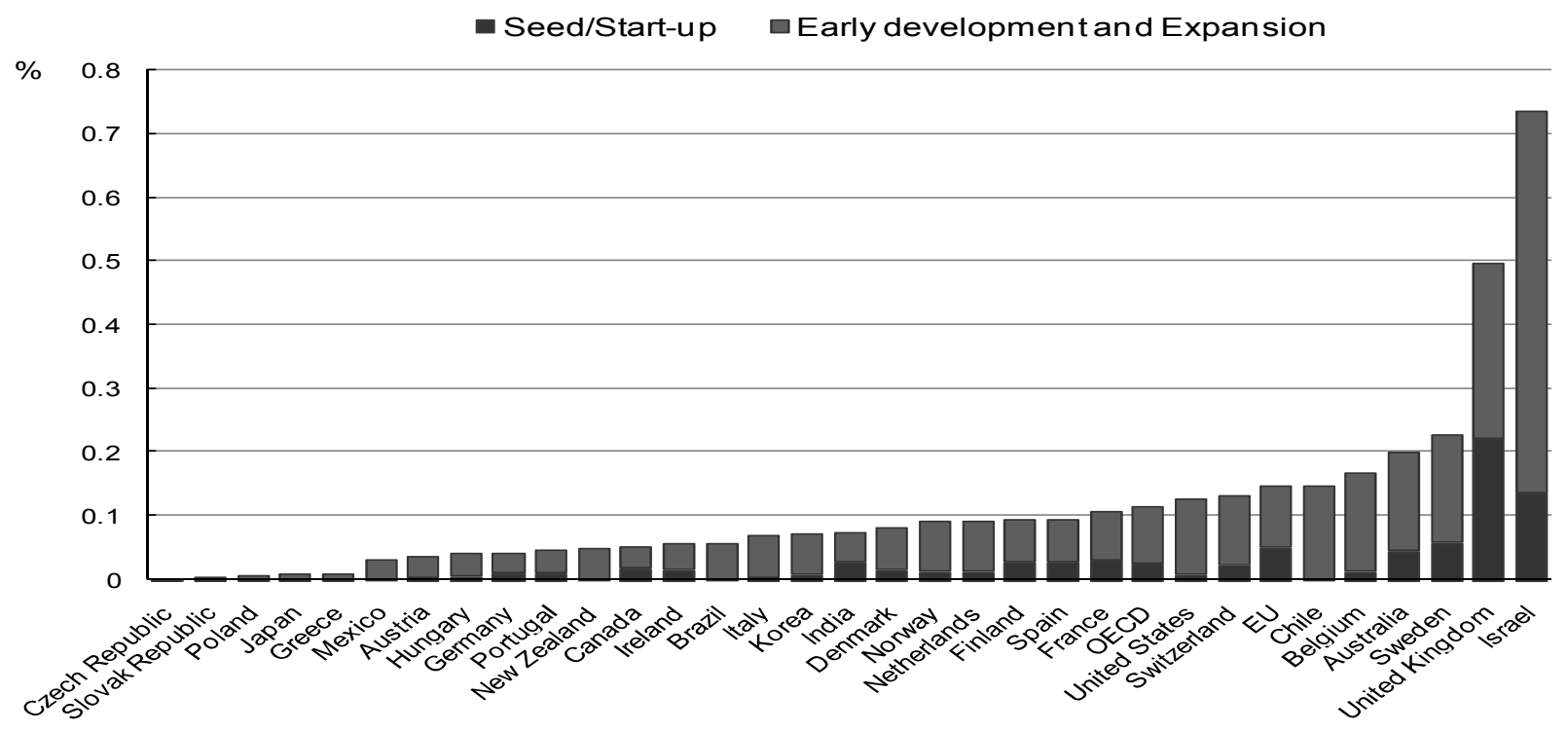

Note: Venture Capital includes Seed, Startup, Early development and Expansion stages. Later stages and Buyouts are excluded except for Chile, Mexico, and Brazil. Total OECD excludes Luxembourg, Turkey and Iceland.

Source: OECD 2008, based on data from Thomson Financial, PwC, EVCA, LVCA and National Venture Capital Associations.

c)

Access to capabilities and to skilled labour

Access to capabilities and skilled labour is strongly conditioned by income levels. Norway, a country with a high level of human capital (high levels of upper-secondary and tertiary education), stands out through its vibrant entrepreneurial culture and large-scale entrepreneurial education at school and university. Early-stage entrepreneurial activity is high and rising, with over $9 \%$ of the adult population (18-64 years) being involved in this activity (2006). Not surprisingly, GEM surveys credit Norway with a 
strong entrepreneurial culture. Female participation in early stage entrepreneurial activities, though, is still subdued. Korea, devoting the largest resources to education in terms of GDP among OECD countries, has strongly improved quality and quantity of human capital. While entrepreneurship education at school and university has been strengthened (since 2002), the eventual transition to entrepreneurial activity is subject to cultural constraints.

In Mexico and Turkey, educational systems still underperform, despite recent progress in increasing access to school education. Opportunities for entrepreneurship education at school and university are sparse. In both countries, the absence of a large pool of skilled workers is a factor hampering innovative activities by small and micro firms. In Mexico, the coverage of educational services lag OECD averages, children spending comparatively few years in formal education. Entrepreneurial training for adults is low notwithstanding entrepreneurial aspirations. In Turkey, education opportunities are limited, creating a large supply of under-educated adults. In addition, cultural factors may hinder the inclination of certain groups, notably women, to opt for entrepreneurship as a professional career.

\section{Entrepreneurship and SME policies}

\section{Overall aims of entrepreneurship policy}

Faced with growing challenges from globalisation and the related shift towards a knowledge-based economy many countries in the early 2000 s altered the stance of entrepreneurship and SME policies. ${ }^{15}$ Stronger emphasis came to be placed upon innovation as a key agent driving firm productivity growth. Emerging as a major target variable of entrepreneurship and SME policies, innovation generally spans a wide range of different forms, including product, process, individual and collaborative innovations. Under the new policy approach, business start-ups and SMEs with a high growth potential (HGSMEs and ISMEs) as well as collaborative innovations have generally been singled out as priority areas.

In varying degrees, Korea, Mexico, Norway and Turkey have all followed this trend. In each case, the year 2004 marked a turning point indicating either a shift towards or a transition to an innovation-focused entrepreneurship policy. A stronger international dimension, reflecting best-practice diffusion, often enriched the new policy approach.

In 2004, Korea announced a plan to restructure its national innovation system. Mexico shifted its policy towards a comprehensive, innovation-based policy approach. Norway created Innovation Norway (2004) implementing part of the Plan for a Comprehensive Innovation Policy (2003). At the same time, Norway designed a new strategy for entrepreneurship education (2004). Turkey began accession negotiations with the EU in 2004 which, three years later, gave rise to a new framework for entrepreneurship and SME policies. The 2007 Operational Programme for Regional Competitiveness (RCOP) has been prepared jointly by central and regional governments in collaboration with the EU Commission.

\section{In search of collaborative innovation}

The reorientation of entrepreneurship and SME policies early 2000 was, in some instances, accompanied by significant 'institution-building'. Mexico created the SME Fund (FONDO PYME, 2004) within the Ministry of Economy, the government's main tool for shaping and implementing innovation-oriented policies. This was followed in 2007 by the creation of the Innovation Fund jointly run by the Ministry of Economy and the National Council of Science and Technology (CONACYT).

15 OECD (2004), Global Knowledge Flows and Economic Development. 
Norway merged four separate support institutions to create 'Innovation Norway' (2004), which became the government's main instrument to implement the innovation strategy (From Idea to Value, 2003). Norway also established the Governmental Investment Fund (2007). Already endowed with a central agency in charge of entrepreneurship and SME polices, Turkey with KOSGEB (1990) and Korea with SMBA (1996) had no need for similar 'institution-building'. Turkey, though, widened KOSGEB's support approach (2007) which, in addition to industry, now includes tourism, information society, R\&D and innovation in regions with a per capita income of less than $75 \%$ of the Turkish average.

Viewing social capital as a vital innovation asset, all countries are increasingly engaged in the creation and expansion of a coherent infrastructure of public and private business 'service stations'. The collective efficiency strategy (collaborative innovation) is based upon the notion that a supportive environment for business activities greatly enhances the productivity of firms at all stages of development.

In Mexico for example, the building of business 'service stations' was followed by the creation of networking links between same types of 'service stations' as well as between different categories of support units. In the period 2001-2007 Mexico developed networks between business development centers, business incubators, centers for productive articulation (CAPs), innovation laboratories and business accelerators. CAPs are mainly private micro or small business units acting as a hub for rendering high added value services to special branches of industry, commerce and services. Business accelerators help HGSMEs and ISMEs during their expansion phase.

All four countries have used 'geographical proximity' as a means to reap higher dividends from research activity. Korea introduced the 'Innovative Cluster City Policy' (2005) aimed at integrating R\&D infrastructures and generating networks between academia, research centers and industry. This policy also strives to transform seven key manufacturing complexes into more innovation-oriented regional hubs. Mexico's Programme for Strategic Projects aims to establish a homogenous infrastructure for business activities, presenting a platform for foreign investment. Mexico has also created industrial parks, productive chains, zones for eco-tourism and commercial centers as part of its Programme for Strategic Productive Projects (2001-2007).

Norway has installed Research Parks and 'Business Gardens' (Business Development Centers) in remote, rural areas deprived of colleges or universities. Acting as networking hubs, Business Gardens function as a partner for firms, investors and researchers. Turkey has set up 'Synergy Focal Points' generalising services and assistance to SMEs. Under the new framework for entrepreneurship and SME policies (RCOP, 2007) Turkey has adopted a more focused 'growth-center approach'. Inside 12 less-developed regions, 15 growth centers with a high growth potential have been identified. About $14 \%$ of all Turkish firms are located in these regions.

\section{Network-building among firms}

Countries have also aimed at increasing horizontal and vertical networking within the business sector in order to enhance the collaboration between firms. Korea has set up a foundation (2006) fostering collaboration between large firms and SMEs via joint R\&D efforts and human resource development. Mexico's National Programme of Suppliers' Development (SDP, 1995) has progressively led to voluntary, strategic alliances between large firms and SMEs. Another Mexican programme (Programme for Strategic Productive Projects) aims at attracting large firms, paving the way for micro firms to become part of groups of competitive, local suppliers. Mexico has also established a network of export centers allowing SMEs to sell products to large exporting firms.

In Norway, SIVA, a state enterprise owned by the Ministry of Trade and Industry, has played a key role in promoting strong regional and local industrial clusters. SIVA has upgraded the infrastructure for 
innovative business activities. Turkey has used an increased flow of advisory services from professional organisations and universities to create stronger links between large and smaller firms. Under the RCOP (2007), Turkey also strives to tighten such connections applying a 'growth center approach' to 12 less-developed regions. RCOP also stimulates the formation of sectoral clustering and inter-regional network building in these regions.

\section{Improving access to new technology and $R \& D$ benefits}

Creating and channeling new technology to all categories of firms figures high on the four countries' policy agenda. Initiatives taken in this domain fall into two categories, one striving to improve R\&D benefits through stronger ties between academia, research centers and the business sector, the other enhancing SMEs' capacity to absorb new technology. In many instances, policy initiatives have used the advantage of geographical proximity, e.g. installing business incubators in universities.

\section{Improving links between academia, research centers and the business sector}

For many years, Korea has been concerned about its lack of overall R\&D efficiency. To improve dividends from substantial R\&D spending Korea has progressively stepped up efforts in this field. The Industry-University-Research Consortium Programme run by SMBA (1993) helped bring public research efforts more in line with the needs of the enterprise sector. Subsequently, both the Technology Transfer Promotion Act 2000 and the Transferred Technology Development Project (2003) strengthened the technology transfer from the public to the private sector. In addition, business incubators have been introduced in some universities and research institutes.

Mexico has established rising numbers of innovation laboratories and business accelerators as a means to strengthen ties between research centers and mature SMEs and HGSMEs. In Norway, research parks and Technology Transfer Offices (TTO, 1993) have promoted the commercialisation of innovation. Both support entities are closely integrated in universities. The FORNY programme (2000) has fostered collaborative ties between the research community and the business sector. Turkey has set up Technology Development Centers (TEKMER), enterprise development centers (IGEM) as well as business incubators near or inside universities. Technical Development Zones (TDZ), concentrating on advanced technologies, also provide an infrastructure for generating and directing knowledge flows to near-by enterprises.

\section{Increasing SMEs' capacity to absorb new technology}

While better collaboration between research centers and firms tends to increase firms' ability to apply new technology, each country has taken additional supporting measures to spur firms' innovative momentum. Korea has built up a series of programmes over time, including the Technology Purchasing Insurance (mid-1990s), the Small Business Innovation Research Programme (KOSBIR, 1998), the InnoBiz Programme (2001), the SME Technology Innovation Programme (2001) and the SME IT implementation support programme. As part of these efforts, business incubators have been introduced in universities, while the use of ICT by small and micro firms has been promoted. To bridge the digitalisation gap between metropolitan and local areas, Korea has also conceived the Regional Cluster for Digitalisation Innovation programme.

Mexico has strongly relied on innovation laboratories and business incubators to support firms' innovative initiatives. Three kinds of incubators prop up start-ups in traditional, intermediate-technology and high-technology sectors. Networks of business incubators (2003) and innovation laboratories (2005) have been set up. Moreover, the Programme for Innovation and Technological Development has promoted the transfer of technology from large to smaller firms in the automobile industry. This has led to the formation of clusters for robots and automation. Norway has also deployed business incubators, reserving a 
special type for heavy industry. In Turkey, TEKMERs and business incubators facilitate SMEs' use of new technology. TEKMERs teach entrepreneurs how to access support services. They also establish better relationships between SMEs and technology service providers, mostly public organisations.

\section{4. $\quad$ Easing access to finance}

A wide range of instruments have been put into place to ease firms' access to credit and venture capital. In Korea, SMEs without collateral and technological know-how receive credit support through guarantee schemes operated by the Korea Credit Guarantee Fund (KCGF) and the Korea Technology Credit Guarantee Fund (KOTEC). The base for guarantees is backed up by financial government support to these organisations. In addition, eligible small firms in the start-up phase can obtain loans from the Small Business Corporation (SBC) at low interest rates.

Mexico's National Guarantee System (2003) and the National Financial Extension Programme (2004) aim to enlarge credit supplies. A novel bidding process for guarantee funds has been set in motion (2005), kindling competition among financial intermediaries in search of loan guarantees. The National Financial Extension Programme, reaching nation-wide coverage in 2006, provides a financial assessment net helping firms enter into credit relationships. Improved credit applications are screened by a nation-wide web of commercial banks' branches.

Norway's 'Innovation Norway Guarantee Scheme' targets SMEs with up to 100 employees. Because of stringent conditionality and low guarantee coverage, private banks rarely use this scheme. Most micro loans are available through the Cultura Bank offering credit guarantees with a better guarantee coverage in collaboration with the European Investment Fund. Funds are also available under grant schemes supporting projects for collaborative innovations.

Turkey extends credit guarantees through the Credit Guarantee Fund (KGF, 1994) and the Union of Turkish Artisans and Craftsmen Credit Cooperatives. Under the SME Finance Facility credits at low interest rates are given to SMEs located in less-developed regions. Under the SELP programme, small loans with a maturity of over a year are extended to SMEs. Aside from these measures, Turkey has extensively used investment allowances as a means to promote investment in fixed assets. The new SME Strategy and Action Plan (2007-2009), the first segment of the $9^{\text {th }}$ Development Plan (2007-2013), provides additional funds for micro loan mechanisms and related advisory services.

\section{Increasing the supply of venture capital}

Korea views venture capital markets as a primary source of finance for start-ups and high-growth businesses. Accordingly, the government has strongly backed the venture capital market by creating venture capital investment funds and setting up venture capital firms and venture capital partnerships. A 'fund of funds' was established in 2004. Mexico, in an effort to increase supplies of venture capital for high-growth firms, introduced the Seed Capital Programme (2005), using partnerships and subsidised loans formulas. Prospective innovative entrepreneurs also benefit from similar support under the FORPRODE Programme. Through a unique investment guarantee (PYME Option), Mexico also promotes the creation of 'Investors Clubs'. These clubs seek a high return on capital through investment in innovative firms.

Given small and fragmented capital markets, Norway has instaured mechanisms to provide risk capital investors with public co-investment schemes (Seed Capital Scheme and Argentum, 2001). A public investment fund was set up in 2007 to meet financial needs of potential high-growth firms. In Turkey, venture capital is mainly supplied by two venture capital investment trusts. KOBI, a public incorporated company, acts as a risk intermediary offering various financial instruments for ISMEs and HGSMEs. ISRISK, a private company, performs similar functions. 


\section{Easing access to entrepreneurship education and training}

To different degrees, all countries have put stronger emphasis upon entrepreneurship education. Injecting entrepreneurial spirits into all levels of education and business stages came to be seen as an engine for future innovation. Korea views entrepreneurship training and education as a key element in promoting business start-ups. Entrepreneurship development programmes have been set up both at secondary and tertiary level (Biz-cool programme, 2003). 'Entrepreneur clubs' at universities develop a 'start-up mindset' in students. Through a public education institute (1982), Korea has also upgraded the quality of the SME workforce. Three regional centers have been established recently, providing in-house training for ICT use.

Mexico's network of Business Development Centers (BDCs, 2001), though not providing direct entrepreneurship training, offers concrete business solutions such as drawing up loan requests based upon the assessment by BDCs of financial needs. Conventional BDCs provide basic support services, especially to subsistence entrepreneurs. 'BDCs Plus' assist ISMEs and HGSMEs. Direct training for entrepreneurs, notably subsistence entrepreneurs, is extended under both the Programme for Training and Strengthening firms' Capabilities and the PROMODE Programme. Since 2005, training options have been differentiated to correspond to different innovation forms.

Mexico's Programme for Training and Strengthening Firms' Capabilities offers three kinds of training: conventional training, specialised training for product and process innovations and training the 'coaches'. Entrepreneurship receives nation-wide attention during the annual SME-week, a national event. Mobile information centers (SME policy vans) spread information about opportunities to benefit from government support. Regular business forums attract 'would-be' entrepreneurs.

Norway launched a national strategy for entrepreneurship education in 2004. The strategy covers all stages of the educational system from primary school to college and university, and includes teacher training. Several universities provide both compulsory and voluntary courses on entrepreneurship, economics and technology. Revised in 2006 the strategy for entrepreneurship education now focuses on support to organisations and other stakeholders (municipalities and trade and industry associations) that normally promote entrepreneurship education. The government also supports 'Junior Achievement-Young Enterprise Norway' (JA-YE, 1997), Norway's largest private supplier of entrepreneurship training. The programme 'Introductory Enterprises', providing expert guidance, assists immigrants in developing entrepreneurial qualities.

Turkey's KOSGEB, through its Enterprise Development Centers (BDC) and Technological Development Centers, operates several incentive and training programmes. KOSGEB's Center for Entrepreneurship disseminates information about potentially viable business opportunities. Market research findings are spread through the networks of IGEMs, TEKMERs and small industrial estates (SSIEs). Information about best practices is also released. For business start ups, KOSGEB has two training programmes, one supplying general educational services, the other offering specialised training given by professional (public or private) organisations.

\section{Entrepreneurship and SME policies and their impact upon firm creation and innovation}

A successful entrepreneurship and SME policy evolves through time with the maturing of both innovative processes and supporting service units. Three policy phases are usefully distinguished, the first one spurring R\&D and innovation so as to create vast segments of ISMES and HSMEs. During the second phase, the innovations are spread through improved scientific networks, specialised institutions and better 
access to venture capital. In the third and final phase, the innovative momentum gathers pace stimulated by learning effects and the transition to the knowledge economy. ${ }^{16}$

Both Norway and Korea have, over the past few years, made significant progress in all three policy phases. This is evident in better co-ordinated R\&D efforts, higher R\&D spending (Korea), better opportunities for training and entrepreneurship education, stronger early stage and innovative activity, better networking facilities and rising ICT diffusion from high levels (Figure 1).

For Mexico and Turkey, the evidence is mixed. In both countries, large industrial firms and MSEs, have made progress in the first two policy phases as outlined above. Novel and enlarged support services, rapidly rising ICT use along with stronger private R\&D efforts have boosted large companies' and MSEs' capacity to compete internationally (stronger growth-oriented activity). The rising use of business incubators, innovation laboratories and geographical bundling of business support units (advantage of geographical proximity) has contributed to this outcome.

At the same time, though, vast numbers of Mexico and Turkey's small and micro firms (large oversupply of subsistence entrepreneurship) lack access to technology, education, training and finance. Injecting a growth-oriented entrepreneurial spirit into these 'excluded' firms demands a broad, balanced policy approach. Better education on all levels, including entrepreneurship education for both men and women, and basic training courses will eventually raise the propensity for business start ups as well as micro firms' capacity to absorb ICT. This calls for non-R\&D based and collaborative innovations making small and micro firms eligible for inclusion in producer networks. Countries need to test simple and costefficient variants of these collaborative innovations like mobile business development centers and mobile banks, which have been successfully used elsewhere.

Until recently, Mexico's and, especially, Turkey's entrepreneurship and SME policies appear to have been tilted towards backing HGSMEs and ISMEs rather than designing comprehensive support programmes for small and micro firms. Turkey's 2007 RCOP programme (2007-2013), though, is based on the principle of a 'bottom-up' convergence of firm productivity levels. Drawn up jointly with the EU commission, RCOP is scheduled to rebalance the policy approach.

Both Mexico and Turkey show positive results for basic training courses (large participation, higher survival rates for micro firms), but they still lack appropriate nation-wide micro-finance mechanisms. This is especially the case for Turkey where small-loan activities are highly underdeveloped, where credit guarantee opportunities are sparse and where credit advisory services are limited. Many micro firms are thus compelled to rely on costly suppliers' credits or on informal money lenders (effective lending rates being a multiple of benchmark interest rates).

Korea is also concerned about large gaps in efficiency levels between successful large firms and less effective SMEs. The duality in the firm population needs to be addressed by helping large manufacturing firms keep their competitive edge, while allowing smaller firms, notably in the service sector, to catch up. An efficient infrastructure of business services, providing differentiated support and training, would allow easier diffusion of knowledge in the lagging business segments. Private R\&D spending, though high by international comparison, is extremely low in the service sector. Tapping this sector's large innovation potential calls for deeper and wider forms of collaborative innovations. Increased vertical network building between large firms and SMEs is one way of spreading chain-based innovations.

16 G. Rosenwurcel (2007), Political and Government Institute, UNSAM, Argentine (see: OECD (2007), SMEs in Mexico, p. 91). 
In Norway, the issue of a two-tier business sector is less apparent. Differences in inter-firm productivity levels are comparatively small, reflecting its high-income position and intensive, wide-spread entrepreneurship education. Nearly the totality of newly created micro firms, for example, has been shown to survive three-year periods. Even so, there is still room for progress which additional collaborative formulae are able to exploit.

\section{Summing up}

Income levels largely condition impediments to entrepreneurial and innovative activities. Mexico and Turkey are marked by a large oversupply of subsistence entrepreneurship, manifest in low efficiency ratios for small and micro firms, high shares of micro firms in the overall firm population and correspondingly low levels of aggregate firm productivity. Low R\&D intensity and weak ICT penetration interact, damping innovative activity, maintaining uncompetitive behaviour in the banking sector, depressing advisory capacity for business services and keeping business activities from being internationalised. Retarding collaborative innovations low-ICT diffusion thus undercuts entrepreneurship and SME policies.

There is a capital shortage in low-income countries reflected in both high real interest rates and a high dispersion of firm-size related lending rates around high interest rate averages. This hits small and micro firms more than proportionately, stifling innovative initiatives of potential and actual entrepreneurs. Underperforming educational systems coupled with a lack of entrepreneurship education and cultural biases perpetuate this web of impediments.

For the higher-income countries, obstacles to entrepreneurial and innovative activities are less binding. However, Korea's sizeable R\&D efforts do not seem to yield commensurate results in terms of innovations (lack of process innovations), while Norway's R\&D intensity looks small relative to the income level. Collaborative innovations are suboptimal in both countries.

\section{Concluding remarks}

The country sample (four countries) is small, but rich in diversity. Two countries, Mexico and Turkey, are at the bottom of the OECD per-capita income ranking. Rapid population growth and low productivity gains, has, in both cases, damped income convergence (Figure 5). At the other end is Norway, enjoying an income level nearly $50 \%$ above the OECD average, and Korea, which stands out by its exceptional pace of real income convergence in recent years. 
Figure 5. GDP per head USD, constant PPPs

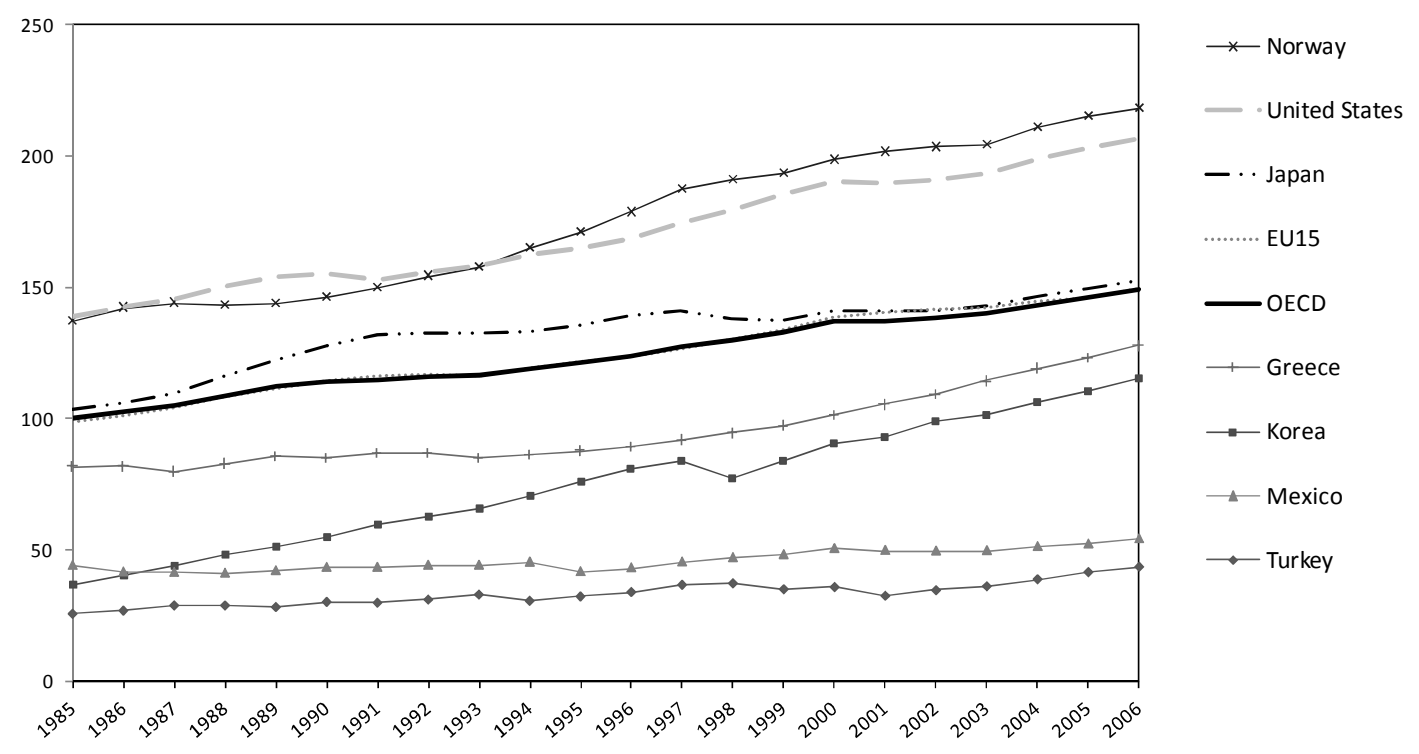

Source: OECD annual national accounts database.

In spite of this diversity, entrepreneurship is an important policy concern to the four countries surveyed. They are all faced by the growing challenge of globalisation and the related shift towards a knowledge-based economy. They all aim to move up these emerging global value chains and they are all convinced of the potential of entrepreneurship policies to reinforce innovation policies and boost productivity growth. Accordingly, they have all implemented active policies towards increasing firms' access to new technologies, to finance and to capabilities and skills.

These four country case studies are aimed at throwing some light on the main policy issues related to entrepreneurship policies. They are meant as a starting point for a more coherent effort by the Committee on Industry, Innovation and Entrepreneurship, together with its Working Party on SMEs and Entrepreneurship, to understand how entrepreneurship policies can help foster innovation. 


\section{KOREA}

\section{Introduction}

Korea's economic development has been marked by a rapid pace of convergence, per capita income having reached two-thirds of the OECD average. In this context, entrepreneurship and SME policies have been used extensively for over a decade to spur innovation and increase productivity in the enterprise sector. In a setting of rapid changes in technology and consumer preferences, supporting the creation of innovative enterprises was rightly seen as a policy priority.

The link between entrepreneurial policy and innovation is by nature indirect. Efficient measures of entrepreneurship policy underpin firm creation and expansion, and by doing so they strengthen innovative activity. Viewed from a wider angle, entrepreneurship policy itself may pave the way for "collective process innovations", augmenting the effects which firm creation and firm expansion normally have on individual innovations.

The first part of this chapter highlights the main features of Korea's enterprise population, identifies main drivers of entrepreneurial activity and presents indicators of entrepreneurship performance. The second part outlines main objectives of entrepreneurship policy and describes principal programmes in four major areas of policy intervention: access to $R \& D$ and technology, access to finance, capabilities and access to skilled labour, and cultural values. The third part provides an evaluation of entrepreneurship policy.

\section{Main features of the enterprise sector and impediments to firm creation \\ 1. Main characteristics of the enterprise sector}

In 2006 there were an estimated 3 million businesses in Korea, employing around 12 million persons (Table 1.1). SMEs ${ }^{17}$ with less than 300 employees accounted for over $99 \%$ of all firms and about $88 \%$ of total employment. Micro firms (0-9 employees) represented $88 \%$ of the enterprise population and $41 \%$ of the employment in 2006, while small firms (10-49 employees) accounted for $8 \%$ of the firm population and $21 \%$ of employment. In comparison, medium (50-299 employees) and large (over 300 employees) enterprises represented respectively $3 \%$ and less than $0.1 \%$ of the enterprise population and employed respectively about $25 \%$ and $12 \%$ of the total number of persons in 2006 (Figure 1.1).

\footnotetext{
17 The definition of business size can be different in some sectors. SMEs in Korea are defined in terms of employees and paid-in capital or revenue and vary depending on industry sectors. For more information on definitions, see Annex 1.A, Table 1 (Response of the Korean government to the 2008 OECD background report).
} 
Table 1.1 Distribution of Employment and Enterprises by firm size in Korea (2006)

\begin{tabular}{|l|rr|}
\hline Size class & Enterprises & $\begin{array}{r}\text { Number of } \\
\text { Employees }\end{array}$ \\
\hline $0-9$ employees & 2671928 & 5159639 \\
& $(88.4 \%)$ & $(41.5 \%)$ \\
$10-49$ employees & 251721 & 2578265 \\
& $(8.3 \%)$ & $(20.7 \%)$ \\
$50-299$ employees & 94138 & 3146746 \\
& $(3.1 \%)$ & $(25.3 \%)$ \\
300 and more employees & $(0.1 \%)$ & 1560438 \\
& 3022053 & 12445088 \\
\hline Total & $12.5 \%)$ \\
\hline
\end{tabular}

Source: Small and Medium Business Administration.

Figure 1.1 Distribution of enterprises and employment by firm size (2006)

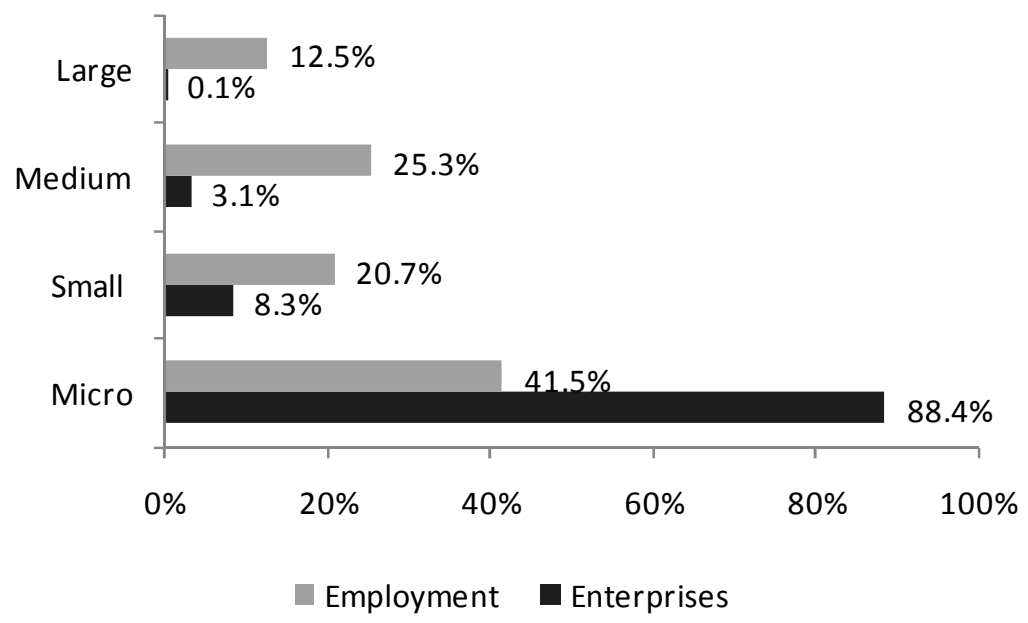

Note: Micro = 0-9 employees, Small $=10-49$ employees, Medium $=50-299$ employees and Large $=300$ employees and more .

Source: Small and Medium Business Administration.

Industries with the largest number of businesses in 2006 are: wholesale and retail (28\%), hotels and restaurants $(20 \%)$, manufacturing $(11 \%)$ and transportation (11\%) (Table 1.2). However, based on employment, manufacturing is the predominant sector in Korea with 340000 establishments employing $27 \%$ of the total number of employees. This means that one enterprise employs an average of ten persons. It is also a sector where productivity is high. In contrast, the services sector suffers from high entry barriers and a low level of productivity (Figure 1.2). Labour productivity in Korea's services sector is only $56 \%$ of that of manufacturing and well below the OECD average. ${ }^{18}$ 
Table 1.2 Distribution of enterprises and employees by sector (2006)

\begin{tabular}{|l|rr|rr|}
\hline Sector & $\begin{array}{r}\text { Number } \\
\text { of firms }\end{array}$ & $\begin{array}{r}\text { Percentage } \\
\text { of firms }\end{array}$ & $\begin{array}{r}\text { Number of } \\
\text { employees }\end{array}$ & $\begin{array}{r}\text { Percentage of } \\
\text { employees }\end{array}$ \\
\hline Wholesale, retail & 860270 & 28.5 & 2436438 & 19.6 \\
Hotels, restaurants & 617566 & 20.4 & 1653278 & 13.3 \\
Other individual services & 456791 & 15.1 & 1207756 & 10.2 \\
Manufacturing & 339149 & 11.2 & 3408997 & 27.4 \\
Transportation & 341038 & 11.3 & 819990 & 6.6 \\
Education Service & 109076 & 3.6 & 437220 & 3.5 \\
Real estate & 104151 & 3.4 & 278702 & 2.2 \\
Construction & 89847 & 3.0 & 834922 & 6.7 \\
Business Services & 86291 & 2.9 & 1070583 & 8.6 \\
Banking and Insurance & 9075 & 0.3 & 138504 & 1.1 \\
Telecommunication & 5980 & 0.2 & 58327 & 0.5 \\
Agriculture, Fishery & 623 & 0.0 & 9354 & 0.1 \\
Mining & 1831 & 0.1 & 15608 & 0.1 \\
Electricity, Gas, Water & 365 & 0.0 & 12409 & 0.1 \\
\hline Total & 3022053 & 100.0 & 12445088 & 100.0 \\
\hline
\end{tabular}

Source: Small and Medium Business Administration.

Figure 1.2 Productivity in the services sector (2003)

Manufacturing $=100$

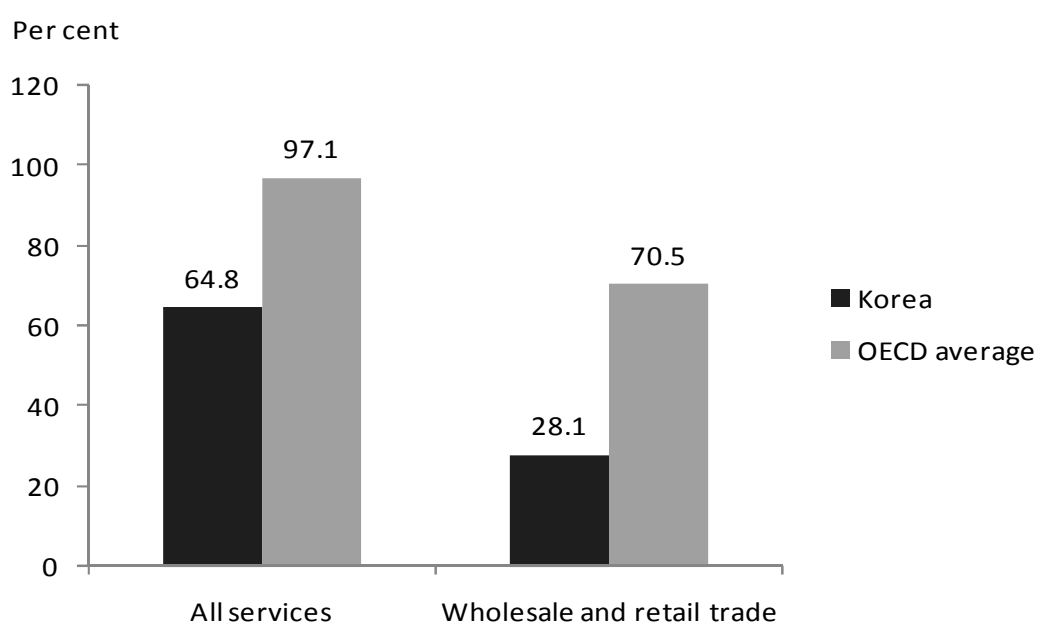

Source: OECD (2007), Economic Surveys Korea. 
Regarding output, manufacturing SMEs are responsible for over half of the manufacturing value added. They also have an important weight in exports: SMEs accounted for $42 \%$ of Korea's total exports in 2002 , this share falling to $32 \%$ in 2007 . Most of SMEs' exports came from the manufacturing sector electronics and electrical components $(28 \%)$, machinery $(22 \%)$, textile $(14 \%)$, chemical $(15 \%)$, steel and metal $(10 \%)$.

Almost half of Korea's population and economic activity are concentrated in the capital region: Seoul, Incheon and Gyeonggi Province. This level of concentration is high compared to other OECD countries (Annex 1.A, Figure 1.A.1).

After the Asian financial crisis in 1997 the number of large firms decreased significantly and so has the share of persons employed by large enterprises. The share of persons employed by SMEs has on the other hand increased (Table 1.3).

Table 1.3 Change in employment

As a percentage compared to the previous year

\begin{tabular}{|l|r|r|r|r|r|r|}
\hline & \multicolumn{1}{|c|}{$\mathbf{2 0 0 1}$} & \multicolumn{2}{|c|}{$\mathbf{2 0 0 2}$} & \multicolumn{1}{|c|}{$\mathbf{2 0 0 3}$} & $\mathbf{2 0 0 4}$ & \multicolumn{2}{c|}{$\mathbf{2 0 0 5}$} & $\mathbf{2 0 0 6}$ \\
\hline $\begin{array}{l}\text { Large } \\
\text { enterprises }\end{array}$ & -18.2 & -7.9 & -1.5 & 3.5 & -10.5 & 7.6 \\
\hline SMEs & 8.7 & 6.7 & 0.9 & -0.6 & 3.4 & 1.0 \\
\hline
\end{tabular}

Source: Small and Medium Business Administration.

Restructuring following the crisis has allowed large enterprises to significantly improve their performance. In contrast, SMEs which largely avoided restructuring have experienced a secular decline in their financial health and profitability. This is apparent in the rising difference in profit margins until 2004 between SMEs and large enterprises (Table 1.4). This polarisation is also apparent in a higher debt to equity ratio for SMEs. In addition, there is a divergence within the SME sector itself with a significant share of very weak firms. ${ }^{19}$

Table 1.4. Profit margins of large enterprises and SMEs

Percentage of sales

\begin{tabular}{|c|c|c|c|c|c|c|}
\hline & 2001 & 2002 & 2003 & 2004 & 2005 & 2006 \\
\hline $\begin{array}{l}\text { Large } \\
\text { enterprises }\end{array}$ & 6.0 & 7.5 & 8.2 & 9.4 & 7.1 & 6.0 \\
\hline SMEs & 4.5 & 5.3 & 4.6 & 4.1 & 4.3 & 4.2 \\
\hline
\end{tabular}

Source: Bank of Korea.

Rates of firm birth have been stable for nearly half a decade and are high compared to other OECD countries: in 2005, 52587 new establishments were registered. While the creation of business start-ups in the manufacturing industry has slowed down, it has increased in the services industry. The number of firms going bankrupt has decreased in recent years, falling from 3214 in 2003, to 2200 in 2005.

The number of businesses owned by women represented $37 \%$ of all businesses in 2005 (as against $35 \%$ in 2000). These are mainly concentrated in the services industry (hotels and restaurants $35 \%$, retail and wholesale $30 \%$ ).

19 OECD (2005), Economic Surveys Korea p.36. 
Despite Korea's regulatory reform efforts since 1997, international indicators show that entry barriers are high. While the start-up time for a new business is reasonable in 2006, the number of procedures and the total cost for starting a business are higher than in most other high-income OECD countries according to World Bank evaluations.

Bankruptcy laws have been amended to facilitate the exit and restructuring of firms. Several fast tracks and less costly bankruptcy processes have been introduced for small firms. The unified bankruptcy law, integrating three bankruptcy-related laws, has allowed firms to choose between several bankruptcy processes, lowering costs as a consequence. According to the 2005 OECD Survey "Policy Questionnaire on Bankruptcy", ${ }^{20}$ possibilities for reorganising a company and chances of getting a fresh start in case of financial difficulties are just above average, compared to other OECD countries. FORA indicators ${ }^{21}$ point to relatively high bankruptcy recovery rates in 2006, indicating that the investor's loss in case of business closure is relatively low.

\section{2. $\quad$ Factors driving firm creation and expansion}

\section{a) Access to new technology and $R \& D$ benefits}

Korea is the world leader in producing ICT goods, and the share of ICT value added in the business sector value added is amongst the highest in the OECD area. Its domestic diffusion of ICT is stronger than the OECD average (Table 1.5), especially considering its per capita income reaching two-thirds of the OECD average. While Korea performs well in terms of broadband infrastructure there is a large digitalisation gap between metropolitan areas and regions. Overall, investment in ICT equipment is lower than in many other OECD countries (Figure 1.3). This can be explained by the high share of small and micro firms in the firm population and their inherent difficulty in absorbing ICT, notably in the services sector. A recent survey conducted by the Small and Medium Business Administration (SMBA) reveals that the informatisation level of SMEs in 2005 only ranked around 50 on a $0-100$ scale. Many SMEs have neither fully integrated the advanced broadband environment and the necessary intra-firm organisational changes, nor inter-firm collaboration linked to the integration of ICT. This is due to lack of awareness, lack of skilled labour and lack of specialist services. In addition, a large number of SMEs are discouraged by medium to longer term costs of IT investment.

Table 1.5 Diffusion of Information and Communication Technology ${ }^{1}$

\begin{tabular}{lcccccccc}
\hline & Mexico & Poland & Turkey & EU-15 & US & Japan & Korea & OECD \\
\hline Standard Access Lines & 15.9 & 29.6 & 26.7 & 43.5 & 59.5 & 40.4 & 57.7 & 43.6 \\
Access Channels & 18.9 & 32.9 & 27.0 & 58.9 & 62.3 & 55.0 & 58.4 & 52.0 \\
Mobile Subscribers & 29.3 & 45.5 & 39.4 & 84.8 & 54.5 & 67.9 & 70.1 & 64.2 \\
$\begin{array}{l}\text { Internet Subscribers to } \\
\text { fixed networks }\end{array}$ & 2.7 & 4.3 & 1.6 & 24.0 & 33.0 & 25.6 & 24.8 & 22.4 \\
Broadband Access $^{2}$ & 0.4 & 0.8 & 0.1 & 5.9 & 9.7 & 10.7 & 24.2 & 7.2 \\
\hline
\end{tabular}

1. Per 100 inhabitants in 2003.

2. "Other" broadband technologies include satellite broadband Internet, fibre-to-the-home Internet access, ethernet LANs, and fixed wireless subscribers (at downstream speeds greater than $256 \mathrm{kbps}$ ).

Source: OECD, SMEs in Mexico, 2007 based on the OECD Communications Outlook, 2005.

The 2005 OECD Survey on Bankruptcy analyses and compares regulation of rehabilitation, liquidation and restructuring of debt and discharge in different OECD countries. 
Figure 1.3. Investment in $I C T^{1}(1985-2003)^{2}$

Percentage of non-residential gross fixed capital formation

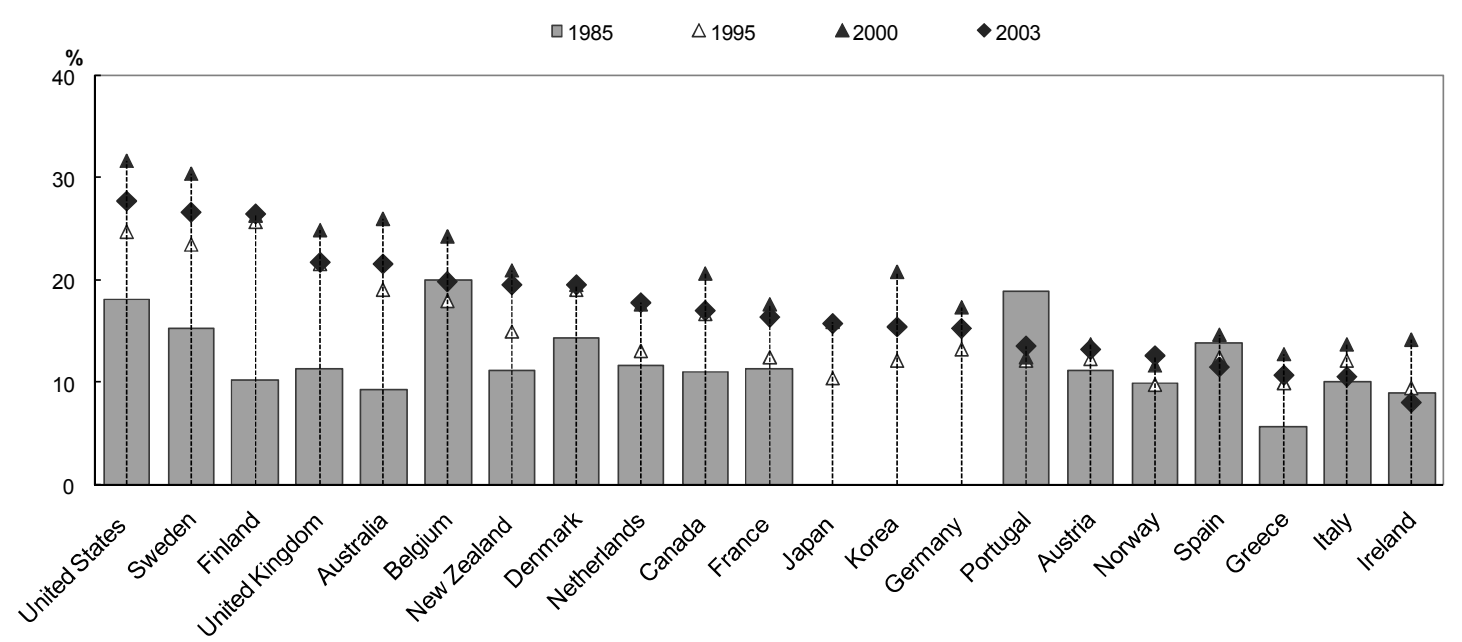

1. ICT equipment is defined here as computer and office equipment and communication equipment; software includes both purchased and own account software. Software investment in Japan is likely to be underestimated, owing to methodological differences.

2. Data for 2003 or latest year available.

Source: OECD Scoreboard 2007.

R\&D spending in 2005 was equal to $3 \%$ of GDP compared to $2.3 \%$ in 1999 . Expenditure is much higher than the $2.3 \%$ OECD average in 2005, Korea being ahead of the United States and just lagging behind Japan in terms of R\&D intensity. This is also the case of business R\&D spending which represented over $2 \%$ of industry value added in $1999,3.2 \%$ in 2005 , as against $2.2 \%$ for OECD countries. ${ }^{22}$ However, according to a number of indicators, Korea may not be getting the full benefit from high government and business R\&D spending. ${ }^{23}$ The output of codified knowledge in the form of patents and publications as measured by the number of triadic patent families is weak.

$R \& D$ expenditure is concentrated in a small number of firms and industries in manufacturing. About three-quarters of business-sector $\mathrm{R} \& \mathrm{D}$ is carried out in high and medium-high technology manufacturing industries; out of these three-quarters, $80 \%$ was concentrated in two sectors, ICT and automobile, one of the highest rates for OECD countries. Overall, Korea's business-sector R\&D activities are concentrated in a relatively small number of larger firms. A recent survey of 12000 firms with in-house research suggests that large enterprises accounted for $78 \%$ of business R\&D expenditure (the top five firms ${ }^{24}$ representing $45 \%$ ) in 2006. R\&D expenditure in the services sector on the other hand is comparatively very low. In 2001 and 2002 the proportion of service-sector enterprises engaged in innovation activity was $25 \%$, well below the EU average of $40 \%{ }^{25}$

22 OECD (2007), Science, Technology and Industry Scoreboard.

23 OECD (2005), Economic Surveys Korea p. 32.

24 Samsung Electronics, LG Electronics, Hundai Motors, Hynix Semiconductors and GM Daewoo Auto and Technology. 
The level of technology transfer from the public sector (universities and government research institutes) to the private sector is weak and insufficient. This is of concern as over half of the public R\&D budget is channeled to public research institutes and one-quarter to universities, while only $10 \%$ of government R\&D funds are directly allocated to SMEs. According to a recent survey from the Ministry of Commerce, Industry and Energy (2006), the technology transfer rate from the public sector and academia to the business sector was about $20 \%$ against respectively $28 \%$ and $41 \%$ for the United States and Canada.

The innovation system is characterised by limited reliance of industry on public scientific research benefits and low responsiveness of public research efforts to business demands. In 2003, 97\% of businessfinanced R\&D was performed by the business sector independently. In terms of innovative output, Korean firms rank rather high regarding product innovation ${ }^{26}$ for large firms, just above average for SMEs. In contrast, both large firms and SMEs rank very low as regards the development of an in-house process innovation $^{27}$ (Annex 1.A, Figures 1.A.2 and 1.A.3). SMEs in Korea tend to collaborate less in innovation activities $^{28}$ than the average of OECD countries (Figure 1.4).

Figure 1.4. Firms collaborating in innovation activities (2002-2004)

As a percentage of all firms

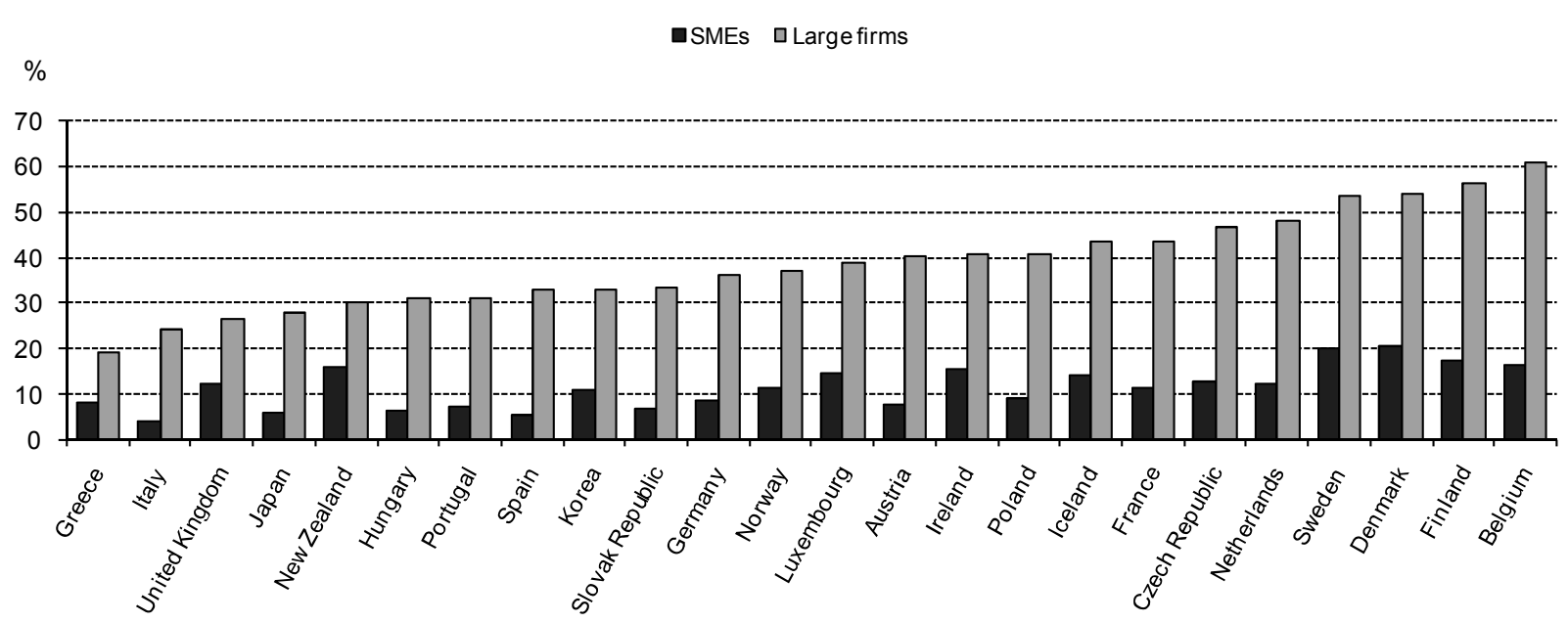

Note: SMEs: 10-249 employees for European countries, Australia and Japan; 10-99 for New Zealand, 10-299 for Korea.

Source: OECD Scoreboard 2007 based on Eurostat.

26 Product innovation is defined as the introduction of a good or service that is new or significantly improved with respect to its characteristics or intended uses. This includes significant improvements in technical specifications, components and materials, incorporated software, user friendliness or other functional characteristics (Oslo Manual, 2005).

Process innovation is defined as the implementation of a new or significantly improved production or delivery method. This includes significant changes in techniques, equipment and/or software (Oslo Manual, 2005).

Collaboration is defined as active participation in joint innovation projects with other organisations (Oslo Manual, 2005) but excludes pure contracting out of work. Collaboration can involve the joint development of new products, processes or other innovations with customers and suppliers, as well as horizontal work with other enterprises or public research bodies. 


\section{b) Access to finance}

The ratio of credit to the private sector from financial institutions is below average compared to other OECD countries and obtaining a bank loan without collateral is difficult. ${ }^{29}$ While loans to SMEs have risen continuously since the 1997 crisis (Figure 1.5) banks' decisions to lend to SMEs still rely heavily on real estate collateral or credit guarantees provided by the public sector. There is a reluctance to accept intangible assets such as innovative ideas, new technology or human capital. The minimum capital required for starting a business ${ }^{30}$ is comparatively high, acting as a major deterrent to firm creation and expansion.

Figure 1.5. Loans of banks to the private sector

KRW trillion

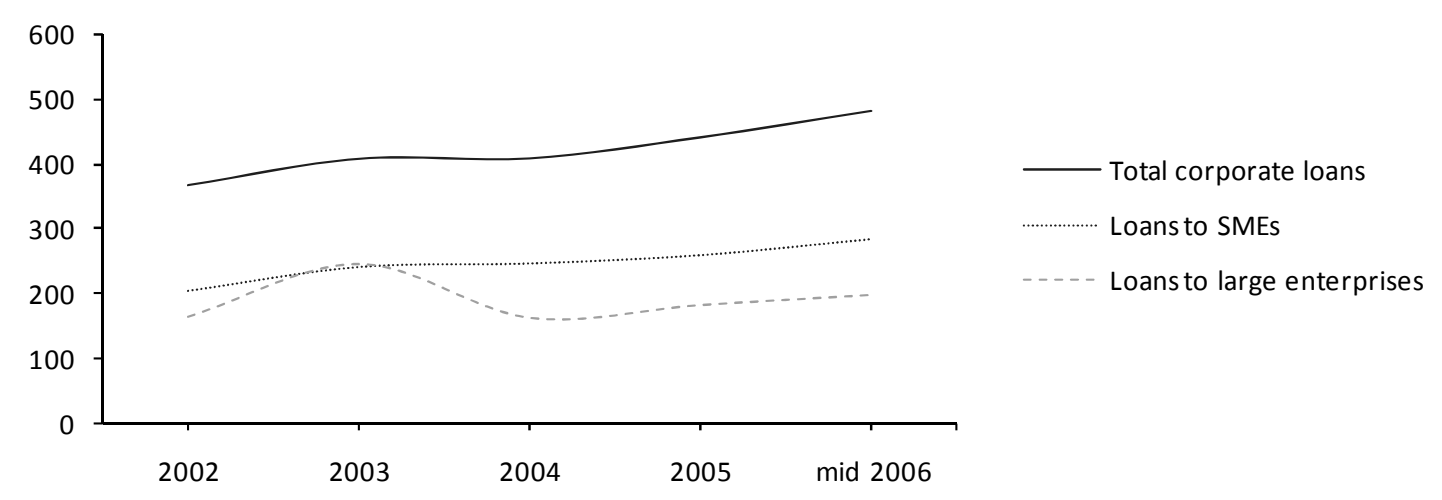

Note: USD 1 amounts to KRW 940 in 2008.

Source: Financial Supervisory Board.

By the end of 2006 the total amount of loans to SMEs reached USD 323 billion (as against USD 261 billion in 2004) while interest rates had reached 6.4\% in 2006 (5.6\% in 2004). Over seven years, real interest rates have decreased substantially (from $6.4 \%$ in 2000 to $4.2 \%$ in 2007 for short-term interest rates; from $7.7 \%$ in 2000 to $4.5 \%$ in 2007 for long-term interest rates). Even so, the level of interest rates has remained high relative to Korea's achievement in terms of per capita convergence. In 2007, Korea's real short-term and long-term interest rates still averaged 4.5\%, a figure close to Mexican rates, Mexico being a country with a much lower per capita income (Table 1.6). In the Euro zone, real interest rates averaged $2 \%$. 2006-2007).

According to data from the World Bank (Doing Business). 
Table 1.6. Real short-term and long-term interest rates (2007)

\begin{tabular}{lcc}
\hline & Short-term interest rate & Long-term interest rate \\
\hline Turkey & 8.2 & 8.4 \\
Denmark & 2.2 & 2.3 \\
Korea & 4.2 & 4.5 \\
Mexico & 4.5 & 4.8 \\
Norway & 3.2 & 3.2 \\
Euro area & 2.1 & 2.0 \\
\hline
\end{tabular}

Note: Real interest rates are nominal interest rates deflated by the GDP deflators.

Source: OECD Economic Outlook, June 2007.

Korea jump-started its venture capital market in 1998 to accelerate business restructuring, slimming large companies and improving conditions for start-ups in knowledge-based industry. At the beginning of 2000, Korea ranked among the leading OECD countries in venture capital investment as a share of GDP. After the crash of the KOSDAQ ${ }^{31}$ in 2000, the number of venture capital firms and the number of funds declined significantly (Figure 1.6). This was also due in part to a tightened certification criterion introduced in $2002^{32}$ after a number of firms had succeeded in being unjustifiably qualified. Venture capital is still provided by the government ${ }^{33}$ (31\% in 2004), banks, corporations and insurance companies, the roles of pension funds and business angels being relatively minor. Investor trust has been missing since the collapse of the venture capital market in 2000/2001 making it difficult for business start-ups to raise funds.

Figure 1.6. Enterprises receiving venture capital

KRW 100 million

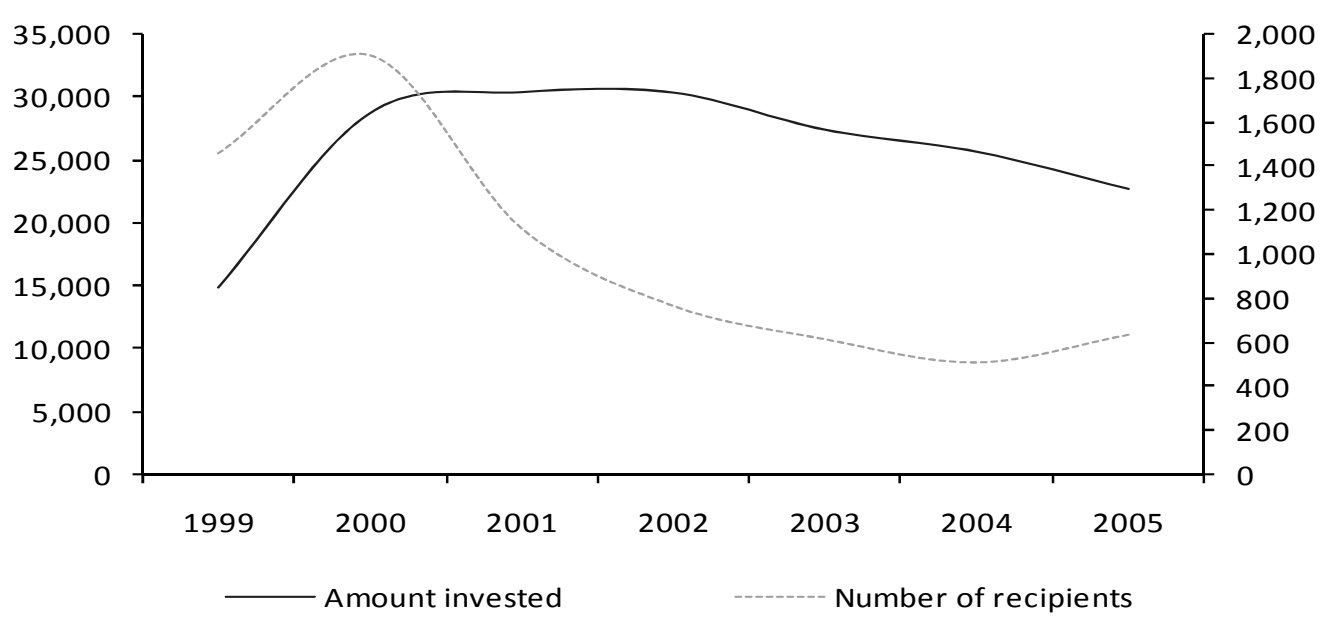

Source: SMBA 2006.

31 KOSDAQ is the electronic stock market division of Korea Exchange.

32 A legal category was created in 1997 with the Special Measures Law for Fostering Venture Businesses for enterprises receiving venture capital, in order to facilitate the creation of small, high-technology firms. To be part of this category, an enterprise must meet one of three conditions (equity investment exceeding $10 \%$ of capital over six months, investment in research and development exceeding $5 \%$ of revenue, or sale of products incorporating patent rights) and be approved by an independent institution.

In other OECD countries, the role of government has gradually been phased-out. 
Venture capital investment per year - in particular early stage venture capital was amongst the highest in OECD countries in $2001,{ }^{34}$ but it has significantly decreased since. Entrepreneurs with innovative, but risky projects find it difficult to have access to venture capital (FORA, 2007). ${ }^{35}$

\section{c) Access to capabilities and to skilled labour}

Korea has achieved impressive results in terms of upgrading the level of human capital over the past 20 years. While the percentage of the population with upper-secondary education is below average for the population aged 45-54, it is amongst the highest of all OECD countries for the population aged 25-34 (Annex 1.A, Figure 1.A.4). Spending on education as a share of GDP is the highest in the OECD, reflecting a high investment in knowledge. Korea's focus on primary and secondary school education has contributed to the outstanding performance of its students by international standards. Korean fifteen-year olds have very high scores in the PISA ${ }^{36}$ test (Annex 1.A, Figure 1.A.5), and a high number of students are pursuing scientific and technical courses.

In tertiary education, however, there has been a decline in quality in the context of a sharp increase in quantity: about $50 \%$ of the population aged 25-34 has completed tertiary education in 2004 (Annex 1.A Figure 1.A.6), against less than $20 \%$ for the population aged $45-54$ (the average for 19 European Union countries is $30 \%$ ). The ratio of students to teaching staff has risen to a level well above the OECD average, while spending per student is about $15 \%$ of the OECD average. The related reliance on private outlays and the limited supply of student loans or grants has created concerns about the access of low-income households to higher education. A survey of business executives ranked the usefulness of Korea's university education $59^{\text {th }}$ out of 60 countries. ${ }^{37}$

\section{Entrepreneurship and SME policies}

\section{Overall aims of entrepreneurship policy}

For about 40 years, SME policies have focused on protecting SMEs' business territory from large enterprises and ensuring SME stability. Since 2004, SME policies have become more market-oriented, pro-competitive and forward-looking, encouraging entrepreneurship and SME innovation. ${ }^{38}$ Korea's SME policy priorities aim to create a positive environment for SMEs allowing any entrepreneur with creative ideas and dynamism to start a new enterprise as well as to increase SMEs' innovative capacity and global competitiveness. Differentiated policy programmes have been implemented depending on the type of SME (Box 1.1). The development of innovative SMEs has nonetheless been at the heart of SME policies and even economic policies as a whole. The creation of the KOSDAQ and the enactment of the law on special measures to promote venture business were designed to feed high-technology start-ups with funds.

\footnotetext{
$34 \quad$ OECD (2007), Science, Technology and Industry Scoreboard.

35 FORA indicators based on data from the World Economic Forum (Global Competitiveness Report 2006-2007).

36 PISA stands for Programme for International Student Assessment.

37 OECD (2005), Economic Surveys Korea p. 32.

OECD (2005), SME and Entrepreneurship Outlook.
} 
Box 1.1 Target groups in SME policies and programmes

- "Innovative and leading SMEs" are those equipped with independent R\&D and commercialisation abilities. They are estimated to represent about $10 \%$ of the total number of SMEs (micro-enterprises excluded). Programmes supporting this group focus on facilitating start-up, technology development and marketing in order to meet global standards.

- Programmes for "Self-reliant SMEs" include revitalising their start-up activities and providing structural improvement. This also includes helping SMEs who lack competitiveness to operate a business switch.

- "Micro-enterprises" refer to self-employed engaged in subsistence sectors (manufacturing, distribution, services). Various support programmes include start-up training and management innovation.

SME policies and programmes have been modified annually in Korea, yielding a wide array of SME support measures (Annex 1.A, Table 1.A.2). In 2004, as much as 76 different programmes were supervised by 12 different ministries. Programmes are structured around four main policy areas: enhancing entrepreneurship and facilitating start-ups, easing access to finance and venture capital markets, promoting technology and increasing innovation capacity, and strengthening human capital.

In recent years, two major plans have affected start-ups and SMEs (Box 1.2). In 2004 a comprehensive programme (Plan to restructure the national innovation system) was launched to restructure the national innovation system. It aimed to: provide effective tax incentives to the business sector to boost R\&D; foster 10000 innovation-driven SMEs through technical and financial assistance, subsidies for employing R\&D personnel and easing regulation on start-up companies; create incentives at tertiary level and reform the primary and secondary school to secure future science and engineering students; strengthen technology diffusion; develop regional innovation clusters and foster Daedeok Science Town as a special R\&D region; strengthen linkages between business, government and universities.

In 2005, a government programme was adopted for small self-employed businesses and the services sector to restructure services, stabilise business activities of the small self-employed and upgrade competitiveness through franchising. Measures included: introducing/strengthening entry barriers in services, establishing regional consulting centers for the self-employed offering tailor-made consulting services and providing financial support to viable businesses via regional credit guarantee funds.

\begin{tabular}{|c|c|}
\hline & Box 1.2. Calendar of major Entrepreneurship and SME Policy events \\
\hline 1996 & $\begin{array}{l}\text { Creation of Small and Medium Business Administration (SMBA) } \\
\text { Creation of KOSDAQ }\end{array}$ \\
\hline 1997 & Law of Special Measures to promote Venture Business \\
\hline 1998 & $\begin{array}{l}\text { Creation of the Presidential Commission on Small and Medium Enterprise } \\
\text { Korea Small Business Innovation Research Programme (KOSBIR) } \\
\text { Implementation of the "Inno-Biz" Programme }\end{array}$ \\
\hline 2000 & Technology Transfer Promotion Act and creation of Korean Technology Transfer Center (KTTC) \\
\hline 2002 & $\begin{array}{l}\text { Tightening of the certification criterion for venture firms on the KOSDAQ market } \\
\text { Creation of the Digital Innovation Consortium Programme and the SME IT implementation }\end{array}$ \\
\hline 2004 & Plan to restructure the national innovation system \\
\hline 2005 & $\begin{array}{l}\text { Programme for small self-employed businesses and for the services sector } \\
\text { Plan for a balanced national development }\end{array}$ \\
\hline 2006 & Promotion of co-operation between large enterprises and SMEs Act \\
\hline
\end{tabular}




\section{Main actors}

The Small and Medium Business Administration (SMBA) established in 1996 is the main actor in the field of entrepreneurship and SME policies (Figure 1.7); the administrator of SMBA is hierarchically at vice-minister level. Its mandate is to plan, implement and evaluate SME policies. A public agency, it reports to the Ministry of Commerce, Industry and Energy (MOCIE). SMBA has 6 offices at its headquarters and 11 regional offices. It employs a total of 630 persons. SMBA's budget amounted to KRW 2 trillion in 2006.

The Small Business Corporation (SBC), which reports to SMBA, was set up in 1979 to implement and fund some of the SME programmes. SBC's budget was KRW 6.5 trillion for 2006 and the loans supplied to 9000 SMEs amounted to KRW 2.1 trillion. Its 748 staff members provide consulting services to about 2500 firms and train 67000 persons every year.

Two independent public guarantee institutions, the Korea Credit Guarantee Fund (KCGF) and the Korea Technology Credit Guarantee Fund (KOTEC) provide credit guarantees to SMEs:

- KCGF was established in 1976 under the provisions of the Korea Credit Guarantee Fund Act. Its mandate is to achieve a balanced development of the national economy by extending credit guarantees to enterprises lacking collateral. It also ensures sound credit transactions through efficient management of credit information.

- KOTEC was founded in 1989 under the Financial Assistance to New Technology Business Act. TCGF provides credit guarantees to new technology based enterprises, to technologically strong SMEs and venture businesses.

The myriad of programmes designed for SMEs in the past decade involved most ministries (Annex 1.A, Table 1.A.2), creating problems of ministerial co-ordination. This has motivated the establishment in 1998 of a Presidential Commission on Small and Medium Enterprise, simplifying and harmonising SME policies. The responsibility for entrepreneurship and SME programmes lies with three ministries: MOCIE, the Ministry of Information and Communication (MIC) and the Ministry of Labour.

Figure 1.7. Major stakeholders of Entrepreneurship and SME policy

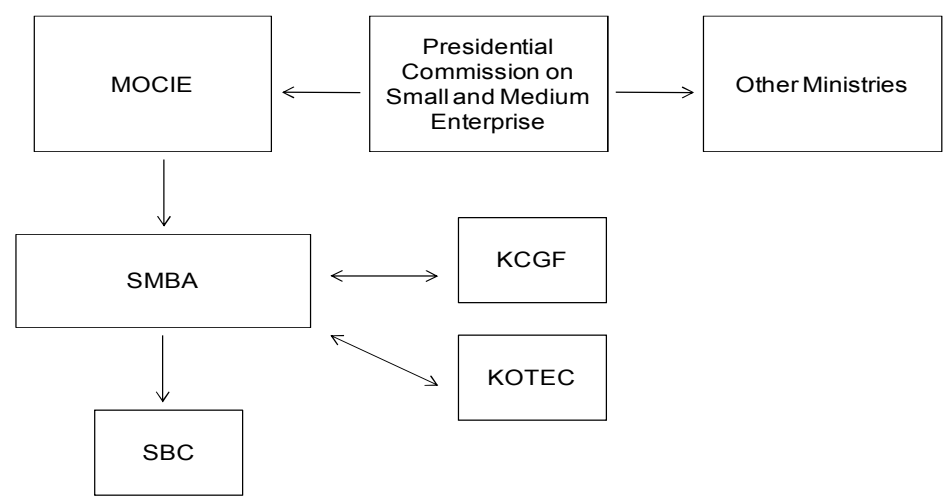

\section{Strengthening entrepreneurial and innovation activities}

a) Access to technology, $R \& D$ benefits and networking activities

Developing SMEs' capacity in terms of technology and knowledge has been a key policy priority since 1998. The size of R\&D funds available for SMEs has been rising continuously since 2001 - SMBA 
R\&D funds represented USD 383 million in 2007 as against USD 139 million in 2001 (see Table 1.7 for the allocation of SMBA's R\&D budget).

Entrepreneurship and SME policies have mainly targeted the promotion of technology-based startups. Programmes (Table 1.8) have consequently focused on four intervention areas: $i$ ) fostering innovative SMEs ii) facilitating commercialisation of R\&D; iii) reinforcing networks between industry, academia and research institutes, but also between large enterprises and SMEs, iv) integrating SMEs in the digitalisation infrastructure.

Table 1.7. Allocation of SMBA's R\&D budget

$$
\text { USD million }
$$

\begin{tabular}{|c|c|c|c|c|c|c|c|}
\hline Programmes & 2001 & 2002 & 2003 & 2004 & 2005 & 2006 & 2007 \\
\hline $\begin{array}{l}\text { Technological innovation } \\
\text { though collaboration }\end{array}$ & - & - & 2.1 & 2.7 & 2.7 & 6.6 & 10.6 \\
\hline $\begin{array}{l}\text { Joint industry-academia } \\
\text { R\&D }\end{array}$ & 37.2 & 40.5 & 36.3 & 41.6 & 44.8 & 49.0 & 56.4 \\
\hline $\begin{array}{l}\text { Technology Purchasing } \\
\text { Insurance for SMEs }\end{array}$ & - & - & 4.3 & 4.3 & $1-.6$ & 17.0 & 32.0 \\
\hline $\begin{array}{l}\text { Effective technology } \\
\text { transfer to SMEs }\end{array}$ & 10.6 & 7.6 & 6.3 & 6.3 & 6.3 & 9.6 & 9.8 \\
\hline $\begin{array}{l}\text { Support to university } \\
\text { technology transfer } \\
\text { centers }\end{array}$ & - & - & 0.5 & 0.3 & 0.3 & - & - \\
\hline $\begin{array}{l}\text { SMEs' Technological } \\
\text { innovation }\end{array}$ & 91.6 & 105.6 & 117.1 & 138.9 & 151.3 & 169.8 & 212.2 \\
\hline $\begin{array}{l}\text { University-industry } \\
\text { collaboration }\end{array}$ & - & - & - & - & - & 7.4 & 29.0 \\
\hline Total R\&D budget & 139.5 & 168.8 & 185.2 & 225.6 & 246.5 & 285.0 & 383.0 \\
\hline
\end{tabular}

Source: Response of the Korean government to the 2008 OECD background report.

Table 1.8. Programme beneficiaries (2006)

\begin{tabular}{|l|c|}
\hline \multicolumn{1}{|c|}{ Programmes } & Number of firm beneficiaries \\
\hline Inno-Biz & 5000 \\
\hline SME Technology Innovation & 1900 \\
\hline Industry-University-Research Consortium & 2700 \\
\hline Innovative Cluster Policy & 1959 \\
\hline Business Incubators & 4300 \\
\hline Digital Innovation Consortium & $8^{1}$ \\
\hline SME IT implementation & 312 \\
\hline
\end{tabular}

1. A Consortium includes universities, research institutes and small enterprises. 
DSTI/DOC(2008)5

\section{Increasing SMEs' innovation capacity}

The Korea Small Business Innovation Research Programme (KOSBIR) was introduced in 1998 to support the technological development of SMEs. Under this programme public institutes and central government agencies are to allocate $5 \%$ of their R\&D budget to the technological development of SMEs.

The Inno-Biz Programme was introduced in 2001 to better identify and foster innovative SMEs. Firms defined as innovative businesses are those which are equipped with superior technology and able to enhance their technological level through their own technological innovation system. The programme aims to help these SMEs grow and become well-established firms by providing them with technology guarantees and preferential treatment on credit loans. In 2006, around 7000 SMEs were classified as "Inno-Biz".

The SME Technology Innovation Programme introduced in 2001 funds SMEs capable of developing new technologies independently. These firms can recover $75 \%$ of their expenses linked to developing new products and enhancing product quality up to certain ceilings (USD 300000 for two years in the case of strategic tasks; USD 100000 for one year in the case of general tasks). Over 1900 SMEs benefitted from the programme in 2005.

To promote SME products with new technology, the government introduced Priority Purchasing of Technology Products in the mid-1990s. Development of new technology by SMEs was encouraged by making public institutions purchase SME products developed with new technology first. Since 2002 the government also introduced a purchasing insurance on new products developed by SMEs: public institutions and large enterprises commission SMEs to develop a new technology and commit to purchase new products over a certain period of time.

Business Incubators (BIs) have been introduced in some universities and research institutes since 1998 in order to increase the chances of survival of newly created firms, and to promote the expansion of newly created technology-oriented enterprises. In 2007, 269 BIs provided facilities and equipment to more than 5000 companies over 3-5 years', $84 \%$ of these BIs being situated in universities. Services and support include amongst others the office or production space, expert consulting services, marketing training and connection to investors. Business incubators, who are overseen by SMBA were downsized for more efficiency between 2005 and 2007 and were scaled-down from over 300 to about 270.

\section{Facilitating technology transfer and commercialisation}

The government adopted the Technology Transfer Promotion Act in 2000 in order to promote technology transfer from the public to the private sector. The Korean Technology Transfer Centre (KTTC) was established to better assess the potential of technology, and develop its financial return, by helping SMEs to commercialise it. Under the Transferred Technology Development Project, SMBA covers additional development costs required to commercialise technologies owned by universities, research institutes and businesses. According to MOCIE, the technology transfer ratio from research institutes and universities has risen from $18.5 \%$ in 2004 to $20.7 \%$ in 2005 .

In 1998, the government introduced a three years leave of absence for professors and researchers in order to incite high-skilled individuals to start an innovative business (see Table 1.9 for the number of businesses created by professors and researchers). The 2007 amendment to the law of special measures to promote venture business has introduced further incentives for starting a businesses using new technology. It allows professors or researchers to make profit out of their technology and creates special areas within universities and research institutions with integrated entrepreneurship facilities. The option of a leave of absence for professors and researchers has been extended to six years and to all forms of business creation. 
Table 1.9. Businesses created by professors or researchers

\begin{tabular}{|l|c|c|c|c|c|c|c|c|c|}
\hline & $\mathbf{1 9 9 8}$ & $\mathbf{1 9 9 9}$ & $\mathbf{2 0 0 0}$ & $\mathbf{2 0 0 1}$ & $\mathbf{2 0 0 2}$ & $\mathbf{2 0 0 3}$ & $\mathbf{2 0 0 4}$ & $\mathbf{2 0 0 5}$ & $\mathbf{2 0 0 6}$ \\
\hline Number of start-ups & 582 & 973 & 1667 & 1837 & 1839 & 2865 & 3144 & 2290 & 2022 \\
\hline
\end{tabular}

Source: Response of the Korean government to the 2008 OECD background report.

The Industry-University-Research Consortium Programme is run by SMBA and was introduced in 1993 to increase the technological capacity of SMEs. Under this programme, universities or research institutes develop technology needed in the manufacturing field in collaboration with SMEs. Stakeholders of regional innovation - Regional Innovation Centers (RRC), Techno Parks, Business Incubators (BIs), Technology Licensing Offices (TLO) - are also involved in the programme. In 2005, about 220 consortia were formed to support 2700 SMEs in developing new technologies.

A network of support for SMEs on intellectual property (IP) matters was established in 2000, involving the Korean Intellectual Property Office (KIPO), the chambers of commerce, the government SME support agencies, local governments, the Korean Patent Attorneys Association (KPAA) and other private partners. It aims to help SMEs acquire IPRs, support commercialisation and reduce costs linked to the patenting of inventions. KIPO and KPAA signed a co-operation agreement whereby SMEs are provided with free patent management services for their first patent application.

\section{Encouraging networking}

The Innovative Cluster City Policy was introduced in 2005 as part of the comprehensive Plan for National Balanced Development (2005-2008). This policy aims to strengthen the industrial complex by integrating R\&D infrastructures and developing networks between academia, research institutions and industry. It aims to transform seven key regional industrial complexes from manufacturing centers into more innovation-oriented regional hubs. As of 2007, 1893 firms, 661 universities and research centers and 303 supporting institutions were involved in the programme.

To allow innovative SMEs to locate their buildings in areas where access to finance, transports, communications and research are high level, the government has provided incentives for private building companies to host innovative SMEs through exemptions from local taxes and expenses since 2001. In the context of the policy for a balanced regional development, a selection of areas were identified as "venture promotion areas" and innovative SMEs were incited to move from the metropolitan area to regional clusters. There are currently 25 priority areas, 8 are situated in the metropolitan region while 17 are dispersed in other regions. A total of USD 144 million were raised by the central government and the local governments (on a one-to-one basis) to allow the creation of favourable business conditions in these identified areas. This has included the creation of business support centers. Between 2002 and 2006, the concentration level of SMEs has increased from $17 \%$ to $22 \%$; the average sales have risen by $56 \%$ while the average employment has increased by $30 \%$.

To address the rising bipolarisation between large companies and SMEs in terms of labour productivity, profits and wages, the Korean government has introduced a new framework to enhance co-operation. Under the 2006 Act on Promoting Cooperation between Large companies and SMEs MOCIE has set up a foundation in collaboration with business to execute policies. Enhanced cooperation takes the form of exchange of information, human resource development, joint efforts in R\&D activities and fair treatment of SMEs. 


\section{Enhancing access to information technology}

As small firms are relatively slow in adopting ICTs and new technologies, the Korean government has created programmes promoting ICT use by small and micro firms. These are run separately or jointly by MOCIE, MIC and SMBA. Programmes often target SMEs in the early stages of e-business adoption or those without e-business experience.

- The Digital Innovation Consortium is run by the SMBA, regional universities, related agencies and consulting firms and assists SMEs in IT strategy, restructuring and in the use of appropriate software.

- With the SME IT implementation support programme, the government provides $80 \%$ of the cost of professional consulting and the planning of IT implementation. Basic software, consulting services and training on the use of software are provided by the SBC and the Korean Chamber of Commerce and Industry.

To bridge the digitalisation gap between metropolitan areas and local regions and to accelerate the digitalisation of SMEs in economically poor areas, the Regional Cluster for Digitalisation Innovation programme created in 2002 seeks to establish a broadband Internet infrastructure and an internal network to lay the foundation for digitalisation. The SMBA designated clusters in 8 regions in 2005 (budget USD 2.1 million).

\section{b) Better access to finance}

The government has provided direct and indirect financing support for SMEs which find it difficult to obtain a bank loan without collateral. Direct financing is provided by venture capital and the KOSDAQ market. Indirect financing services are provided through a guarantee system (security assurance service) for SMEs which are ineligible for bank loans, due to a lack of collateral and technology.

Two organisations are involved in the credit guarantee schemes. SMEs can borrow funds from banks through the Korea Credit Guarantee Fund (KCGF) or the Korea Technology Credit Guarantee Fund (KOTEC). In 2006, KOTEC provided a total of KRW 931 billion worth of guarantees to 7314 beneficiaries and KRW 90 billion to 348 enterprises at incubation stage. KCGF had KRW 28 trillion worth of credit guarantees for the same year, the number of firm beneficiaries being 203096 . The base for guarantees is strengthened through financial government support to these organisations. The stock of guarantees represented 6\% of GDP in 2004 and covered almost one-third of total lending to SMEs. On average, credit guarantees have an average duration of five years.

Eligible small business owners, enterprises in the start-up phase, technology-oriented SMEs or SMEs awaiting reorganisation can also obtain loans from the SBC at a low interest rate. The total policy funds allocated in 2007 amounted to KRW 12 trillion (0.16\% of GDP). In addition, Bank of Korea's regulation on loan operation of financial institutions calls for banks to allocate more than $60 \%$ of their loan increases to SMEs. Since 2004, an insurance programme, the Account Receivable Insurance Programme, has been set up to protect SMEs against failure to collect payment and risks of resulting bankruptcies.

The Korean government puts strong emphasis upon venture capital markets as a primary source of funds for financing start-ups and high-growth businesses. To revitalise the supply of finance to SMEs, the government has supported the venture capital market by creating venture capital investment funds, setting up venture capital firms and venture capital partnerships. In 2006, the SMBA planned to create USD 500 million worth of venture investment funds, by setting up 102 venture capital firms and 400 venture capital partnerships. A "fund of funds" amounting to USD 1 billion was also created by the 
government in 2004 to finance investment funds for venture businesses and therewith to meet long-term financing needs of the capital market. SMBA is also trying to revitalise the venture capital market by creating a USD 120 million active secondary fund aimed at buying the shares unlisted on KOSDAQ.

Since 1998 the government introduced tax benefits (including income tax reductions) to induce individual investors to fund innovative SMEs. If an investment is made through a venture fund or through an association of individual investors, $10 \%$ of the amount invested (or $50 \%$ of the gross annual income) is deducted from the gross income if the investment is over a period of more than five years. If an investment is made in a company that was founded or transformed within the last three years, resulting capital gains are exempt from tax if the investment is over a period of five years. The Korea Business Angel Network (KBAN) provides support for venture investment.

\section{c) Better access to entrepreneurial education and training}

A key element in Korea's entrepreneurship and SME policies has been the promotion of business start-ups through: entrepreneurship training, enhancing entrepreneurial spirit and providing young, would-be entrepreneurs with assistance to succeed in starting their business.

Both short-term and long-term entrepreneurship training programmes have been set up. Since 2004, five universities in Korea (notably Hoseo University and Jungang University) have launched a five-year pilot entrepreneurship programme, "Entrepreneur Graduate Schools", to train "start-up specialists". The education programme called "Start-up Course" created in 2002 on the other hand is a short-term training provided by local universities and specialised institutes. The course is designed to improve management skills of entrepreneurs and therewith to raise the start-up success rate. Around 100 courses are offered each year. In addition, a special "Technology start-up programme" was set up in universities in 2005 to target potential entrepreneurs with technological knowledge. It includes customised support programmes, training and network-building at the pre start-up stage. About 300 graduates benefit from the programme every year, $50 \%$ of them starting their business following the completion of the course.

Entrepreneurship development programmes have been set up both at secondary and tertiary level to raise the entrepreneurial mindset in youth. The "Biz-cool programme", created in 2003 for teenagers, has been implemented in middle and high schools as a pilot project. By 2007, more than 150000 students had benefitted from the programme (Table 1.10). The course includes financial education, self-management, business start-up and business administration and aims to develop students' business mentality and entrepreneurial spirit. It has also evolved from conventional lectures to practical courses involving visits to SMEs and start-up simulation.

Table 1.10. Participants in the Bizcool programme

\begin{tabular}{|l|c|c|c|c|c|}
\hline Participants & $\mathbf{2 0 0 3}$ & $\mathbf{2 0 0 4}$ & $\mathbf{2 0 0 5}$ & $\mathbf{2 0 0 6}$ & $\mathbf{2 0 0 7}$ \\
\hline Schools & 50 & 80 & 100 & 83 & 94 \\
\hline Students & 10000 & 23000 & 23000 & 32000 & 53000 \\
\hline Instructors trained & 320 & 340 & 210 & 182 & 150 \\
\hline
\end{tabular}

Source: Response of the Korean government to the 2008 OECD background report.

Since 1997, the government also supports "Entrepreneur clubs" at universities, with funds and training to favour a start-up mindset in students and to promote entrepreneurship. College students are 
trained as future entrepreneurs, enhancing creativity and frontier spirit. Currently more than 960 of these clubs exist in over 370 universities and have reached about 16000 students.

Efforts have also been made to upgrade the quality of the SME workforce. The first SME center, a public education institute, was set up in 1982 in Ansan City to improve the work skills of SME employees at an affordable cost. In addition, three regional centers were established recently. The centers provide about 800 different short-term in-house training programmes ranging from production technology, IT/automotion, quality assurance to digital technology. In 2007, 69025 SME employees benefitted from this training.

Finally, SMBA is supporting part of the expenses linked to consulting services provided to SMEs. Consulting firms need to register with SMBA to provide services including advice on business model, management and technology to start-ups lacking administrative skills and know-how. By 2007, 176 consulting firms were collaborating with SMBA. Government funds allocated to this programme amounted to USD 2.9 million in 2007 compared to USD 1 million in 2002.

\section{Entrepreneurship and SME policies and their impact upon firm creation and innovation}

Korea has placed entrepreneurship and SME policy at the core of governmental action for over a decade. A special institution responsible for small and medium enterprises (SMBA) was created in 1996 and a Presidential Commission was set up in 1998, showing the determination to have a comprehensive, well-designed and well-coordinated policy approach. Although a myriad of programmes have been created for various SME categories, policy has mainly promoted innovative start-ups and supported industrial SMEs in upgrading their innovation potential.

Entrepreneurship policy has rightly focused on facilitating access to finance both directly, through the creation of an extensive credit guarantee scheme, and indirectly, through the venture capital markets. Many programmes have also strengthened innovative activity, increasing ICT use by SMEs, facilitating the commercialisation of research, creating knowledge networks to unleash the innovation potential of SMEs. The introduction of entrepreneurial education at school and at universities in 2003 and the creation of business incubators at universities have strengthened innovation trends further. Initiatives over the past three years have increased networking opportunities and local knowledge diffusion. As a result, entrepreneurial activity in Korea has been dynamic with stable birth rates and declining death rates for firms. The average life of firms has thus lengthened.

There is nonetheless room for using entrepreneurship and SME policy further to activate the potential of the innovation system. SME and entrepreneurship policies have been overly ambitious in attempting to address various needs of small business. This lack of policy focus has raised problems of overlapping and co-ordination between different ministries and government agencies. In addition, it has led to a lack of clear and overarching policy priorities helping SMEs to restructure and increase their competitiveness and innovation potential.

Indicators point to a duality in the firm population, meaning that policies need to address both helping larger firms in the manufacturing sector keep their competitive edge, while allowing smaller firms, notably in the services sector, to catch up in terms of productivity rates. An efficient infrastructure of business services providing differentiated support and training would allow easier diffusion of knowledge in the business sector. Results on the output of codified knowledge show that Korea is far from receiving the full benefits from its high investment in R\&D. This implies that there is large scope to improve networks between the different actors of the innovation framework. 


\section{The need for stronger networks to spread knowledge and reap the benefits from $R \& D$}

As reflected by the high level of $R \& D$ expenditure, innovation has been a strong policy priority in Korea for over a decade. Programmes have focused on supporting innovative start-ups and upgrading the innovation potential of existing SMEs. The Technology Transfer Promotion Act was adopted in 2000 to increase the commercialisation potential of research. The Inno-Biz Programme and the SME Technology Innovation Programme were introduced in 2001. The 2002 Digital Innovation Consortium and the SME IT implementation programmes aimed to improve use of ICT by small enterprises. More recent policy initiatives have strengthened networking activities, through an increased information exchange between business and research sectors, between large and small enterprises (2006 Act on Promoting Cooperation between Large companies and SMEs), through the creation of regional clusters (2005 Innovative Cluster City Policy).

A number of indicators, however, suggest that Korea is not reeping the full benefits from the continuous increase in government and business R\&D expenditure. Expenditure is concentrated on a limited number of firms in the manufacturing sector and outcomes of research are more geared towards product than process innovations. This raises concerns as Korea approaches the technology frontiers in different areas and firms need to develop their own technological capabilities. The innovation potential of the services sector is largely untapped - in 2001 the services sector accounted for only $13 \%$ of business $\mathrm{R} \& \mathrm{D}$ - and productivity in this sector is unusually low.

Korea's innovation system would greatly benefit from collaborative (collective process) innovations taking the form of deeper and wider networking among academia, research centers, business development centers and the business sector. The current insufficient co-operation between the business sector and universities or government research institutes means that there is little entrepreneurial attempt to commercialise the findings of public research and that the technology transfer from the public to the private sector is low. This also acts as a barrier to the mobility of researchers who are deterred from entering business laboratories. Making potential entrepreneurs aware of support options and helping them to apply for assistance or make the most of credit funds could ease barriers to firm creation. Concentrating efforts on building an infrastructure disseminating the findings of research and providing subsequent business advice would thus be a major step in augmenting Korea's collaborative innovation potential.

Stimulating growth-oriented entrepreneurial activity also involves increasing vertical networkbuilding between SMEs and large enterprises to spread chain-based innovations. Korea could build further on the co-operation between SMEs and large enterprises with well-designed vertical suppliers' development programmes integrating SMEs in vertical supply chains. Such links in services would notably allow raising productivity levels in this sector and reversing the rising bipolarity between small and large enterprises.

In order to spread scientific and technological knowledge, enhanced horizontal collaboration between SMEs in the same sector could be further strengthened by using best practice and building on clustering activities. This would also involve building an efficient infrastructure of differentiated business services managed by public or private institutions.

\section{Changing cultural attitudes towards entrepreneurship through education and training}

Entrepreneurial education for aspiring entrepreneurs and basic entrepreneurial training courses for actual entrepreneurs are known to be highly efficient in overcoming psychological barriers to firm creation and in removing inefficiencies in the production process. Entrepreneurship education has received increasing attention since 2003 with the creation of the Biz-cool programme for secondary and tertiary level and the launching of two-year pilot entrepreneurship programmes at universities (Entrepreneur 
Graduate Schools). Short-term training is also provided by universities or specialised institutes to improve management skills of entrepreneurs.

Although significant progress has been made in the domain of education and training in half a decade, there is still room for improvement. Cultural values are traditionally rather reticent towards firm creation. Starting a business has been and is still perceived as a difficult and risky project. In addition, the success rate of businesses created by highly skilled entrepreneurs such as researchers and professors has not been as high as expected, acting as a deterrent for well-educated individuals to start their own business.

To reverse this trend and attract potential entrepreneurs into self-employment a better support infrastructure is needed (business incubators, business development centers, expert consulting services) in order to encourage firm creation and reduce the risk of failure. Surveys ${ }^{39}$ show that the image of small business in Korean society is still relatively low management instability, poor working environment and low competitiveness. This calls for increased entrepreneurship education opportunities for younger generations to change public knowledge and social perception of entrepreneurial activities.

In addition, there is a need to invest more in human capital at the tertiary education level to succeed in the educational domain and ensure an adequate supply of high-skilled human capital, strengthening innovation trends. Educational opportunities should also be extended to all segments of the firm population through differentiated training opportunities in order to help inefficient micro firms raise their productivity level.

\section{Improved financial infrastructure}

Korea has set up a comprehensive financial system to support start-up businesses and SMEs through a strong national credit guarantee system and a relatively high level of early stage venture capital. Yet, it is still difficult for entrepreneurs to obtain a bank loan without collateral, real interest rates still remain relatively high and international indicators (FORA, 2007) suggest that it is comparatively difficult for entrepreneurs to raise funds for risky projects.

The credit guarantee scheme has facilitated access to finance for a high number of beneficiaries. However, insufficient analysis of credit risks has allowed a number of SMEs recording losses to survive and the extension of the term of credit guarantees has delayed the restructuring of the small enterprise sector, eroding the competitiveness and independence of SMEs. This aid needs to be reduced by rescaling credit guarantees through the introduction of a better credit rating system and increased expertise in assessing loan applications from firms that have no or little collateral. This would improve the selection of beneficiaries and shorten the duration of the credit schemes.

With the 1997 "Act on Special Measures for the Promotion of Venture Businesses" the government has aimed to develop the venture business sector to shift the weight of the economy to start-ups in knowledge-based industries. The government jump-started the venture capital market by providing equity capital from the public sector, generous tax incentives for venture capitalists and equity guarantees. Venture capital investments were centered on firms certified by government and receiving a number of benefits (reduced minimum capital requirement, tax exemptions, loans for start-ups, credit guarantees relaxed listing for KOSDAQ).

So far, the role played by individual investors (business angels) and pension funds has been limited as the capital market is still relying heavily on the injection of government funds. To create a well-functioning financial system, the role played by the government needs to be gradually phased-out. The private sector's 
role in venture funding on the other hand should be increased. Leveraging and diversifying private sources of venture capital would allow moving small firms away from the dependence on public debt guarantees and public funding.

\section{Concluding remarks}

Many steps have been taken to lift impediments to the creation and expansion of innovative firms. Korea has also been active in the area of education and training, as entrepreneurship has been introduced in the curricula to improve skills of actual and potential entrepreneurs. The need for a focused, balanced and well-coordinated entrepreneurship and SME strategy nonetheless remains.

There are signs that Korea may not be benefitting from the high level of public and private R\&D investment due to insufficient collective process innovations. To release the innovative capacity of the system and facilitate the emergence of innovative start-ups, policy would need to focus on network building, improving scientific-technological networks and facilitating the creation of vertical and horizontal links between enterprises. This can be achieved through broadened support programmes (including the non-industrial sector) and an extended range of differentiated business support services, reducing the productivity gap between services and manufacturing sectors, between small and large enterprises.

Despite efforts to ease access to finance for small enterprises and start-ups through extensive credit guarantee scheme and the regular injection of government funds into the venture capital market, there are still major impediments to firm creation in this area of policy intervention. It is difficult for entrepreneurs to access collateral-free funds, and real interest rates remain high relative to Korea's achievement in terms of per capita convergence.

Finally, success in the entrepreneurial domain will only be ensured if Korea invests further in entrepreneurial education and training to reverse psychological barriers to firm creation. This calls for increased entrepreneurship education opportunities for younger generations based on best practice. These need to be complemented by easing entry barriers for start-ups and extending business support services to reduce the risk of failure when starting a business. 
Box 1.3. Policy recommendations

\section{Improve programmes and policy co-ordination}

Streamline and reduce the number of programmes to assist SMEs

Adopt a differentiated policy approach reflecting the duality of the firm population in order to help smaller firms to catch up in terms of productivity rates, while allowing larger firms in the manufacturing sector to maintain a competitive edge

Reduce the number of procedures and total costs when starting a business

Improve policy co-ordination between the different ministries

\section{Reap benefits from R\&D spending}

Build an efficient structure of integrated and differentiated business services Stimulate horizontal network links between SMEs to facilitate process innovation Increase co-operation and knowledge exchange between research institutes, universities and business Provide support to professors and researchers starting their own business

Develop clustering activities based on international best practice

Stimulate creation of vertical chains between compatible SMEs and large enterprises

\section{Invest further in human capital and potential entrepreneurs}

Improve quality of tertiary education to ensure supply of high-skilled human capital Change social perception of the entrepreneur through increased entrepreneurship education opportunities Provide potential entrepreneurs with a better support infrastructure to change the perception of risk when starting a business

Extend education opportunities to all segments of firm population taking into account differentiated training needs

\section{Improve financial infrastructure}

Reduce role of collateral and loan guarantees in obtaining bank loans

Use credit advisors to increase banks' expertise in credit rating

Rescale credit guarantees to better support start-ups and restructure the SME sector

Reduce government's weight in venture capital market

Increase role of private investors and pension funds in equity capital provision 
ANNEX 1.A

Table 1.A.1. Definition of SMEs in Korea

\begin{tabular}{|l|l|l|}
\hline \multicolumn{1}{|c|}{ Sector } & Employees & Capital in-paid or Sales (KRW) \\
\hline Manufacturing & Less than 300 & Capital: 8 billion \\
\hline Mining, Construction, Transportation & Less than 300 & Capital: 3 billion \\
\hline $\begin{array}{l}\text { Large Retail Stores, Hotels, } \\
\text { Computer -related business, Medical, } \\
\text { Engineering service, } \\
\begin{array}{l}\text { Telecommunications, Hospitals and } \\
\text { Broadcasting. }\end{array}\end{array}$ & Less than 300 & Sales: less than 30 billion \\
\hline $\begin{array}{l}\text { Seed and Seeding Production, Fishery, } \\
\text { Electric, Gas and Waterworks, Film, } \\
\text { Assorted services (tourism, warehouse), } \\
\text { etc. }\end{array}$ & Less than 200 & Sales: less than 20 billion \\
\hline $\begin{array}{l}\text { Wholesales, R\&D services, } \\
\text { Production intermediation, etc. }\end{array}$ & Less than 100 & Sales: less than 10 billion \\
\hline Others & Less than 40 & Sales: less than 5 billion \\
\hline
\end{tabular}

Source: Response of the Korean government to the 2008 OECD background report. 
Figure 1.A.1. Regional dispersion in GDP per capita in OECD countries (Index of Gini 2001)

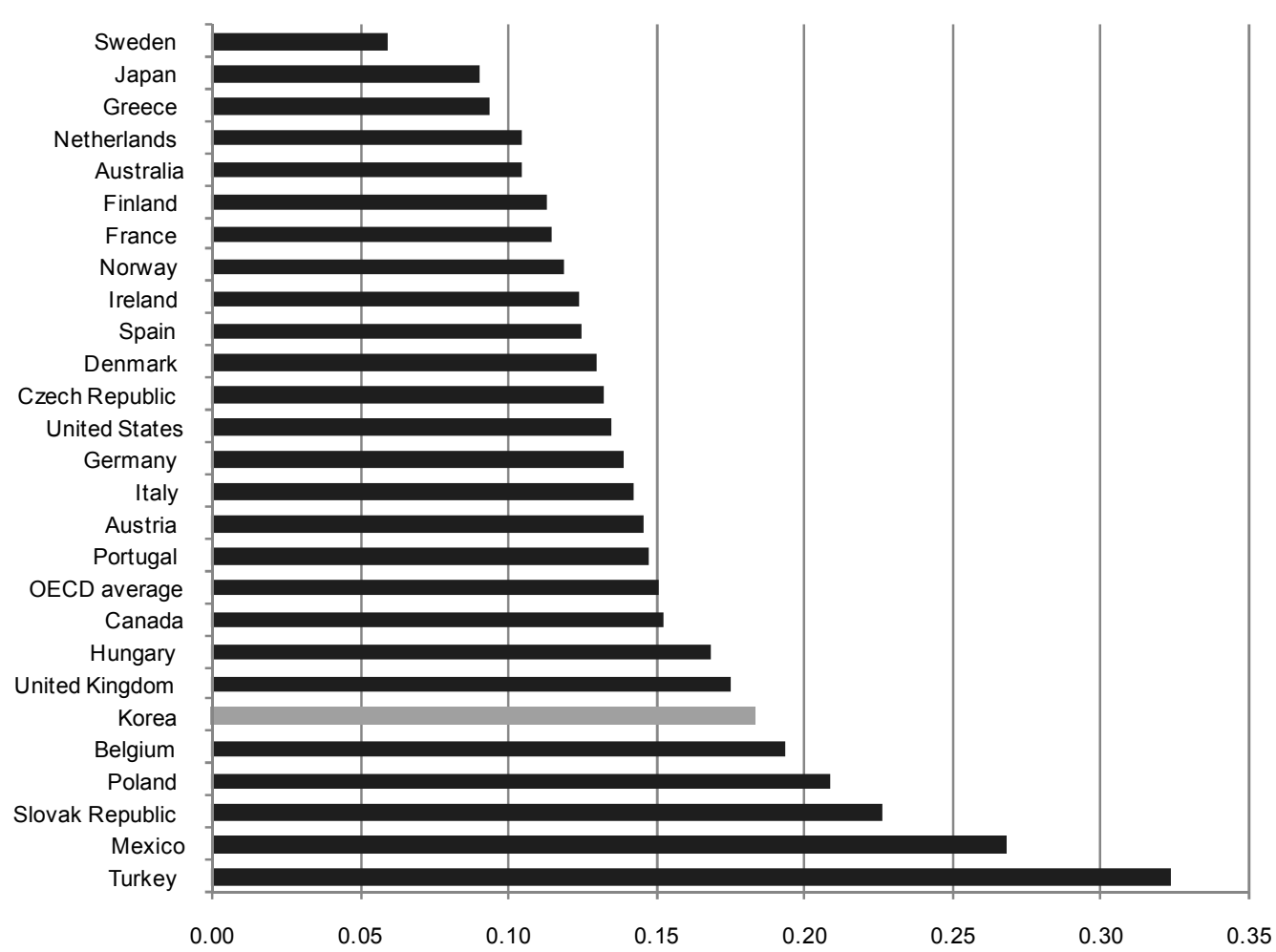

Note: Gini coefficient with GDP per capita in territorial units weighted by population. 2000 data for Mexico, Norway, Poland and Turkey.

Source: OECD, Regions at a glance, 2005. 
Figure 1.A.2. Firms that developed in-house process innovation (2002-2004)

As a percentage of all firms

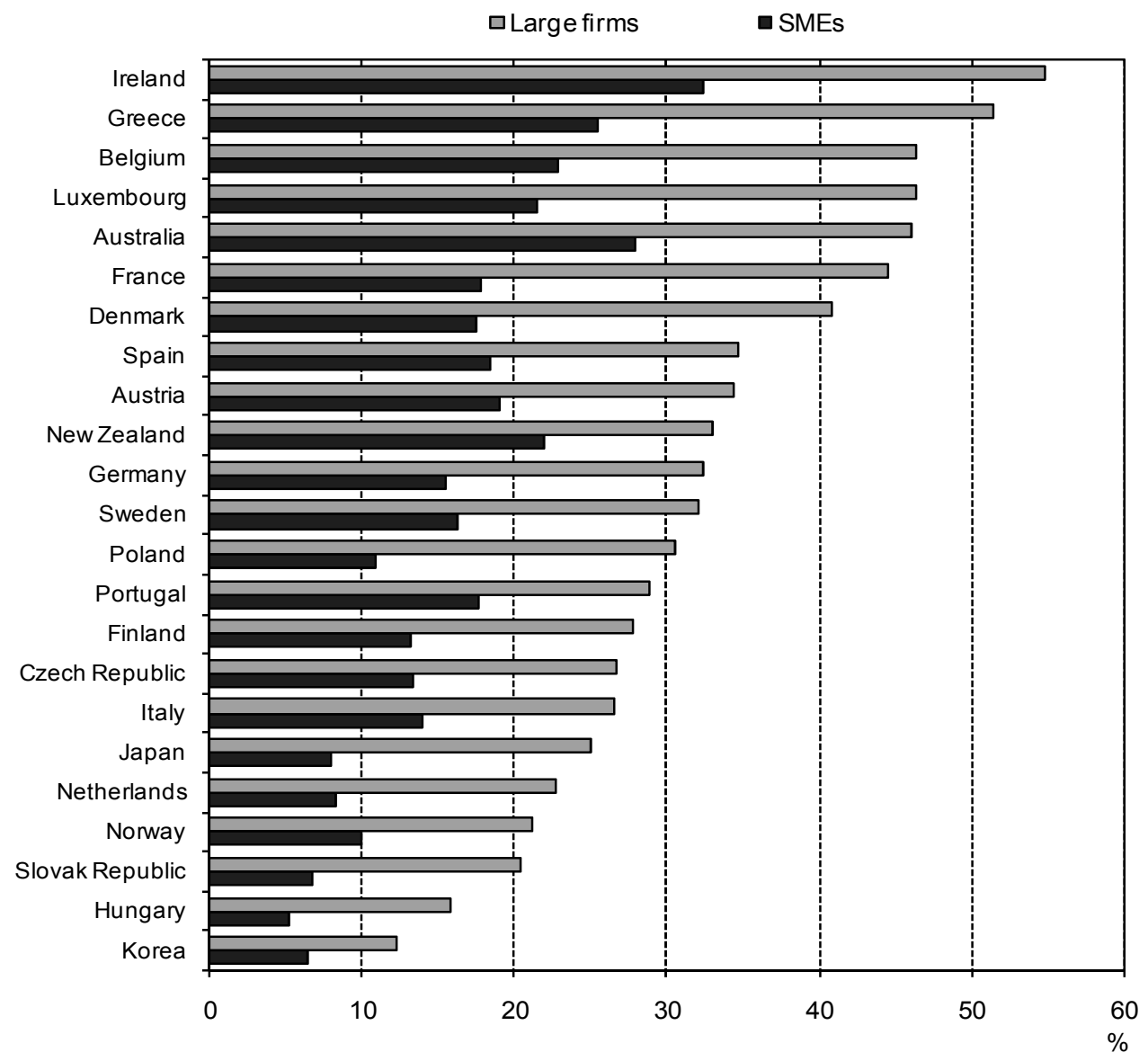

Source: OECD Science, Technology and Industry Scoreboard, 2007. 
Figure 1.A.3. Firms that developed in an in-house product innovation (2002-2004)

As a percentage of all firms

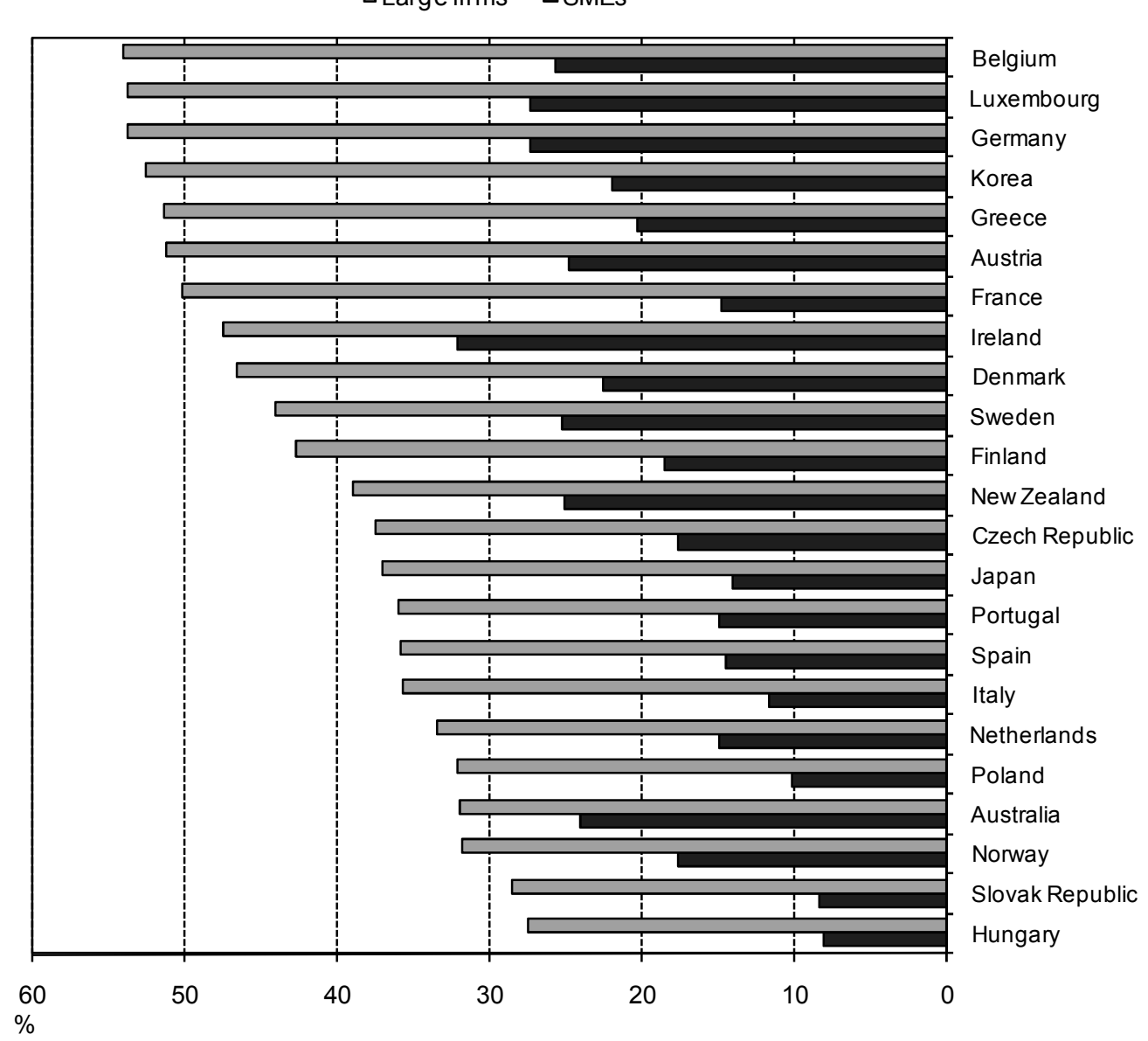

Source: OECD Science, Technology and Industry Scoreboard, 2007. 


\section{DSTI/DOC(2008)5}

Figure 1.A.4. Upper-secondary education, percentage of population aged 25-34 and 45-54 (2004)

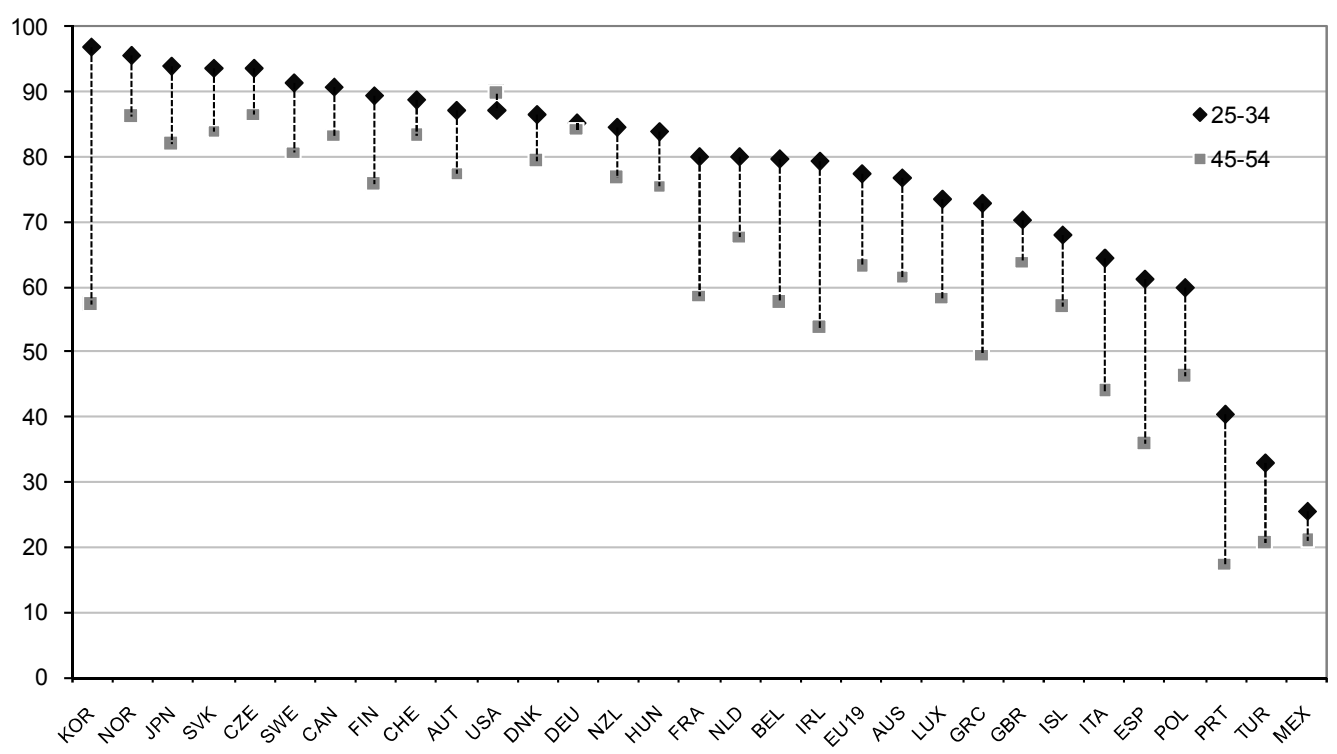

Source: OECD, Education at a Glance, 2006.

Figure 1.A.5. Average of PISA scores in reading, mathematics and science ${ }^{1}$

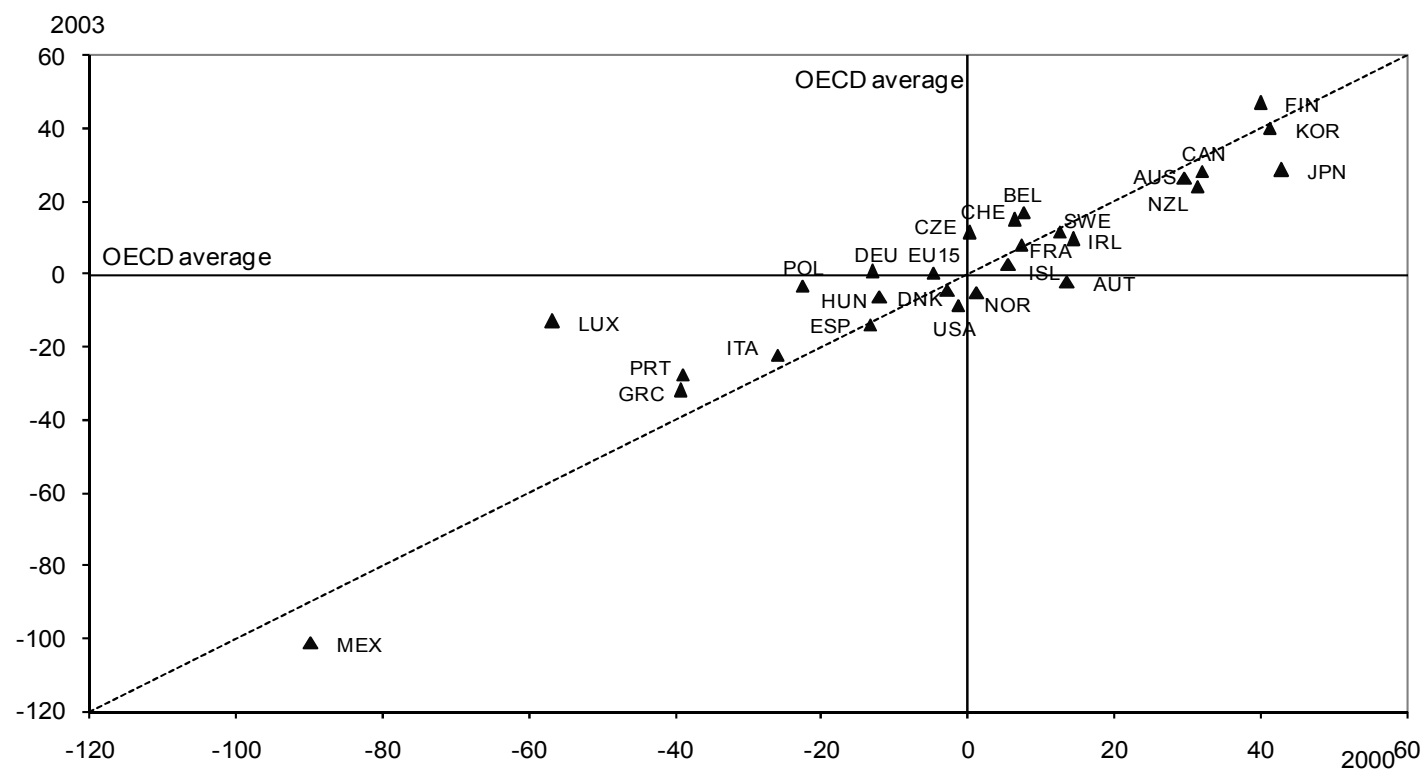

1. PISA stands for Programme for International Student Assessment.

Source: OECD, Learning for Tomorrow's World, PISA 2003. 
Figure 1.A.6. Tertiary education, percentage of population aged 25-34 and 45-54 (2004)

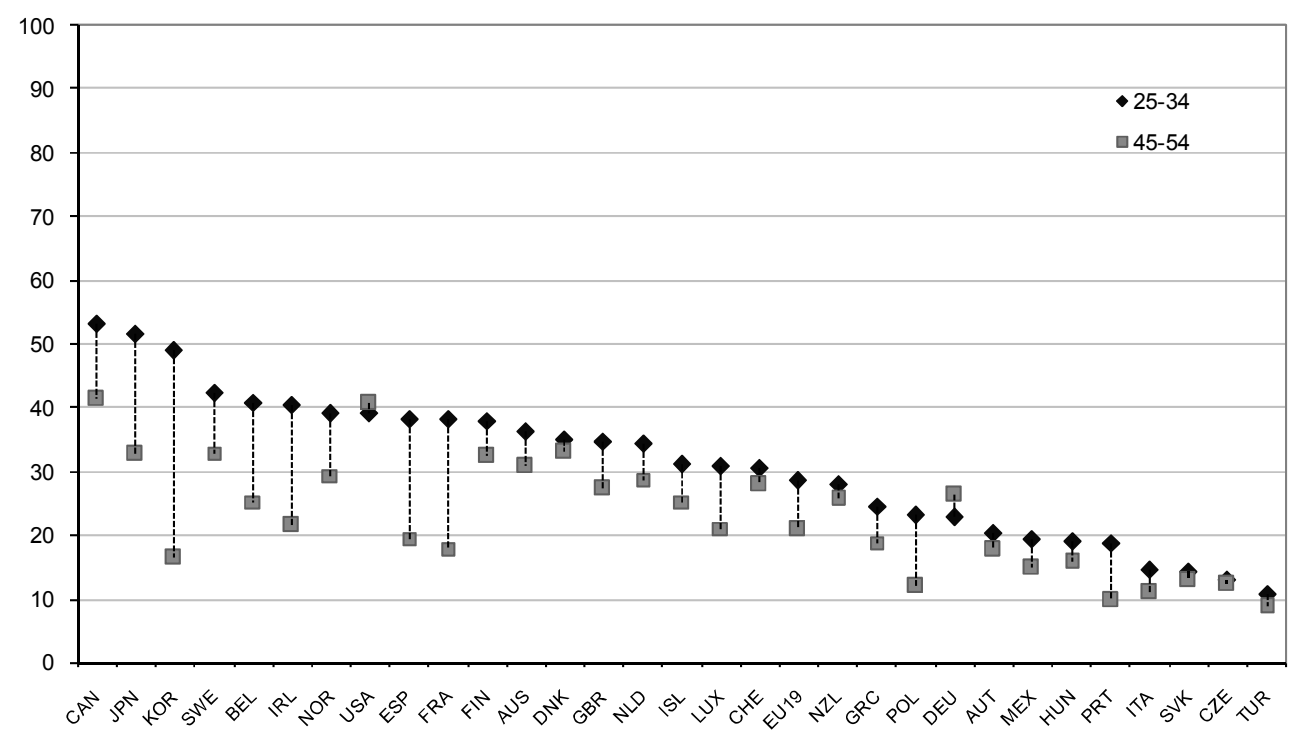

Source: OECD, Education at a Glance, 2006. 
Table 1.A.2. Programmes to assist SMEs

Billion KRW in 2004

\begin{tabular}{|c|c|c|c|}
\hline Ministry & Outlays & $\begin{array}{c}\text { Number } \\
\text { of programmes }\end{array}$ & Selected programmes \\
\hline $\begin{array}{l}\text { Small and Medium Business } \\
\text { Administration }\end{array}$ & 2767 & 17 & $\begin{array}{l}\text { - Restructuring support } \\
\text { - Start-up support } \\
\text { - Stable operation support } \\
\text { - Regional SME support } \\
\text { - Technology development support } \\
\text { - Venture company support }\end{array}$ \\
\hline $\begin{array}{l}\text { Ministry of Commerce, Industry } \\
\text { and Energy }\end{array}$ & 861 & 20 & $\begin{array}{l}\text { - Industrial technology development support } \\
\text { - Modemisation of distribution network support } \\
\text { - Activation of industrial complex support } \\
\text { - Energy saving support }\end{array}$ \\
\hline Ministry of Agriculture and Forestry & 112 & 3 & $\begin{array}{l}\text { - Rice processing factory support } \\
\text { - Agricultural product processing support } \\
\text { - Agricultural machine product support }\end{array}$ \\
\hline $\begin{array}{l}\text { Ministry of Information } \\
\text { and Communication }\end{array}$ & 439 & 8 & $\begin{array}{l}\text {-Information and communication technology development support } \\
\text { - Leading technology development and distribution support } \\
\text { - Multi-media industry support } \\
\text { - Software development support }\end{array}$ \\
\hline Ministry of Labour & 288 & 10 & $\begin{array}{l}\text { - Workplace accident prevention support } \\
\text { - Workplace environment improvement support } \\
\text { - Company nursery facility support }\end{array}$ \\
\hline Ministry of Environment & 69 & 4 & $\begin{array}{l}\text { - Anti-pollution facility support } \\
\text { - Environmental technology development support } \\
\text { - Recycling industry support }\end{array}$ \\
\hline Ministry of Culture and Tourism & 153 & 4 & $\begin{array}{l}\text { - Film promotion fund support } \\
\text {-Sporting goods development support }\end{array}$ \\
\hline Ministry of Science and Technology & 154 & 4 & $\begin{array}{l}\text { - Technology development support } \\
\text { - New technology project investment support }\end{array}$ \\
\hline Ministry of Maritime Affairs and Fisheries & 32 & 3 & $\begin{array}{l}\text { - Marine product distribution support } \\
\text { - Fishing net support }\end{array}$ \\
\hline Ministry of National Defence & 10 & 1 & - Defence industry support \\
\hline $\begin{array}{l}\text { Ministry of Construction } \\
\text { and Transportation }\end{array}$ & 69 & 1 & $\begin{array}{l}\text { - Standardising construction material support } \\
\text { - General freight terminal construction support }\end{array}$ \\
\hline Ministry of Health and Welfare & 8 & 1 & - New drug development support \\
\hline Total & 4962 & 76 & \\
\hline
\end{tabular}

Source: OECD, Economic Surveys Korea, 2005 based on information from SMBA. 


\section{MEXICO}

\section{Introduction}

Over the past few years, Mexico has placed rising emphasis on entrepreneurship policy as a principal means of stimulating innovation. Ongoing globalisation and the associated shift to a knowledge-based economy have revived worldwide interest in firm creation as a major agent of innovation. Entrepreneurship policy affects the whole range of entrepreneurial activities, including the pre-start, start up and post-start up phases of enterprise life. ${ }^{40}$

The link between entrepreneurial policy and innovation is, by nature, indirect. Efficient measures of entrepreneurship policy underpin firm creation and growth. In doing so, they strengthen innovative activity. Policy lead times, though, vary with the type of entrepreneurship policy. For instance, introducing entrepreneurship education in schools and universities is bound to affect innovation trends only in the longer run. The same is true of reducing cultural biases against entrepreneurial activities. In contrast, more immediate effects may spring from dismantling barriers to finance as well as setting up well-focused training courses for both subsistence entrepreneurs and business counsellors (teachers training programmes).

Viewed from a wider angle, the design of entrepreneurship policy itself may constitute an 'innovation', augmenting the effects which firm creation and firm expansion normally have on individual innovations. Mexico, as will be shown in this chapter, exemplifies this approach, using policy-induced collective process innovation as a main vehicle for stimulating individual product, process and market innovation.

The first part of this chapter highlights salient features of Mexico's enterprise population, identifies main obstacles to entrepreneurial activity and presents indicators of entrepreneurship performance. The second part outlines main objectives of entrepreneurship policy and describes principal programmes, in four major areas of policy intervention: access to $R \& D$ and technology, access to finance, capabilities and access to skilled labour, and cultural values. The third part provides an evaluation of entrepreneurship policy.

\section{Main features of the enterprise sector and impediments to firm creation}

Mexico's enterprise population is highly polarised, myriads of inefficient micro firms (abundance of subsistence entrepreneurs) co-existing with few efficient small, medium-sized and larger firms (growthoriented entrepreneurs). There are around 6700 large and medium-sized enterprises and nearly 4 million micro firms in the formal economy, most of which are unprofitable. The informal economy includes about the same number of micro firms.

Suffering from under endowment of tangible and intangible capital, overstaffing and consequent negative levels of total factor productivity, micro firms account for much of Mexico's overall productivity weakness. Notwithstanding macroeconomic stability, aggregate productivity has risen more slowly over 
the ten years to 2005 than in any other OECD country. For a country with a low per capita income and correspondingly large catching-up opportunities, this outcome is paradoxical (Annex 2.A, Figure 2.A.1).

\section{Main characteristics of the enterprise sector}

The Mexican enterprise sector is characterised by the disparity between the competitive and exportoriented 6700 large and medium-sized enterprises and the often unprofitable and inefficient 4 million micro firms. ${ }^{41}$ The diversity of the small and medium-sized enterprises (SME) population is reflected in the regional disparities in terms of social and economic development. For each of the three major economic sectors - manufacturing, retail and services - the regional pattern shows a particularly dominant presence of micro-firms in the South-eastern regions. By contrast, large and medium-sized firms display a relatively strong presence in the more prosperous Northern regions. ${ }^{42}$ The regional distribution of GDP per capita in Mexico is amongst the least equal compared to other OECD countries (Figure 2.1). Benefits of Mexico's increasing integration into the global economy have been unevenly distributed with some states being better placed than others for reaping the fruits of better access to international markets.

Figure 2.1. Regional dispersion in GDP per capita in OECD countries (Index of Gini 2001)

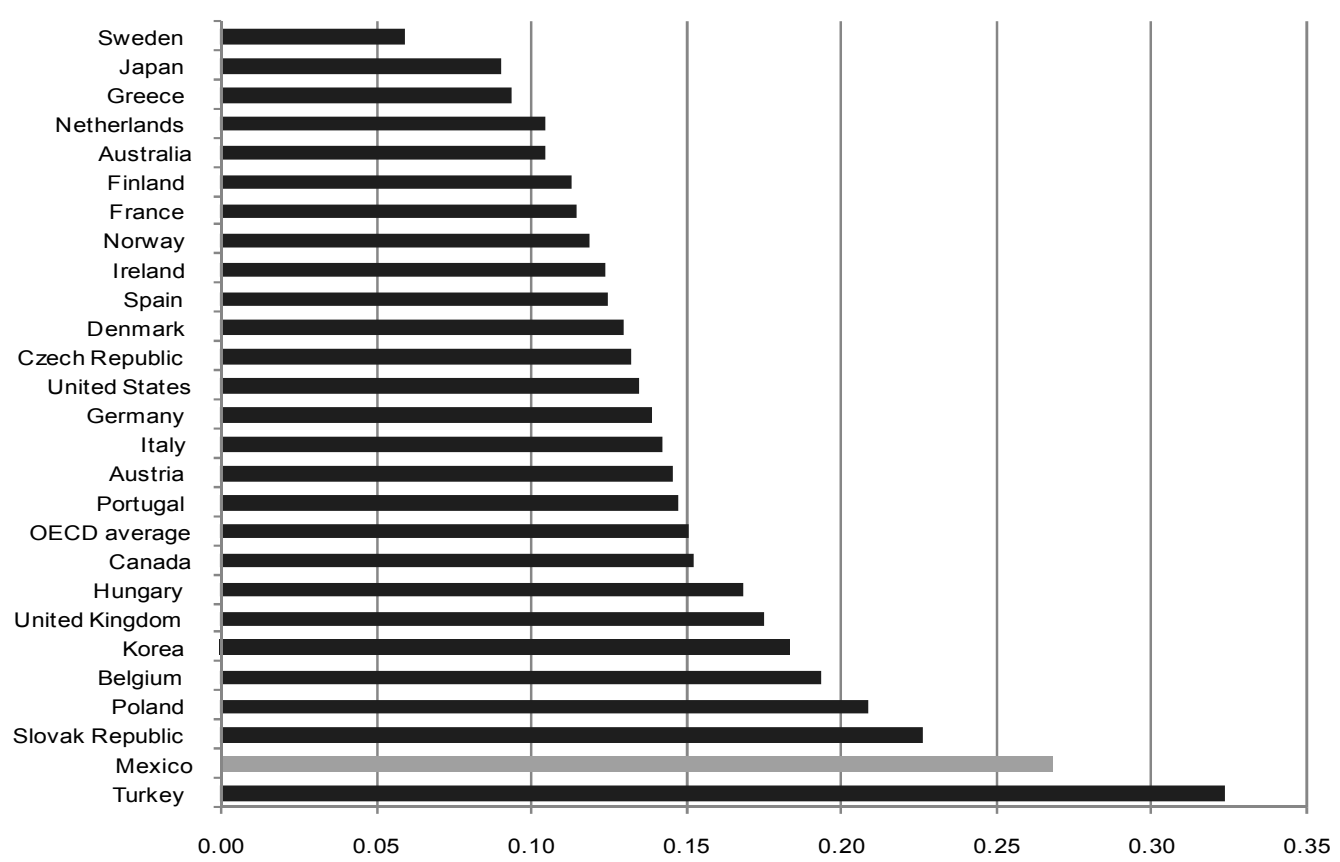

Note: Gini coefficient with GDP per capita in territorial units weighted by population. 2000 data for Mexico, Norway, Poland and Turkey.

Source: OECD, Regions at a glance, 2005.

41 In the Mexican definition, Micro-enterprises have between 0-10 employees in manufacturing, retail and services. Small enterprises have between 11-50 employees in manufacturing and services, up to 30 employees in retail. Medium-sized enterprises have between 51-250 employees in manufacturing, 31 and 100 employees in retail, 51 and 100 employees in services.

OECD (2006), OECD Territorial Reviews: The Mesoamerican Region - South-eastern Mexico and Central America, OECD Publications, Paris. OECD (2006), The New Rural Paradigm: Policies and Governance, OECD Publications, Paris. 
SMEs play a vital role in Mexico's economy. They are estimated to account for about $99 \%$ of all enterprises generating 52\% of the GDP in 2006 and representing nearly three quarters of total employment. Most SMEs are micro-firms, this degree of predominance exceeds that observed in most other OECD countries (Figures 2.2 and 2.3). This is also reflected by the high level of self-employment in comparison to most other OECD countries (Figure 2.4).

Figure 2.2. Percentage of enterprises by size class in the manufacturing sector (2003)

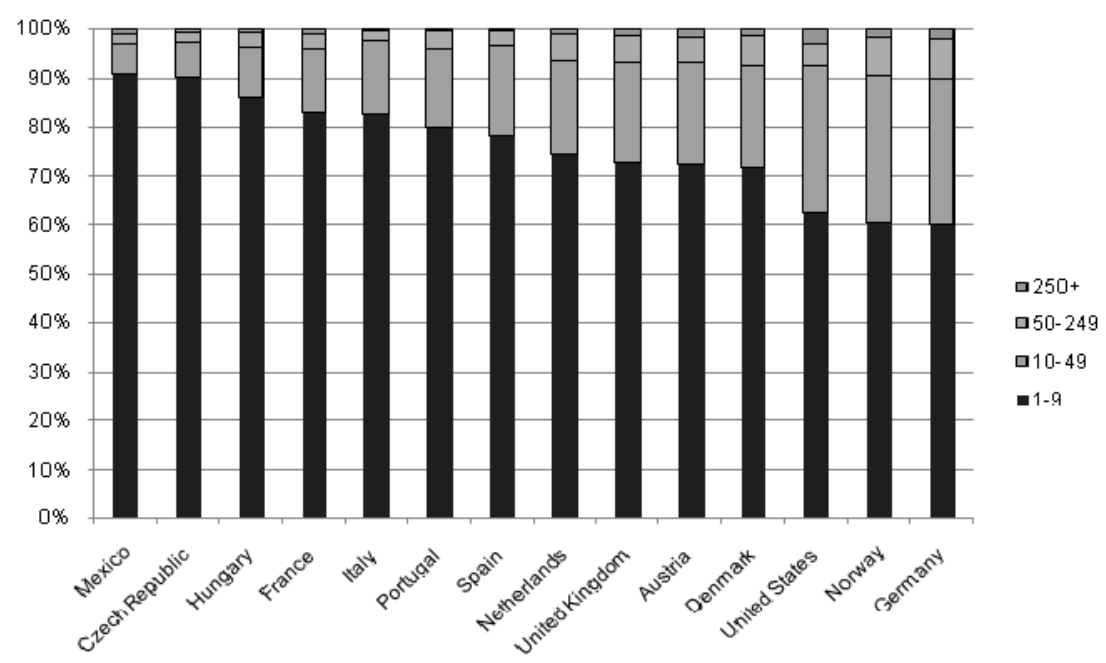

Note: For the United States, size classes are: 1-9, 10-99, 100-499 and 500+. For all countries but Mexico, size classes 10-19 and 2049 have been merged (10-19 and 20-99 for the United States).

Source: OECD Database Business by Size Class. Data for Mexico is from INEGI.

Figure 2.3. Percentage of employees by size class in the manufacturing sector (2003)

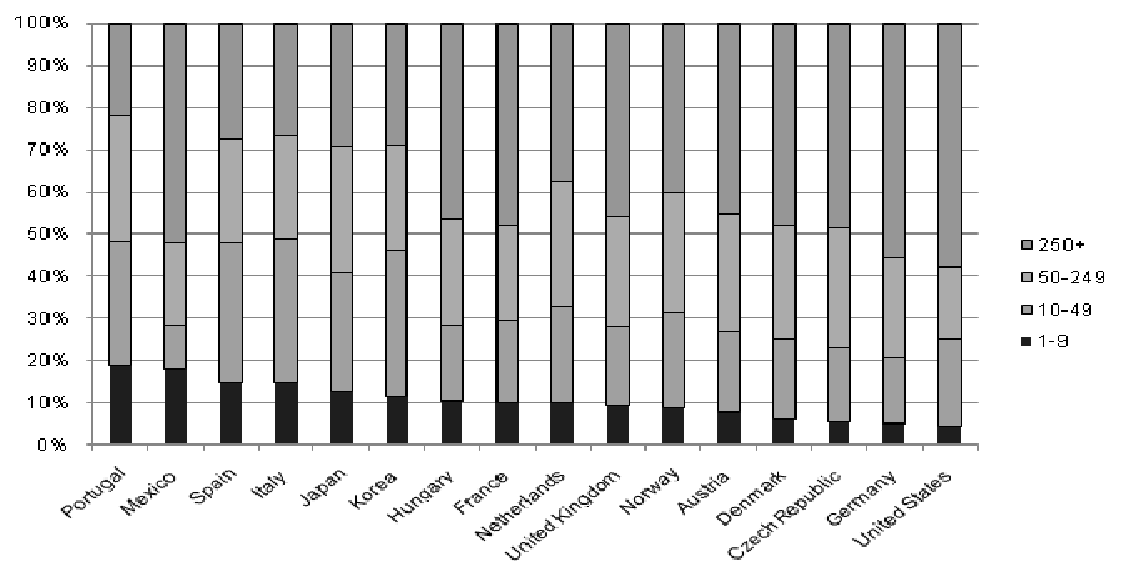

Note: For the United States, data comes from 2002. Size class discrepancies: for the United States, size classes are: 1-9, 10-99, 100-499 and 500+; for Mexico, size classes are: 0-10, 11-50, 51-250 and 250+; for Korea, size classes are 1-9, 10-49, 50-199 and 200+. For all countries but Mexico, size classes 10-19 and 20-49 have been merged (10-19 and 20-99 for the United States).

Source: OECD Database Business by Size Class. Data for Mexico is from INEGI. 
Figure 2.4. Total self-employment rates (2005)

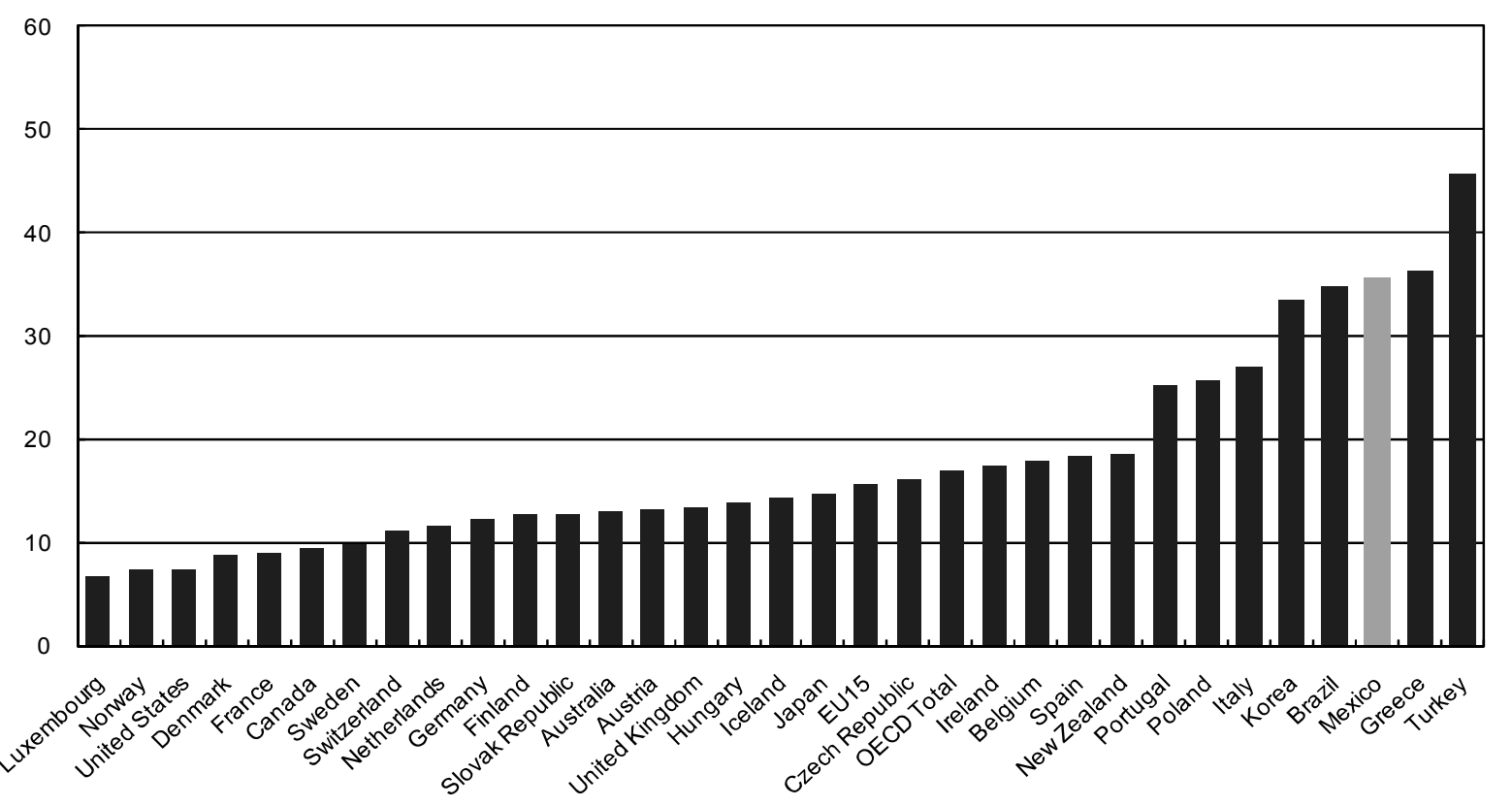

Note: As a percentage of total civilian employment, 2005 or latest available year.

Source: OECD Factbook 2007, Economic, Environmental and Social Statistics.

Micro-firms in Mexico employ around 8 million persons (38.3\% of total employment). While the number of small enterprises (139000) and medium-sized firms (32000) are fractions of the SME population, they account for one third of total employment (Figure 2.5).

Figure 2.5. Distribution of Employment and Enterprises by Firm Size in Mexico (2003)

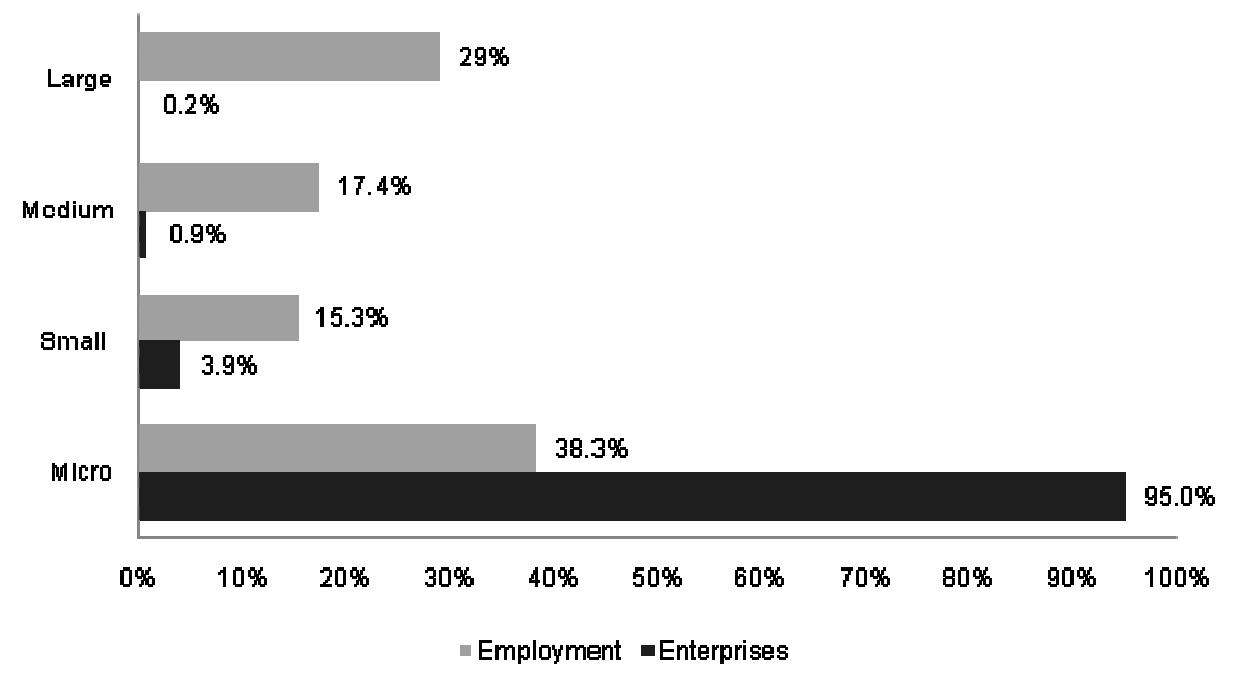

Note: Micro=0-10 employees; Small=11-50 employees in manufacturing and services and up to 30 employees in retail; Medium=51-250 employees in manufacturing, 31-100 employees in retail and 51-100 employees in services.

Source: OECD, SMEs in Mexico, 2007. Data is from CANACINTRA and INEGI. 
The data points to a fragmented production structure and a highly polarised profile of employment and productivity levels. The typical firm is small and mostly family owned and run. About nine tenth are located in retail, services and agriculture and their output is oriented towards local markets. Only a small share of micro-firms are located in manufacturing (just over 300 000); they are on the other hand very present in retail trade (Table 2.1). In contrast, a small segment of internationally competitive firms that are mainly situated in the metropolitan areas of Mexico and Monterrey are endowed with modern equipment and with a strong culture of innovation.

The average survival time of newly created firms is short, a substantial portion of them closing down before two years after birth. Many firms are unable to generate profits reflecting negative levels of total factor productivity. Unaware of available government support, they do not participate in "association networks" and continue to suffer from low levels of human capital, limited access to finance and inadequate use of technology. Their contribution to the total output is weak.

Finally, a significant portion of Mexico's working force is active in the informal economy. Employment in the informal sector was estimated at 10.5 million people in 2002, representing about one quarter of the whole labour force. ${ }^{43}$

Table 2.1. SMEs by Sector (2005)

\begin{tabular}{|c|c|c|c|c|c|}
\hline \multirow[b]{2}{*}{ Sector } & \multirow[b]{2}{*}{$\begin{array}{c}\text { Total } \\
\text { Number }\end{array}$} & \multicolumn{4}{|c|}{ Percentage of Enterprises } \\
\hline & & Micro & Small & Medium & Large \\
\hline Manufacturing Sector & 328718 & 90.9 & 6.0 & 2.2 & 0.9 \\
\hline Food & 123308 & 95.3 & 3.4 & 1.0 & 0.4 \\
\hline Textile & 47400 & 86.9 & 8.5 & 3.4 & 1.3 \\
\hline Wood & 17729 & 95.7 & 3.4 & 0.8 & 0.1 \\
\hline Paper & 17165 & 88.0 & 8.5 & 2.8 & 0.8 \\
\hline Chemical & 7706 & 49.7 & 28.7 & 16.6 & 5.0 \\
\hline Non metallic minerals & 25037 & 93.4 & 5.0 & 1.2 & 0.4 \\
\hline Basic metallic & 1250 & 61.8 & 21.5 & 12.1 & 4.6 \\
\hline Equipment and machinery & 77373 & 89.9 & 6.4 & 2.4 & 1.4 \\
\hline Other industries & 11732 & 89.1 & 7.2 & 2.5 & 1.2 \\
\hline Retail Trade & 1580587 & 97.0 & 2.1 & 0.6 & 0.2 \\
\hline Services & 1013743 & 94.7 & 4.3 & 0.5 & 0.5 \\
\hline
\end{tabular}

Source: CANACINTRA and INEGI.

\section{Factors driving firm creation and expansion}

A web of chronic impediments stifle firm creation, including lack of R\&D benefits, lack of finance, shortage of skilled labour, high-quality education, training and business services. These obstacles are particularly strong for small and micro firms weighed down by under equipment of tangible and intangible capital.

43 The statistical office INEGI has started to produce a defined measure of the informal sector which considers employment and output of «non-structured» sectors such as street vendors and or micro-enterprises. See OECD (2007), SMEs in Mexico, Paris. 
Mexico's technological gap (as measured by the diffusion of information and communication technology, ICTs) is sizeable, even considering its position as a low per-capita income country (Table 2.2). In 2003, Mexico significantly lagged behind Turkey (a country with a comparably low per capita income) in terms of standard access lines, access channels and mobile subscribers. While prices are high compared to other OECD countries (Annex 2.A, Figures 2.A.2 and 3) the technological gap mainly reflects low awareness of ICT presenting profitable business opportunities. Moreover, inadequate R\&D efforts account for weak trends in product and process innovation. R\&D expenditure, though rising from $0.3 \%$ in 2001 to $0.5 \%$ of GDP in 2005, is still low by international standards (the OECD average being $2.2 \%$ in 2005). R\&D weakness is notably pronounced in the domain of private business: private R\&D spending accounts for only one-third of Mexico's total R\&D expenditure, the corresponding ratio for the OECD being roughly twice as large. Overall, private R\&D spending amounted to $0.2 \%$ of GDP in 2005 as against $1.5 \%$ for the OECD area.

Table 2.2. Diffusion of Information and Communication Technology ${ }^{1}$

\begin{tabular}{lcccccccc}
\hline & Mexico & Poland & Turkey & EU-15 & US & Japan & Korea & OECD \\
\hline Standard Access Lines & 15.9 & 29.6 & 26.7 & 43.5 & 59.5 & 40.4 & 57.7 & 43.6 \\
Access Channels & 18.9 & 32.9 & 27.0 & 58.9 & 62.3 & 55.0 & 58.4 & 52.0 \\
Mobile Subscribers & 29.3 & 45.5 & 39.4 & 84.8 & 54.5 & 67.9 & 70.1 & 64.2 \\
$\begin{array}{l}\text { Internet Subscribers to } \\
\text { fixed networks }\end{array}$ & 2.7 & 4.3 & 1.6 & 24.0 & 33.0 & 25.6 & 24.8 & 22.4 \\
Broadband Access $^{2}$ & 0.4 & 0.8 & 0.1 & 5.9 & 9.7 & 10.7 & 24.2 & 7.2 \\
\hline
\end{tabular}

1. Per 100 inhabitants in 2003.

2. "Other" broadband technologies include satellite broadband Internet, fibre-to-the-home Internet access, ethernet LANs, and fixed wireless subscribers (at downstream speeds greater than $256 \mathrm{kbps}$ ).

Source: OECD, SMEs in Mexico, 2007 based on the OECD Communications Outlook, 2005.

\section{b) Access to finance}

Access to business finance has been difficult. In 1996-2003, Mexico's bank overhead costs and net interest margins were, on average, among the highest in the OECD area (Annex 2.A, Figures 2.A.4 and 5), a sign of ingrained banking inefficiency. While both nominal and real interest rates have fallen since 2000 they have stayed well above US levels (Table 2.3). In 2007, the real short-term interest rate was still twice as high as the US equivalent, pointing to a capital shortage characteristic of a low-per capita income country. 
Table 2.3. Nominal and real short-term interest rates

\begin{tabular}{ccc}
\hline & $\mathbf{2 0 0 1}$ & $\mathbf{2 0 0 7}$ \\
\hline Nominal short-term interest rate & & \\
Mexico & 12.2 & 7.3 \\
United States & 3.7 & 5.3 \\
\hline Real short-term interest rate ${ }^{1}$ & & \\
Mexico & 5.9 & 5.2 \\
United States & 1.5 & 2.6 \\
\hline
\end{tabular}

1. Nominal interest rate deflated by GDP deflator.

Notwithstanding progress, lack of financing at a reasonable cost has kept on undermining entrepreneurial activity. While the growth of direct bank credit to enterprises rebounded strongly in 2004-2005, ${ }^{44}$ it became subsequently unstable (Figure 2.6). Overall, bank lending to the private sector (including mortgage and consumer credit) has remained among the lowest in the OECD area.

Figure 2.6. Trends in Domestic Credit to the Private Sector

Year-on-year percentage change in real terms

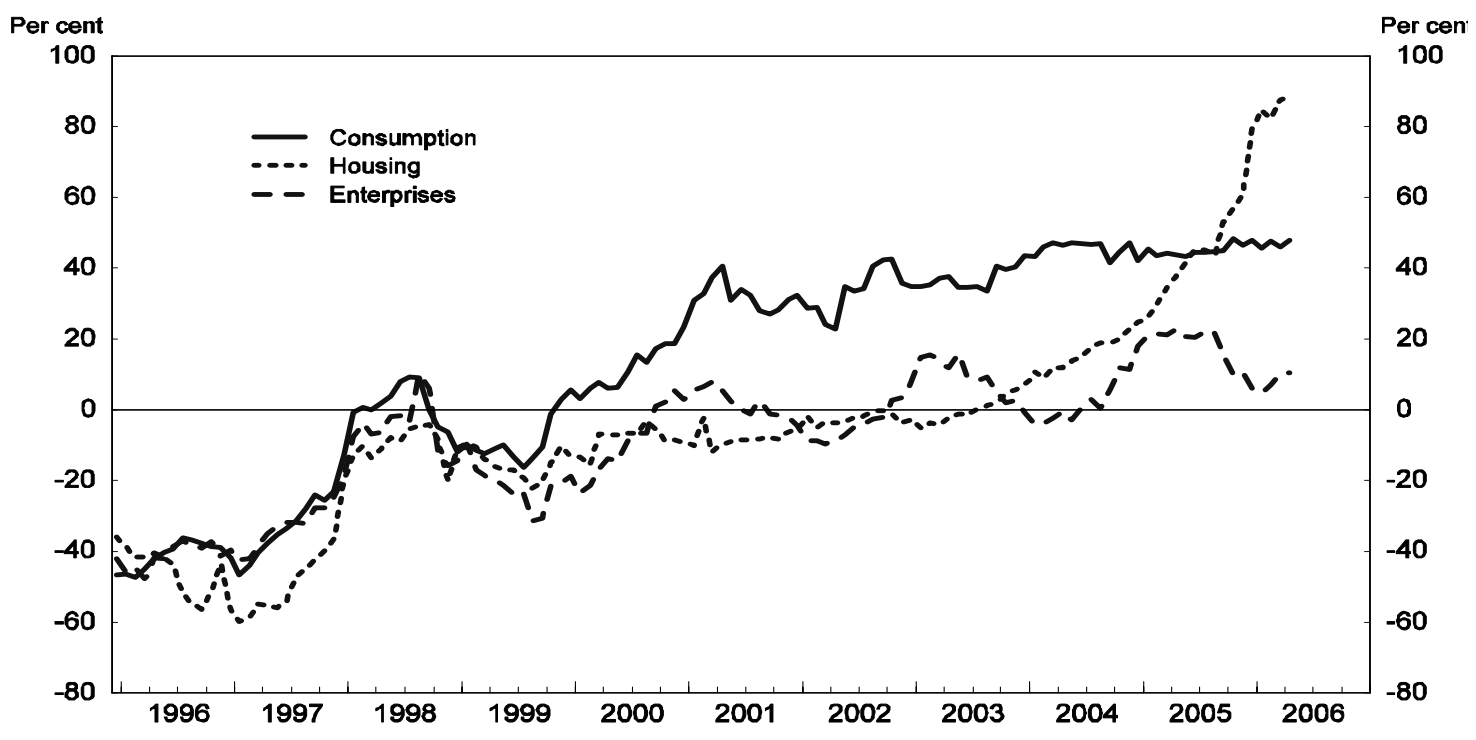

1 . Direct credit by commercial banks.

Source: OECD, SMEs in Mexico, 2007. Data is from the Bank of Mexico.

Inside the business sector, financing is marked by sharp asymmetries between large and small companies. Small and medium-sized enterprises are still facing the greatest difficulties in accessing bank

After the crisis in 1995 bank profitability recovered in Mexico and non-performing loans declined. Growth in domestic credit to the private sector was however slow to recover: bank credit to the private sector exhibited negative real annual growth throughout the late 1990s and into the early 2000 s except for a brief period in 1998. 
financing given their higher risk and lack of access to foreign borrowing. While larger companies in tradable sectors have access to bank credit, SMEs rely mainly on costly suppliers' credit. ${ }^{45}$ This has adverse effects on investment and innovation activities. In 2005, suppliers' credit accounted for two-thirds of finance for small enterprises (Table 2.4). In comparison, banks are in nearly $80 \%$ of cases the main source of financing for EU-based SMEs. ${ }^{46}$

The supply of bank credit to the business sector has been further limited due to the longstanding lack of adequate rules for recovering guarantees and to the uncertainties about the application of the new legal framework following the 2003 reform. ${ }^{47}$ Shortcomings in the application of the bankruptcy and credit guarantee law and in credit assessment affect smaller firms more acutely than larger firms, creating important asymmetries.

Table 2.4. Sources of Enterprise Finance in Mexico (2005)

(in percentage)

\begin{tabular}{lrrrr}
\hline \multirow{2}{*}{ Source of Finance } & \multicolumn{4}{c}{ Companies } \\
\cline { 2 - 5 } & Small & Medium & Large & AAA \\
\hline Suppliers' credit & 66.7 & 57.2 & 52.3 & 44.8 \\
Commercial Banks & 13.7 & 19.8 & 21.1 & 34.5 \\
Foreign Banks & 0.9 & 2.9 & 3.1 & 6.9 \\
Development Banks & 1.7 & 1.2 & 3.1 & 0.0 \\
Other Sources & 17.0 & 18.9 & 20.4 & 13.8 \\
Total & 100 & 100 & 100 & 100 \\
\hline
\end{tabular}

1. Includes head office and other companies of corporate groups.

Source: OECD, SMEs in Mexico, 2007. Data is from CANACINTRA and Banxico, 2005.

\section{c) Access to capabilities and to skilled labour}

Human capital is still the lowest in the OECD due to a grossly underperforming educational system. Over the past decades, Mexico has made major progress in increasing school enrolment. While the volume of educational services has increased, there are doubts about whether the additional funding is delivering expected results. Both the quality and coverage of educational services remain far behind OECD best practices. Mexican children still spend comparatively few years in formal education and do not benefit from it as much as they should. Many children, especially the poor ones, still leave school before completing compulsory education. Literacy and numerical skills of students are by far the lowest of all OECD countries (Annex 2.A, Figure 2.A.6 on average PISA ${ }^{48}$ scores in reading, mathematics and science). More so than in other OECD countries, the poor educational attainment of the working-age population is reproduced from one generation to the next (Annex 2.A, Figures 2.A.7 and 8).

The transition between school and work also presents some major weaknesses with students being unable to find jobs matching their skills. Reforms were launched in 2004 to better match the curricula of the various systems of professional schooling with the needs of the productive sector. OECD experience shows that close connections between professional schools and the business sector are appropriate.

\footnotetext{
45 Bonturi, M. (2002), "Challenges in the Mexican Financial Sector", OECD Economics Department Working Papers No. 339, Paris.

OECD (2007), The SME financing gap.

OECD (2004), OECD Reviews of Regulatory Reform: Mexico, Progress in implementing regulatory reform.

PISA stands for Programme for International Student Assessment.
} 
In addition, Mexico like several other OECD countries has a low training culture for adults with only a small share of employees (often the most qualified workers and employees of larger firms) being involved in training programmes. While cultural perceptions about entrepreneurial activity are generally positive, opportunities for entrepreneurship education continue to be sparse. In firms, the lack of innovative momentum often reflects "old style" management preventing both the hiring of highly qualified managers and purchases of sophisticated business services.

\section{Entrepreneurship and SME policies}

\section{Overall aims of entrepreneurship policy}

Entrepreneurship policy makers have been facing the complex task of lifting a highly fragile and heterogenous firm population out of structural weakness. Adopting a strong and flexible policy approach, Mexico designed a new policy framework in 2000 aimed at making enterprises more efficient. The 2000 Entrepreneurial Development Plan (EDP), created within the National Development Programme (NDP) (2001-06), served as a central axis for the government's new economic policy (Box 2.1).

\section{Box 2.1. Calendar of Major Entrepreneurship and SME Policy Events}

$2000 \quad$ National Development Programme (NDP) for 2002-2006 Entrepreneurial Development Plan (EDP) for 2001-2006

2001 Creation of Under Ministry for SMEs in the Ministry of Economy Creation of National Guarantee System for SMEs

2002 Establishment of Enterprise-Rapid-Opening System (SARE)

2003 Reform of National Guarantee System

2004 Creation of the SME Observatory

Creation of SME Fund

Creation of Financial Extension System

2005 Shift to innovation-based SME policy

2006 Creation of the 'Fund for Funds' supplying equity and venture capital for long-term investment projects

2007 Creation of Technology Innovation Fund

The EDP called on stakeholders of entrepreneurship policy (Federal, State, local governments, private sector associations and research communities) to co-operate and develop joint strategies to strengthen the business sector. With this aim in mind, the federal government progressively put into place mechanisms apt to improve participatory processes and vertical and horizontal policy co-ordination. In the process, administrative powers were decentralised, creating room for state and local governments and intermediaries to shape and implement entrepreneurship projects.

Policy emphasis was initially placed upon lessening severe financial constraints hindering firm creation and firm expansion. Micro finance was seen as a key route to supplying funds to firms which normally have no access to traditional banking (subsistence entrepreneurs). Subsequently, though, (2004), the focus of entrepreneurship policy was shifted towards innovation. Innovation became the central policy axis permeating each policy category and releasing various externalities through cross-fertilisation. The new, incoming government (December 2006) further reinforced the innovation-oriented stance of entrepreneurship and SME policies, establishing in 2007 the Fund for Technological Innovation (Fondo de Innovacion Technologica). 
Building on concepts and recommendations from the Oslo Manual (OECD, 1999) and current innovation theory, the 2004 strategy of entrepreneurship encouragement identifies five forms of innovation (market, product, process, organisational and business innovation). It also seeks to identify the impact of innovation by distinguishing between incremental effects (marginal gains from process improvements) and powerful effects from radically new products and processes (incremental versus radical innovation).

In this framework, strong emphasis has been placed on networking as a form of collective process innovation (collaborative innovation). Social capital is seen as a vital innovation asset capable of improving enterprises' access to knowledge services, financial resources and technology. As a result, institutions began to speed up and broaden the flow of information, diffusing best practices, innovation tools and technology. The collective innovation approach is based on the idea that firms influence the local business culture, creating trade links and easing risks of innovation failures. Besides, knowledge-intensive business services (interlinkers) are seen to create and strengthen a supportive environment for business activities by providing firms with access to venture capital, skilled labour, technical assistance, other experienced entrepreneurs and educational institutions. The policy also recognised the productive and geographical diversity of Mexico's enterprises (systemic model for growth). Although different regions have different needs, some may take innovative policy initiatives which others may choose to emulate.

The federal government's main tool for shaping and implementing innovation-oriented entrepreneurship policy measures has been the SME Fund (Fondo Pyme) established in 2004. The SME Fund is run by the Under Ministry for SMEs created in 2001. In line with best practices, the Fund applies the principle of co-financing, having firms contribute their own resources for innovation-related projects. The SME Fund disburses subsidies through various intermediaries, including universities, R\&D and technology centres, chambers, associations and foundations. Variable and temporary public-private partnerships have thus become a central element of entrepreneurship policies. The government has relied upon a 'trigger approach', imparting central policy impulses with a view to releasing widespread policy effects ('multiplier function'). The Fund for Technological Innovation (2007) complements the SME Fund's innovation-oriented operations (see below).

Since its inception, the SME Fund has drawn up a comprehensive set of support programmes, some of them directly spurring incubation of business invention and innovation (Box 2.2) (OECD, SMEs in Mexico, 2007). These programmes seek to stimulate innovations through better access to new technology, R\&D benefits and finance, while also offering better opportunities for entrepreneurial training and education. The SME Fund's budget totalled an estimated US 200 million in 2006.

Since April 2007, the SME Fund's innovation-oriented programmes have been backed up by the Fund for Technological Innovation (2007). Run by the Ministry of the Economy and the National Research Council (CONACYT) and endowed with USD 55 million, the new Fund supports innovation projects under three strategic 'support lines': Development and technological innovation; creation and consolidation of groups or centres pursuing activities of engineering, design, research and technological development; and association-sponsored efforts of technological innovation. The guiding principle of the Fund's operations is a prompt transmutation of $R \& D$ benefits (inventions) into innovations through entrepreneurial activity. To this end, it promotes interactions between the business sector and the research community. 
Box 2.2. Selected Strategic Support Programmes (2005)

\section{Better access to new technology}

1. The Programme for Innovation and Technological Development

2. The National System of Business Incubators

\section{Better access to finance}

3. The National Credit Guarantee Programme

4. The National Financial Extension Programme

5. The Capital for Development Schemes

\section{Better access to entrepreneurial education and training}

6. The Business Development Centres Network

7. The Programme for training and strengthening firms' capabilities

8. The National Network of Productive Articulation

\section{Strengthening entrepreneurial and innovation activities}

\section{a) Better access to new technology and $R \& D$ benefits}

The Mexican government views deepened and expanded networking linkages among different enterprise support units (business incubators, innovation laboratories, business development centres, centres of productive articulation), intermediate organisations and different levels of government as a condition sine qua non for accelerating the flow of new technology and R\&D benefits. Effective webs of connections act as catalysts for diffusing new technology and rendering tailor-made initiatives of entrepreneurship policy more efficient. Networking programmes are thus seen as a kind of collective process innovation. Under this policy, activities of vertical networking have relied on both 'top-down' and 'bottom-up' approaches.

\section{The Programme for Innovation and Technological Development}

Put into place after the establishment of the SME Fund in 2004, the programme supports innovative and R\&D activities by way of augmenting the firm's ability to absorb and access new technology and specialised knowledge. The Programme for Innovation and Technological Development strives to establish links between firms and principal centres of applied research and technological development. Its lines of action mainly concern mature and fast-growing SMEs (HGSMEs). Sustained expansion of these firms often requires linkages with national and international networks. To this end, the programmes favour the creation of two kinds of enterprise support units: business accelerators (Aceleradores de Negocios) and innovation laboratories (Laboratorios de Innovacion en Nichos Especializados).

- Business accelerators are all those organisations, institutions and specialised enterprises capable of identifying, assisting and financing technically-oriented firms during their expansion phase. In this capacity, business accelerators help HGSMEs strengthen innovative efforts, conquer new markets at home and abroad, attract business angels' investment and become part of international value chains. As a result, a web of business accelerators has been gradually built up since 2004 consisting in 2006 of six national units (three privately run accelerators and three units run by institutions of higher education) and four international accelerators. 
- Innovation laboratories are run by Higher education institutions and centres of applied research and act as service providers supporting firms' R\&D efforts and innovative activities. In 2005, a network of innovation laboratories was set up, connecting all laboratories specialised in the design, prototyping and testing of micro electronic mechanisms MEMS (e.g. States of Puebla, Chihuahu and Mexico City). The Programme for Innovation and Technological Development has also promoted the transfer of technology from large to smaller firms in the automobile industry and underpinned the formation of clusters for robots and automation.

\section{The National System of Business Incubators}

Partially inspired by successful foreign programmes, in 2003 the federal government launched a business incubator programme (the National System of Business Incubators) aimed at lengthening the life of newly created enterprises. Previously, more than $50 \%$ of newly created firms went out of business two years after birth. The National System of Business Incubators (2003) offers a wide range of support services, including feasibility studies of market opportunities and administrative services including offices, skilled labour and information about access to finance and new technology. Services offered by business incubators appeal particularly to young entrepreneurs. About $80 \%$ of entrepreneurs using business incubators are 25-35 years old.

There are three variants of business incubators.

- The traditional one assisting the birth of firms in traditional sectors with standard material and immaterial input requirements. The usual incubation period for this category is about three months and at most six months.

- The second variant (intermediate technology incubator) assists the birth of those firms which require knowledge inputs from specialised institutions, large firms and strategic innovation networks. The usual incubation period is between 12 and 18 months.

- The third variant (high technology incubator) supports nascent firms in the domain of information technology, biotechnology, microelectronics, wireless technologies, robots, automation, nanotechnology and new, high-quality materials (e.g. ceramics). The normal incubation period for this category is about two years.

Since its inception in 2003 and up til 2007, the incubator programme led to the creation of 423 business incubators, which, in almost equal proportions (nearly one half), specialise in the use of traditional and intermediate technology (first and second variants). High-technology incubators account for less than 5\% of the total. The incubators, in turn, induced the creation of 5676 firms in 2003-2007, more than half of which use intermediate technology. High-technology firms accounted for $5 \%$ of incubatorinduced new businesses (Table 2.5). About 60\% of financial support (an estimated USD 20 million) has come from the Federal, State and local governments, the remainder (USD 10 million) being financed by academia and the private sector. The average financial support per incubator-induced firm creation totalled USD 5500 in 2004-2007.

To ensure the continuity of the incubator programme, an autonomous National Council of Business Incubators (Consejo Nacional de Incubadoras de Empresas) was established. This council acts as a 'window' for obtaining information about business incubators, paving the way for a national network of business incubators. 
Table 2.5. Business Incubators and Enterprises

\begin{tabular}{rrrrrr}
\hline & & 2004 & 2005 & 2006 & 2007 \\
\hline \multirow{2}{*}{ Incubators } & Total (cumulative) & 95 & 196 & 307 & 423 \\
\hline \multirow{2}{*}{ of which } & Traditional firms & 25 & 63 & 149 & 197 \\
& Intermediate technology & 64 & 124 & 145 & 210 \\
& High technology & 6 & 9 & 13 & 16 \\
\hline \multirow{2}{*}{ Enterprises } & Total & 2113 & 3144 & 4779 & 5676 \\
\hline of which & Traditional Firms & 588 & 1418 & 2754 & 1695 \\
& Intermediate technology & 1482 & 1691 & 1967 & 3498 \\
& High technology & 43 & 35 & 58 & 283 \\
\hline
\end{tabular}

Source: OECD, SMEs in Mexico, 2007. Data is from the Under Ministry for Small and Medium Enterprises, Ministry of Economy.

\section{b) Better access to finance}

Under the Entrepreneurial Development Plan (EDP) for 2001-06, better access to finance has been a key lever for strengthening entrepreneurship and enterprise development. Accordingly, the authorities swiftly established grids of financial support lines extending credit guarantees at reduced cost. Financial institutions were called upon to create, modify and consolidate financial instruments so as to meet highly differentiated firms' needs. These policy initiatives were strengthened and refined with the shift to an innovation-based entrepreneurship policy in 2004.

Three programmes emerged as main elements in the authorities' endeavours to deepen and widen the flow of financial funds to aspiring enterprises: The National Guarantee Programme; the National Financial Extension Programme; and the Capital for Development Schemes.

\section{The National Guarantee System}

Creating new financial instruments in the form of guarantee funds, the National Guarantee System (Sistema Nacional de Garantia, 2003) has strongly raised supplies of affordable financial resources. Adopting the portfolio approach, the Ministry of Economy enlarged the range of financial products, portfolio lines becoming broader as a consequence. Guaranteed credits are mostly of a short-term nature, nine-tenths of firms' credit demand serving the purpose of financing working capital. The default rate of Mexican guarantee programmes $(0.92 \%)$ is far below the international standard of $5 \%$ pointing to low levels of moral hazard.

The distribution of risk between the Ministry of Economy, NAFIN (State Development Bank) and financial institutions has been shown to be efficient. The operation of credit guarantee programmes has also prompted private financial institutions to extend new loans to SMEs, while developing new financial products. The associated rise in bank profitability has contributed to the establishment of new financial institutions.

A bidding process for guarantee funds was started in 2005, kindling competition among financial intermediaries keen to obtain loan guarantees. Under the bidding procedure, the amount of guarantee funds rises with a rising leverage index and falling interest rates. In the previous setting, with direct provision of guarantees, the leverage of SME Fund resources was only 2 pesos of credit for each peso of funding. The auction technique raised the credit/fund ratios to 65 in 2007. Guarantee coverage falls into the range 
between 60 and $80 \%$, which is high enough to avoid the use of collateral requirements and sufficiently low to escape from moral hazard. In 2003 and 2005, the flow of credit funds was also stimulated by new legislation facilitating the recovery of collateral. Nevertheless, legal proceedings have remained costly and long.

\section{The National Financial Extension Programme}

Established in 2004, the National Financial Extension Programme (Red Nacional de Extensionismo) provides a financial assessment net, helping firms enter into credit relationships. During the first phase, professional credit advisors assess the firm's financing needs, select the most suitable loan products and assist entrepreneurs in their credit negotiations. In a second phase, they monitor the subsequent use of credit funds.

Through their nationwide network of branches, commercial banks help firms in the process of screening and improving credit applications. As a result, banks' risks perceptions have decreased, increasing supplies of pre-approved credits and lowering costs of credit approval. In 2006, the National Financial Extension Programme reached nationwide coverage, with all 32 Mexican States participating in the programme. Six hundred professional credit advisors, authorised by the Ministry of Economy, have helped process firms' credit applications and monitor the subsequent use of credit funds. In 2006, over 8000 firms benefited from cost-free credit advice and surveillance ( $0.3 \%$ of the firm population).

\section{The Capital for Development Schemes}

Two sub-programmes serve the purpose of increasing the supply of venture capital for growthoriented entrepreneurs: the Seed Capital Programme (Programma Capital Semilla PYME) and the Fund of Productive and Infrastructural Development Projects (FOPRODE). In addition, the authorities sponsor the creation of investment clubs and other instruments to channel private venture capital to innovative firms.

- Under the Seed Capital Programme (2005), financial intermediaries and incubators release capital funds for firm creation. The supply of venture capital ranges from USD 10000 to USD 200 000, depending upon the nature of planned firm creation (traditional, intermediate and high-technology firms). This sub-programme targets potential entrepreneurs with little or no experience in entrepreneurial activity. The Seed Capital Programme injects capital under twin formulas of partnership capital and quasi-capital.

- Under the partnership formula, entrepreneurs remain owners of their newly created company. Seed capital is released for a period of up to four years, the business incubator being the business associate. Financial resources are disbursed to the business incubator centres, allowing them to enter into a contractual, strategic partnership with the entrepreneur. Profits and losses are shared at the end of the contract period. The success of this programme largely hinges upon business incubators and intermediate organisations providing adequate follow-up to the release of capital funds.

- Under another variant of the Seed Capital Programme, quasi-capital is provided in the form of a loan at a subsidised annual interest rate of $6 \%$, the initial grace period of 6,12 or 18 months depending upon the nature of the planned enterprise traditional, intermediate or high technology). This scheme can also be operated by business incubator centres or financial intermediaries (non-bank banks). Requirements for own funds are $20 \%$ for traditional firms and $15 \%$ for non- 
traditional firms. Since the inception of this variant at the end of 2005, 302 entrepreneurs have benefited from this programme.

- The second sub-programme (FOPRODE) is a pilot project programme (2004) providing funds between USD 25000 and USD 100000 over a period of three to four years at a subsidised interest rate of $6 \%$ with a grace period of one year. FOPRODE mainly supports prospective innovative entrepreneurs with no proven entrepreneurial background, no credit file, no credit guarantees and no collateral. The FOPRODE programme is operated and managed by an intermediate organisation with national coverage, allowing local governments to participate. Local financial institutions are able to identify and evaluate projects as well as to formalise credit contracts, manage and recover credit portfolios. Investment proposals are received and assessed via an electronic window operating through Internet. In 2006, more than 200 firms benefited from this scheme.

Another avenue used for supplying venture capital are Investors' Clubs, which are 'civil organisations' composed of investors intent on realising high rates of return on capital through investments in innovative firms. For individual members, investment clubs reduce operation costs and risks and augment investment capacity. For entrepreneurs, investment clubs release private venture capital which is otherwise unavailable. The PYME Option (2006) represents a unique type of investment guarantee designed to spur the creation of investment clubs and venture capital funds geared towards early stage investing.

Beneficiaries of PYME Option are firms engaged in innovative, high value added or export-oriented activities or which are clearly oriented towards integration in industrial chains. PYME Option offers investors flexible procedures to cover the risk in case of business failure. The amount of capital covered has a ceiling of USD 500000 and a limit of $70 \%$ of investment projects, a duration of coverage ranging from three to five years.

\section{c) Better access to entrepreneurial education and training}

Some programmes shown in Box 2 focus on improving entrepreneurship education and training as well as widening access to skilled labour and business services: the Business Development Centres Network, the Programme for Training and Strengthening Firms' Capabilities and the National Network of Productive Articulation. The new, incoming government (December 2006) has stepped up efforts to broaden and upgrade entrepreneurial education so as to augment the participation in entrepreneurial activity.

\section{The Business Development Centres Network}

Business development centres (BDCs or Centros de Desarrollo Empresaria) are locally established support units providing a wide range of basic and more sophisticated firm support services. Mexico's BDCs provide 'business solutions', but no direct entrepreneurship training, e.g. helping firms draw up loan requests based upon BDC assessment of financial needs. Services rendered by public BDCs are free of charge, while private BDCs demand a moderate fee (OECD, SMEs in Mexico, 2007).

Sponsored by chambers of commerce, industry and educational institutions, BDCs have been developed since 2001 as part of the 2001-2006 Entrepreneurial Development Plan (EDP). By the end of 2007, public and private BDCs numbered more than 170. 
There are two types of BDCs:

- Conventional BDCs provide basic firm support services (especially to subsistence entrepreneurs).

- BDCs Plus contribute to creating favourable framework conditions for innovative firms (high-value-added investment projects, growth-oriented entrepreneurs).

Since 2004, BDCs are subject to systematic monitoring by the SME Fund. The SME Fund has issued terms of reference for what constitute 'standard' or 'required' BDC operations. These efforts at harmonisation seek to augment BDC efficiency, paving the way for creating an effective network of BDCs. Such a network tends to induce mutual learning processes triggered by information exchange.

In pursuit of this aim, the SME Fund has helped establish pilot BDC groups, which exchange views about how to run themselves more efficiently. A standardised management system has been designed which BDCs need to apply in order to obtain operational authorisation from the Ministry of Economy. Pilot groups have also identified efficient ways in which BDCs can employ e-learning and the Internet as a platform for spreading entrepreneurship training programmes. The BDC approach adopted by the SME Fund allows the most dynamic BDCs to be identified, enabling them, at a later stage, to grow into a strong nucleus of the BDC network.

\section{The Programme for Training and Strengthening Firms' Capabilities}

The second programme is concerned with opening access to education and training. This programme aims at creating and upgrading entrepreneurial human capital allowing a better absorption of new technologies in all areas of entrepreneurial activities (managerial and administrative skills as well as marketing strategies). The programme facilitates access to training for owners and managers, especially of micro firms (subsistence entrepreneurs): through this programme, consultants provide systematic and methodological training to firms. Well-focused workshops and interviews with managers and workers, however brief, have led to significant productivity improvements.

Since 2005, training options have been increasingly adapted to their potential impact on different forms of innovation. The SME Fund also encouraged firms to participate in interactive processes of information and knowledge exchanges, thereby stimulating the collective efficiency of different enterprise groups. As noted above, Mexico's entrepreneurship policies consider collective efficiency as a vital innovation asset.

The Programme for Training and Strengthening Firms' Capabilities offers access to three types of training: conventional training for administrative, commercial, financial and productive activities; specialised training for product and process innovations; and training the 'coaches'.

Special training efforts were also undertaken under the so-called PROMODE programme which helps large numbers of potential subsistence entrepreneurs opening their retail shop. The target for 2006 was to offer training support for as many as 160000 firms in the retail sector.

\section{The National Network of Productive Articulation}

The third programme seeking to improve entrepreneurship education, training and business services is the National Network of Centres of Productive Articulation (Centros de Articulacion Productiva, CAP). An outgrowth of private initiatives, CAPs are micro or small business units (support units) acting as a hub for 
rendering high-value-added business services to selected branches of industry, commerce and services. At the end of 2005 , CAPs totalled 81.

CAPs may serve to create databases of potential customers for producers of well-defined products and services, allowing swift adaptation of design and production to changing consumer needs. CAPs also serve to scrutinise investment projects of affiliated enterprises and help upgrade training of both entrepreneurs and coaches. Finally, CAPs provide consultation services for potential network members, inducing 'wouldbe' entrepreneurs to become firm creators.

\section{d) Reducing the cultural bias against entrepreneurial activity}

Entrepreneurship receives nation-wide attention during the annual week for SMEs, a national event. The SME week has been successful in attracting 50000 firms by providing on-the-spot information, training and network opportunities. Mobile information centres (SME policy vans) spread information about opportunities to benefit from government support. Finally, business fora, partly financed by the SME Fund, are organised throughout the year, attracting 'would-be' entrepreneurs. In 2004-06, close to 18000 micro firms have been able to establish first contacts with bigger firms and institutions.

\section{Entrepreneurship and SME policies and their impact upon firm creation and innovation}

Faced with a strongly ailing firm population, Mexico has adopted a new, evolutionary and differentiated policy approach. Being flexible and comprehensive in nature, entrepreneurship policies (2001-06) have reduced impediments to entrepreneurial activity and innovation in three major areas: R\&D and technology, finance, capabilities and access to skilled labour. The innovation-oriented focus of entrepreneurship policies was sharpened in 2007 with the creation of the Fund for Technological Innovation. Run by the Ministry of Economy and the National Research Council, the new Fund complements SME support programmes designed by the SME Fund, Mexico's main tool for SME and entrepreneurship policies.

The principal policy instrument employed for impediment reduction has been collective process innovation ('institutional road building'). Such collaborative innovations have partly taken the form of creating horizontal and vertical network links between entrepreneurial support units (business incubators, innovation laboratories, business developments centres and business accelerators). Along with an expanded range of support units, 'institutional road building' has progressively raised the efficiency of central policy impulses imparted by the SME FUND (Table 2.6).

Table 2.6. Entrepreneurship policy: stages of firm evolution

\begin{tabular}{|c|c|c|c|c|}
\hline \multirow{2}{*}{$\begin{array}{l}\text { Entrepreneurship } \\
\text { policy }\end{array}$} & \multicolumn{4}{|c|}{ Stages of firm evolution } \\
\hline & Pre-birth & Birth & Expansion & Internationalisation \\
\hline \multirow[t]{4}{*}{$\begin{array}{l}\text { Support Units and } \\
\text { Programmes }\end{array}$} & $\begin{array}{l}\text { Business } \\
\text { Incubators }\end{array}$ & $\begin{array}{l}\text { Business } \\
\text { Development } \\
\text { Centres }\end{array}$ & $\begin{array}{l}\text { Business } \\
\text { Development } \\
\text { Centres }\end{array}$ & $\begin{array}{l}\text { Business } \\
\text { Accelerators }\end{array}$ \\
\hline & & $\begin{array}{l}\text { Investment } \\
\text { Clubs }\end{array}$ & $\begin{array}{l}\text { Innovation } \\
\text { Laboratories }\end{array}$ & \\
\hline & & Training & $\begin{array}{l}\text { Business } \\
\text { Accelerators }\end{array}$ & \\
\hline & & & Training & \\
\hline
\end{tabular}


The 'collective efficiency approach' has also been applied to stakeholders of entrepreneurship policy, i.e. different levels of government, intermediate organisations (non-banking banks, foundations, business associations, international organisations) as well as educational and research institutions. In line with best practice, administrative powers have been decentralised, contributing to improved policy co-ordination at all levels of government. State and local governments have thus been able to participate more actively in the design and execution of novel entrepreneurship policy projects.

\section{Improved access to new technology, benefits from R\&D and networking facilities}

The innovation-oriented policy approach has facilitated access to new technology by way of establishing and expanding networks of enterprise support units, including business incubators, innovation laboratories, business accelerators, centres of applied research and technological development. Both the rising number of the support units and expanded and deepened linkages among them as well as sharply rising numbers of programme beneficiaries testify to a significantly improved climate for innovation diffusion. In 2006, the SME Fund spent about $30 \%$ of its budget on these programmes.

In 2004-07, business incubators induced the creation of nearly 5700 firms (1.5\% of Mexico's firm population), two-thirds of which have used intermediate technology. Product and process innovations have also been fostered by business accelerators for high-growth SMEs.

\section{Improved access to finance}

Firms' access to finance has become much easier with the introduction of innovation-oriented policy measures. The supply of short-term credit funds from both banks and non-banks has strongly risen with innovative guarantee procedures (auction mechanism), a vastly increased number of financial instruments, improved information flows between credit institutions and upgraded advice for credit-seeking enterprises (National Guarantee Programme and National Financial Extension Programme).

The default rate of Mexican guarantee programmes is very low by international comparison, mainly reflecting reasonable guarantee coverage and a well-balanced distribution of risk between the Ministry of Economy, the State Development (NAFIN) and financial institutions. Improved supply conditions have allowed interest rates for short-term bank credits to enterprises to fall relative to standard short-term interest rates. Reduced cost of finance, apart from stimulating entrepreneurial activity, has also encouraged 'informal' entrepreneurs to join the formal economy.

The bulk of increased credit volumes has gone to small and medium-sized enterprises (growthoriented entrepreneurship). By contrast, micro credits, totalling USD 308 million in 2005 or USD 77 per each micro enterprise in the formal economy, remained small, especially relative to potential bank credit demand of subsistence entrepreneurs. Altogether, the SME Fund used 30\% of its resources for easing firms' access to finance in 2006.

Starting from low levels, the supply of venture capital and longer-term credit funds has also increased (Capital for Development Schemes). Reflecting reduced barriers to finance, interest rates for credits to enterprises have decreased relative to standard interest rates. Transaction costs have also been reduced by the removal of collateral requirements for some categories of credits and by upgraded credit advice.

\section{Improved access to skilled labour and business services}

Several programmes, absorbing more than $40 \%$ of the SME Fund's resources, have enlarged and upgraded the access to skilled labour and business services (Business Development Centres Network (BDCs), Programme for Training and Strengthening Firms' Capabilities). Increased supplies of business services are evident in the expansion of business development centres (BDCs), the establishment of new 
high-quality service centres (centres of productive articulation, CAPs) and rising numbers of well-focused workshops and interviews.

Stricter monitoring and network building have improved the quality of BDCs' services. Moreover, since 2005 training options have been adapted to potential impacts of different types of innovation. Finally, large numbers of subsistence entrepreneurs have benefited from basic training services, triggering widespread non-R\&D innovations and raising production efficiency (PROMODE programme).

\section{Concluding remarks}

Overall, Mexico's new innovation-oriented policy effort has been unprecedented in both scale and depth. Gauging aggregate policy effects, though, is still difficult. Policy lead times are long, most statistical data is inadequate, and appropriate evaluation procedures are not yet in place. Even so, a number of encouraging signs have emerged, pointing to a positive impact of new innovation-oriented policies. On the input side, the number of entrepreneurs receiving some kind of policy help has surged, rising to an estimated 254000 in 2006 compared with 13000 in 2000. Two-thirds of enterprises receiving support in 2006 were micro firms. For some categories of firms, access to finance has become less difficult. On the output side, the average survival time of new firms has lengthened over the past few years, partly reflecting the rising weight of incubator-induced firms in the pool of newly created firms. The network of business incubators has been considerably expanded.

Positive signals notwithstanding, room for still better entrepreneurship policy efforts remains large. Sluggish productivity trends, reflecting firms' inefficient production modes, call for strongly increased government resources. ${ }^{49}$ Much stronger emphasis should be placed on improving firms' access to new technology, finance and skilled labour. Continued network building, designing new financial instruments, increased supplies of basic advisory and training services as well as better facilities for entrepreneurship education are essential for lifting vast numbers of subsistence entrepreneurs out of poverty and inefficiency. 
Box 2.3. Policy recommendations

\section{Increase resources for entrepreneurship and SME policies}

Increase financial resources available to the SME Fund

Use incremental resources for expanding networks of support units, notably in the less-developed regions

\section{Improve access to new technology, benefits from R\&D and networking facilities}

Strengthen efforts to raise non-R\&D based innovations, especially in less-privileged regions

Reinforce links between innovation -oriented support units and BDCs

Increase the number of tailor-made business incubators in less-privileged regions

\section{Improve access to finance}

Enlarge and strengthen the national SME Guarantee Programme

Broaden micro firms' access to finance, making use of mobile micro banks

Enlarge the range of financial instruments

Increase banks' capacity for 'small-scale' lending

\section{Improve access to skilled labour and business services}

Expand basic training courses for entrepreneurs

Expand network of BDCs (and use mobile BDCs) in less privileged regions

Strengthen links between BDCs and entities in charge of providing training and consultancy services

Raise young people's awareness of entrepreneurial prospects

Provide entrepreneurship education in schools, universities and research centers 


\section{ANNEX 2.A}

Figure 2.A.1. Change in relative volume indices of GDP per capita (1992-2005)

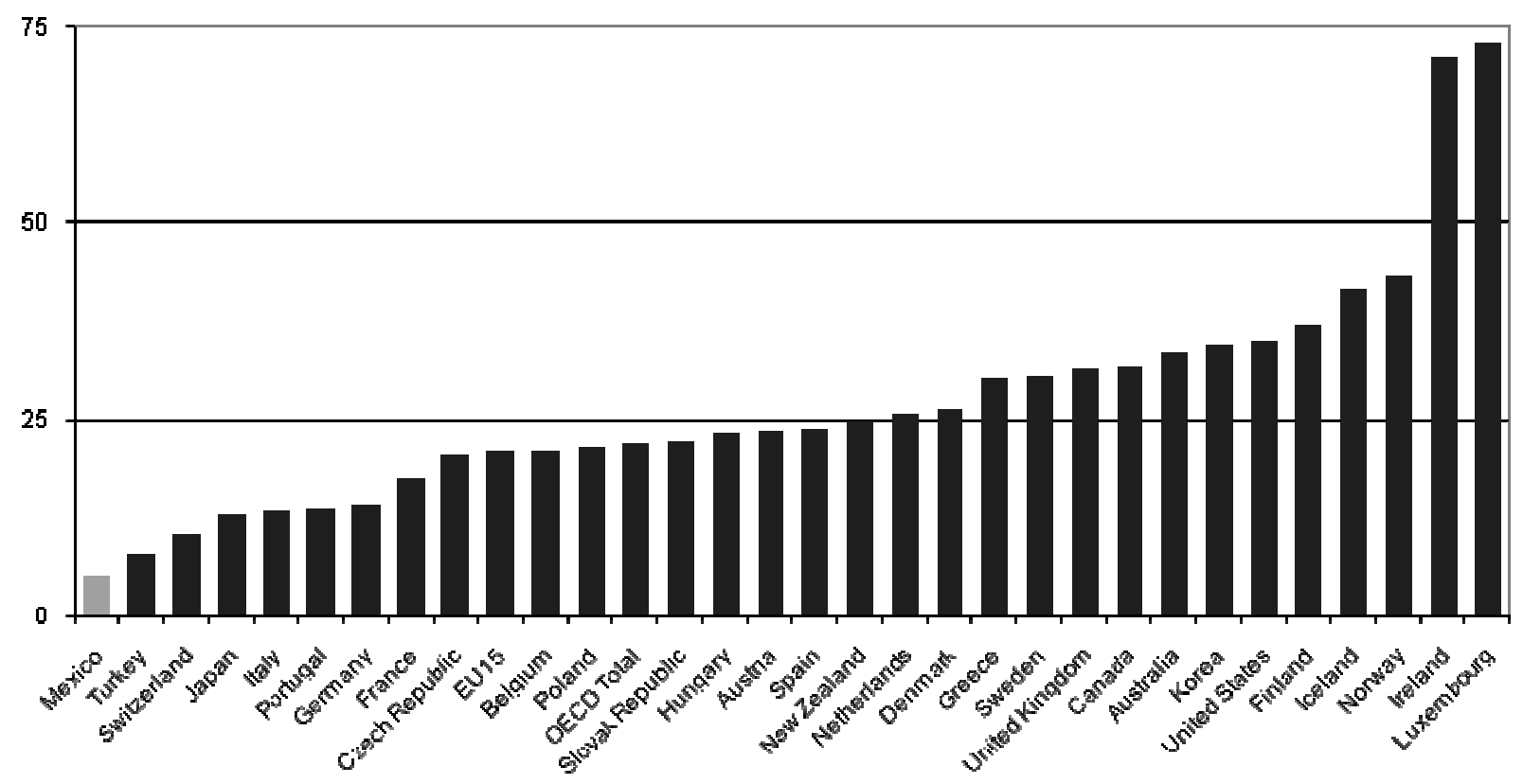

Note: OECD $=100$, absolute differences between the 2005 and 1992 indices.

Source: OECD Factbook 2007; Economic, Environmental and Social Statistics. 
Figure 2.A.2. OECD basket of low-user mobile telephone charges, May 2007

Annual charge, USD PPP, including tax

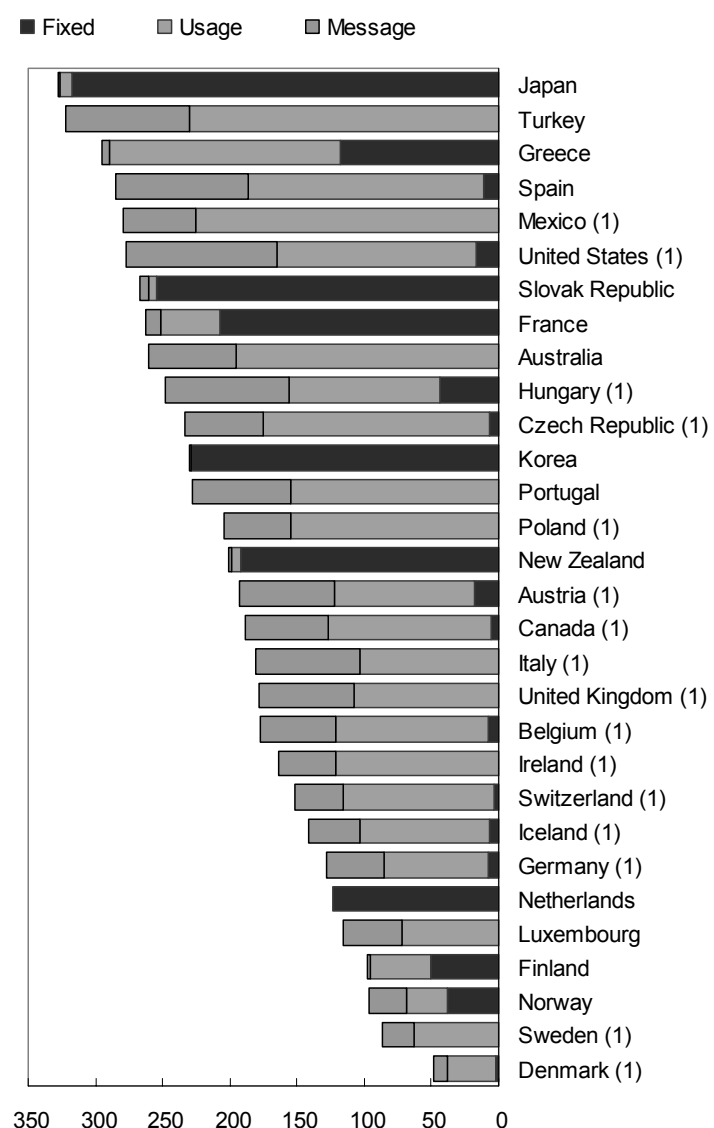

Figure 2.A.3. Broadband prices per Mbit/s and prices for monthly subscription ${ }^{2}$, October 2006

USD PPP, including tax

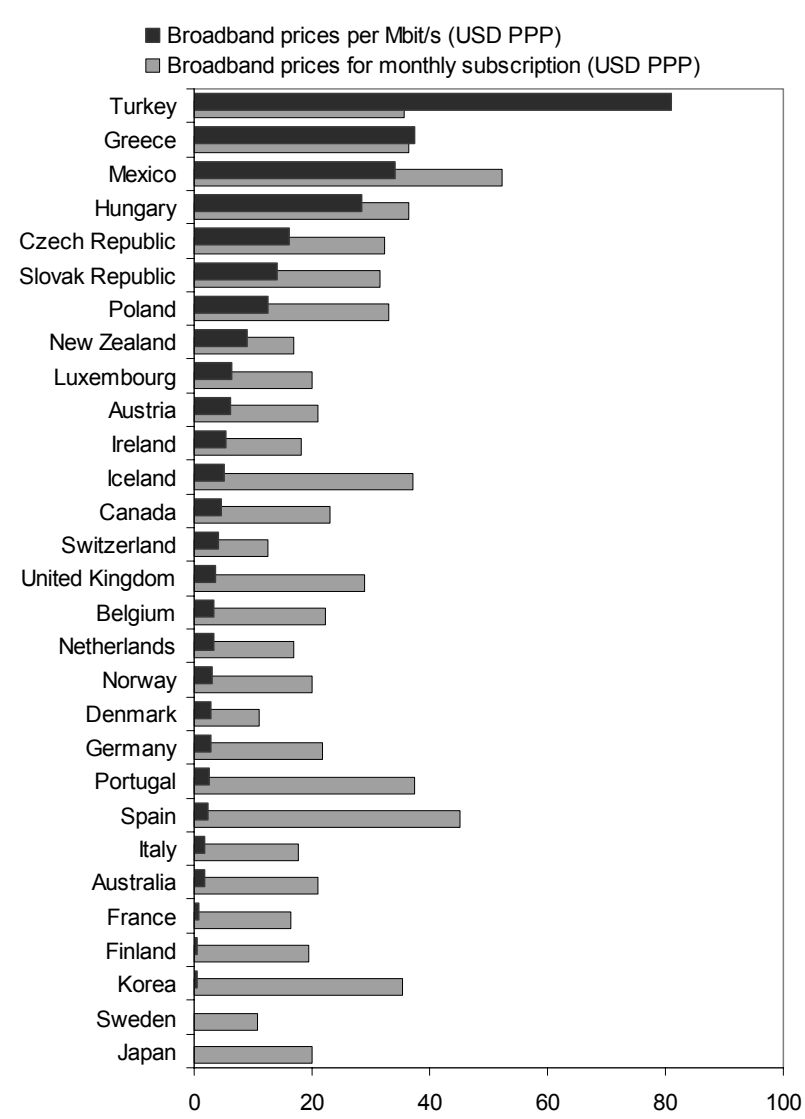

1 . Package using pre-paid card.

2. Prices selected are the lowest observed price per Mbit/s and the lowest observed price for a monthly subscription which has an entry-level 256 kbit/s connection.

Source: OECD Science, Technology and Industry Scoreboard, 2007. 
Figures 2.A.4. and 5. Bank activities: costs and interest margins

Overhead costs

Average 1996-2003

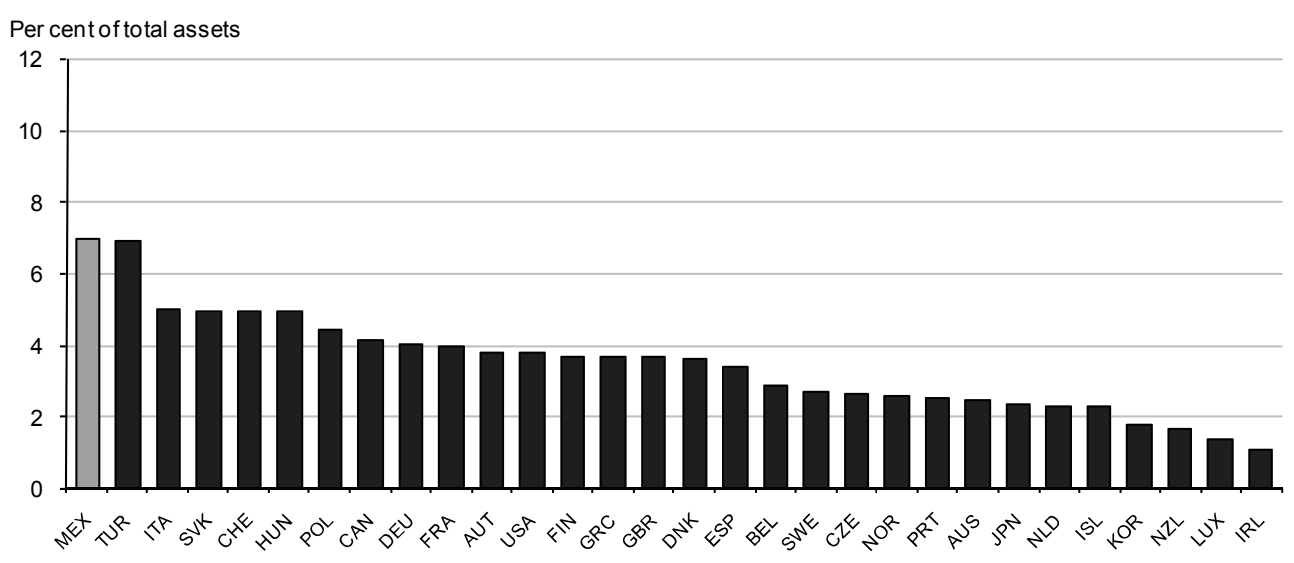

Net interest margins

Average 1996-2003

Per cent of total interest-bearing assets

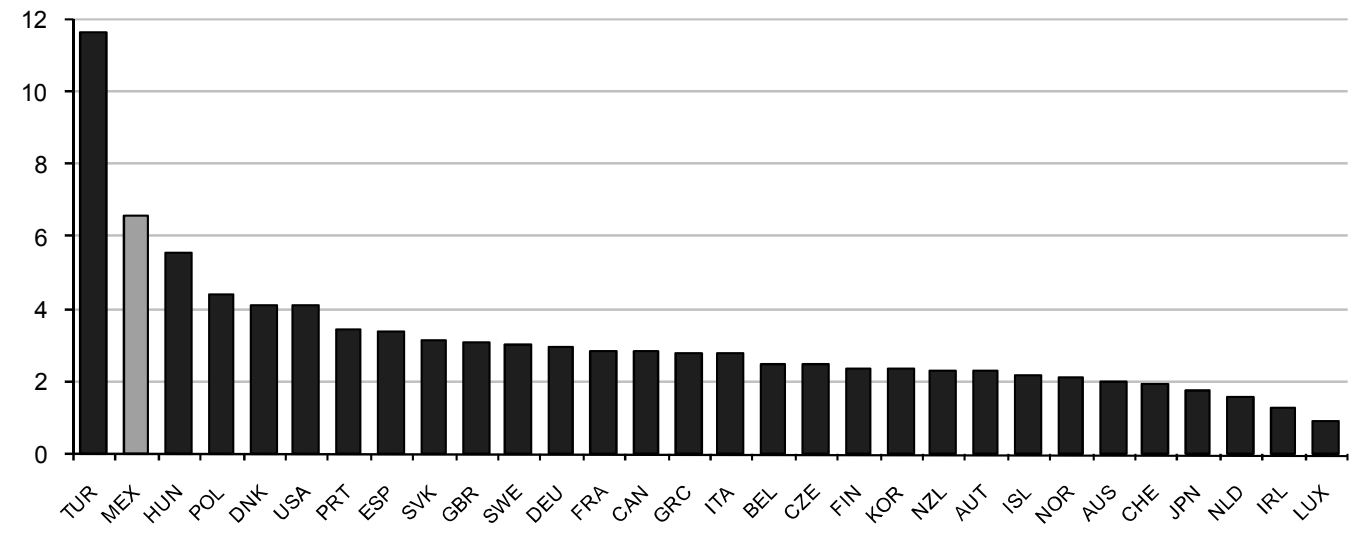

Source: OECD, Going for Growth, 2006. 
Figure 2.A.6. Average of PISA scores in reading, mathematics and science ${ }^{1}$

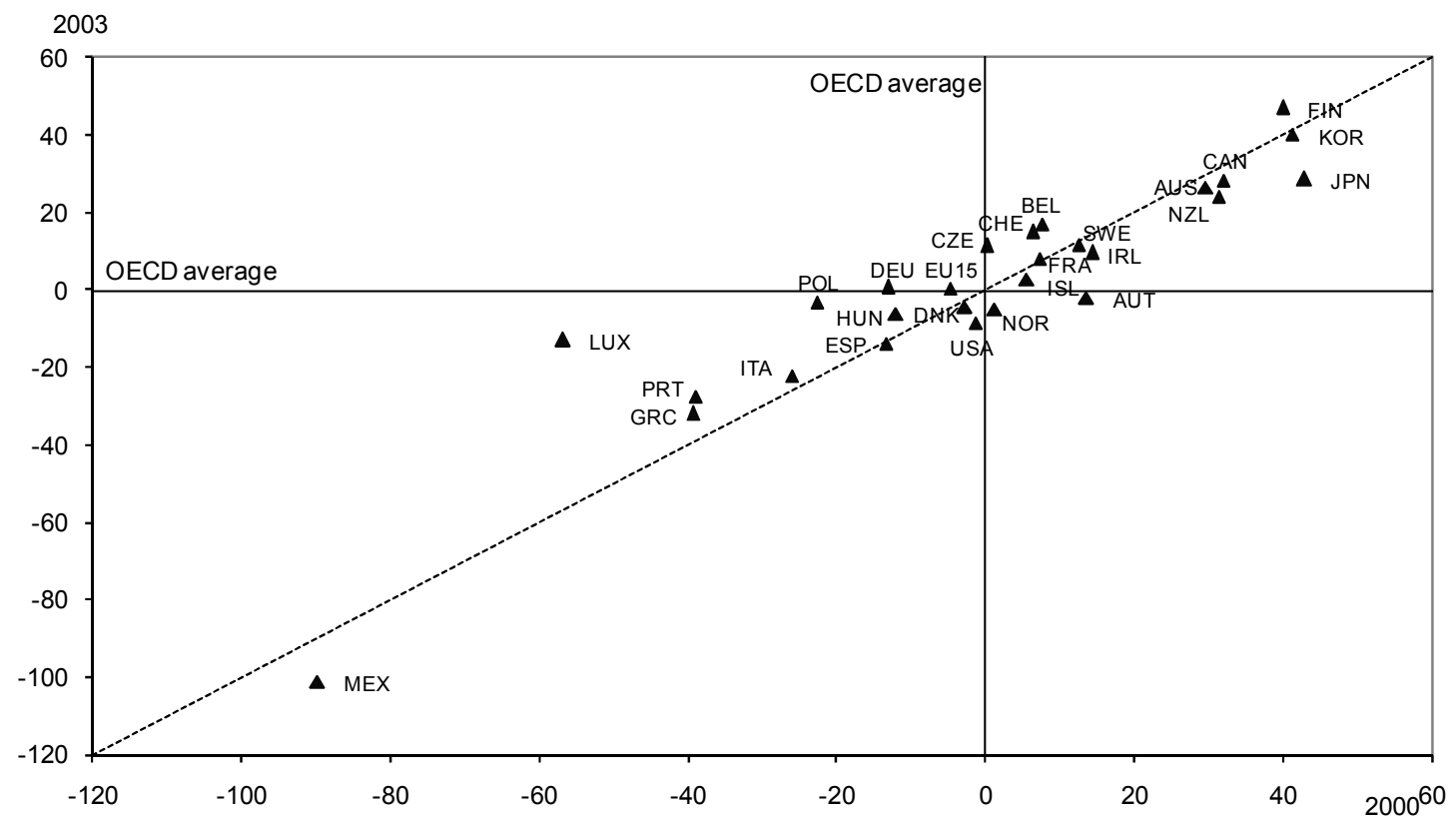

1. PISA stands for Programme for International Student Assessment.

Source: OECD, Learning for Tomorrow's World, PISA 2003.

Figure 2.A.7. Upper-secondary education, percentage of population aged 25-34 and 45-54 (2004)

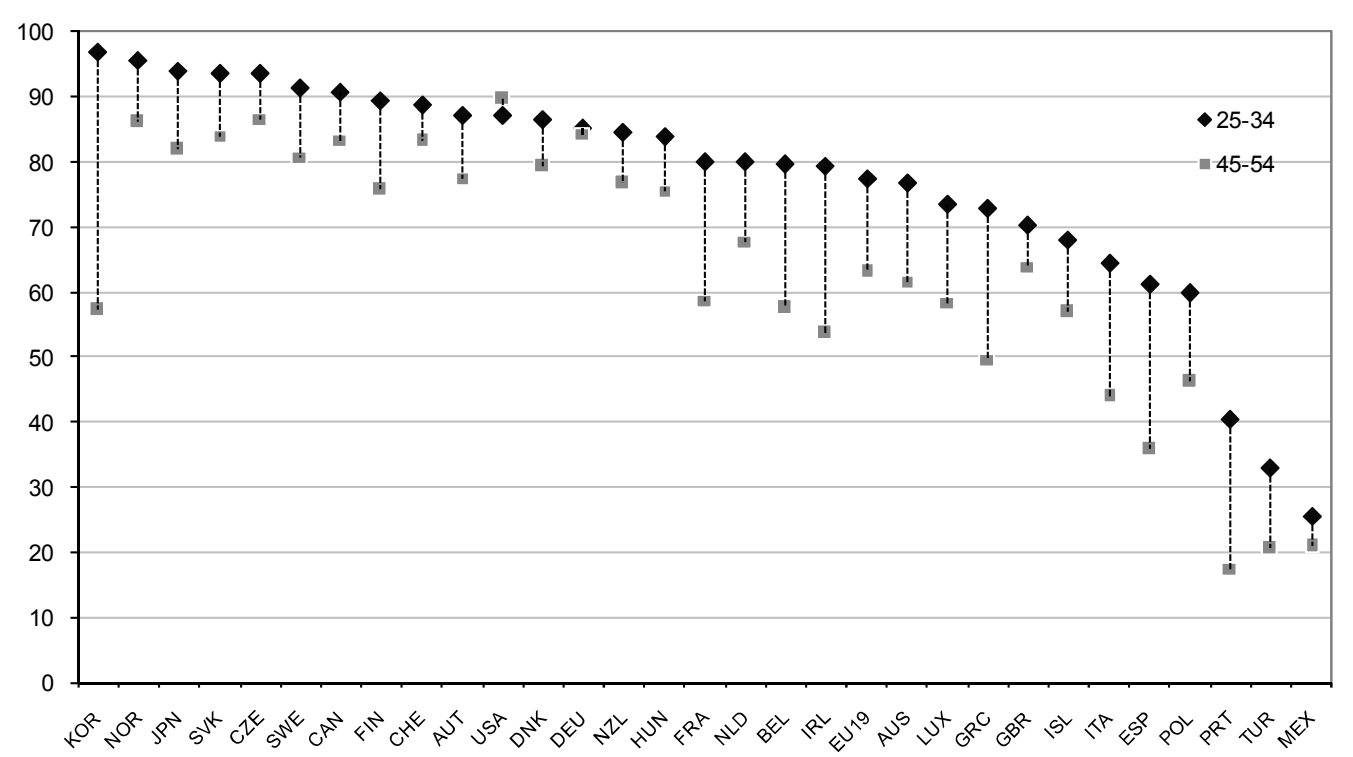

Source: OECD, Education at a Glance, 2006. 
Figure 2.A.8. Tertiary education, percentage of population aged 25-34 and 45-54 (2004)

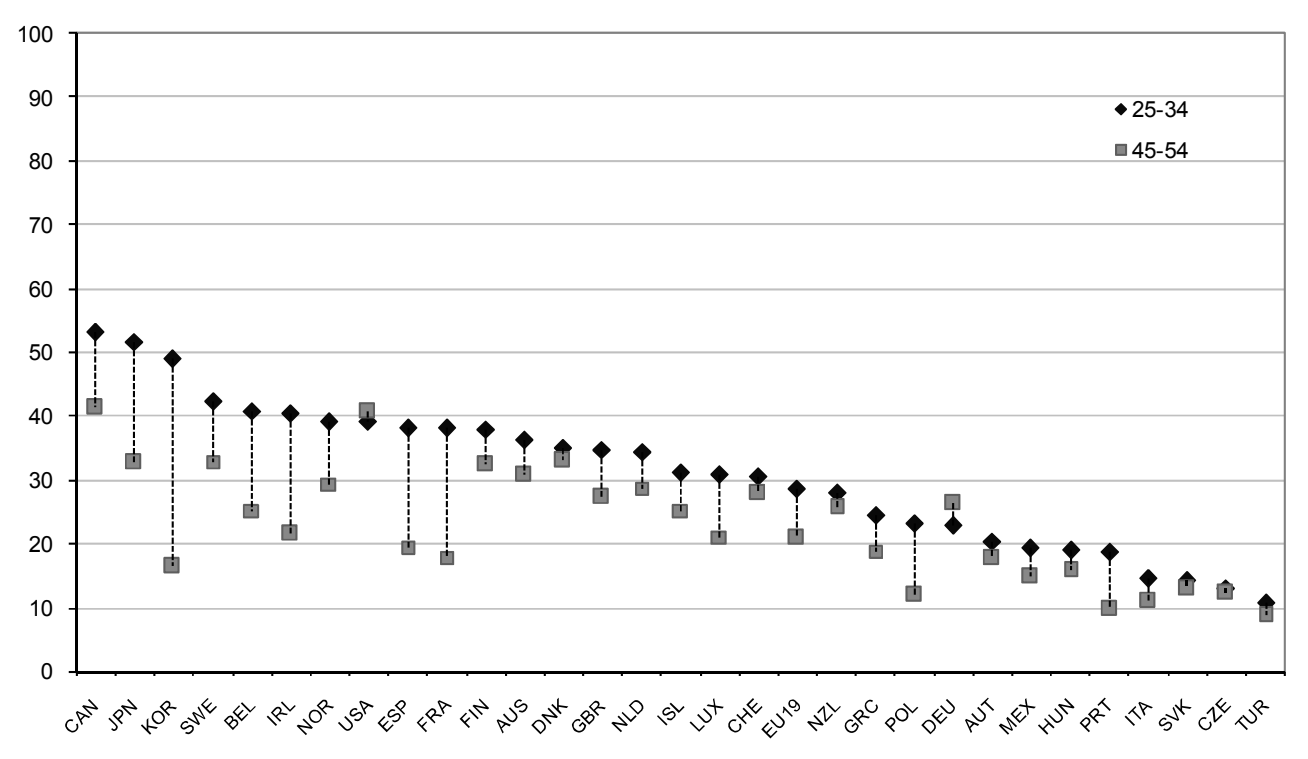

Source: OECD, Education at a Glance, 2006. 


\section{NORWAY}

\section{Introduction}

Norway is committed to implementing entrepreneurship and SME policies as a tool for speeding up the pace of innovation and restructuring the business sector. Entrepreneurship policy is rightly seen as a crucial element for spurring the birth and growth of firms in a setting of rapid changes in consumer preferences, trade, technology, innovation and access to resources. The link between entrepreneurial policy and innovation is, by nature, indirect. Efficient measures of entrepreneurship policy underpin firm creation and growth, and in doing so, they strengthen innovative activity. Viewed from a wider angle, entrepreneurship policy itself may pave the way for 'collective process innovations', augmenting the effects which firm creation and firm expansion normally have on individual innovations.

The first part of this chapter highlights the main features of Norway's enterprise population, identifies main drivers of entrepreneurial activity and presents indicators of entrepreneurship performance. The second part outlines main objectives of entrepreneurship policy and describes principal programmes in four major areas of policy intervention: access to $R \& D$ and technology, access to finance, capabilities and access to skilled labour, and cultural values. The third part provides an evaluation of entrepreneurship policy.

\section{Main features of the enterprise sector and impediments to firm creation}

\section{Main characteristics of the enterprise sector}

Norway's business structure is characterised by large numbers of micro firms (Figure 3.1), representing over $90 \%$ of the firm population in 2007 . Nearly two thirds of the enterprise stock has no employees. In the private non-oil sector, there are only a few large companies.

Figure 3.1. Distribution of enterprises by firm size (2007)

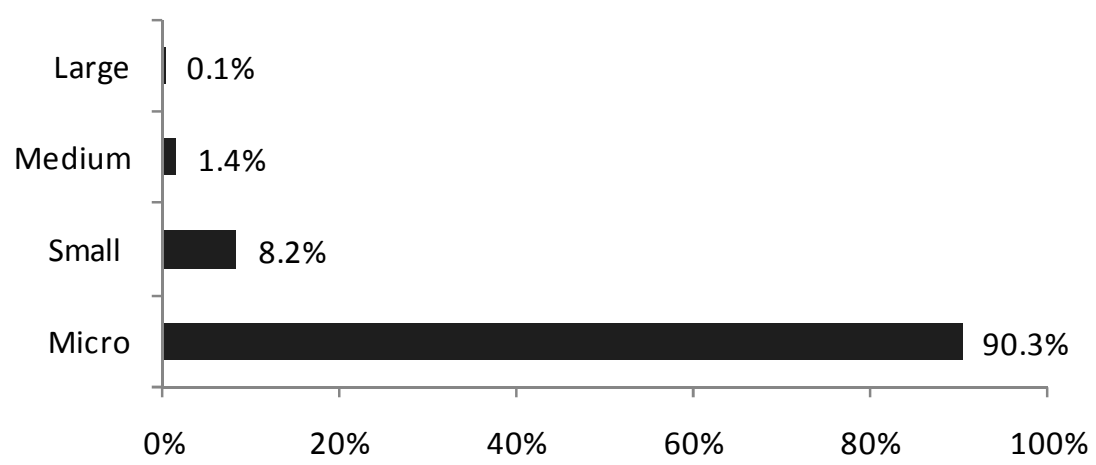

Note: Micro $=$ 0-9 employees, Small = 10-49 employees, Medium = 50-249 employees, Large $=250$ and more employees. Source: Statistics Norway. 
The business sector relies on SMEs: in 2004, 348081 SMEs $^{50}$ with less than 100 employees comprised $99.5 \%$ of the stock of enterprises and employed about $63 \%$ of the total number of employees. Their turnover represented about 53\% of the total enterprise turnover. In comparison 1540 larger enterprises with more than 100 employees represented about $0.5 \%$ of the stock of enterprises in 2004 , employed about $37 \%$ of the total number of employees and represented about $47 \%$ of the total turnover (Table 3.1).

Table 3.1 Enterprises, employment and turnover by firm size (2004)

\begin{tabular}{lrrr}
\hline Size class & Enterprises & $\begin{array}{r}\text { Turnover } \\
(\mathbf{1 ~ 0 0 0 ~ N O K )}\end{array}$ & $\begin{array}{r}\text { Number of } \\
\text { Employees }\end{array}$ \\
\hline 0-9 employees & 326489 & 777739423 & 480194 \\
& $(93.4 \%)$ & $(25.8 \%)$ & $(31.0 \%)$ \\
$10-49$ employees & 19819 & 582843222 & 368458 \\
& $(5.7 \%)$ & $(19.3 \%)$ & $(23.8 \%)$ \\
$50-99$ employees & 1773 & 225002019 & 121591 \\
& $(0.5 \%)$ & $(7.5 \%)$ & $(7.9 \%)$ \\
100 and more employees & 1540 & 1434275979 & $(37.3 \%)$ \\
& $(0.4 \%)$ & $(47.5 \%)$ & 1548480 \\
\hline Total & & &
\end{tabular}

In industries such as construction, real estate, wholesale and retail, financial services and primary industries, SMEs accounted for more than $99 \%$ of businesses in 2004 , while in other sectors such as transportation and communication, hotels and restaurants, the share was slightly lower (98\%). In manufacturing, $98 \%$ of the enterprises were SMEs, with a comparatively strong presence of medium-sized firms employing between 10 and 250 persons. In contrast, the share of micro firms is comparatively low (Annex 3.1, Table A.3.1).

Given the importance of its resource-based economy, only $7 \%$ of the enterprises in Norway are in the manufacturing sector (Table 3.2). Norway has few high-technology industries outside the petroleum sector. The share of low-tech manufacturing production in the total manufacturing output is about $80 \%$, a considerably higher figure than almost any OECD country. Low-tech, however, does not entail low productivity: the level of productivity is high in general. Norway enjoys a high level of GDP per capita, which cannot be only explained by rising oil and gas exports. ${ }^{51}$ In Norway, SMEs are defined as companies with less than 100 employees. Large firms are defined as companies with more than 100 employees.
} 
Table 3.2 Share of enterprises and employment by sector (2006)

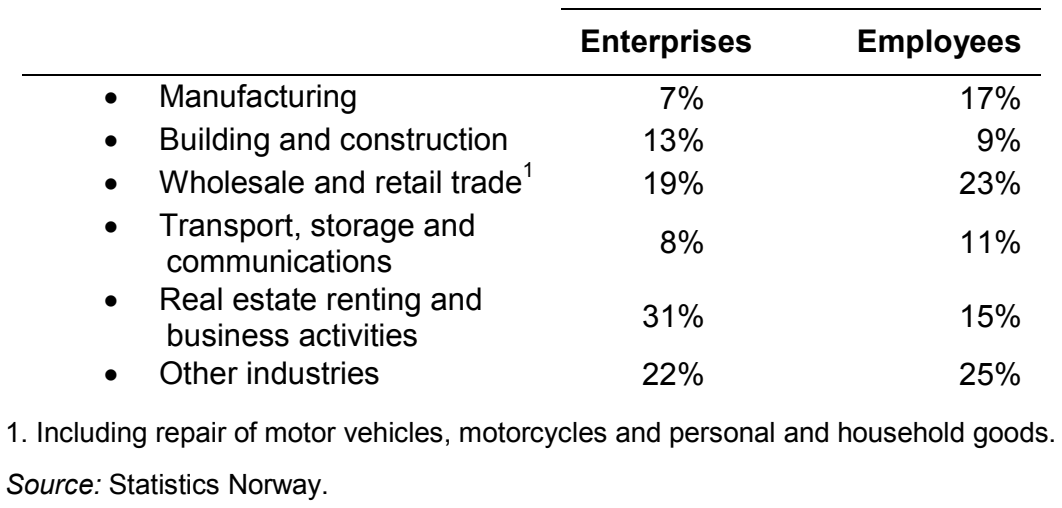

The distribution of the firm population by size class is rather homogenous across different counties and regional dispersion of GDP per capita is far below the OECD average (Annex 3.A, Figure 3.A.1). Counties situated in the southern part of Norway (Oslo, Akershus, Rogaland, Hordaland) host more enterprises than northern counties such as Finnmark, Troms and Nord-Trondelag that are more remote from the capital and more sparsely populated. The counties situated in the southern part of Norway are also the ones that host most of the large enterprises.

Rates of firm birth and death are high by international comparison (Figure 3.2). In 2006, 51246 companies were established (16\% of the stock of companies) and 41121 (13\% of the enterprise stock) were dismantled, while 3032 enterprises went bankrupt, representing $1 \%$ of the company stock. The survival rate for self-run enterprises (with no employees) is low relative to the survival rate of other SMEs, with only $17 \%$ of self-run firms created in 2001 surviving for more than three years.

The magnitude of start-ups from 2006 partly reflects new legislation on the taxation of dividends. Dividends paid by one company to another are exempt from taxation. There are also advantages in owning property through companies. The implicit financial incentive has led to stronger firm creation.

According to the 2005 OECD Survey "Policy Questionnaire on Bankruptcy"52 possibilities for reorganising a company and chances of getting a fresh start in case of financial difficulties appear to be lower in Norway than in other OECD countries, where early warning systems for financially distressed companies, fast track mechanisms for reorganisation or fast track discharge proceedings for legitimate bankruptcies are available. FORA indicators also show that bankruptcy recovery rates are high compared to other OECD countries, indicating that the investor's potential loss is limited in case of business closure. $^{53}$

\footnotetext{
52 The 2005 Survey on Bankruptcy analyses and compares regulation of rehabilitation, liquidation and restructuring of debt and discharge in different OECD countries.

FORA (2007), Quality Assessment of Entrepreneurship Indicators.
} 
Figure 3.2. Birth and death rates

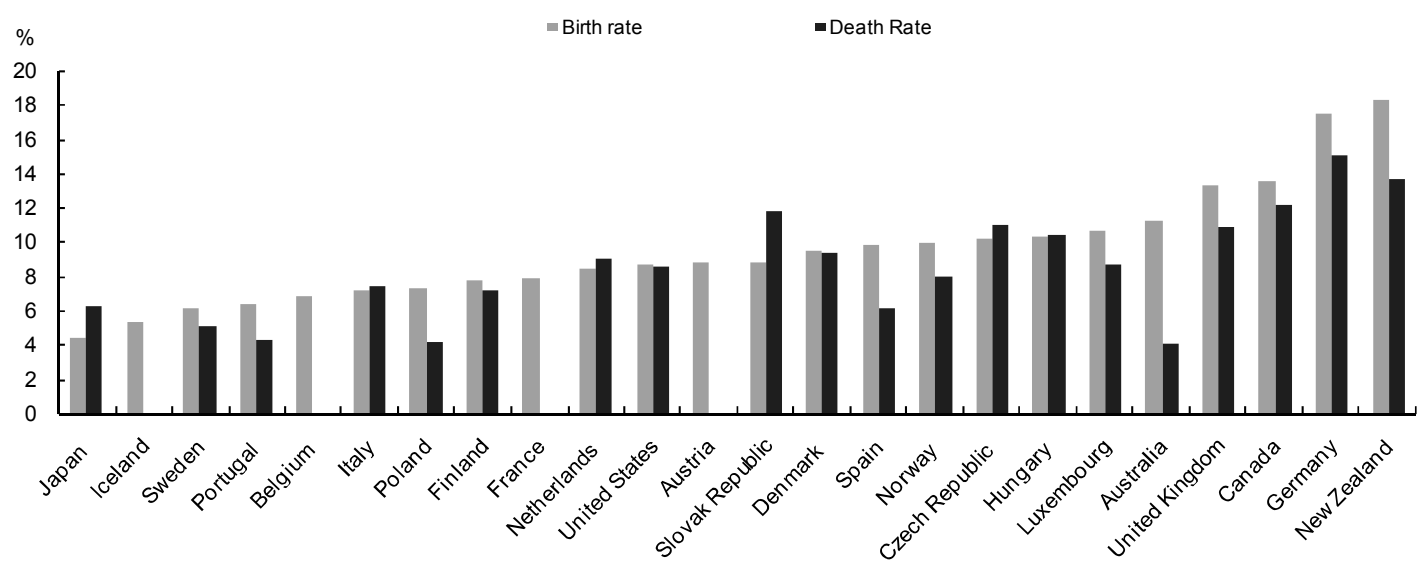

Source: OECD Scoreboard 2007.

\section{Factors driving firm creation and expansion}

a) Access to new technology and R\&D benefits

Penetration of information and communication technology (ICTs) is high and basic telecommunication connections are available at a reasonable price. The number of broadband subscribers for instance is amongst the highest in OECD countries although prices are higher than in some neighbouring countries (Annex 3.A, Figure 3.A.3). The total use of wideband/broadband in industry has increased by $24 \%$ between 2006 and 2007. Besides, mobile telephone charges are low as it is also the case in other Nordic countries (Annex 3.A, Figure 3.A.2). Investment in ICT equipment and software nonetheless been lower in Norway than in other OECD countries between 2000 and 2003 (Figure 3.3). Perceived barriers to the usage of ICT by enterprises include the shortcomings of the software received, the expenses linked to IT as well as the inflexibility of IT suppliers. ${ }^{54}$

\footnotetext{
$54 \quad$ Information from Statistics Norway.
} 
Figure 3.3. Investment in ICT ${ }^{1}(1985-2003)^{2}$

Percentage of non-residential gross fixed capital formation

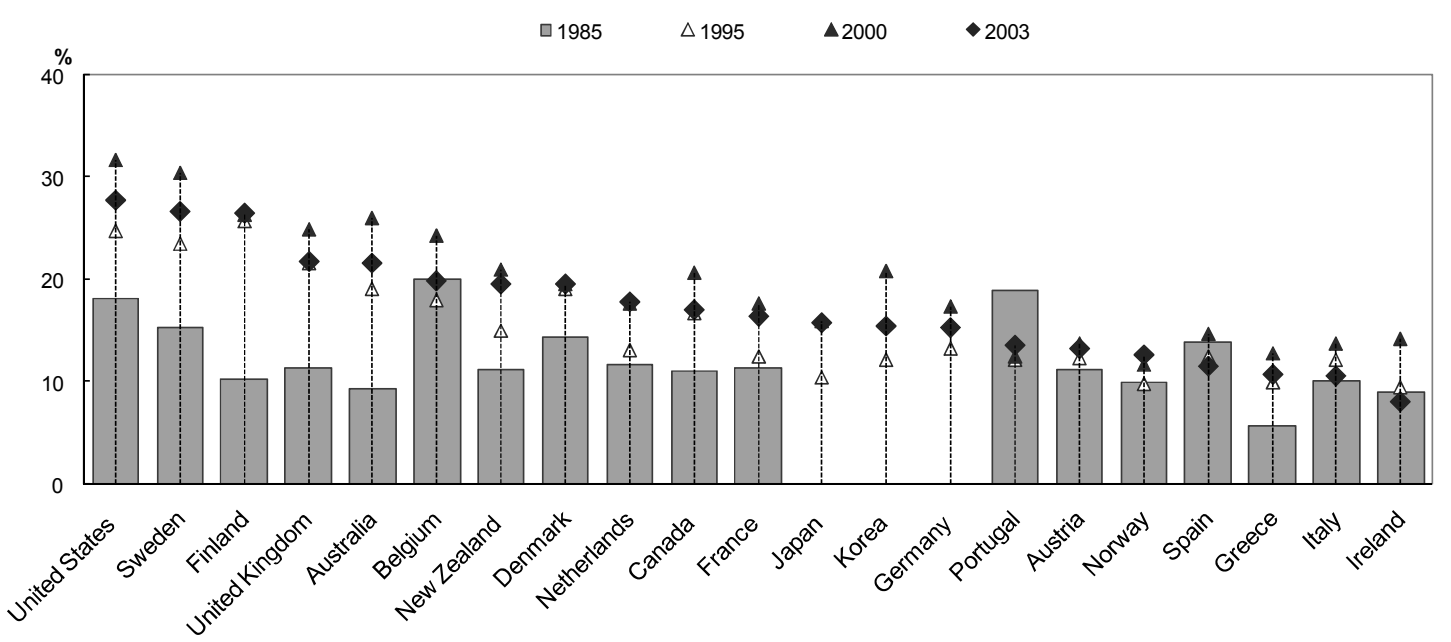

1. ICT equipment is defined here as computer and office equipment and communication equipment; software includes both purchased and own account software. Software investment in Japan is likely to be underestimated, owing to methodological differences

2. Data for 2003 or latest year available.

Source: OECD Scoreboard 2007.

Total spending on R\&D ( $1.5 \%$ of GDP) is significantly lower than the $2.3 \%$ average of OECD countries in 2005. Most countries with lower R\&D spending also have lower per capita income (Annex 3.A, Figure 3.A.4). The ratio has been lower than that of EU countries for more than 20 years and there is no sign of convergence. Private sector R\&D spending is particularly low, business R\&D spending amounting to only $1.2 \%$ of industry value added compared to $2.2 \%$ for OECD countries in 2005 (Annex 3.A Figure 3.A.5). The gap in private R\&D spending is very large relative to other high per capita income countries (Denmark, Sweden or Switzerland), notwithstanding an R\&D tax credit scheme introduced in 2002 (Skattefunn).

According to national surveys, only $26 \%$ of Norwegian enterprises conducted innovation-related activities in the period 2002-2004. ${ }^{55}$ The reported innovation activity is a little lower than for the period 1999-2001 (29\%). SMEs seem to lag behind many other OECD countries in terms of product and process innovation (Annex 3.A, Figures 3.A.6 and 7). SMEs in Norway collaborate less in innovation activities than elsewhere, notably compared to other Nordic countries (Figure 3.4). 
Figure 3.4. SMEs collaborating in innovation activities (2002-2004)

As a percentage of all firms

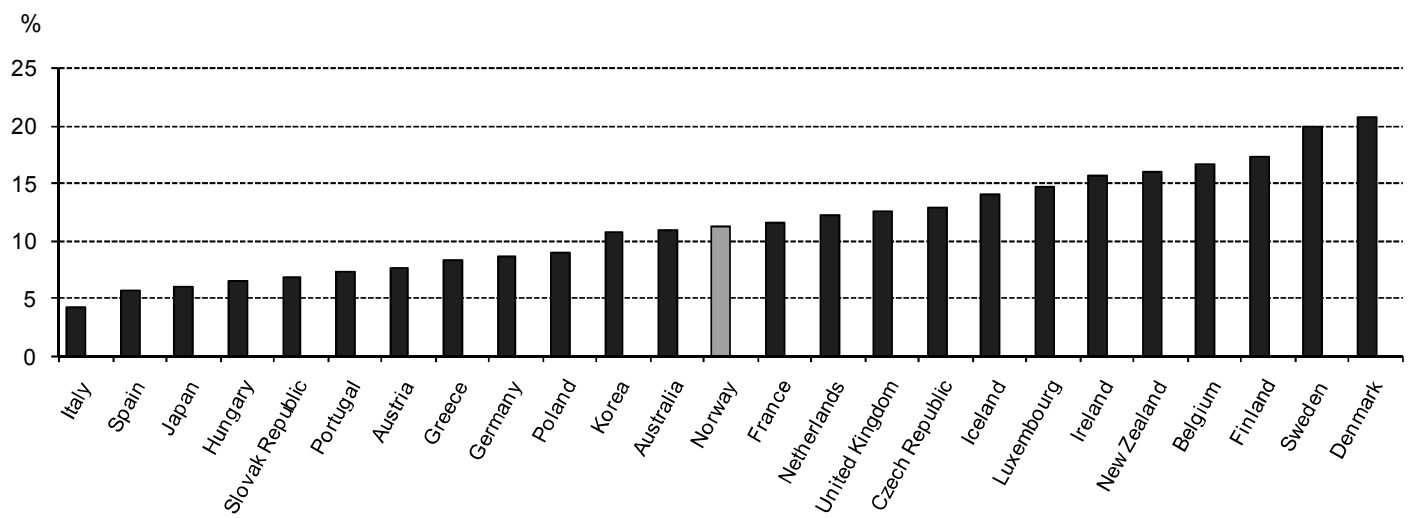

Note: SMEs: 10-249 employees for European countries, Australia and Japan; 10-99 for New Zealand, 10-299 for Korea.

Source: OECD Scoreboard 2007 based on Eurostat.

b)

Access to finance

The banking system seems relatively efficient - interest rates and risk premiums are modest, both from a historical perspective and compared to other OECD countries (Annex 3.A, Figure 3.A.8). Access to bank loans seems adequate, including loans without collateral, an important source of finance to many entrepreneurs who lack transferable securities and other assets that can serve as collateral. Overall, access to loans without collateral appears to be easier than in many other OECD countries, ${ }^{56}$ which may explain the declining use of government guarantee schemes in recent years.

Norway's equity market, on the other hand, is relatively underdeveloped, with private equity investment equal to around $15 \%$ of GDP as against $25 \%$ of GDP in the EU. ${ }^{57}$ According to data from the Norwegian Private Equity and Venture Capital Association (NVCA), local institutions or the state provide most of the funds for the venture capital market. Private investors supply only about one-third of the total. While supplies of venture capital are larger than in many other OECD countries, they fall short of levels seen in other Nordic countries, especially in the domain of early-stage funding (Figure 3.5).

\footnotetext{
$56 \quad$ FORA (2007), Quality Assessment of Entrepreneurship Indicators.

57 OECD (2007), Economic Surveys Norway.
} 
Figure 3.5. Venture Capital investment as a percentage of GDP

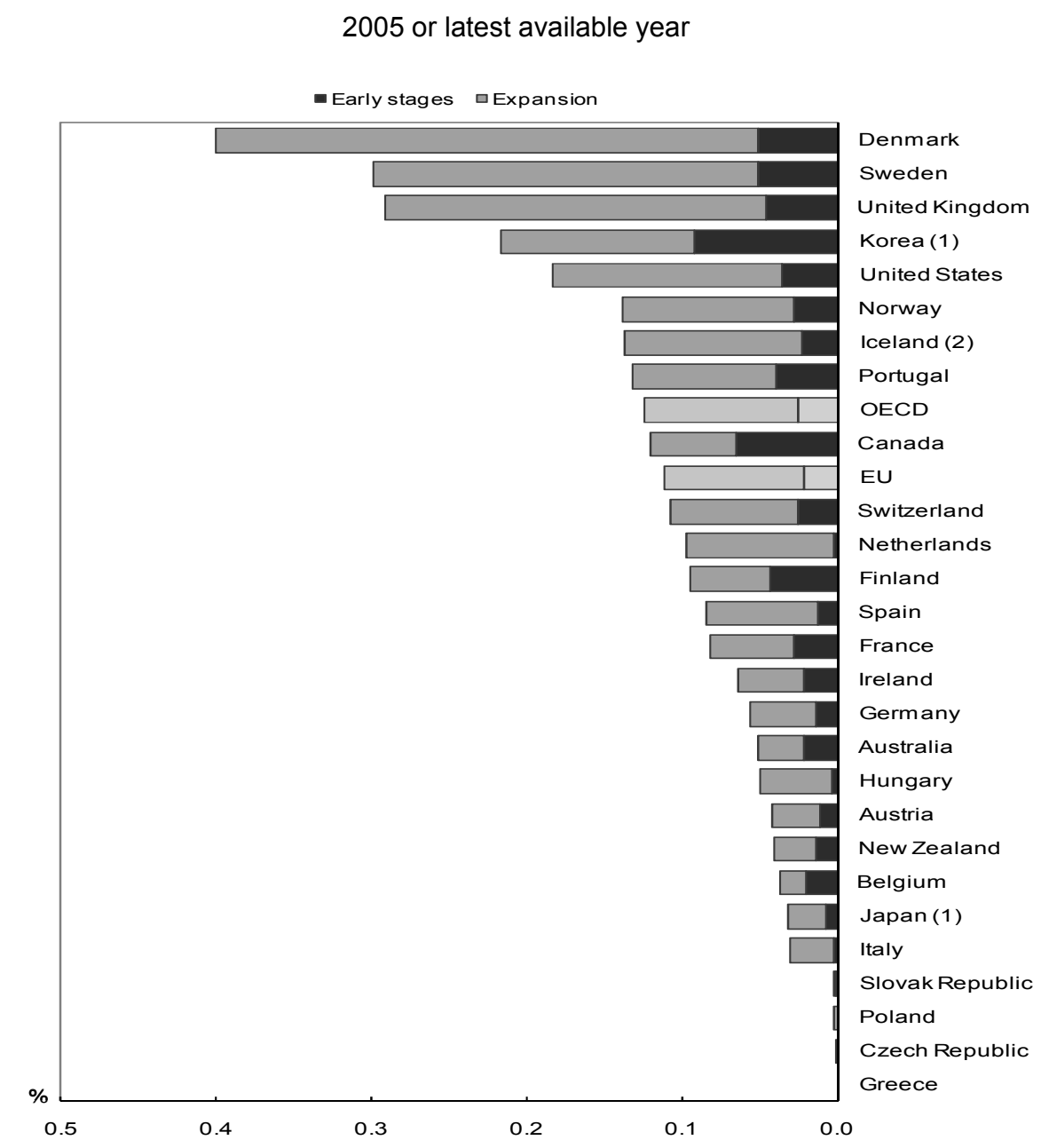

(1) 2001 data.

(2) 2002 data.

For New Zealand (2005), allocation between early stages and expansion is an estimation based on the 2001 allocation.

Source: OECD Scoreboard 2007, based on data from EVCA (Europe); NVCA (United States); CVCA (Canada); AVCAL (Australia), NZVCA (New Zealand); Asian Venture Capital Journal "The 2003 Guide to Venture Capital in Asia" for Japan and Korea.

\section{c) Access to capabilities and to skilled labour}

Norway has been successful in building a high level of human capital. Average years spent in formal education for both men and women are among the highest in the OECD and have been so for many decades. Norway ranks very high in terms of upper-secondary education and about $40 \%$ of the population aged 25-34 had at least tertiary education in 2004 (Annex 3.A, Figures 3.A.9 and 10). The number of students pursuing scientific and technical courses has, however, fallen, and Norwegian students score less than most other advanced OECD countries in the PISA test (Annex 3.A, Figure 3.A.11).

\section{d) Cultural factors}

Surveys (GEM 2006) indicate that Norway has a strong entrepreneurial culture, having a high earlystage entrepreneurial activity rate for a country with a high GDP per capita income. Over $9 \%$ of the adult population (18-64 years) was involved in early stage entrepreneurial activities in 2006 (versus 7\% in 
2004). There are however significant differences by gender. Although the share of female participation in early stage entrepreneurial activities has increased from $24 \%$ in 2005 to $32 \%$ in 2006, it still remains relatively low: under $6 \%$ of women were involved in early stage entrepreneurial activities in 2006 against $12.3 \%$ of men.

Entrepreneurship in Norway is highly opportunity-driven and is not based on necessity. According to surveys, being more independent is the main motivation for pursuing entrepreneurial activities. Increasing income ranks as a lower motivation.

As in other countries, tax and regulatory requirements influence the choice between becoming an employee, or being self-employed. Compared to employees, the self-employed have lower social security contributions while being entitled to lower social benefits. However, the self-employed may choose to establish a private limited company and employ themselves. By doing this, they have to pay both the employers' national insurance contribution and the social security contribution as an employee. In exchange, they receive social benefits as an employee.

\section{Entrepreneurship and SME policies}

\section{Overall aims of entrepreneurship policy}

A Plan for a Comprehensive Innovation Policy was launched in October 2003 (Box 3.1). The plan, known as "From Idea to Value", aims at better co-ordinated and targeted efforts for innovation and improved harmonisation of Entrepreneurship and SME policy. The plan is the result of broad co-operation between a number of ministries, including the Minister of Local Government and Regional Development, the Minister of Education and Research, the Minister of Agriculture, the Minister of Petroleum and Energy and the Ministry of Trade and Industry.

The Plan highlights five main policy areas central to innovation policy with specific objectives and measures in each area (general conditions for trade and industry; knowledge and competency; research, development and commercialisation; entrepreneurship - starting a new business; and electronic and physical infrastructure). While Ministries issue national guidelines, the county administrations are responsible for the regional strategies. The plan From Idea to Value builds on previous policy efforts to simplify regulation affecting business (Simplifying Norway Action Plan, 2002) and to facilitate the process of establishing and running a business (Bedin Internet service). 


\begin{tabular}{|c|c|}
\hline & 3ox 3.1 Calendar of major Entrepreneurship and SME Policy events \\
\hline 1998 & $\begin{array}{l}\text { Creation of Business gardens } \\
\text { Creation of national and regional seed capital funds } \\
\text { Creation of the Internet service Bedin }\end{array}$ \\
\hline 1999 & Creation of the Norwegian fund for innovation and research \\
\hline 2000 & Establishment of the FORNY programme \\
\hline 2001 & Creation of the government-owned fund-of-fund investor Argentum \\
\hline 2002 & $\begin{array}{l}\text { Simplifying Norway Action Plan } \\
\text { Introduction of the Norwegian Centers of Excellence scheme } \\
\text { Creation of Technology Transfer Offices at Universities } \\
\text { Tax credit scheme for R\&D expenditure (Skattefunn) }\end{array}$ \\
\hline 2003 & $\begin{array}{l}\text { Plan for a Comprehensive Innovation Policy (From Idea to Value) } \\
\text { Launching of the Norwegian Centres of Excellence scheme } \\
\text { Creation of Foundation "Micro Invest" }\end{array}$ \\
\hline 2004 & $\begin{array}{l}\text { New strategy for Entrepreneurship education } \\
\text { Creation of Innovation Norway }\end{array}$ \\
\hline 2005 & White paper on research \\
\hline 2006 & $\begin{array}{l}\text { Revised strategy for Entrepreneurship education } \\
\text { Introduction of the Norwegian Centers of Expertise scheme }\end{array}$ \\
\hline 2007 & $\begin{array}{l}\text { Creation of a Governmental investment fund } \\
\text { Preparation of the White paper on innovation }\end{array}$ \\
\hline
\end{tabular}

The Plan for a Comprehensive Innovation Policy provides a framework for SME and Entrepreneurship policy. Companies in an early stage and SMEs "with potential and ambitions for growth" have been defined as priority areas. The aim for Entrepreneurship policy is to speed up the pace of innovation and restructuring of the Norwegian business sector through start-ups. This is notably to be achieved through a strengthened Norwegian culture of entrepreneurship with special attention to the younger population. The Strategy for Entrepreneurship in Education (2004), which aims to integrate entrepreneurship in the curriculum, was launched in this context and has been revised in 2006. The revised version of the education strategy was presented at the conference "Entrepreneurship education in Europe: Fostering entrepreneurial mindsets through education and learning" in Oslo in October 2006.

For SMEs, network-based innovation and restructuring has been targeted with designated focus areas of regional or local nature. The idea is to meet the restructuring needs of local communities or regions where key industries and innovation systems are either to be restructured, or developed. Finally, policy has aimed at increasing innovation across the Norwegian business sector and at increasing the number of innovation projects based on market demand.

\section{Main actors}

Entrepreneurship and SME policies are designed, implemented and monitored by three Ministries: the Ministry of Trade and Industry, the Ministry of Education and Research and the Ministry of Local Government and Regional development (Figure 3.6). Three major agencies support the policies: Innovation Norway, the Industrial Development Corporation (SIVA) and the Research Council of Norway $(\mathrm{RCN})$. Various supporting sub-units carry through business development and innovation at regional and national levels. 
Figure 3.6. Major stakeholders of Entrepreneurship and SME policy

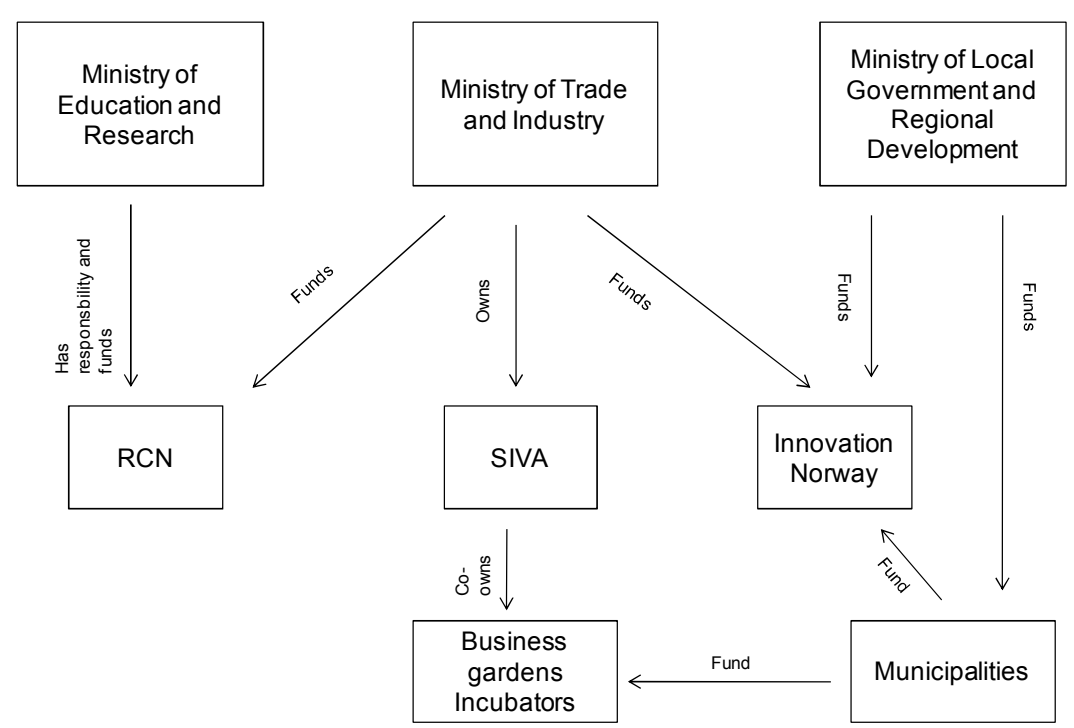

Innovation Norway, ${ }^{58}$ created in 2004 to implement the innovation strategy, offers an improved and better co-ordinated access to the full spectrum of public support for business and innovation. Innovation Norway is funded primarily by the Ministry of Trade and Industry and the Ministry of Local Government and Regional development. Its main objective is to promote business development and increase the competitiveness of individual companies and groups of companies throughout the country; to release the commercial opportunities of the districts and regions. To achieve this, Innovation Norway delivers services ranging from financing, linking companies to know-how and helping to create networks. It also assists in restructuring and revitalising specific industries and regions. Services provided include for example the provision of seed capital to start-up firms together with the private sector. Innovation Norway also promotes R\&D contracts (IFU) where as two parties (normally an SME supplier and a customer) commit to developing an innovative product, service or process which is new to the market. Innovation Norway's budget for 2008 is NOK 2500 million and NOK 1840 million (for the loan and guarantee framework).

SIVA, a state enterprise owned by the Ministry of Trade and Industry, has been in charge of improving the national infrastructure for innovative business activities. This has been achieved through increased networking, the promotion of strong regional and local industrial clusters and an increased range of business services. As a result, a large number of business development centers, business gardens and incubators have been set up in the different Norwegian counties in recent years and are co-owned by SIVA. The annual budget for SIVA in 2007 was NOK 100 million.

The Research Council of Norway (RCN) promotes and supports basic and applied research as well as research-driven innovation in all sectors and branches. RCN is a strategic body which identifies areas where efforts are needed, allocates research funds and evaluates results. It acts as a contact point, networkbuilder and administrator of programmes where private industry, R\&D institutions and universities are involved. The Ministry of Education and Research has administrative responsibility for RCN and is also its largest contributor. The Ministry of Trade and Industry provides about $20 \%$ of the budget to finance projects relating to industrial R\&D projects. RCN's annual budget for 2007 was more than NOK 5 billion.

58 Innovation Norway is a merger of four previously separate institutions: the Norwegian Industrial and Regional Development Fund (SDN), the Norwegian Trade Council (NTC), the government's Advisory Board for Investors and the Norwegian Tourist Board. 
a) Access to technology, $R \& D$ benefits and networking activities

Supporting private $R \& D$

A tax credit scheme (Skattefunn) was introduced in 2002 to encourage private R\&D and innovation. Since its inception it has received strong support from the business sector. Approval of projects is given by the RCN according to R\&D content. The qualifying projects must generate new knowledge in a broad sense that favours the development of new products, processes or services. There are no regional or sectoral constraints. Skattefunn provides a $20 \%$ deduction of R\&D costs, up to NOK 4 million, per firm and per year for internal projects and an additional NOK 4 million for R\&D purchases from universities and institutes. Large companies benefit from an $18 \%$ deduction ${ }^{59}$ with ceilings being the same. Enterprises that have no or insufficient taxable income are paid the equivalent as a grant. The scheme is neutral between qualifying projects, regions, sectors and the tax position of qualifying firms. It nonetheless lowers the marginal cost of R\&D in small enterprises or low R\&D spenders more than in larger ones.

Facilitating business and networking activities

The system set up to promote business and networking activities is comprehensive and consists of Business gardens, research parks and incubators. SIVA has a key role in promoting strong regional and local industrial clusters. It builds networks between regional, national and international $R \& D$ environments. These are developed through a functional infrastructure of investments and networking. Investments are made in venture companies, innovative companies, incubators and network companies.

As the Norwegian government's policy goal is to unleash innovation capability and increase wealth creation in all parts of the country, SIVA's strategy deploys a variety of instruments in order to address the needs of different parts of the country.

Business gardens (or Business development centers) were established in 1998 as a support scheme under the Ministry of Local Government and Regional Development. This scheme is one of the concepts designed for the most rural areas of Norway: 45 business gardens have been developed across Norway to enhance entrepreneurship and new business development in remote areas without colleges or universities. Business gardens locate knowledge-based companies in innovative networks to stimulate innovation in SMEs and the development of new enterprises. They have a multi-stakeholder approach which makes them networking hubs: they function as a partner for companies, investors and R\&D environments.

Incubators aim to provide entrepreneurs with resources in the form of expertise, business experience, consultants and capital - mainly from Universities and R\&D institutions. nineteen incubators have been established across Norway. Depending on performances, each incubator receives approximately NOK 3.5 million over 5 years. The scheme is financed by the Ministry of Local Government and Regional Development. The new incubator programme is oriented towards regional innovative environments; SIVA therefore focuses on developing regional expertise in business incubation.

Industry incubators are types of incubators that are tied to heavy industry companies or to a unification of industry companies (instead of being bound to a research environment). The main function of the incubator is to identify business ideas and to find entrepreneurs ready to start new businesses. The industry companies are central to the success of the incubator, as they would provide premises, competence 
and leadership. These companies also engage on purchasing products or services of the newly established businesses over some time.

Transfering new technology and commercialising R\&D

Research parks are closely and formally connected to leading universities and colleges and contribute to increased regional value creation by applying research results in complicated products, processes and services. They act as innovative clusters where businesses, R\&D and public programmes together allow innovation and the commercialisation of innovation.

Technology Transfer Offices (TTO) were set up in Norwegian universities as from 1993 to facilitate commercialisation of research and development by assisting academics who are unfamiliar with procedures involved to exploit their finding financially. They are staffed by 10-15 persons, and offer scientists and students evaluation of their business ideas, patenting, licensing and advisory services on how to start a company and business development. From 2003, all universities and colleges in Norway were instructed to contribute to the commercialisation of new ideas from the institutions.

The FORNY programme was established in 2000 to enhance the commercialisation of research with considerable market potential. It is a joint programme between the RCN and Innovation Norway which funds activities making researchers and research institutions focus on the commercial potential of research results, the process of establishing a new company or licence, the cost of verification of technology and scholarships for researchers. FORNY works through institutions that employ the researchers, through the TTO of these institutions, a selection of their co-operating innovation companies and science parks. The FORNY funding can cover up to $50 \%$ of the costs related to these activities. In 2006, FORNY had a budget of NOK 120 million.

\section{b) Better access to finance}

Given conditions prevailing in the Norwegian financial sector (see above), recent government programmes have justifiably focused on improving access to equity capital for enterprises by strengthening the equity market and by improving communication between enterprises and investors. A special focus has been to give enterprises sufficient access to capital in early stages, especially for projects involving new technology and knowledge-based businesses. Risk loans have been used for innovation and development project funding, as well as for investments in fixed assets. Some loan guarantee and grant schemes remain (see Box 3.2). 
Box 3.2 Loan guarantees and grant schemes

Guarantees have been available to reduce the risk factor in connection with loans and operating credits from other financing institutions. Grants have financed development projects such as product or process development or market development. Grant schemes have for example been given to stimulate close co-operation in product development between a costumer company and different suppliers.

The Innovation Norway guarantee scheme targets SMEs with up to 100 employees. The guarantee covers losses up to $50 \%$ on loans granted by private banks. The loans are normally extended for working capital, the banks establishing collaterals in borrowers' assets. These guarantees are seldom used ${ }^{60}$ because of stringent conditionality: private banks must sell all assets serving as collateral for a guaranteed loan before the guarantees will be in effect.

Most micro loans are available through the Cultura Bank which has different loan schemes, offering a guarantee scheme in co-operation with the European Investment Fund (EIF). Start-up loans are subject to an upper limit of EUR 25 000. The EIF covers 75\% of the loss guarantee. Cultura Bank is co-operating with Network Credit BA which helps entrepreneurs establish network groups, which makes them eligible for receiving micro loans through the "Micro Invest" foundation. ${ }^{61}$ The foundation has become a guarantee institution backing loans awarded by the Cultura Bank.

The private equity market in Norway is small and fragmented by European standards and it appears as one of the weakest capital offerings available to SMEs. To address this market gap in funding for new firms, notably in the early phases, the Norwegian government instaured mechanisms to provide risk capital investors with public co-investment schemes (the Seed capital scheme and Argentum). The government also recently set up a public investment fund to allow a broader flow of financial funds available to enterprises with high growth potential.

- The Seed capital scheme is a public/private partnership administered by Innovation Norway, on behalf of the Ministry of Trade and Industry. Each part contributes half of the capital stock in the seed capital funds; there is an equal share between subordinated loans from the government and a mixture of equity and subordinated loans from investors. The funds which are privately owned invest equity capital in start-up businesses with high value added potential. The aim of the seed capital scheme is to increase the share of high growth companies. These funds are supposed to have a long-term perspective on the investments and supply enterprises with competence. Government provides risk-relief to private investors through a loss-fund. The loss-fund for each fund accumulates to NOK 341.75 million. Recent amendments to the seed capital schemes have been introduced to make follow-on investments easier for private investors as previous restrictions on follow-on investments had been met with investor resistance.

- Argentum is a government-owned fund-of-fund investor in the private equity sector that was established in 2001 and is governed by the Norwegian Ministry of Trade and Industry. It has been set up to develop a fragmented private equity sector mainly composed of the State and wealthy private individuals. Through its investments, Argentum aims to facilitate access to international venture capital and to develop an internationally competitive private equity environment in Norway. It invests through either established or new fund management structures. Argentum focuses on attracting fund managers to Norway based on existing strong industries. Only a small portion of capital is allocated to purely international funds. All investments have private majority ownership. The government provided NOK 2.65 billion to the fund.

$60 \quad$ Six guarantees during 2006 and 2007 of NOK 6 million.

61 Established in 2003, this foundation is funded by Network Credit BA and Cultura Bank. 
- The new Governmental investment fund (created in 2007) is a national investment fund fostering new established companies with high growth potential. It aims to facilitate commercialisation of globally oriented and competitive projects at an early stage by offering long-term risk capital. Five priority areas have been identified: environment, tourism, energy, coastal and maritime industries.

To increase transparency in the venture capital market and to facilitate the release of private venture capital, Innovation Norway has supported private initiatives to increase the flow of information between businesses and risk capital investors (Connect Norway, Seed Forum Norway, Venturelab). It has notably provided financial support to the establishment of Business Angel Networks. No organised network with adequate mechanisms for connecting investors and entrepreneurs existed in the past.

Entrepreneurship Education

In 2004 the government launched a national Strategy for Entrepreneurship in Education. The government put forward several new and concrete initiatives designed to promote education and training for entrepreneurship. The purpose of the strategy is to profile entrepreneurship as an educational objective and training strategy. Entrepreneurship in education is perceived as an important tool in fostering a culture for entrepreneurship and positive attitudes towards entrepreneurs. Teaching entrepreneurship is expected not only to strengthen confidence in the ability to succeed as an entrepreneur, but also to improve the ability to assess the profitability of different projects.

The strategy addresses the entire educational system from primary school to college and university and also includes teacher training. ${ }^{62}$ It was developed in co-operation by three ministries: the Ministry of Education and Research, the Ministry of Trade and Industry and the Ministry of Regional Development and Local Government. An inter-ministerial reference group allows collaboration between the different ministries and the follow-up of the strategy.

The strategy was revised in 2006, and an important part focuses on the support to organisations and other stakeholders that promote entrepreneurship education. It motivates educational institutions, municipalities and country municipalities to establish training in entrepreneurship in close collaboration with trade and industry and other stakeholders of the local environment (e.g. local business and the social sector). Training in entrepreneurship requires close collaboration between schools, the local business and the social sector.

At primary, lower and upper secondary level, entrepreneurship education is emphasised differently in schools and its extent in different counties varies significantly. The Government supports "Junior Achievement - Young Enterprise Norway" (JA-YE) in the context of its strategic plan. JA-YE, established in 1997, is the largest private supplier of entrepreneurship training in Norway and supports government efforts to increase the supply and quality of entrepreneurial education. It has a national administration and local branches in all counties. It provides training and teacher training at all stages of education. In 2005/2006, 12000 pupils took part in 1900 enterprises in 300 upper secondary schools. The Ministry of Trade and Industry, the Ministry of Local Government and Regional Development and the Ministry of Education and Research allocated NOK 16.8 million to the organisation in $2007 .{ }^{63}$

\footnotetext{
62 In 2005/2006 about 20 teacher training institutions provided post and further education programmes. 
Regarding Higher Education, a number of Universities and colleges provide both compulsory and elective subjects of study within entrepreneurship, especially linked to education in economics and technology. ${ }^{64}$ Programmes targeted to some specific professions do not seem sufficiently developed, however. Courses also include practice and are done in collaboration/partnerships with local business. A wide range of initiatives has promoted entrepreneurship at Higher Education level (Box 3.3). The Norwegian Research Council is currently working on a scheme allowing doctoral dissertations to be written in collaborative projects between universities and the business sector.

Adults may receive education and training. The concept of "Introductory Enterprises" has been launched where immigrants can develop their abilities in entrepreneurship under expert guidance. It has been moduled on the JA-YE concept. Currently six pilot projects have been launched in six different municipalities.

Box 3.3 Initiatives promoting entrepreneurship in Higher Education

- $\quad$ Europrise: practical entrepreneurship training developed by EINET (European network for education in entrepreneurship) which includes practical experience of founding an existing enterprise. It is provided at a number of colleges in collaboration with Innovation Norway, county municipalities and regional trade and industry.

- JA-YE Norway provides the concept of "Student Enterprise" to universities and colleges and can be run for 12 months.

- "Innovation Net": a network established by colleges which includes providing courses for employees and students in various subjects, notably entrepreneurship.

- StartNorge: is an organisation for students who are interested in enterprise founding and innovation. It is meant to be a power center for students and has 10 local associations.

- Business-oriented Educational Programme: established by the Norwegian Research Council. The programme intends to develop interplay between SMEs and state colleges to increase innovation and regional development capacity.

The majority of Norway's counties have local and regional development programmes that include the promotion of entrepreneurship. Regional and local authorities support and fund different initiatives about $10 \%$ of the funds for regional development were used for paving the way for entrepreneurship and the establishment of new enterprises in 2006. Funds have been allocated to partnerships between stakeholders such as the business sector, providers of teaching, educational institutions, municipalities and other organisations.

\section{Entrepreneurship and SME policies and their impact upon firm creation and innovation}

Norway is known for its commitment to entrepreneurship policy as a major tool for spurring the birth and growth of firms. Given continual changes in consumer preferences, trade, technology, innovation and access to resources, entrepreneurship is rightly seen as a crucial element shaping an economy's adaptive and innovative capacity. A high per capita income country with relatively well functioning financial

64 The Centre for Entrepreneurship at the University of Oslo provides a number of courses in Entrepreneurship and innovation, for example: a Master of Science in Innovation and Entrepreneurship; a programme "From Idea to Enterprise"; a HUMSAM-Course on how to establish a business. 
markets, Norway has placed entrepreneurial education at the centre of its entrepreneurship policy, which itself is an integrated part of the 2003 Plan for a Comprehensive Innovation Policy.

Helped by favourable macro-economic conditions and low barriers to entrepreneurship, this policy approach has contributed to a rising entrepreneurial activity. This is evident in recent strong firm creation and high numbers of pupils and students taking courses in entrepreneurial education. Surveys show Norway being one of the most entrepreneurial countries in Europe, second only to Iceland in 2006.

On firms level, entrepreneurial quality is partly reflected in the efficiency of manufacturing micro firms employing less than 10 persons. Compared to most other countries, Norway's micro firms exhibited high output shares relative to their respective firm population shares in 2001-2002 (Table 3.3). Micro firms represented $61 \%$ of manufacturing firms in 2002, the lowest OECD share after Ireland, but produced more than $6 \%$ of manufacturing output, one of the highest output shares (Annex 3.A, Table 3.A.1). The implicit efficiency ratio of 0.10 (output share divided by firm population share) was comparatively high. In contrast, small and medium-sized manufacturing firms (employing 10-249 persons) suffered from comparative disadvantages, efficiency levels lagging behind those of most other OECD countries (Table 3.3).

Table 3.3 Efficiency ratio ${ }^{1}$ by firm size ${ }^{2}$ in manufacturing (2002)

\begin{tabular}{lrrrr}
\hline Country & $\begin{array}{c}\text { less than } \\
\text { ten }\end{array}$ & $\mathbf{1 0 - 4 9}$ & $\mathbf{5 0 - 2 4 9}$ & $\mathbf{2 5 0 +}$ \\
\hline Norway & & & \\
Australia & 0.10 & 0.57 & 3.56 & 29.2 \\
Austria & 0.10 & 0.60 & 3.93 & 42.2 \\
Belgium & 0.06 & 0.58 & 4.69 & 35.6 \\
Czech Republic & 0.08 & 0.81 & 5.10 & 60.5 \\
Denmark & 0.07 & 1.34 & 8.85 & 86.6 \\
Finland & 0.09 & 0.67 & 3.89 & 37.7 \\
France & 0.05 & 0.81 & 4.83 & 68.8 \\
Germany & 0.14 & 0.89 & 4.79 & 66.8 \\
Greece & 0.04 & 0.29 & 2.33 & 31.8 \\
Hungary & $\ldots .0 .19$ & 1.46 & 17.2 \\
Ireland & 0.05 & 0.19 & 6.30 & 87.7 \\
Italy & 0.03 & 0.89 & 1.40 & 19.1 \\
Japan & 0.14 & 1.69 & 13.30 & 37.6 \\
Netherlands & 0.07 & 0.40 & 3.29 & 44.3 \\
New Zealand & 0.07 & 0.85 & 4.92 & 84.5 \\
Poland & 0.11 & 1.03 & 9.15 & 71.0 \\
Portugal & 0.11 & 1.45 & 8.03 & 88.6 \\
Slovak Republic & 0.12 & 1.14 & 7.05 & 12.0 \\
Spain & 0.05 & 0.20 & 1.08 & 9.20 \\
Sweden & 0.11 & 1.17 & 8.45 & 82.3 \\
United Kingdom & 0.06 & 1.00 & 5.97 & 39.7 \\
\hline
\end{tabular}

1. Output share divided by enterprise share (Annex I, Table 1).

2. Number of persons employed.

Source: OECD SME and Entrepreneurship Outlook, 2005.

The economy-wide strength of micro firms is also manifest in high survival rates. Nearly $99 \%$ of those firms which were established in 2001 and survived until 2004, employed fewer than 20 employees. Particularly high survival rates were noted for small and micro-enterprises in construction, wholesale retail trade, repair, hotels, restaurants, financial intermediation, real estate, education, health and social work. 
New entrepreneurship policy initiatives taken over the past three years have maintained the momentum of spurring entrepreneurial and innovative activities. Highlights of these policy efforts have been increased networking and financing opportunities through SIVA, RCN and Innovation Norway.

\section{Stronger entrepreneurial activity through enlarged education opportunities}

Gauging direct effects of new policy initiatives is always difficult, policy lead times being long and varying with policy categories. Even so, it is striking to note that the percentage of the population of working age engaged in early-stage- entrepreneurial-activities (ESEA) increased strongly in 2005 and 2006 after falling during the previous three years. The observed rise in ESEA was particularly strong for women, whose share in ESEA increased to 32\% in 2006 from 25\% a year earlier.

Stronger ESEA trends also testify to the work of the Junior-Achievement-Young Enterprise (JA-YE) Norway, an organisation which assists government efforts to raise the supply of entrepreneurial education opportunities. According to a study made by the North Trondelag Research Institute in 2005, participants of the JA-YE's Company Programme display a much stronger propensity to start a business $(16.6 \%)$ than the population in general $(7.5 \%)$.

Improved educational opportunities along with new tax provisions, ${ }^{65}$ grants for start-ups and incubator use have contributed to the recent acceleration of firm creation, start-ups rising from 43000 in 2004 to 51000 in 2006, an increase of 7000 firms. This compares with a rise of 3000 newly created firms in 2001-2003. Increases in recent start-ups were particularly strong in financial intermediation, construction, transport, storage and communication, real estate and business services, social and personal services. Buoyant business start-ups also reflected a simplified regulatory setting, a consequence of the Simplifying Norway Action Plan (2002-2003).

\section{Stronger innovative activity through networks and better incentives}

In the domain of innovative activity, recent data point to similar, positive developments. After falling in the early years of the new millennium, the number of both patent applications and patents granted increased strongly between 2004 and 2006. Coincident recoveries are also noted for the number of applications and awards for trademarks and design. Private R\&D spending, habitually low by international comparison, appears to have picked up.

In varying degrees, these hopeful trends have been associated with several new innovation-oriented policy measures (see Box 3.1), including the Norwegian Centres of Excellence Scheme (2002) funded by the Norwegian Fund for Innovation and Research, Technology Transfer Offices at Norwegian Universities (2003), stronger rights for employees making inventions (2002), the tax credit scheme for R\&D expenditure (Skattefunn) (2002), the Plan for a Comprehensive Innovation Policy (From Idea to value) (2003), units commercialising public R\&D (FORNY programme, 2000) and Innovation Norway, a key institution emerging from the merger of four innovation-fostering institutions (2004). Nevertheless, there is room for more strongly exploiting geographical proximity as a means to group ISMEs and venture capital suppliers around universities and other research facilities (creation of technological 'hotbeds').

Offering better access to the full range of public support facilities, Innovation Norway has strengthened entrepreneurs' innovative activities. Entrepreneurial groups sponsored by Innovation Norway

There are elements in the tax system which have contributed to an increase in the number of start-ups in recent years. Dividends exceeding the normal rate of return are not taxed if they are given to another company. Dividends from companies to private persons, however, are taxed. In addition, the tax system provides incentives for persons to own property through companies. 
have integrated entrepreneurs into a network of 'peer entrepreneurs' offering social support as well as professional advice. In addition, activities performed by the SIVA have increased the range and quality of business support services. This has taken the form of larger numbers of business development centres (business development gardens) and business incubators. As a result, the networking infrastructure for industrial start-ups has improved.

\section{Progress in improving access to finance}

Signs suggesting easier access to finance are mixed. On the one hand, falling interest rates and risk premiums along with rising supplies of venture capital indicate low barriers to entrepreneurship finance. Yet recent surveys show entrepreneurs still citing lack of capital as the main obstacle for entrepreneurial activities. This may in part be an issue related to problems with business plans, or to the scalability of business ideas. Some potential investors indicate that there is not a lack of capital, but a lack of good ideas. At any rate, spreading best financial practices has become urgent in the light of the rising capital demand linked to stronger ESEA rates. This calls for a fluid financing continuum at all stages ${ }^{66}$ of formal and informal finance before the entry into regulated capital markets.

Access to equity capital may have become easier with the national and regional seed capital schemes. A similar effect may have resulted from Argentum, the government-owned fund-of-fund investor in the private equity market, which has released larger amounts of funds to establish an internationally competitive market for private equity. Recent data on larger supplies of venture capital rising from low levels validate these policy initiatives. Even so, the average amount invested by business angels has remained low by international comparison and the amount of seed capital remains inadequate.

According to the recent $O E C D$ Economic Survey of Norway, the small amount of seed capital available for start-ups possibly reflects in part the restrictions on the class of assets that can be invested in by insurance companies and pension funds. The Survey recommends that these restrictions be relaxed. The Survey also argues that the borrowing conditionality for obtaining seed capital from Innovation Norway is too restrictive and that it could be lightened.

In addition, given the relative efficiency of the Norwegian banking system and the plentiful availability of bank loans (including without collateral), it may not be justified to maintain the existing myriad of guarantee schemes. These should be phased out, as the corresponding government funds could be more productively used to further increase the availability of risk capital to entrepreneurs, including by expanding the network of business angels. In this context, the existing schemes that mix guarantees and coinvestment could also be simplified and re-focused.

\section{Concluding remarks}

While early signs of recent entrepreneurial policy action are encouraging, the need for a mediumterm, balanced strategy for entrepreneurship and SME policy remains strong. At the level of stakeholders, policy co-ordination does not seem to be a serious problem, but a certain streamlining of responsibilities (simplification) may be warranted to avoid duplication. This may require a systematic evaluation of policy programmes, which goes beyond the scope of this chapter.

As far as co-ordination is concerned, special attention should be given to collective process innovation taking the form of improved vertical and horizontal networking among business support services, research institutions, universities and the business community, to overcome structural under-spending in private $\mathrm{R} \& \mathrm{D}$.

66

OECD (2006), The SME Financing Gap. 
Interest in entrepreneurship can be kindled further by better targeting entrepreneurial education at university level. Moreover, as the number of social assistance beneficiaries is relatively high for a lowunemployment country, initiatives and courses in entrepreneurship in adult education need to better target these beneficiaries with the goal of enlarging the pool of potential entrepreneurs. In this context, entrepreneurship education programmes could be better integrated with existing active labour market policies (vocational, counseling and other training programmes).

Success in the educational domain will inevitably result in stronger demand for early-stage risk capital. Similar effects will flow from 'technological hotbeds' exploiting advantages of geographical proximity for research, investment and finance. New and better networking activity among suppliers of risk capital (investors' clubs, business angels network, etc.) will help increase access to finance. Taken together, the proposed policy measures will eventually equip Norway with an entrepreneurial infrastructure that will increase its capacity to meet future challenges.

\section{Box 3.4 Policy recommendations}

\section{Enlarge entrepreneurship opportunities}

Strengthen entrepreneurship education at university level with better targeted programmes

Design special entrepreneurship programmes for social assistance beneficiaries

Create early warning systems for financially distressed companies, fast track mechanisms for reorganisation and fast track discharge proceedings for legitimate bankruptcies to increase re-start rates

\section{Improve co-ordination and access to programmes}

Ensure better policy co-ordination by streamlining the number of programmes

Engage in a systematic evaluation of policy programmes

Step up combined efforts to establish and expand technological hotbeds

Enlarge and deepen networking activities among different categories of business support services

\section{Improve access to finance}

Expand network of business angels

Simplify public system of risk capital schemes

Relax conditionality for seed capital borrowing through Innovation Norway

Relax restrictions on the class of assets that can be invested in by insurance companies and pension funds

Phase-out loan guarantee schemes 


\section{ANNEX 3.A}

Table 3.A.1. Distribution of output and enterprises ${ }^{1}$ by firm size $^{2}$ in manufacturing (2002)

In percent

\begin{tabular}{|c|c|c|c|c|}
\hline Country & less than 10 & $10-49$ & $50-249$ & $250+$ \\
\hline \multicolumn{5}{|l|}{ Output share } \\
\hline Norway & 6.2 & 16.9 & 27.1 & 49.6 \\
\hline Australia & 7.6 & 13.0 & 16.1 & 63.3 \\
\hline Austria & 4.6 & 12.7 & 25.8 & 57.0 \\
\hline Belgium & 6.0 & 12.6 & 20.9 & 65.0 \\
\hline Czech Republic & 6.2 & 10.2 & 23.0 & 60.6 \\
\hline Denmark & 6.3 & 14.0 & 23.2 & 56.5 \\
\hline Finland & 4.6 & 9.2 & 17.4 & 68.8 \\
\hline France & 11.2 & 12.5 & 16.3 & 60.1 \\
\hline Germany & 2.6 & 7.9 & 19.6 & 69.9 \\
\hline Greece & & 15.0 & 24.9 & 60.1 \\
\hline Hungary & 4.4 & 8.4 & 17.0 & 70.2 \\
\hline Ireland & 1.2 & 6.0 & 20.5 & 72.4 \\
\hline Italy & 11.7 & 24.4 & 25.2 & 38.7 \\
\hline Japan & 3.6 & 15.7 & 28.0 & 52.7 \\
\hline Netherlands & 5.4 & 16.0 & 25.6 & 53.1 \\
\hline New Zealand & 9.2 & 15.7 & 24.7 & 50.4 \\
\hline Poland & 9.7 & 9.4 & 24.1 & 56.8 \\
\hline Portugal & 9.1 & 19.1 & 27.5 & 44.3 \\
\hline Slovak Republic & 2.6 & 6.7 & 18.5 & 72.2 \\
\hline Spain & 8.9 & 21.5 & 23.7 & 46.0 \\
\hline Sweden & 5.4 & 10.8 & 17.9 & 65.9 \\
\hline United Kingdom & 6.7 & 12.4 & 21.4 & 59.5 \\
\hline \multicolumn{5}{|c|}{ Enterprise share } \\
\hline Norway & 60.6 & 29.4 & 7.6 & 1.7 \\
\hline Australia & 72.6 & 21.8 & 4.1 & 1.5 \\
\hline Austria & 71.0 & 21.8 & 5.5 & 1.6 \\
\hline Belgium & 79.4 & 15.5 & 4.1 & 1.0 \\
\hline Czech Republic & 89.2 & 7.6 & 2.6 & 0.7 \\
\hline Denmark & 71.4 & 21.1 & 6.0 & 1.5 \\
\hline Finland & 84.0 & 11.4 & 3.6 & 1.0 \\
\hline France & 81.6 & 14.0 & 3.4 & 0.9 \\
\hline Germany & 62.1 & 27.3 & 8.4 & 2.2 \\
\hline Greece & & 79.4 & 17.1 & 3.5 \\
\hline Hungary & 87.2 & 9.4 & 2.7 & 0.8 \\
\hline Ireland & 39.0 & 42.0 & 15.2 & 3.8 \\
\hline Italy & 83.4 & 14.4 & 1.9 & 0.3 \\
\hline Japan & 50.9 & 39.2 & 8.5 & 1.4 \\
\hline Netherlands & 74.7 & 18.9 & 5.2 & 1.2 \\
\hline New Zealand & 81.3 & 15.3 & 2.7 & 0.6 \\
\hline Poland & 89.7 & 6.5 & 3.0 & 0.8 \\
\hline Portugal & 78.9 & 16.7 & 3.9 & 0.5 \\
\hline Slovak Republic & 44.2 & 32.7 & 17.2 & 6.0 \\
\hline Spain & 78.4 & 18.4 & 2.8 & 0.5 \\
\hline Sweden & 85.4 & 10.8 & 3.0 & 0.8 \\
\hline United Kingdom & 71.7 & 21.0 & 5.9 & 1.5 \\
\hline
\end{tabular}

1. Number of establishments for Australia and Japan.

2. Number of persons employed.

Source: OECD SME and Entrepreneurship Outlook, 2005. 
Figure 3.A.1. Regional dispersion in GDP per capita in OECD countries (Index of Gini 2001)

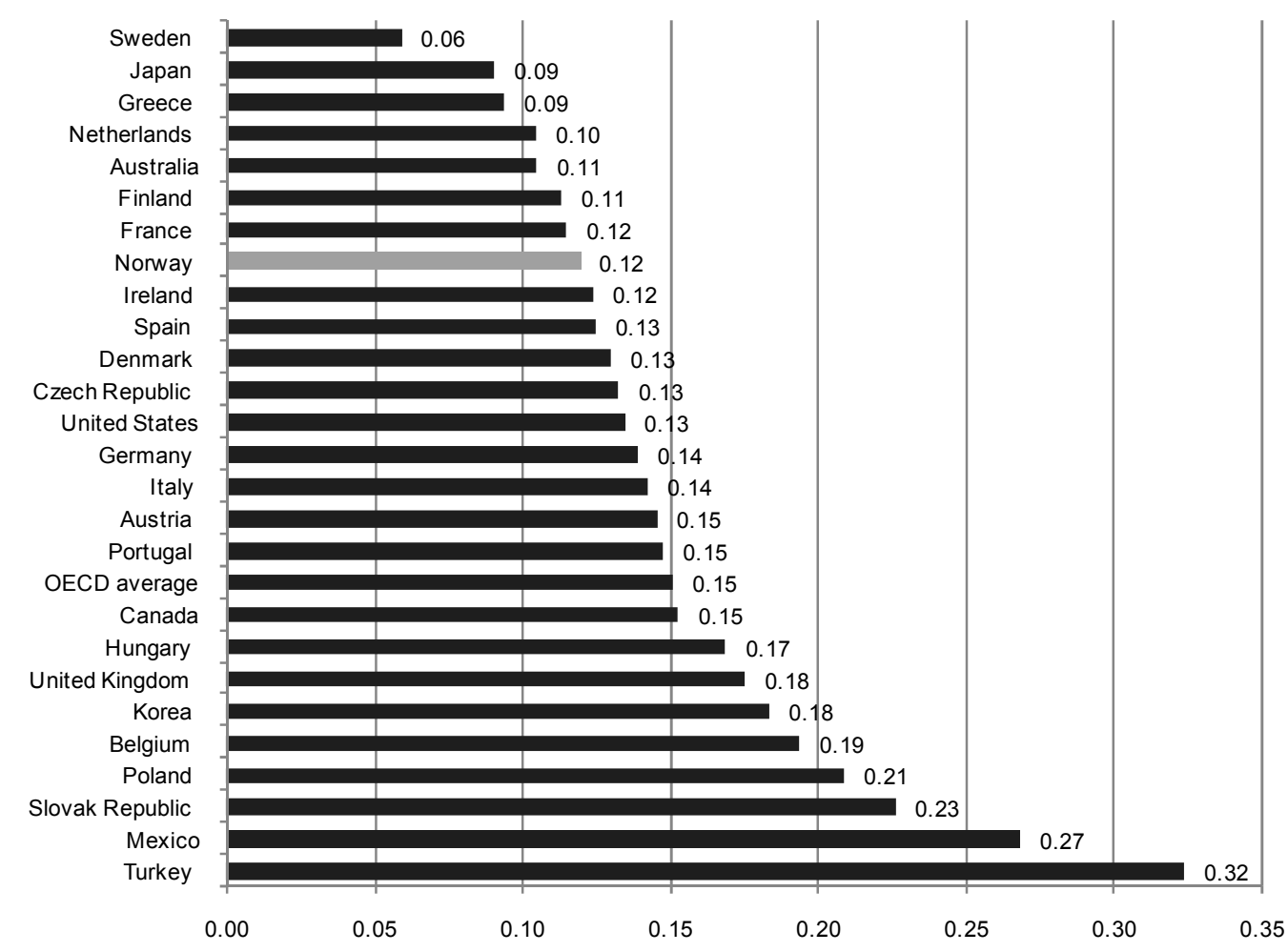

Note: Gini coefficient with GDP per capita in territorial units weighted by population. 2000 data for Mexico, Norway, Poland and Turkey.

Source: OECD, Regions at a glance, 2005. 
Figure 3.A.2. OECD basket of low user mobile telephone charges, May 2007

Annual charge, USD PPP, including tax

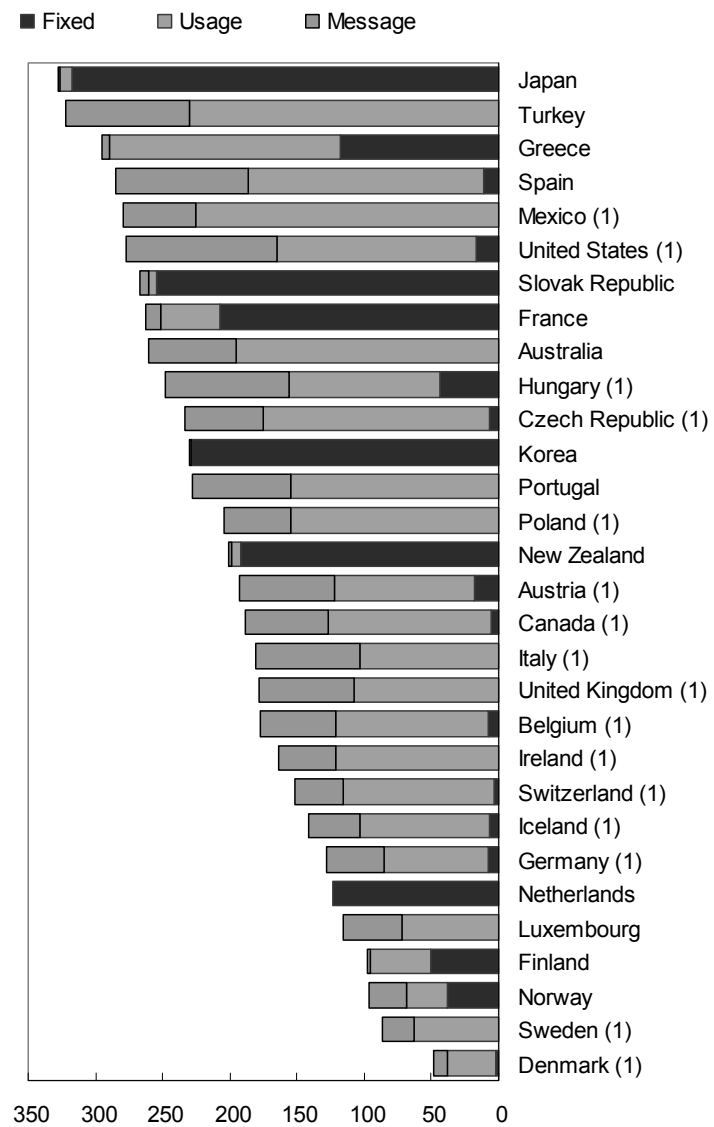

Figure 3.A.3. Broadband prices per Mbit/s and prices for monthly subscription ${ }^{2}$, October 2006

USD PPP, including tax

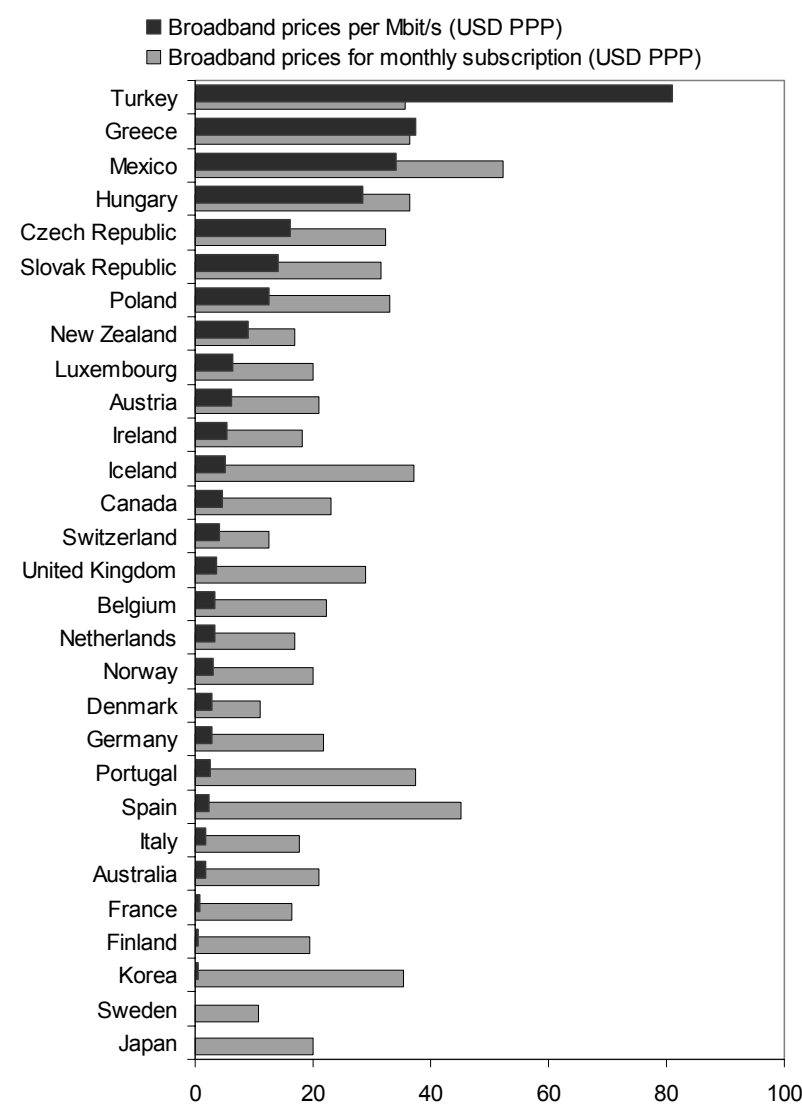

1. Package using pre-paid card.

2. Prices selected are the lowest observed price per Mbit/s and the lowest observed price for a monthly subscription which has an entry-level $256 \mathrm{kbit} / \mathrm{s}$ connection.

Source: OECD Science, Technology and Industry Scoreboard, 2007. 
Figure 3.A.4. R\&D intensity ${ }^{1}$

2005 or latest available year

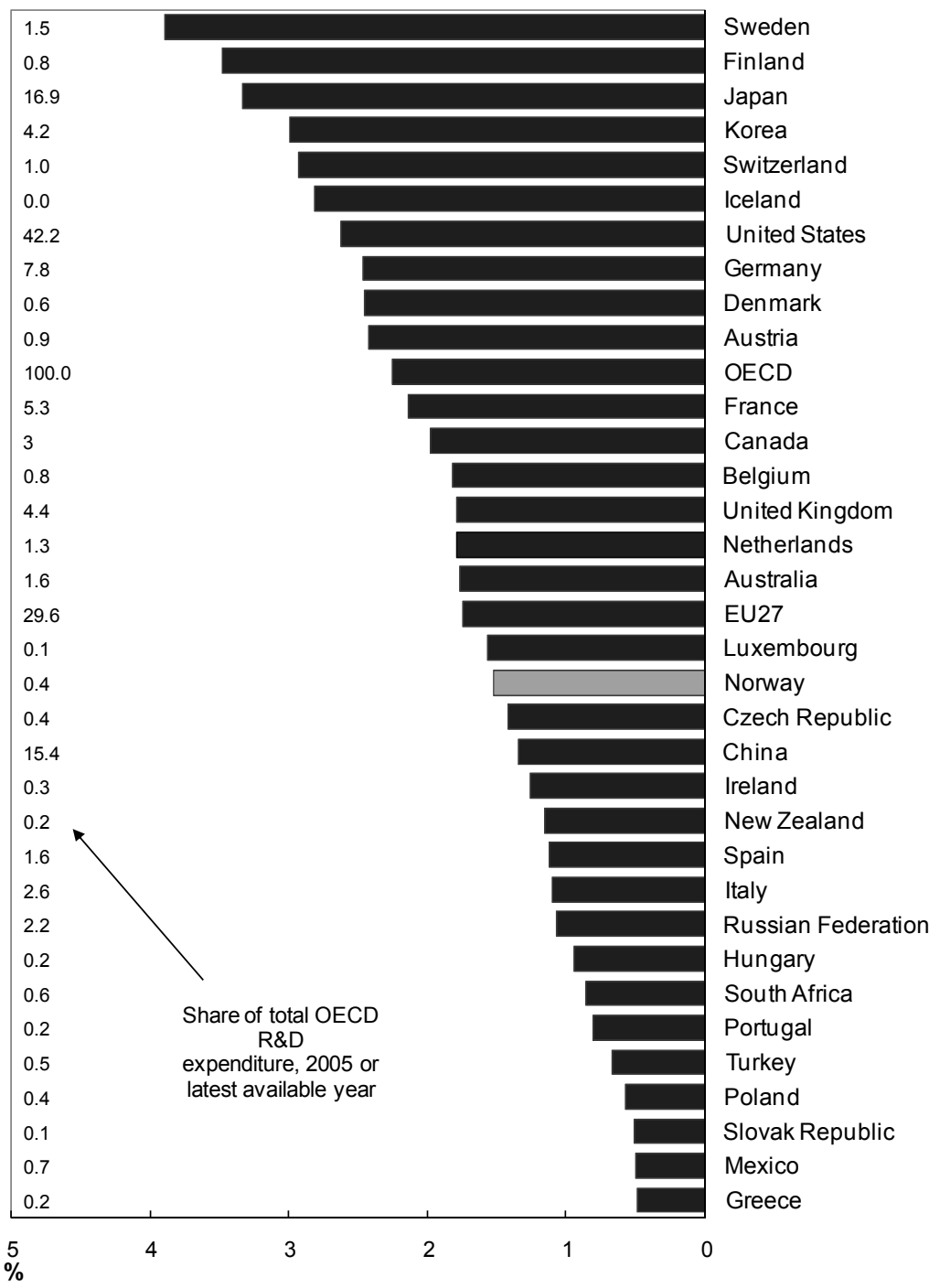

1. Gross domestic expenditure on R\&D as a percentage of GDP.

Source: OECD Science, Technology and Industry Scoreboard, 2007. 
Figure A.3.5. Business R\&D intensity ${ }^{1}$

2005 or latest available year

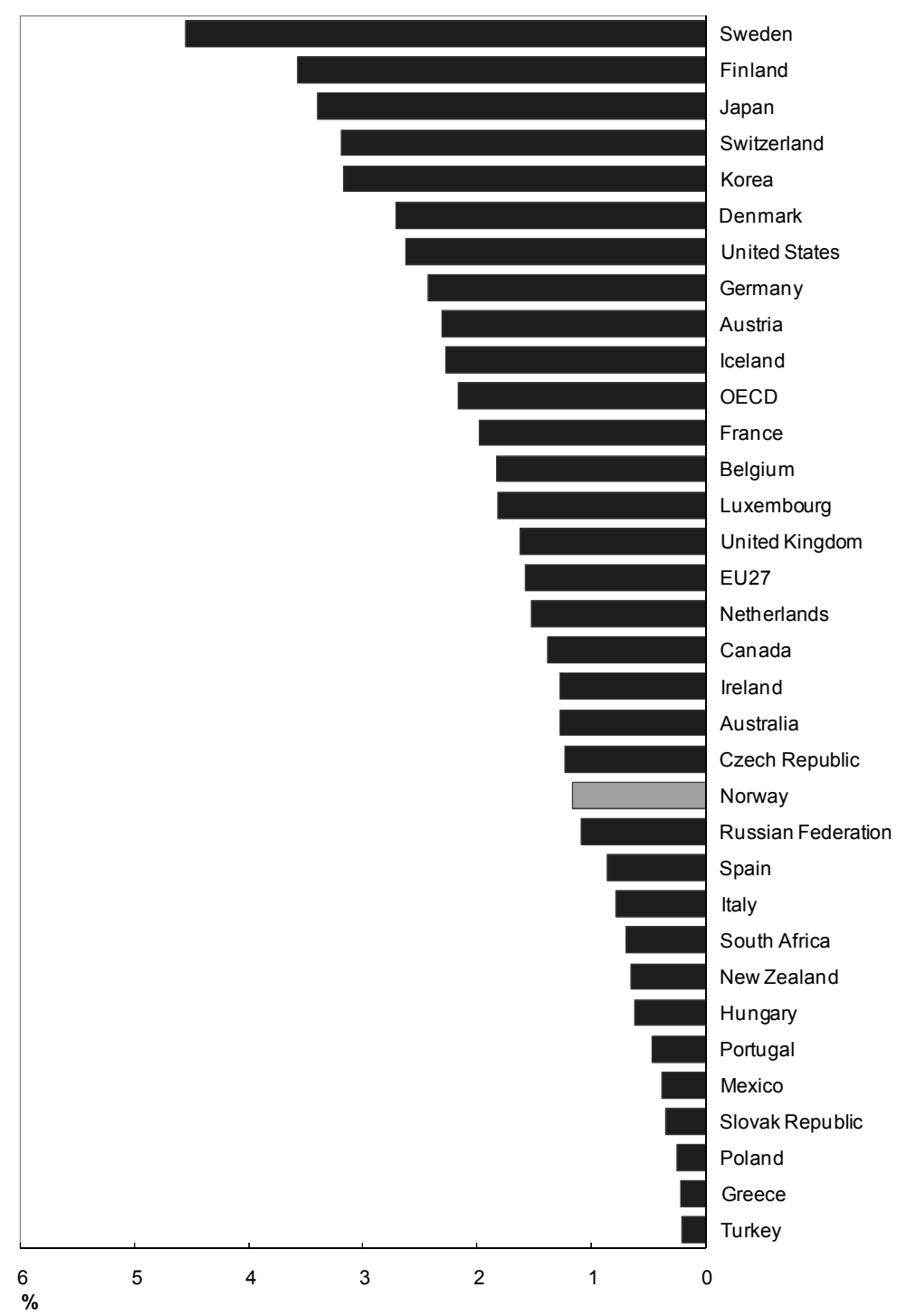

1. Business enterprise expenditure on $R \& D$ as a percentage of industry value added. Source: OECD Science, Technology and Industry Scoreboard, 2007. 
Figure A.3.6. SMEs that developed an in-house product innovation (2002-2004)

As a percentage of all firms

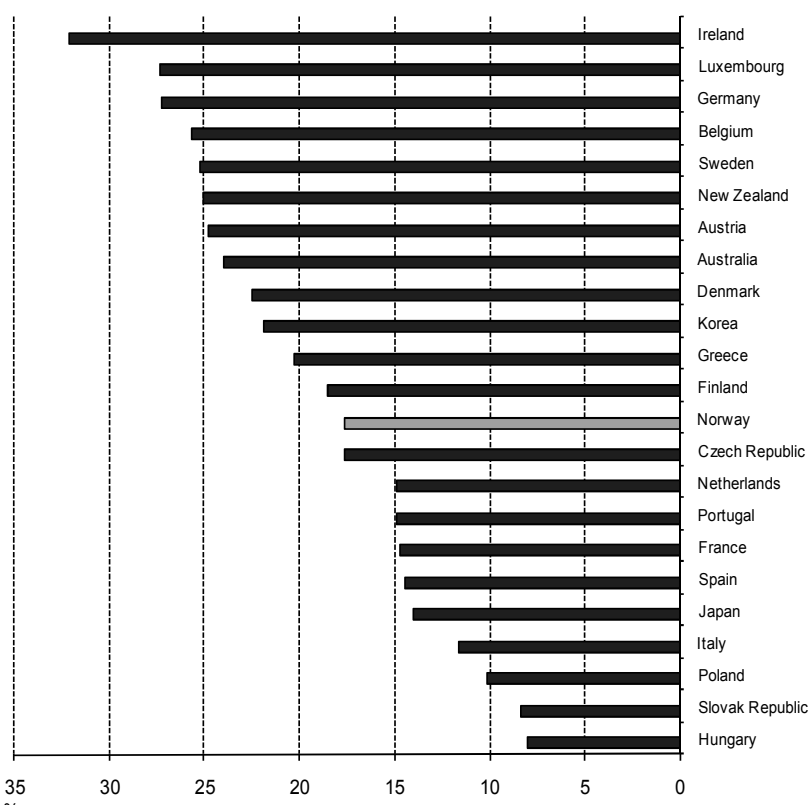

Figure A.3.7. SMEs that developed an in-house process innovation (2002-2004)

As a percentage of all firms

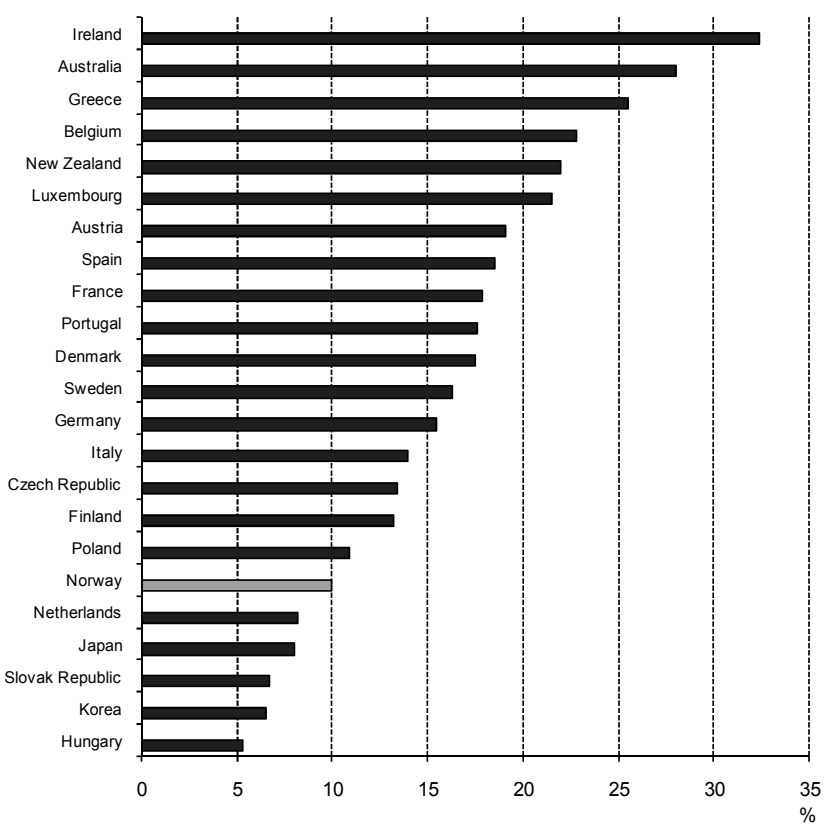

Note: SMEs: 10-249 employees for European countries, Australia and Japan; 10-99 for New Zealand, 10-299 for Korea.

Source: OECD Scoreboard 2007, based on Eurostat.

Figure A.3.8. Net interest margins

Average 1996-2003

Per cent of total interest-bearing assets

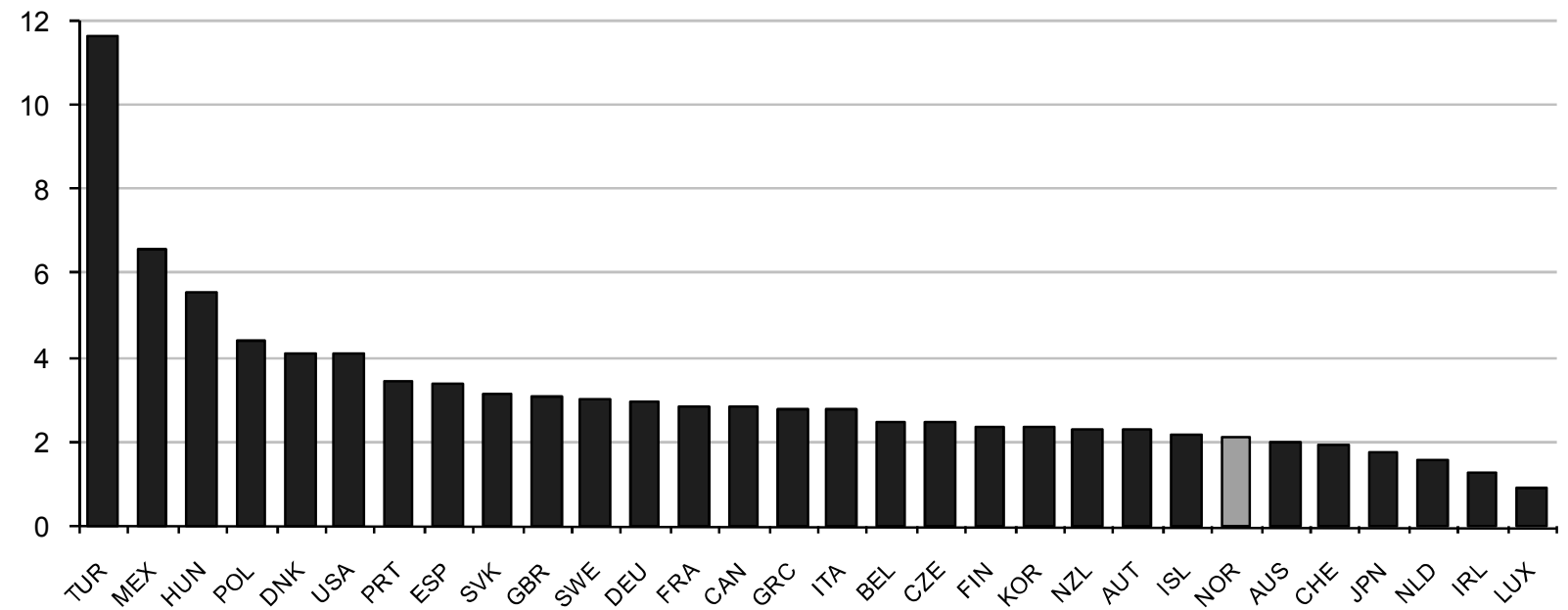

Source: OECD, Going for growth, 2006. 
Figure 3.A.9. Upper-secondary education, percentage of population aged 25-34 and 45-54 (2004)

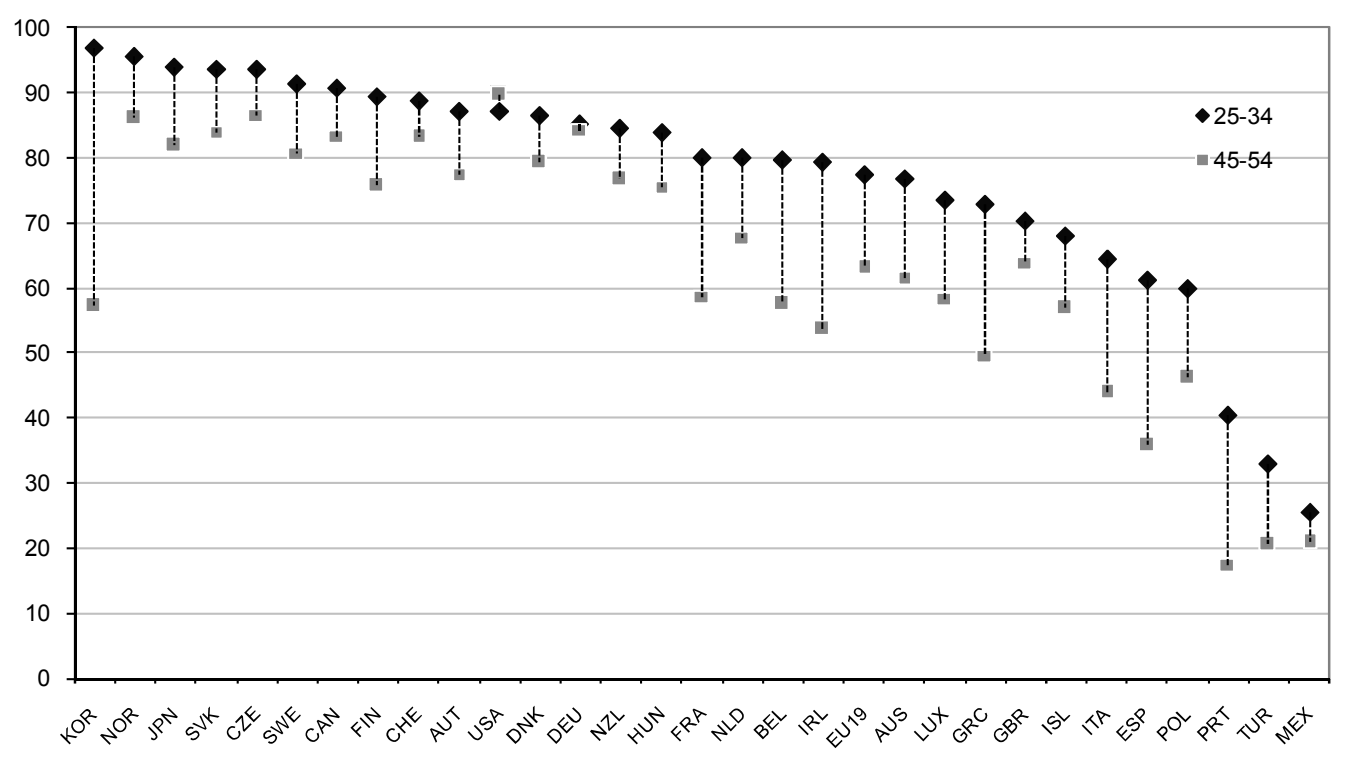

Source: OECD, Education at a Glance, 2006.

Figure 3.A.10. Tertiary education, percentage of population aged 25-34 and 45-54 (2004)

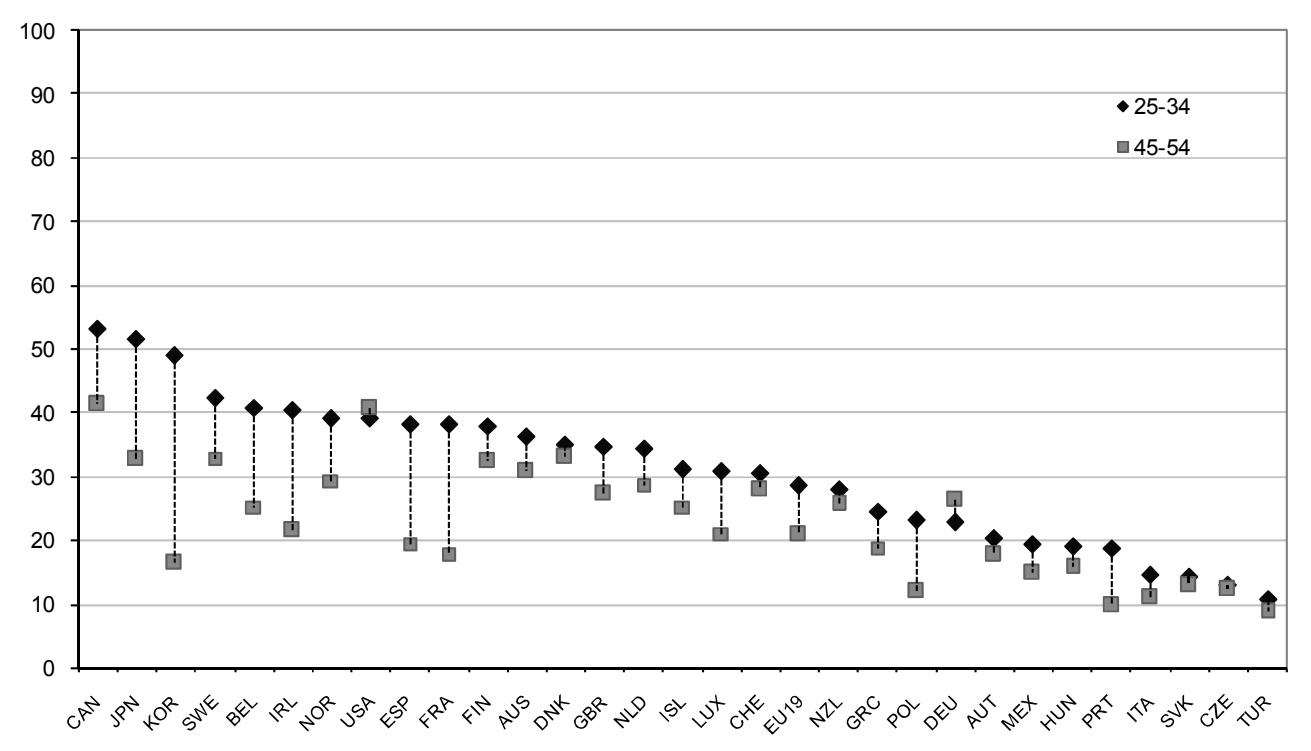

Source: OECD, Education at a Glance, 2006. 
Figure 3.A.11. Average of PISA scores in reading, mathematics and science ${ }^{1}$

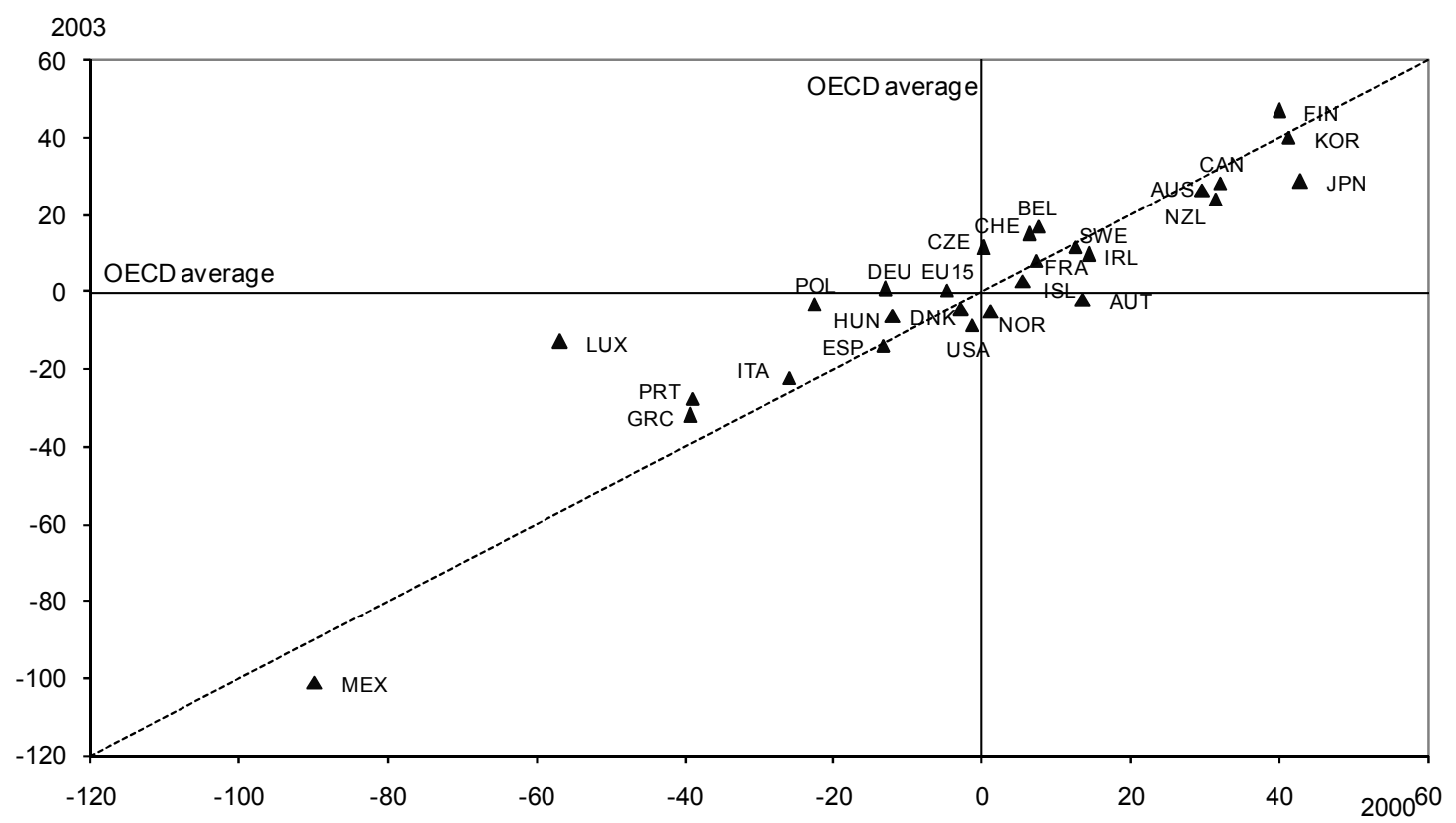

1. PISA stands for Programme for International Student Assessment.

Source: OECD, Learning for Tomorrow's World, PISA 2003. 
DSTI/DOC(2008)5

\section{TURKEY}

\section{Introduction}

Turkey's output increased by one half in the 2002-07 period, representing the strongest pace of growth among OECD countries. Catching-up gains notwithstanding, Turkey's GDP per capita is still comparatively low (around 30\% of the Euro zone). The root of continued underperformance is low overall productivity, reflecting dismal efficiency levels in the sector of small and micro firms. In contrast, large and medium-sized firms, benefiting from international partnerships and competition, are highly efficient. This points to a highly skewed distribution of productivity performance across business categories.

In this setting, the creation and enlargement of firms is increasingly seen as a major potential agent driving innovation and productivity enhancement. Over the past few years, entrepreneurship policies have been correspondingly adapted to strengthen entrepreneurial activities including at the pre-start, start-up and post start-up phase of business life.

The link between entrepreneurship policy and innovation is, by nature, indirect. Efficient measures of entrepreneurship policy underpin firm creation and growth, and in doing so they invigorate innovative activity. Policy lead times though, vary with the type of entrepreneurship policy. Introducing entrepreneurship education in schools and universities is bound to affect innovation trends only in the long run. The same is true of easing cultural biases against entrepreneurial activities. In contrast, more immediate effects may spring from dismantling barriers to finance as well as setting up well-focused training courses for both subsistence entrepreneurs and business counsellors (teachers' training programmes). Viewed from a wider angle, entrepreneurship policy itself may constitute an 'innovation', augmenting the effects which firm creation and firm expansion normally have on individual innovations.

The first part of this chapter highlights salient features of Turkey's firm population, identifies main impediments to entrepreneurial activity and presents indicators of entrepreneurship performance. The second part outlines main objectives of entrepreneurship policy and describes principal programmes in four major areas of policy intervention: access to $R \& D$ and new technology, access to finance, capabilities and access to skilled labour and cultural values. The third and final part provides an evaluation of entrepreneurship and SME policies.

\section{Main features of the enterprise sector and impediments to firm creation \\ 1. Main features of the enterprise sector}

Turkey's enterprise sector is marked by two major asymmetries. Small and medium-sized firms (SMEs) constitute the near-totality of all firms $(99.6 \%$ in 2002) displaying one of the highest degrees of predominance among OECD countries. While SMEs represent three-quarters of total employment in 2002 (77\%), they account for only one-quarter of total output (27\%). Only about one-third of Turkey's SMEs in export. In contrast, a tiny number of large enterprises (employing more than 250 persons) generate nearly 
three-quarter of value added (73\%) with a work force equal to one-quarter of total employment (23\%) (Table 4.1). ${ }^{67}$

Table 4.1 Output and employment shares 2002

(in \%)

\begin{tabular}{|l|c|c|}
\hline & Output share & Employment share \\
\hline Large enterprises $(>250$ employees $)$ & 73 & 23 \\
\hline SMEs (excluding micro firms) & 19 & 43 \\
\hline Micro firms $(<10$ employees) & 8 & 34 \\
\hline
\end{tabular}

Source: Turkstat.

The second asymmetry concerns the SME sector itself. As is normal for a country with a large agricultural sector and a correspondingly low per capita income, micro firms (with less than 10 persons) constitute $96 \%$ of SMES (2002). Making up 34\% of total employment, micro firms, produce no more than $8 \%$ of overall output. In contrast, SMEs (excluding micro firms) representing less than $5 \%$ of all enterprises produce around $19 \%$ of overall value added, while absorbing $43 \%$ of total employment.

In manufacturing, SMEs are similarly predominant, around 246000 micro firms coexisting with only 1100 large enterprises (with more than 250 persons) and 25600 SMEs (employing more than 9 persons and less than 250 persons) in 2002 (Table 4.2). Turkey's proportion of micro firms in manufacturing (90\%) is among the highest in the OECD area, far exceeding shares recorded by high-income countries such as the United States, Germany and Norway (around 60\%). The average size of SMEs in manufacturing is small (4.8 persons in 2003) and even smaller for micro firms (3.1 persons). Overall, Turkey's firm population (excluding rural enterprises and individual farmers) totalled 2 million in 2004, service and manufacturing enterprises accounting, respectively, for $86 \%$ and $14 \%$ of the firm population. 
DSTI/DOC(2008)5

Table 4.2 Output and employment shares in manufacturing 2002

\begin{tabular}{|l|c|c|c|}
\hline & Number of firms & Output share & Employment share \\
\hline $\begin{array}{l}\text { Large firms } \\
\text { employees) }\end{array}$ & 1083 & 66 & 31 \\
\hline $\begin{array}{l}\text { SMEs (excluding micro } \\
\text { firms) }\end{array}$ & 25610 & 28 & 42 \\
\hline $\begin{array}{l}\text { Micro firms employees } \\
(<10 \text { employees) }\end{array}$ & 245789 & 6 & 27 \\
\hline
\end{tabular}

Note: Large firms are defined here as firms with over 150 employees; Micro firms as firms between 0 and 9 employees.

Source: Turkstat (2002).

The economy-wide and manufacturing data shown above reveal huge gaps in productivity levels across three major categories of firms:

- Large firms (> 250 employees) are highly efficient by both international and Turkish standards. Their entrepreneurial presence, though, is weak. There are only 910 large enterprises in manufacturing compared with 3000 large manufacturing firms in Mexico, another low per capita income country. Large firms in the formal sector have a robust physical and human capital base. Being well connected to international markets and partners, they have been able to achieve strong productivity gains over the past five years.

- Medium-sized firms (MSEs) (50-249 employees) excluding small firms and micro firms, are less productive than large firms. But helped by vibrant entrepreneurship, MSEs have been the most dynamic component of Turkey's business sector over the past decade. MSEs operate in all manufacturing and service activities, and particularly in tradable sectors such as textiles, clothing, metal working, machinery, food and furniture. They have grown in the traditional industrial centres of Istanbul, Izmir and Bursa and, more typically, in a range of Anatolian towns (Denizli, Gaziantep, Kayseri and Eskisehir). Organised industrial zones established in these towns have provided the infrastructure for exceptionally fast output growth. Because of their ability to nurture a large population of high-growth firms, these towns have been dubbed 'Anatolian Tigers'.

- Micro firms (< 10 employees), which are dominant in agriculture and numerous in clothing, metal working, food industries, retail trade, construction and transportation, are grossly inefficient by both national and international standards. Their biggest handicap is weak human capital stock and a deficient equity base. Many micro firms have no other regular employees than their family members. In France, Italy and Portugal, micro firms' output share is nearly twice as high as in Turkey, while their weight in the firm population is much lower. 
Figure 4.1. The skewed distribution of labour mobilisation and labour productivity
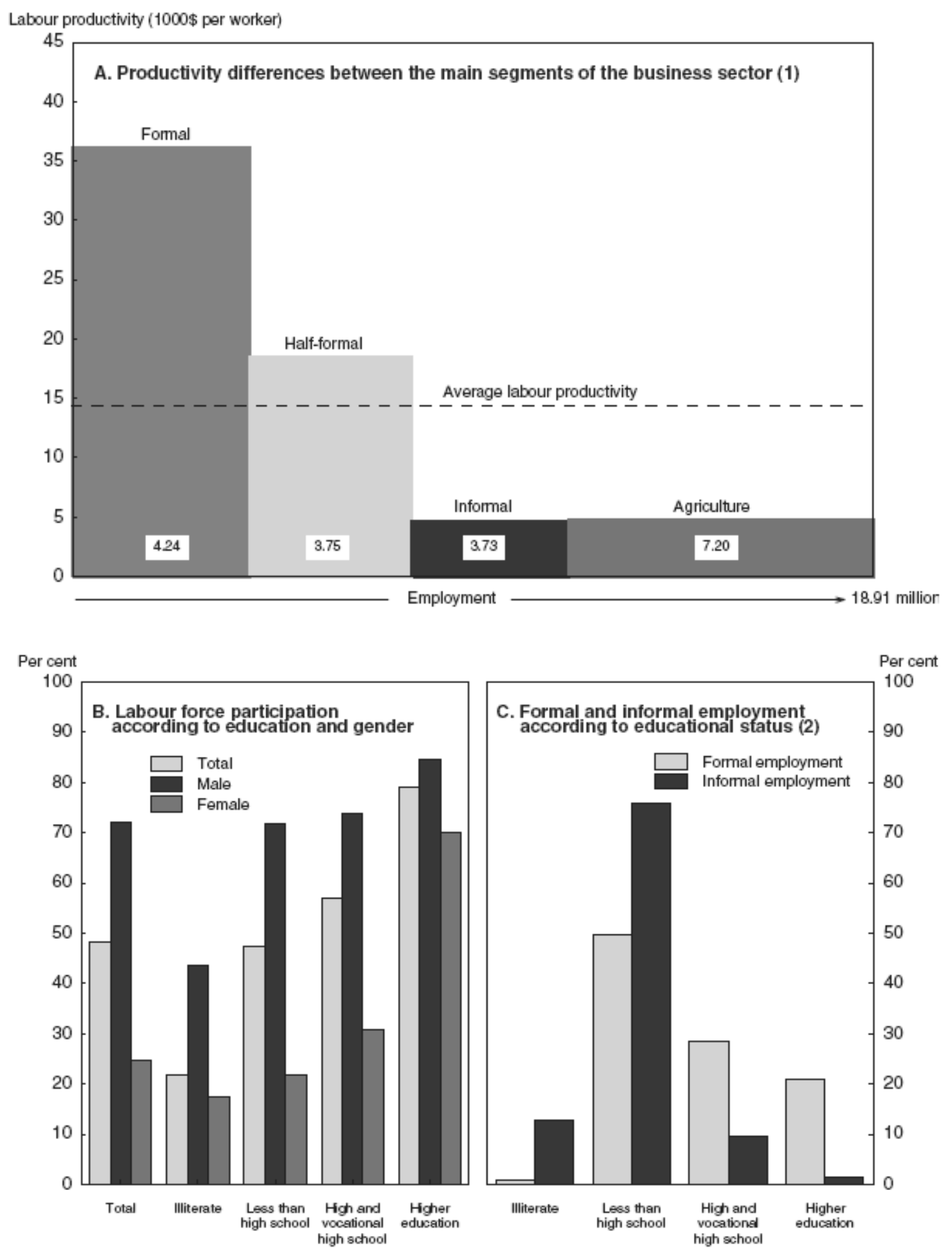

1. OECD estimates.

2. Share of formal and informal sector workers in the working age population with given educational background.

Source: OECD Economic Surveys, Turkey, 2006 based on data from TURKSTAT, SPO. 
The productivity gap is also large between formal and informal enterprises. Half-formal firms have achieved a significant catching-up in the past decade and are now at an intermediate level of efficiency (Figure 4.1). A large part of Turkey's working force is active in the informal economy which produces roughly one half of formal SMEs' value added. The scale of informal activities is negatively correlated with the size of firms as well with the level of educational attainment.

No less than three-quarters of micro firms have regular recourse to informal activities as against one tenth of medium-sized firms. ${ }^{68}$ Agriculture, where micro firms abound, is almost entirely informal, employing one third of the work force at depressed levels of productivity. Many high-growth MSEs are partly engaged in informal activities, using contracting-out procedures to avoid the full burden of formality (semi-informal firms). In contrast, large firms appear to be firmly anchored in formal activities.

The three tiers of efficiency levels thus point to major imbalances of entrepreneurial activity. There is an 'oversupply' of ineffective subsistence entrepreneurship and a correspondingly strong lack of efficient growth-oriented entrepreneurial activity. This dichotomy shows up in both a high self-employment rate and a large regional dispersion of GDP per capita. Both indicators top levels shown by other OECD countries in 2001 (Figures 4.2 and 4.3). Reflecting population distribution, more than $80 \%$ of SMEs are located in four major regions (Marmara, Aegean Sea, Central Anatolia and the Mediterranean coastal region), the remaining SMEs being present in the Black Sea region and in South-Eastern and Eastern Anatolia.

Labour market conditions are marked by low activity rates (around $75 \%$ for men, $28 \%$ for women and a combined average of $52 \%$ in 2002). More than half of dependently employed women (5.5 million women) are unpaid family workers, most of them working in agriculture. Female entrepreneurial activity is extremely low (3-4\% of the female labour force), mainly reflecting lack of education, work experience and adverse cultural biases.

Figure 4.2 Total self-employment rates (2005)

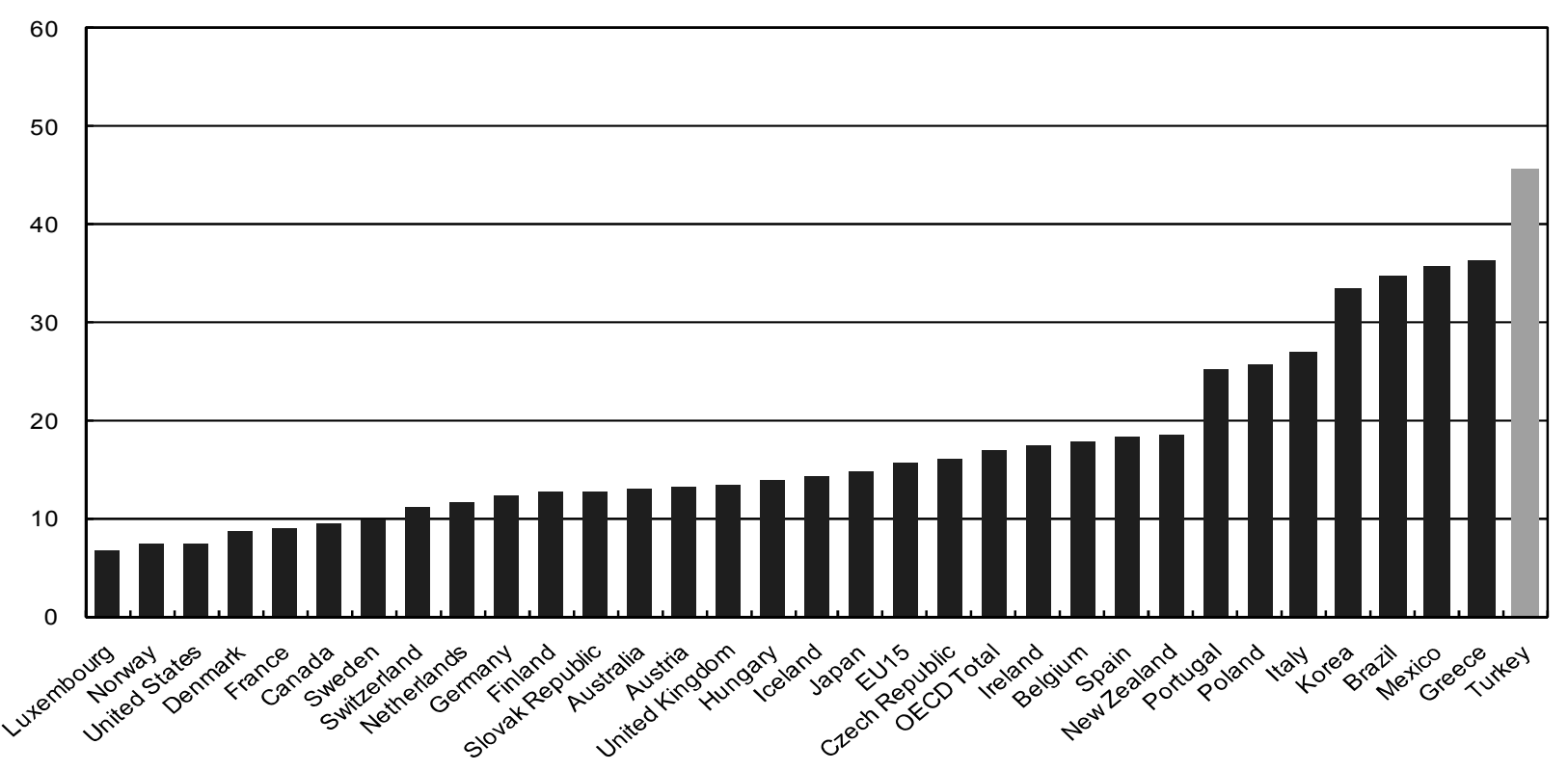

Note: As a percentage of total civilian employment, 2005 or latest available year.

Source: OECD Factbook 2007, Economic, Environmental and Social Statistics.

68

OECD (2006), Economic Surveys Turkey, p. 91. 
Figure 4.3 Regional dispersion in GDP per capita in OECD countries (Index of Gini 2001)

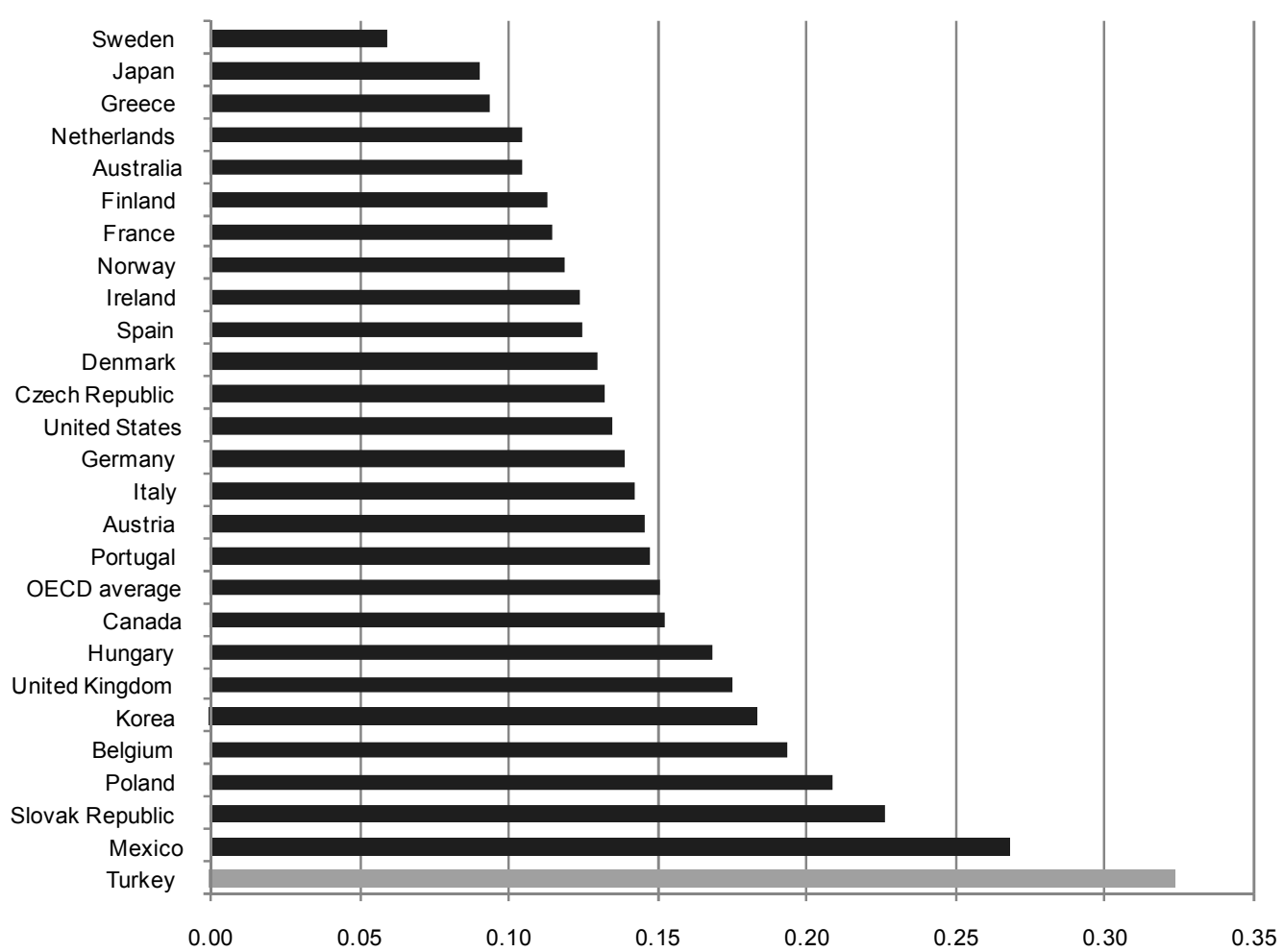

Note: Gini coefficient with GDP per capita in territorial units weighted by population. 2000 data for Mexico, Norway, Poland and Turkey.

Source: OECD, Regions at a glance, 2005.

\section{2. $\quad$ Factors driving firm creation and expansion}

A set of chronic impediments hamper firm creation, including lack of new technology, R\&D benefits, finance, skilled labour and business services. These constraints are particularly severe for small and micro firms, weighed down by an under endowment of both tangible and intangible capital. The main impediment faced by large firms and MSEs is a heavy regulatory framework in the formal economy, which is way out of line with international standards.

MSEs operating in the grey zone of semi-formality are hindered by lack of transparency, reducing the flow of credit and capital funds at affordable cost. Small and micro firms compensate a thin resource base with benefits from illegal activities (low operating costs and low entry and exit costs), while facing rising domestic and international competition. According to partial and anecdotal evidence, many micro firms have recently gone out of business, reducing employment in both tradable and non-tradable activities. ${ }^{69}$ This points to deepening structural handicaps.

\section{a) Access to new technology and $R \& D$ benefits}

While rapid progress has been made since the inception of the customs union with the EU in 1996, investment in information and communication technologies (ICT) has remained low (Table 4.3). SMEs' awareness of e-business offering profitable business opportunities is still low. While Turkey's large

69

OECD (2006), Economic Surveys Turkey. 
companies reached parity with the EU in terms of Internet access in 2005 (99\%), SMEs' access lagged far behind, the gap being negatively correlated with firm class size. Moreover, even though more than three-fifths of SMEs (excluding micro firms) have a computer, the size of the information and technology sector amounted to only $0.8 \%$ of GDP as against $3.3 \%$ for the EU15 average. Thus, the usage of ICT, though rising, has left so far no marked impact on SMEs' competitive position. ${ }^{70}$ The depressed state of technology has its main roots in weak innovative activity which is variously ascribed to:

- An extremely low ratio of R\&D expenditure to GDP (0.8\% in 2005). R\&D personnel as a share of total employment is still among the lowest in OECD countries notwithstanding a sharp rise in the number of full-time equivalent R\&D personnel per 10000 total employment over the past few years. Most R\&D employees work for universities as distinct from research institutions. Most developed countries display the opposite constellation.

- Insufficient $R \& D$ efforts in the private sector. The share of the business sector in total $R \& D$ expenditure is low (around 34\% as against the OECD average of 65\%) mainly reflecting limited awareness of potential benefits flowing from R\&D activities. The number of SMEs carrying out high-technology based activities is low. The co-operation between academia, public institutions and industry is weak. Benefits from public research activities are rarely commercialised, while industry's needs tend to be overlooked. Most research proposals originate in large cities in the Western part of the country where most research centres and laboratories are located.

- Inadequate funding for co-operative projects at universities, research laboratories and equipment. Despite a university-based intellectual potential, university-industry interactions have remained weak.

- Lack of finance for innovations and R\&D. Tax incentives have been modest, most of the support going to large firms.

Table 4.3. Diffusion of Information and Communication Technology ${ }^{1}$

\begin{tabular}{|c|c|c|c|c|c|c|c|c|}
\hline & Mexico & Poland & Turkey & EU-15 & US & Japan & Korea & OECD \\
\hline Standard access lines & 15.9 & 29.6 & 26.7 & 43.5 & 59.5 & 40.4 & 57.7 & 43.6 \\
\hline Access channels & 18.9 & 32.9 & 27.0 & 58.9 & 62.3 & 55.0 & 58.4 & 52.0 \\
\hline Mobile subscribers & 29.3 & 45.5 & 39.4 & 84.8 & 54.5 & 67.9 & 70.1 & 64.2 \\
\hline $\begin{array}{l}\text { Internet subscribers to } \\
\text { fixed networks }\end{array}$ & 2.7 & 4.3 & 1.6 & 24.0 & 33.0 & 25.6 & 24.8 & 22.4 \\
\hline Broadband access $^{2}$ & 0.4 & 0.8 & 0.1 & 5.9 & 9.7 & 10.7 & 24.2 & 7.2 \\
\hline
\end{tabular}

1. Per 100 inhabitants in 2003.

2. "Other" broadband technologies include satellite broadband Internet, fibre-to-the-home Internet access, ethernet LANs, and fixed wireless subscribers (at downstream speeds greater than $256 \mathrm{kbps}$ ).

Source: OECD, SMEs in Mexico, 2007 based on the OECD Communications Outlook, 2005. 
Thanks to partnerships and financial linkages with multinational companies, large firms generally have quick access to new technology, R\&D benefits and best practices. Some infrastructure costs, though, related to information technology, are high by international comparison. Turkey still records far the highest broadband prices per Mbit/s in the OECD area. By contrast, technological deficiency is acute for small and micro firms, which suffer from shortages of human capital and financial resources, poorly functioning markets and lack of understanding. In this setting, entrepreneurial demand for business support services has remained low. There are signs of modest progress, though, R\&D spending rising to $0.8 \%$ of GDP in 2005 from $0.61 \%$ in 2003 . Moreover, the number of Turkish scientists' publications has risen sharply, reaching nearly 14000 in 2004 compared with 9300 in 2002.

\section{b) Access to finance}

Real interest rates, though sharply declining since 2001, have remained high by international comparison. Turkey's short-term and long-term real interest rates averaged $8.3 \%$ in 2007 (Table 4.4) as against $4.6 \%$ for Mexico, a country with a comparable per-capita income, and $2 \%$ for the Euro area. Official interest rates naturally represent a floor (minimum rates), with only a few large, top-graded companies being able to borrow funds at this cost. For the overwhelming majority of other firms, real interest rates are much higher, implying steep required rates of return on planned investment. The unusually high level of capital user cost reflects both inefficient financial markets and a large current account deficit of the balance of payments. The large excess of imports over exports $(7.5 \%$ of GDP in 2007) necessitates high internal interest rates so as to attract capital inflows on a scale which maintain relative exchange rate stability.

A lack of formal credit funds and equity capital at affordable cost thus constitutes a severe constraint to firm creation and firm expansion. Most banks refrain from making loans to SMEs reflecting the government's dominant lender position and the lack of banking skills to underwrite such loans effectively. As a result, less than $5 \%$ of available bank credit has been provided to industrial SMEs, which, as shown above, account for no less than $99.5 \%$ of all industrial establishments. Despite rebounding credits to the private sector following the banking crisis of 2000-01, most banks still lack basic expertise of how to lend funds to SMEs.

Table 4.4 Real short-term and long-term interest rates (2007)

\begin{tabular}{lcc}
\hline & Short-term interest rate & Long-term interest rate \\
\hline Turkey & 8.2 & 8.4 \\
Denmark & 2.2 & 2.3 \\
Korea & 4.2 & 4.5 \\
Mexico & 4.5 & 4.8 \\
Norway & 3.2 & 3.2 \\
Euro area & 2.1 & 2.0 \\
\hline
\end{tabular}

Note: Real interest rates are nominal interest rates deflated by the GDP deflators.

Source: OECD Economic Outlook, June 2007.

As informal firms' financial accounts understate the true dimension of their activities, SMEs find it difficult to win support from properly supervised banks. In the past, Turkish banks used to provide informal and semi-informal firms with a limited amount of credit through a system of informal books and bilateral information. Dynamic medium-sized enterprises (MSEs) still refrain from making ample use of formal banking and financial services, formal credit costs being high, while benefits from informal operations continue to be substantial. These enterprises are funded, to a large extent, by own-equity and inter-enterprise trade credit, which serve as the main financing channels. 
MSEs' semi-informality is likely to become a serious hindrance in communication with other partners such as joint-venture candidates, technology suppliers and new customers. Standard banking and financial services will be increasingly needed, as the demand for and the potential supply of medium-to-long-term investment credit is bound to rise rapidly. Enterprises' investment for modernisation and long-term assetbuilding implies increased demand for such funding. Recent entries of prime international banks have widened the range of financial instruments for large firms and $M S E s,{ }^{71}$ thus easing barriers to finance. In contrast, micro firms' access to finance is severely restricted by high costs of suppliers' credits, lack of banks' ability to conduct small loan-operations and shortages of micro financial instruments backed by government guarantees. There is no comprehensive micro-loan mechanism operating in Turkey.

A 2005 survey of "Small Enterprise Finance in Turkey" (653 firms) conducted by Bankakadmie International with the support of the EU and the Kreditanstalt für Wiederaufbau (Germany) revealed stringent collateral requirements by commercial banks as being the most important barrier to finance $(83 \%$ of firms) followed by "excessively high interest rates" (54\% of firms) and cumbersome bureaucratic procedures (26\%). As a result, SMEs, especially in manufacturing, find it difficult to obtain sufficient capital for their investment projects, notably in the start-up phase. Lack of start-up capital is seen as a fundamental bottleneck for firm creation, SMEs having difficulties in providing required guarantees or collateral. Insufficient capital appears to be the fundamental bottleneck for start-ups.

There are only two operational venture capital investment trusts, ISRISK, a private company founded in 2001 and KOBI, a public incorporated company acting as an efficient risk capital intermediary which provides financial instruments to promising SMEs. The number of SMEs using venture capital is estimated at $2 \%$, a low number by international standards. Moreover, for credit guarantees, there is only one organisation, the Credit Guarantee Fund Operating Research J.S.C. (KGF). Operating in Turkey since 1994,. KGF, an intermediary organisation, permits SMEs with inadequate collaterals to apply for bank credits reducing banks' risks and increasing the number of their customers. A comprehensive system of micro-finance does not exist in Turkey.

Thanks to the financial reform process, which began in 2001, financial institutions (banks, factoring and leasing companies) appear to have become more willing to provide funds for SMEs, contributing to the rise in the ratio of credits to GDP to $41 \%$ in 2006 from $23 \%$ in 2002 . The volume of factoring and leasing also increased, reaching, respectively, EUR 12 billion and EUR 4 billion in 2006. Overall, though, financial institutions still view SME financing as being risky, yielding little profit. Supply and demand side obstacles SME finance still reflect ineffective and insufficient numbers of financial instruments. ${ }^{72}$

\section{c) Access to skilled labour and business services}

While recent decades have seen a swift expansion of access to school education, the quality of education remains low at the majority of schools. ${ }^{73}$ Education opportunities are unevenly distributed as the education system focuses on good quality education for the most able students. Resources being skewed towards the 'high end', the education system favours students from higher-income families who, after university graduation, join the formal economy as employees. In this setting, the most binding human capital deficiencies are to be found at the middle and low ends of the labour market. The stock of undereducated adults is large, adversely affecting entrepreneurial activities of small and micro firms. While opportunities for receiving entrepreneurship education and adult training opportunities are sparse, cultural

\footnotetext{
$71 \quad$ OECD (2006), Economic Surveys Turkey.

72 Ministry of Industry and Trade, Regional Competitiveness Operational Programme, November 2007.

73 OECD (2006), Economic Surveys Turkey.
} 
factors hinder peoples' propensity to choose entrepreneurship as a career. This is especially true for women whose participation in entrepreneurial activity is extremely low.

On the level of micro firms, the under endowment of human capital is the primary factor, shutting out innovative activities and perpetuating low efficiency levels. On the level of MSEs semi-formality and lack of funds often prevent purchases of high-quality managerial services and business services capable of diffusing best-practice technology. High-skilled managers themselves avoid reputational and legal risks associated with running semi-formal companies.

Access to business services supplied by public or private support units is constrained by chronic demand deficiency. This varously reflects reduced visibility of available services and relatively high cost for private counselling. The small average size of Turkish SMEs and, in particular, the large proportion of micro firms, may contribute to these failings of the markets for support services. ${ }^{74}$ Opportunities for receiving entrepreneurship education per se are sparse.

\section{Entrepreneurship and SME policies}

\section{Overall aims of entrepreneurship and SME policies}

For many years, Turkey's entrepreneurship and SME policies has been geared towards enhancing productivity and competitiveness through spurring R\&D spending, innovation and the diffusion of ICT. In 2002 new programmes and funding schemes were designed to this effect. These support programmes focused on industry, often leaving out service activity. A broader industrial foundation was viewed as being critical for both stronger international integration and reduced regional imbalances.

Entrepreneurship and SME policies in Turkey have been shaped over the past few years by a number of factors (Box 4.1), including:

- The creation in 1996 of the Customs Union with the European Union. As a result, Turkish industry became increasingly exposed to international competition, while SME support programmes began to be designed within a framework of international co-operation.

- The ratification in 2002 of the European Charter for Small Enterprises which established an international framework for conducting efficient SME policies. By adopting the EU-Charter for SMEs, Turkey pledged to take concrete steps to conceive programmes and projects in all important SME policy areas, including on-line access, access to finance and access to education and training for entrepreneurs. Turkey considers the Charter as the foundation for its long-term SME strategy (medium-term to long-term enterprise (SME) development strategy). ${ }^{75}$

- Establishment of the EU-legal framework for Pre-Accession Assistance (IPA) (2006), ${ }^{76}$ (Annex 4.A).

- Implementation of the "Basel II" prudential rules (2007).

- Preparation of the Operational Programme for Regional Competitiveness (RCOP) (2007).

OECD (2004), Small and Medium-sized Enterprises in Turkey, Issues and Policies, p. 20.

OECD (2004), Small and Medium-sized Enterprises in Turkey, Issues and Policies, p. 53.

The EU legal framework for Pre-Accession assistance was established with the Council Regulation (EC) No $1085 / 2006$ of 17 July 2006. 


\begin{tabular}{|c|c|}
\hline \multicolumn{2}{|r|}{ Box 4.1. Calendar of Major Entrepreneurship and SME Policy Events } \\
\hline 1990 & Creation of KOSGEB \\
\hline 1996 & Creation of Customs Union with European Union \\
\hline 1999 & Recognition of Turkey as a candidate country for EU-membership \\
\hline \multirow[t]{3}{*}{2000} & Adoption of OECD Bologna Charter \\
\hline & Creation of Telecommunications Authority \\
\hline & National Convergence Programme to the EU acquis (2001-2005) \\
\hline \multirow[t]{4}{*}{2002} & Ratification of the European Charter for SMEs \\
\hline & Participation in the Business Environment Simplification Task Force (BEST) \\
\hline & $\begin{array}{l}\text { Action Plan for Business Support Activities (local and regional cluster programmes } \\
(2003-2005))\end{array}$ \\
\hline & Industrial Policy (towards EU Membership) (2002-2007) \\
\hline \multirow[t]{2}{*}{2003} & Adoption of Urgent Action Plan \\
\hline & Specific Action Plan (2004-2006) \\
\hline \multirow[t]{3}{*}{2004} & Opening of EU accession negotiations \\
\hline & Liberalisation of telecommunications sector \\
\hline & Adherence to the Istanbul OECD Ministerial Declaration ${ }^{77}$ \\
\hline 2005 & Partial privatisation of Turk Telekom A.S. \\
\hline \multirow[t]{4}{*}{2006} & Alignment of SME support programmes on EU-definitions \\
\hline & Adoption of $9^{\text {th }}$ Development Plan \\
\hline & Adoption of SME Strategy and Action Plan (2007-2009) \\
\hline & Establishment of EU legal framework for Pre-Accession Assistance (IPA) \\
\hline \multirow[t]{2}{*}{2007} & Implementation of the "Basel II" prudential rules \\
\hline & $\begin{array}{l}\text { Preparation of Operational Programme for Regional Competitiveness (RCOP) in the } \\
\text { context of the EU instrument for pre-accession (IPA) }\end{array}$ \\
\hline
\end{tabular}

Priorities for enterprise and industrial policy are customarily set out in multi-annual development plans, which present a general policy framework. More detailed policy objectives are laid out in mediumterm (three-year) programmes, while annual programmes identify specific policy measures, a time frame and the allocation of responsibilities among different government branches and other policy stakeholders. Highlights of entrepreneurship and SME policy over the past few years included:

- The five-year National Convergence Programme to the EU acquis (2001-05). Aimed at improving SMEs' efficiency and competitiveness, the plan promoted the diffusion of bestpractices to upgrade product quality and innovation and technology capacity through modern management techniques, new financial instruments and partnerships with universities and foreign companies. The plan also called for better service delivery to SMEs creating and expanding specialised support units (service stations).

- The Urgent Action Plan adopted by the High Planning Council in November 2003. The implementation of this plan, prepared in the context of EU pre-accession, is one of the priorities

77 The Istanbul OECD Ministerial Declaration was adopted after the $2^{\text {nd }}$ OECD Ministerial conference on "Promoting Entrepreneurship and Innovative SMEs in a Global Economy". 
of the SME Charter of the 2003 Turkish National Programme for the adoption of the EU acquis. The purpose of the plan was to raise the transparency of existing policies and programmes; to define clearly the respective responsibilities for public and private organisations and to identify a set of required activities. The plan was prepared by the SME Study Group composed of various organisations mapping out SME strategies.

- The Specific Action Plan for 2004-06. This plan was geared towards buttressing industrial SMEs by raising their level of technology, enlarging the flow of financial funds and augmenting the quality of their products. Implementing this plan has been facilitated by a new consultative committee involving private-sector representatives who work in unison with the State Planning Organisation (SPO).

\section{A new framework for entrepreneurship and SME policies}

\section{a) The $9^{\text {th }}$ Development Plan (2007-2013)}

A new phase of entrepreneurship and SME policies has opened up with the adoption in 2007 of the $9^{\text {th }}$ Development Plan covering the period 2007-2013. This plan focuses on stronger R\&D spending and innovation as indispensable structural tools to bolster the business sector. Aimed at lifting R\&D spending to $2 \%$ of GDP in 2010 from $0.8 \%$ in 2005 the plan envisages the upgrading and expansion of the R\&D infrastructure. To this end, public research institutes will be strengthened and private research centres established. Academic R\&D activities will be increasingly oriented towards industrial needs implying stronger collaborative links between universities and industry. The Plan also intends to complete the building of Technology Development Zones (TDZs) and to create Technology Transfer Centres. Financial underpinning of these projects is scheduled to come from new financial instruments capable of expanding scarce supplies of venture capital for innovative SMEs (ISMEs) and high-growth SMEs (HGSMEs). Innovative firms striving to overcome pressure from foreign low-cost competition will benefit from special incentives.

The $9^{\text {th }}$ Development Plan also embodies a special strategy for balanced regional development. Aimed at reducing stark regional disparities through stronger regional competitiveness the Plan adopts a 'Growth Centres Approach'. Under this approach, geographical areas with a high-growth potential are identified, mainly inside less-developed regions. The main function of such growth centres is to install a balanced physical and social infrastructure capable of generating new industrial 'focal points'. According to the Plan, such infrastructural 'magnets' will eventually attract investment from both outside the region and from outside Turkey. This 'Growth Centres Approach' is also integrated into the Strategic Coherence Framework as agreed by the EU-Commission in June 2007.

Accordingly, the SME Strategy and Action Plan (2007-2009), covering the first three-year segment of the $9^{\text {th }}$ Development Plan, focuses on lending support to new, innovative and competitive enterprises, correcting past programme failures and a more stringent monitoring of policy outcomes. The plan singles out several priority areas, including entrepreneurship development, firm creation, integration of SMEs into international markets and national and international networks, improvement of the business environment, diversification of financial instruments and expansion of technological and innovative capacity. In pursuit of this aim, the plan offers training programmes for SMEs, encouraging them to participate in European Technology Platforms. It also supports post-graduate studies of industry at university level Industrial Thesis Supporting Programme (SANTEZ Project) and prepares the conversion of technology 'incubators without walls' into technology development centres.

The $9^{\text {th }}$ Development Plan and the SME Strategy and Action Plan have been shaped in line with the 2006 EU legal framework governing pre-accession assistance (Annex 4.A). 


\section{Principal stakeholders of entrepreneurship and SME policies}

The government's main tool for implementing industrial entrepreneurship policy has been KOSGEB, (Small and Medium Industry Development Organisation), a Public Agency affiliated with the Ministry of Industry and Trade. Established by law in 1990 and subject to private law in all its transactions, KOSGEB's mandate is to increase the weight and effectiveness of industrial SMEs and raise their competitiveness. In line with this mandate, KOSGEB has designed numerous support programmes to enhance technological skills, stimulate entrepreneurship, upgrade labour skills, spur R\&D efforts and disseminate information which is relevant to SMEs. Programmes are developed by different directorates within KOSGEB and they are implemented by the Enterprise Development Centers (IGEMs), the Technology Development Centers (TEKMERs) and the Synergy Focal Points (Box 4.2). In 2007, KOSGEB employed 651 persons. Public expenditure associated with its programmes totalled TYL 10582112 in 2007.

KOSGEB's TEKMERs act as incubators providing support for technology development through know-how, material, equipment and office space. They have been established through protocols signed between KOSGEB and universities and chambers of commerce; they service both start-ups and existing innovative SMEs. In the areas where TEKMERs do not exist 'business incubators without walls' provide services to SMEs, excluding office allocation. IGEMs are mainly established in organised industrial zones and provide services to manufacturing SMEs.

'Synergy Focuses' have been launched in 2004 to generalise services and assistance given to SMEs. Exemplifying a new co-operation model (collaborative innovation) 'Synergy Focuses' are established in co-operation with the Union of Chambers and Commodity Exchanges of Turkey (TOBB), Unions of Artisans, Cooperatives of Artisans, Management Boards of Organised Industrial Zones (OIZ) and Small Scale Industrial Estates (SSIE) as well as with SME foundations and associations.

Box 4.2. KOSGEB Service, Support and Research Centres

- Entrepreneurship Development Directorate

- Regional and Local Development Directorate

- Market Research and Export Promotion Directorate Centre

- SME Financial Research Directorate

- SME Loan Management and Monitoring Directorate

- Training and Consultancy Directorate

- Foreign Relations Directorate

35 Enterprise Development Centres (IGEM)

20 Technology Development Centres (TEKMER)

75 Synergy focal points (intermediate 'service stations' placed between KOSGEB and TOBB)

Source: $\quad$ OECD Project on HSMEs, Innovation, Intellectual Assets and Value Creation, Turkey's submission to the OECD Working Party on SMEs and Entrepreneurship (WPSMEE). 
Other government branches involved in industrial entrepreneurship and SME policy include the Undersecretariat of the Treasury which is responsible for State aid for SME investment. The Under Secretariat of Foreign Trade helps deploy programmes to spur SME creation. Business organisations such as the TOBB and the Confederation of Tradesmen and Artisans of Turkey (TESK) play an important role in implementing SME policies. Other non-governmental organisations involved in innovation-oriented entrepreneurship and SME policy include the Technology Development Foundation of Turkey (TTGV).

\section{4. $\quad$ Strengthening entrepreneurial and innovative activities}

a) Better access to new technology, $R \& D$ benefits and networking activities

A key element in Turkey's efforts to raise the level of enterprises' technology has been the expansion and deepening of services support programmes, including a better adaptation of research activities to business needs. Five main stakeholders are active in this field: the Ministry of Industry and Trade, KOSGEB, the State Planning Organisation (SPO), the Technology Development Foundation of Turkey (TTGV) and the Scientific and Technological Research Council of Turkey (TUBITAK). KOSGEB's programmes, notably those applied by Enterprise Development Centres and Technology Development Centres, are based upon best practice models from Europe, Asia and North America. Various 'services stations' provide a broad range of support services to new and existing small businesses in manufacturing which strive to augment output, marketing and export capacity.

Under KOSGEB's programmes, small firms have access to managerial and technical assistance, capital space, R\&D benefits and management training. In addition, they receive subsidies for recruiting and managing personnel. In 2006, 2767 small enterprises received assistance from both types of centres. Public spending related to these activities amounted to TYK 15187258 . TEKMER staff, a total of 53 SME experts, provide consulting assistance, acting as guides to outside resources and not as direct service providers per se.

Teaching entrepreneurs how to access support services and convincing them to make use of technological assistance is the most important function performed by TEKMERs. ${ }^{78}$ They also help establish better relationships between SMEs and technology service providers which are predominantly public organisations. To strengthen the interaction between SMEs and universities, TEKMERs and business incubators have begun to be established near universities. Currently, there are 20 TEKMERs located in university campuses. Three of them are located in less-developed regions (NUTSII regions) supporting 110 firms. In addition there are 7 'incubators without walls' located in Industrial Zones and along with TEKMERs they support about $1400 \mathrm{R} \& D$ projects. Private companies (Ericsson, Koc Holding and Siemens) have established business incubators of their own.

Another programme creating ties between academia and the business sector is SANTEZ. This programme sponsors graduate studies based upon requests by industry and stimulates the transmutation of invention into innovation through innovation-oriented SMEs. Financial support of up to $75 \%$ of the project budget is provided by the Ministry of Industry and Trade while the rest is covered by the company commercialising the output.

In addition, Technology Development Zones (TDZs) have been created to help bridge the gap between research activity and business needs. TDZs promote the use of high/advanced technologies and related R\&D capabilities through co-operation between universities, research institutes and the productive sector. Financial support is granted for land, infrastructure and construction of management buildings. 
TDZs benefit from tax exemptions and incentives until 2014. There are 28 TDZs in Turkey of which 18 are operational. They are mainly established by universities. Currently, nearly 800 firms are linked to TDZs (99\% of SMEs) and over 2500 R\&D projects are underway.

Another stakeholder building links between universities, research centres and enterprises is the State Planning Organisation (SPO) which issues guidelines for research, technology, development and innovation. The Scientific and Technological Research Council of Turkey (TUBITAK) implements programmes to strengthen the collaboration between industry and the research community: ISBAB supports initiatives to establish scientific and technological cooperation networks. EUREKA provides R\&D network assistance for the 'Support Program for R\&D Projects Market Platform'. Other TUBITAK programmes stimulate private R\&D efforts and start-ups of innovation-oriented SMEs (TEKNOGISIM).

$K O S G E B$ has also taken action to increase the flow of advisory services from professional organisations and public institutions (universities) so as to create stronger links between SMEs and large enterprises. This is being achieved through novel incentive mechanisms inducing SMEs to take advantage of information and experience gathered by universities. TDCs and Chambers of Industry assist actual and potential entrepreneurs to make use of both business incubators without walls and Innovation Relay Centres (IRC). IRCs (a total of two, in 2007 Anatolia IRC and Ege IRC) have been incorporated into the EU-IRC Network. Networking activity has also been strengthened with the creation of Synergy focal points ' intermediate service stations' placed between KOSGEB and TOBB.

Sectoral networking activity by NGOs has been intensified with the 'Fashion and Textile Cluster' (2003), an EU-funded project launched by the Istanbul Textile and Apparel Exporters' Association (ITKIP). The 2007 RCOP stimulates the formation of sectoral clustering and inter-regional network building in the 12 NUTSII regions. The networking 'technology' (collective process innovation) is based upon results from EU-funded clustering and research projects, (GAP GIDEM, and SME development project) executed by UNDP in conjunction with GAP Regional Development Administration for sectors like marble, textile, confection and organic agriculture.

The Technology Development Foundation of Turkey (TTGV) - a non-governmental independent not for profit organisation in the science and research sector - also supports projects from the corporate sector. The Foundation funds projects of Technoparks, TEKMERs, venture capital funds, start-up funds and joint technology development projects. It has also supported the commercialisation of R\&D activities and risk sharing. TTGV has provided USD 165 million to 473 technology development projects.

\section{b) Better access to finance}

Several targeted investment credit programmes serve to reduce user cost of capital and to overcome the banking system's chronic inability to provide sufficient funds for SMEs. These programmes include:

- Release of funds by the Treasury to the Halk Bank, the Industrial Development Bank and other banks. Loan parameters are established by agreement with the banks, the banks underwriting loans and taking responsibility for defaults.

- Following the signature of a protocol between KOSGEB, HalkBank Vakifbank and Ziraat Bank in 2003, KOSGEB subsidises interest rates of credits provided by these banks. Under these protocols, soft loans are extended to SMEs beset by short-term liquidity problems. While the loans are accorded by banks, interest expenses are financed partially or fully by KOSGEB. In 2003, more than 1600 enterprises received EUR 70 million, a small amount relative to overall bank loans. 
- Repayable medium-term subsidies for industrial SMEs participating in KOSGEB's IGEMs and TEKMERs. These subsidies are mainly used for investment in equipment and technology.

- Loans for the creation of small industrial estates or organised industrial zones opening access to quality industrial space with the necessary utilities and central services. About two-thirds of the industrial estates are privately funded. The government continues to release funds for the creation of new estates, notwithstanding evidence of large excess capacity in many existing ones.

- Investment allowances which are granted automatically at a rate of $40 \%$ to all investors purchasing or producing fixed assets subject to depreciation with a value of more than TKL 5 million. The State Aid Programme for SME investment is implemented by the Under Secretariat of the Treasury.

- KOSGEB's financial incentives for business start ups of up to the equivalent of EUR 10000 for fixed investment and operating expenses. Capital funds for fixed investment up to EUR 8000 must be paid back. Capital funds for operating expenses (up to EUR 2 000) do not have to be paid back. Technological business start ups receive stronger financial support. Funds for fixed investment must be repaid over a 4-year period, usually with a 1 year grace period. Start ups in less-developed areas benefit from longer grace periods and more favourable repayment schedules. Non-payback support is granted for counselling, R\&D applications, publication of $\mathrm{R} \& \mathrm{D}$ findings, leasing space in techno parks and export promotion purposes.

- Exemption of import duties and value-added tax payments for investment in equipment.

- Under the SME Finance Facility bank credits have been extended to SMEs located in development areas at attractive interest rates. Surprisingly, the credit line provided by the Kreditanstalt für Wiederaufbau has been underused. Banks have also lent funds to SMEs under the Small Enterprise Loan Programme (SELP) concentrating on small loans with a maturity of over a year. The SELP programme has had a noticeable impact on local economies and secondary markets, enabling 2300 job creations and saving 15300 jobs. $^{79}$

- In 2007, the "Basel II" prudential rules have been implemented augmenting the transparency of MSEs' financial accounts. This is expected to stimulate supplies of long-term credits and venture capital.

Credit guarantees for SMEs are mainly provided by KGF, the Credit Guarantee Fund, and TESKOMB, the Union of Turkish Artisans and Craftsmen Credit Cooperatives. Established in 1994, KGF, an intermediary organisation, enables access to credit for SMEs with inadequate collateral. In 2005, KGF granted EUR 82 million worth of guarantees for 982 firms, mostly manufacturing firms (85\%), while 5\% of total guarantees were extended to firms located in the Eastern Anatolian region. The amount of guaranteed credit per unit of manufacturing firm population (EUR 410) is low. TESKOMB, an umbrella organisation covering 921 Artisan and Craftsmen Credit and Guarantees Cooperatives, offers guarantees for credits extended by Halbank. About $12 \%$ of artisan and craftsmen enterprises benefit from this guarantee.

To reduce financial barriers for SMEs in less-developed regions, the IPA - RCOP (2007-2013) (Annex 4.A) intends to establish and support micro-loan funds and equity finance mechanisms, including venture capital funds, seed capital and start-up capital in the manufacturing and the tourist sector. Advisory and consultancy services are scheduled to enhance the effects of these measures. 
Venture capital is supplied by KOBI and ISRISK, venture capital investment trusts. KOBI, a public incorporated company, acts as a risk capital intermediary offering a range of financial instruments for ISMEs and HSMEs. ISRISK is a private company established in 2001.

c)

Better access to entrepreneurship education and training

To upgrade entrepreneurial labour, KOSGEB, through its IGEMs and TEKMERs, operates a number of employment support programmes. Both types of centres offer managerial and technical assistance for hiring skilled labour. Public funds cover $60 \%$ of labour cost in developed regions for 12-18 months. Firms located in less-developed regions receive a higher employment subsidy ( $80 \%$ of labour cost). KOSGEB applies strict rules for maximum salaries to be paid for newly hired skilled labour. Technology-based companies with R\&D activities receive special training support from TEKMERs to absorb new software and information services.

In parallel, KOSGEB's Centre for Entrepreneurship seeks to spur entrepreneurial activity by releasing information about potentially viable business opportunities. Using market research findings which it has sponsored or conducted the centre makes the information available through the network of IGEMs, TEKMERs, OIZs and SSIEs. In addition, the centre systematically reviews and documents successful business practices for inclusion in the KOBINET project, the SME network. The aim is here to stimulate entrepreneurs' use of the Internet, inviting them to enter e-commerce.

KOSGEB's programme for business start ups offers two types of training. General educational services are supplied through KOSGEB's facilities dealing with basic managerial and technical issues. Specialised training is provided by professional organisations (public or private) for entrepreneurial activities not covered by KOSGEB's courses. The support ratio for general and special training is regionally differentiated. $K O S G E B$ covers up to $100 \%$ of the cost for general education services and up to $80 \%$ and EUR 3500 per firm for specialised training.

In 2004-2007, more than 15000 persons received vocational training through KOSGEB's EU-Media Projects on Clothing and Shoe Making. Thanks to this training, about 2500 persons were able to find employment.

\section{Entrepreneurship and SME policies and their impact upon firm creation and innovation}

In its 2004 peer review of Turkish policies aimed at SMEs, the OECD deplored the general lack of crucial elements for a proper policy evaluation. ${ }^{80}$ At that time, Turkey had no exhaustive statistical census of firms on the basis of homogenous definitions and criteria. Large numbers of firms in the informal economy escaped investigation. Moreover, little was known about the cost of the support programmes for SMEs. Some estimates for direct budgetary costs were available, but indirect costs caused by tax allowances were hard to quantify. Last, but not least, large segments of the economy, such as tourism and services, lay outside the scope of specific support policies.

Four years later, at the time of writing, most of these impediments are still hindering a proper, detailed policy assessment. Broad indicators, though, point to significant progress having been made over the past few years. This is manifest in better access to new technology, stronger R\&D spending, rising numbers of R\&D personnel, improved business support services and networking facilities (collaborative innovations) and enlarged business training opportunities. 
In terms of Internet access, Turkey's large firms have reached parity with the EU in 2005 . R\&D expenditure, albeit still low by international standards, has risen to $0.8 \%$ of GDP in 2005 . The range of KOSGEB's support and research centres has widened, triggering welcome interactions between research centres, universities and the business sector (synergy focal points, TEKMERs, IGEMs, TDZs, and 'business incubators without walls'). Finally, the number of entrepreneurial training beneficiaries and training instructors has strongly increased, auguring stronger entrepreneurial and innovative activity.

Looking ahead, the recent strong internationalisation of Turkey's entrepreneurship and SME policies is destined to strongly stimulate innovative activity. The opening of EU-accession negotiations (2004), the establishment of an EU legal framework for Pre-Accession Assistance (IPA) (2006) and the alignment of SME support programmes on EU definitions (2006) are certain to impart new impulses to Turkey's structural reform. The entrepreneurial and innovative dimension of this drive has found its principal expression in the 2007 Regional Competitiveness Operational Programme (RCOP) (2007-2013), one of the RCOP's main measures being to promote R\&D, innovation, the usage of technology and the increased transfer of knowledge.

A constituent of Turkey's reform policy, RCOP rightly aims at strengthening competitiveness through stronger entrepreneurship, better collaborative innovations and faster diffusion of ICT. In pursuit of these aims, it adopts a 'growth centre approach', identifies economic 'magnets' (growth centres with a highgrowth potential) and relies on a 'bottom-up' approach (interaction between nucleus and periphery). RCOP has also aimed at increasing regional co-operation by ensuring the interaction of 'growth centers' with their hinterland and by connecting target regions to the rest of the country. Representing a coherent new framework for entrepreneurship and SME policies RCOP seeks to redress ingrained structural imbalances which past policies have failed to correct.

\section{a) The need for a broader support programme approach}

There is a strong need to broaden the support programme approach. For many years, Turkey has favoured industrial SME assistance providing relatively high levels of support for comparatively small numbers of firms. These trends have broadly continued in 2007, 2223 industrial SMEs benefiting from KOSGEB's support programme and 9826 industrial SMEs receiving KOSGEB's support credit. The greater part of entrepreneurial assistance for industry went to firms with more than 10 employees. This kind of aid concentration naturally mirrors business owners' and managers' level of educational attainment, a key factor determining firms' propensity to demand assistance and their capacity to absorb government help.

While Turkey, a participant in the European BEST-programme, has increasingly applied European standards to SME support programmes, assistance continued, until recently, to be biased in favour of industry shutting out large segments of the economy (wholesaling, retailing and tourism). A different, broader policy approach, awarding smaller assistance to a much larger number of potential entrepreneurs and SMEs in all economic sectors, could be more effective in spurring innovation and firm creation. For this reason, KOSGEB's mandate has been extended in 2008 to cover some categories of non-industrial SMEs.

A broader support policy approach based on best-practice programmes is known to be effective in making greater numbers of small and micro firms more efficient. In its latest Economic Survey of Turkey (2006) the OECD underscored the importance of sectoral productivity convergence: "Raising productivity in the least productive sectors and firms would significantly increase average productivity levels. This convergence implies overcoming the deep duality persisting in the labour market as the uneven educational background of individuals determine their degree of participation in the labour force notably women and their ability to work in the formal vs. informal sectors." A broader policy approach, though, requires a 
strongly improved policy co-ordination among principal stakeholders of entrepreneurship and SME policies. Being a condition sine qua non for improving the implementation, monitoring and evaluation of support programmes these organisational and institutional desiderata have been integrated into the 2007 RCOP.

\section{b) The need for entrepreneurial education and training opportunities}

Achieving greater productivity convergence among different firm categories (highly efficient large firms, efficient medium-sized firms and inefficient small and micro firms) requires a strong extension of educational opportunities to all segments of the society. In the long run, entrepreneurship policies tend to strengthen innovation trends through the systematic introduction of entrepreneurial education in schools and universities, the expansion of computer use in schools and universities and the creation of small innovation laboratories in schools. Opportunities for entrepreneurial education should also be extended to research centres, allowing researchers to eventually establish firms. A case in point is France's public IT-research institute INRIA which, through in situ entrepreneurship education, has helped researchers set up their own firms. Overall, Turkey's progress in the domain of entrepreneurial education appears to be fractional relative to adjustment requirements.

Basic entrepreneurial training courses for aspiring and actual entrepreneurs are known to be highly effective in quickly removing inefficiencies of production via process innovation. This includes making entrepreneurs aware of support options and teaching them how to apply for assistance and how to put credit funds to best use. In this domain, Turkey has made significant progress over the past few years, as is evident in the rising number of training beneficiaries and instructors.

\section{c) The need for differentiated support services and network building}

Given large gaps between levels of educational attainment, the provision of support services, whether in the area of human capital, finance or technology, should be in consonance with the size of firms, firm owners educational attainment and related productivity levels. As it stands, the system of service providers (support units) has not yet fully embraced the heterogeneity of firms and potential entrepreneurs in both breadth and depth. On the other hand, low visibility of existing programmes has led, in some areas, to low demand for support services. The 'growth centres' approach adopted by the $9^{\text {th }}$ Development Plan and RCOP (2007-2013), widening the range of support services and augmenting their visibility, should strongly narrow the gap between demand and supply.

Providing better educational and training opportunities for aspiring and actual entrepreneurs is now rightly seen as requiring flexible network building among different categories of service providers. One priority area is elementary training services for micro firms which could be vastly expanded using collaborative innovations (collective process innovations). These include using mobile business development centres which offer training services in the 'hinterland' of less developed regions as well as using mobile banking vans which extend micro-credits secured by new financial instruments. The programmed interaction between 'growth centres' and the 'periphery' is a step in the right direction. While progress has been made in standardising and certifying training activities, there is little evidence of experience-sharing among Turkey's public training support units. Such sharing needs to be encouraged using best-practice experience gathered by other countries.

\section{d) The need for a new financial infrastructure}

Notwithstanding a welcome rise in SMEs' bank credit over the past few years, there is a persistent important lack of funds (credit supplies and venture capital), financial instruments, support services and efficient financial networking activity. On the supply side, real interest rates, though falling, are still 
extremely high by international comparison. The underlying capital shortage implies high required rates of return on capital, damping firm creation, firm expansion and innovation. Moreover, real interest rates are negatively correlated with firm size, micro firms facing particularly steep barriers to finance. In this setting, the internationalisation of SME activities takes on particular importance as rising SME exports reduce the current account deficit, widening the space for interest rates to decline. In this sense, raising SME exports tends to ease SMEs' access to finance with the passage of time.

A narrow range of banking and financial services aggravates Turkey's structural scarcity of capital. Private banks are not accustomed to extending credits to small and micro firms on a large scale. There is little expertise in assessing loan applications from firms which have no or little collateral. Moreover, a comprehensive loan guarantee programme modelled on successful systems applied by Germany, the World Bank or Mexico does not exist nor is there a government-sponsored, large network of certified credit advisors.

A broad financial infrastructure for micro firms is inexistent. There is a strong need to expand micro financial services, establishing a comprehensive network of micro finance institutions. Experience in other countries shows that using mobile banking vans along with mobile business development centres helps low-income clients overcome strong barriers to finance. In the absence of such a financial infrastructure, banks find it rational to engage in credit rationing regardless of firms' willingness to accept more stringent credit terms. ${ }^{81}$ Provisions contained in the RCOP appear to be small relative to large adjustment requirements in this area.

On the credit demand side, small and micro firms' credit requests thus continue to be restrained by stringent collateral requirement, and high interest rates charged by informal money lenders. Firms generally view stringent collateral requirements by commercial banks as being the most important barrier to finance, while insufficient venture capital represents the fundamental bottleneck for start-ups. There are only two operational venture capital investment trusts in Turkey.

In an appropriate financial setting, private banks and intermediate financial institutions are shielded by an efficient, national guarantee programme under which credit funds are channelled to small and micro firms at affordable cost. This setting would also include new financial instruments, a vastly expanded network of credit advisory services for these enterprises and information exchange among all financial stakeholders. Credit transaction costs would fall, easing small and micro firms' entry into the formal economy.

Through state-owned banks, the government has made credit available to develop small-scale industrial estates (SSIE) with access to industrial space, utilities and central services. In addition, numerous tax incentives and offsets (tax credits) serve to stimulate the SMEs' purchases of capital equipment. But however useful such measures may have been for a few companies, they cannot replace the potential benefits from a comprehensive support structure meeting, with resilience, the financial needs of different business categories.

While MSEs and large enterprises generally escape from credit restraints, they continue to face an acute shortage of venture capital and business angels, damping innovative initiatives. In 2005, most Turkish MSEs remained reluctant to publish financial statements audited by independent, external auditors. Only 3-4\% of registered MSEs appear to have standard business plans, slowing the inflow of long-term 
capital. From 2007, however, the implementation of the "Basel II" prudential rules is expected to change the way banks allocate capital to risk. ${ }^{82}$

\section{e) The need for stronger vertical linkages}

Upgrading the tangible and intangible human capital of SMEs paves the way for building vertical links with large companies. In many countries, the growing specialisation of industries has led to more diversified production modes, with many semi-finished goods assembled to produce final products. Several low per capita income countries, in collaboration with the United Nations Development Programme $(U N D P)$, have drawn up programmes for suppliers' development allowing SMEs to become members of vertical supply chains. Such links have been created in industry as well as in the services sector (e.g. hospitals and restaurants in Mexico).

Involving continuous interactions between large firms and SMEs, vertical links strengthen process innovations of both suppliers and final producers. ${ }^{83}$ Despite the creation of Organised Industrial Zones and small-scale industrial estates, Turkey still has ample room for exploiting the potential of such chain-based innovations. Activating this potential should become possible with the RCOP's 'growth centre' approach. The 2005 EU-funded project 'Development of a Clustering Policy in Turkey' should contribute to the process of enhanced network building.

\section{Concluding remarks}

A successful entrepreneurship and SME policy evolves through time with the maturing of both innovative processes and supporting service units. Three policy phases can be usefully distinguished, the first one spurring R\&D and innovation so as to create vast segments of ISMEs and HSMEs. During the second phase, the innovations are spread through improved scientific-technological networks, specialised institutions and better access to finance (including venture capital). In the third and final phase, the innovative momentum gathers pace stimulated by learning effects and the transition to the knowledge economy.

As regards large, industrial firms and MSEs, Turkey has, over the past few years, made significant progress in the first two policy phases of this process. This is evident in stronger R\&D efforts, better education and training opportunities, stronger innovative activity and expanded support services and networking facilities. As a result, most large firms and many MSEs are internationally competitive. At the same time, though, this progress has been unequal, as vast numbers of small and micro firms outside industry (oversupply of subsistence entrepreneurship) continue to lack access to technology, education, training and finance.

Stimulating the growth-oriented entrepreneurial activity of these "excluded" firms requires broadened support programmes (covering non-industrial sectors), tailor-made network building (bundling of micro firms for vertical and horizontal purposes) as well as better policy co-ordination among major stakeholders of entrepreneurship and SME policy. It also requires determined efforts to use international best practices to bring real interest rates down from abnormally high levels. Experience has shown that falling interest rates combined with rising supplies of collateral-free funds will ease firms' entry into the formal economy. Moreover, creating collaborative innovations will help small and micro firms enter international markets. Rising SME exports will then contribute to reducing the large current account deficit, opening doors for interest rates to fall. This sequence points to the indirect link connecting the internationalisation of SME activities and the easing of barriers to finance. Focusing coherent policy programmes on the more

\footnotetext{
$82 \quad$ OECD (2006), Economic Survey of Turkey, p. 129. 
vulnerable segments of the business sector thus constitutes a pre-condition for achieving stronger economic convergence with the EU.

The new framework for entrepreneurship and SME policies (2007-2013) established by the Pre-Accession Process largely meets these concerns. Fully implemented the RCOP is bound to show that innovative and entrepreneurial activities are co-dependent.

Box 4.3. Policy recommendations

\section{Broaden Support Programme Approach}

Extend entrepreneurship and SME policy support to include non-industrial firms

Create a simplified analytical framework for a broadened support programme approach

Differentiate support programmes to meet basic needs of vastly different business categories (large firms, MSEs and small and micro firms)

Expand, deepen and rebalance the existing system of business support services

\section{Improve Policy Co-ordination}

Improve inter-ministerial co-operation

Establish regular contact and information exchange among KOSGEB, TOBB and TESK

Conduct regular surveys of SMEs' perceptions about different support options

Create an efficient evaluation culture

Accelerate the collection of business-sector data on the basis of recently accepted EU-definitions

\section{Improve entrepreneurial education and training opportunities}

Enlarge the range of educational opportunities for the benefit of all segments of society Establish innovation laboratories in schools

Introduce entrepreneurship education in schools, universities, laboratories and research centres

Expand basic training courses for entrepreneurs

Make entrepreneurs more aware of existing support policy options

\section{Strengthen support services and network building}

Reduce current asymmetries of support services

Adapt support services more closely to the needs of aspiring and actual entrepreneurs

Strengthen regular information and experience-sharing among same types of support units

Create network links between different categories of support centres

Use mobile support centres (vans) to provide assistance for firms in remote areas

Exploit more strongly the advantages of geographical proximity (creating firms near universities, research centres)

Establish horizontal network links among small (micro) firms

Create vertical links between homogenous groups of small (micro) firms and large firms

\section{Improve Access to Finance}

Introduce a nation-wide credit guarantee system

Reduce the role of collateral in credit extension

Upgrade the banking sector's ability to lend to SMEs

Design special (multi-disciplinary) programmes for micro firms

Use mobile banking vans and mobile credit advisory centres

Augment number of credit advisors and maintain monitoring after credit extension

Enlarge the range of financial instruments for all business categories

Use best-practice to augment supplies of venture capital

Strengthen interaction between public and private venture-capital suppliers. 


\section{ANNEX 4.A}

\section{The EU-Instrument for Pre-Accession Assistance (IPA) (2006)}

The $9^{\text {th }}$ Development Plan (2007-2013) and the SME Strategy and Action Plan have been shaped in close correspondence with the 2006 EU legal framework governing pre-accession assistance for 'candidate' countries. The EU Instrument for Pre-Accession Assistance (IPA) covering the period 2007-2013 helps aspiring countries qualify for the receipt of EU structural funds guiding them on their path to eventual EU membership. IPA assists these countries in their efforts to align themselves on EU standards and policy practices. It distinguishes between five intervention areas (components). These comprise Transition Assistance and Institutional Building, Cross-Border Cooperation, Regional Development, Human Resources Development and Rural development. The intervention area 'Regional Development' consists of three sub-components one of which 'The Operational Programme for Regional Competitiveness' (RCOP, 2007-2009) provides a new framework for Turkey's entrepreneurship and SME policies (Figure 4.A.1).

Figure 4.A.1. The EU- Instrument for Pre-Accession Assistance (IPA), Intervention Areas and Operational Programmes

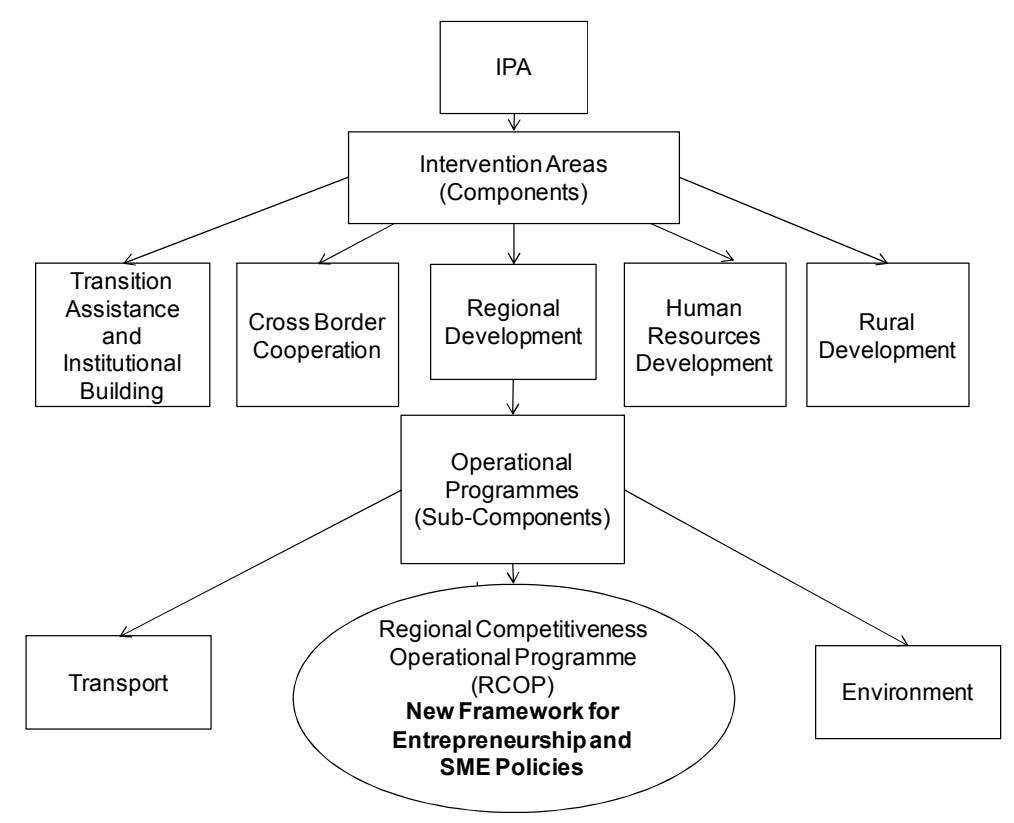

As a 'candidate country' Turkey is entitled to be receiving assistance in each of IPA's five intervention areas. The programming, implementation, monitoring and evaluation of the IPA assistance processes constitute indispensable tools to qualify Turkey for the receipt of EU structural funds. Concrete 'outputs' of the IPA process are so-called Operational Programmes, one of which is the Operational Programme for Regional Competitiveness (RCOP). The thrust of Turkeys' new entrepreneurship and SME policies are enshrined in this programme. RCOP has been prepared by the Ministry of Industry and Trade in collaboration with central and regional policy stakeholders, the EU Commission and the State Planning Organisation (SPO). Its operating structure is provided by the Ministry of Industry and Trade (Figure 4.A.2). 
Figure 4.A.2. Organigramme of $\mathrm{RCOP}^{1}$ Operating Structure

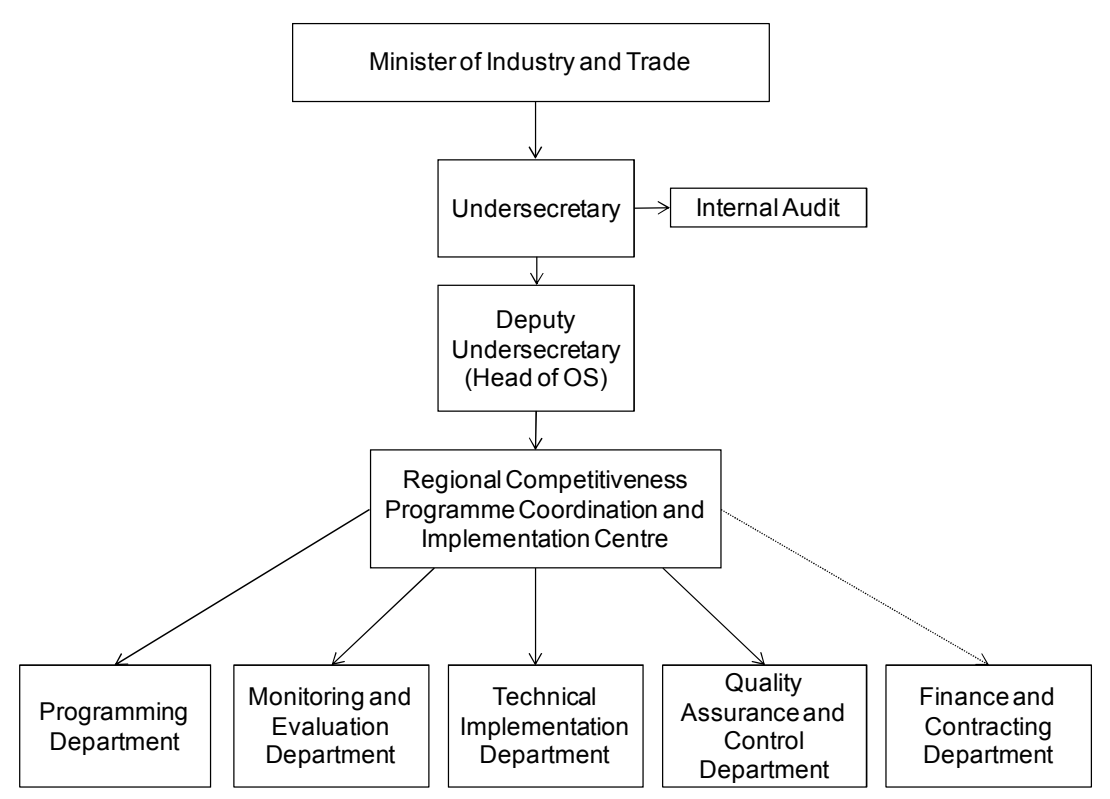

Note: Regional Competitiveness Operational Programme (November 2007)

RCOP, a principal policy instrument to achieve faster convergence with the EU, has two main priorities: the improvement of the business environment ('macro scale intervention axis') and the bolstering of enterprise capacity and entrepreneurial activity ('micro scale intervention axis'). Widening KOSGEB's mandate, RCOP focuses on manufacturing, tourism, information society, R\&D and innovation in regions with a per capita income of less than $75 \%$ of the Turkish average ('thematic and geographical concentration'). According to this criterion, there are 12 underdeveloped regions (NUTSII regions or nomenclature of territorial units) where $26 \%$ of all firms are located, mostly in the Eastern part of the country. Inside these regions, 15 growth centres with a high growth potential have been identified harbouring about $14 \%$ of all firms. Under the macro-scale intervention axis, RCOP strives to establish an effective R\&D, innovation, ICT and tourism infrastructure.

To this end, RCOP places strong emphasis upon inter-regional co-operation as well as upon interaction between 'growth centres' and their hinterland (interaction between nucleus and periphery) and between target regions and the rest of the country (collaborative innovation or collective process innovation). Under the micro-scale intervention axis, RCOP seeks to develop export-oriented innovative HSMEs relying on a wider range of better business consultancy services. The integration of SMEs into international markets is rightly seen as a key route to reducing Turkey's large current account deficit. A smaller excess of imports over exports creates room for lower domestic interest rates, thereby easing firms' access to finance. 